

\section{HOW TO OBTAIN EIA PRODUCTS AND SERVICES}

For further information on any of the following services, or for answers to energy information questions, please contact EIA's National Energy Information Center:

National Energy Information Center (NEIC)
Energy Information Administration
EI-30, Forrestal Building
Washington, DC 20585

(202) 586-8800

(202) 586-0727 (fax)

TTY: (202) 586-1181

E-mail: infoctr@eia.doe.gov

\section{Electronic Products and Services}

EIA's Internet Site Services offer nearly all EIA publications. Users can view and download selected pages or entire reports, search for information, download EIA data and analysis applications, and find out about new EIA information products and services.

World Wide Web: http://www.eia.doe.gov

FTP: ftp://ftp.eia.doe.gov

EIA also offers a listserve service for EIA press releases and other short documents. Sign up on the EIA World Wide Web site.

EIA's CD-ROM, Energy InfoDisc, contains most EIA publications and major energy database applications. The Energy InfoDisc, produced quarterly, is available for a fee from STAT-USA, Department of Commerce, 1-800-STAT-USA.

The Comprehensive Oil and Gas Information Source (COGIS), a bulletin board service, contains data files from most of EIA's oil-and gas-related reports. It is available for a fee from STAT-USA, on 1-800-STAT-USA.

EIA's Electronic Publishing System (EPUB) bulletin board contains data files, directories, and forecasts from most EIA reports. It can be accessed free of charge by dialing (202) 586-2557.

\section{Printed Publications}

EIA directories are available free of charge from NEIC. Recent periodicals and one-time reports are available from the Government Printing Office. Older reports are available from the National Technical Information Service:

\author{
Superintendent of Documents \\ U.S. Government Printing Office \\ P.O. Box 371954 \\ Pittsburgh, PA 15250-7954 \\ (202) 512-1800; (202)-512-2250 (fax)
}

\author{
National Technical Information Service \\ U.S. Department of Commerce \\ Springfield, VA 22161 \\ 5285 Port Royal Road \\ 1-(800) 553-6847; (703) 321-8547 (fax)
}

Cover: A geographic representation of the six market regions used in this report, highlighting the predominant natural gas supply position of the Southwestern States (center). Several major pipelines within each region are displayed as are the locations of selected natural gas market center/hubs (red stars).

Released for Printing: May 7, 1998

Q8 Printed with soy ink on recycled paper

GPO Stock No: 061-003-01032-6

Questions concerning the contents of this report should be directed to James Tobin, (202) 586-4835. 


\title{
Deliverability on the Interstate Natural Gas Pipeline System
}

May 1998

\author{
Energy Information Administration \\ Office of Oil and Gas \\ U.S. Department of Energy \\ Washington, DC 20585
}




\section{DISCLAIMER}

This report was prepared as an account of work sponsored by an agency of the United States Government. Neither the United States Government nor any agency thereof, nor any of their employees, makes any warranty, express or implied, or assumes any legal liability or responsibility for the accuracy, completeness, or usèfulness of any information, apparatus, product, or process disclosed, or represents that its use would not infringe privately owned rights. Reference herein to any specific commercial product, process, or service by trade name, trademark, manufacturer, or otherwise does not necessarily constitute or imply its endorsement, recommendation, or favoring by the United States Government or any agency thereof. The views and opinions of authors expressed herein do not necessarily state or reflect those of the United States Government or any agency thereof. 


\section{Preface}

Deliverability on the Interstate Natural Gas Pipeline System examines the capability of the national pipeline grid to transport natural gas to various U.S. markets. The report quantifies the capacity levels and utilization rates of major interstate pipeline companies in 1996 and the changes since 1990, as well as changes in markets and end-use consumption patterns. It also discusses the effects of proposed capacity expansions on capacity levels.

The report consists of five chapters, several appendices, and a glossary. Chapter 1 discusses some of the operational and regulatory features of the U.S. interstate pipeline system and how they affect overall system design, system utilization, and capacity expansions. Chapter 2 looks at how the exploration, development, and production of natural gas within North America is linked to the national pipeline grid. Chapter 3 examines the capability of the interstate natural gas pipeline network to link production areas to market areas, on the basis of capacity and usage levels along 10 corridors. The chapter also examines capacity expansions that have occurred since 1990 along each corridor and the potential impact of proposed new capacity.

Chapter 4 discusses the last step in the transportation chain, that is, deliverability to the ultimate end user. Flow patterns into and out of each market region are discussed, as well as the movement of natural gas between States in each region. Chapter 5 examines how shippers reserve interstate pipeline capacity in the current transportation marketplace and how pipeline companies are handling the secondary market for short-term unused capacity. Four appendices provide supporting data and additional detail on the methodology used to estimate capacity.

The main data sources (see Appendix D) used for the analysis include: (1) annual capacity reports and accompanying Format 567, "System Flow Diagrams," filed with the Federal Energy Regulatory Commission (FERC) by major interstate pipeline companies (18 CFR \$284.12 and \$260.8); (2) FERC Form 11, "Natural Gas Pipeline Monthly Statement" (1995 and earlier years); (3) FERC Form 2, "Annual Report of Major Natural Gas Companies"; (4) Energy Information
Administration (EIA), Form EIA-176, "Annual Report of Natural and Supplemental Gas Supply and Disposition"; and (5) Form EIA-191, "Underground Natural Gas Storage Report." Complementary data were obtained primarily from the EIA, Natural Gas Annual 1996, DOE/EIA-0131(96) or earlier issues.

Deliverability on the Interstate Natural Gas Pipeline System was prepared by the EIA, Office of Oil and Gas, under the direction of Kenneth A. Vagts (202/586-6401). General information concerning this report may be obtained from Joan E. Heinkel (202/586-4680), Director of the Natural Gas Division. Detailed questions on specific sections of the publication may be addressed to the following analysts:

- Chapter 1. "Introduction," James Tobin (202/586-4835).

- Chapter 2. "Access to Supplies and Production Regions," William A. Trapmann (202/586-4835).

- Chapter 3. "Deliverability on the Interstate Network," James Tobin.

- Chapter 4. "Deliverability to Markets," James Tobin.

- Chapter 5. "Access to Transportation Markets," Barbara Mariner-Volpe (202/586-5878) and Mary E. Carlson (202/586-4749).

The overall scope and content of the report was supervised by James Tobin. Overall coordination of the report was provided by James Thompson. Significant analytical contributions were made by the following individuals:

Jay K. Mitchell—Chapter 2

Michael J. Tita-Chapter 5

Lillian H. "Willie" Young-Chapter 3.

Desktop publishing support was provided by Margareta Bennett.

\section{Preceding Page Blank}




\section{Contents}

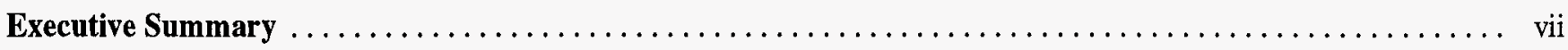

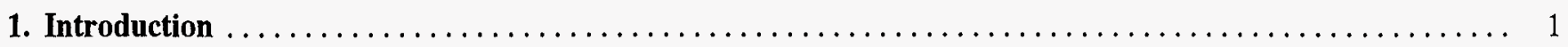

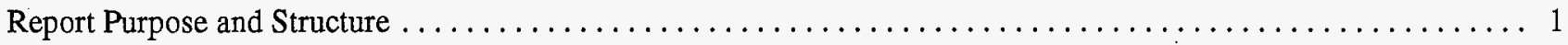

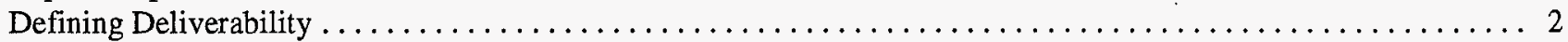

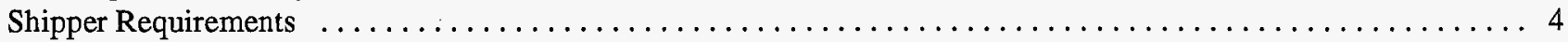

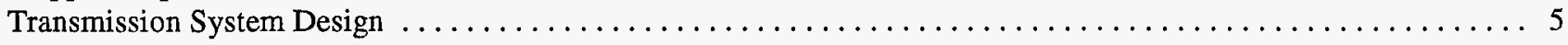

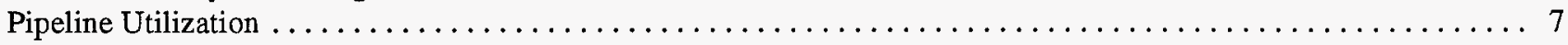

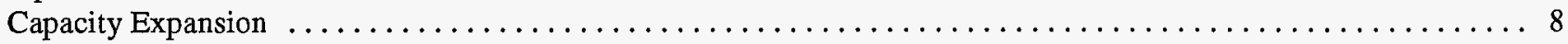

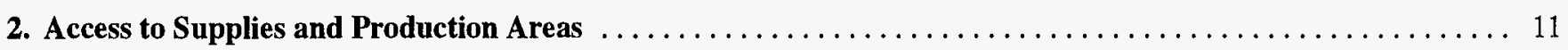

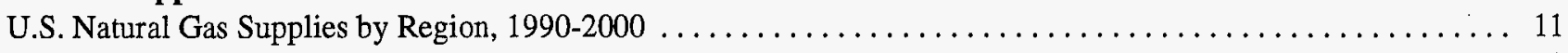

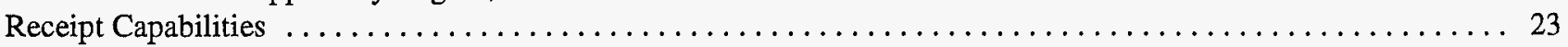

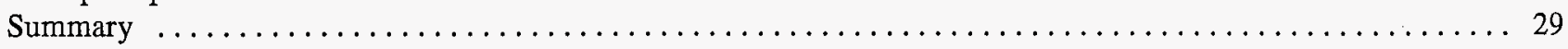

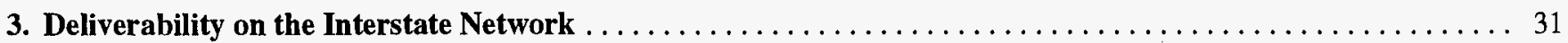

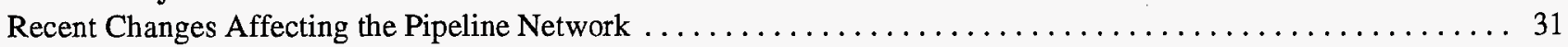

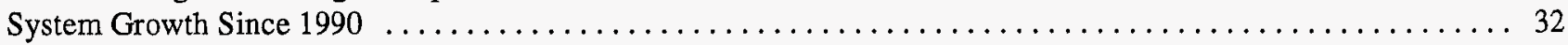

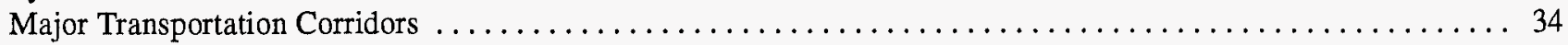

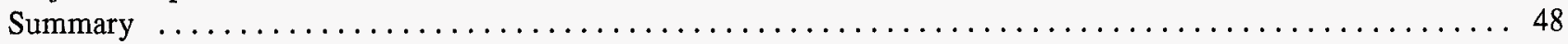

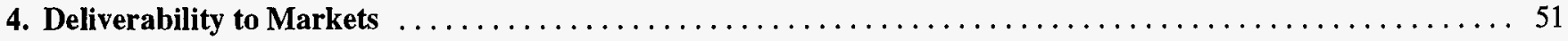

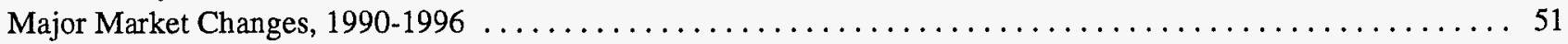

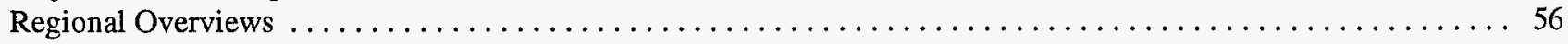

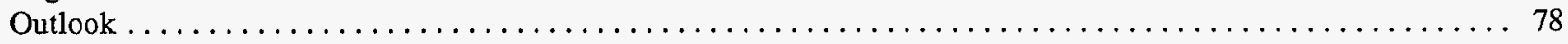

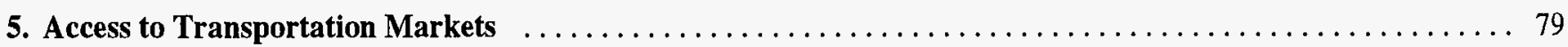

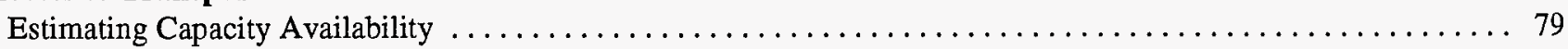

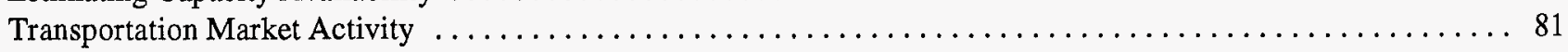

Characteristics of Firm Capacity Held by Different Types of Shippers $\ldots \ldots \ldots \ldots \ldots \ldots \ldots \ldots \ldots \ldots \ldots \ldots 87$

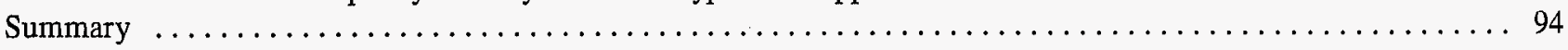

Appendices

A. State-to-State Natural Gas Pipeline Capacity and Usage Levels . . . . . . . . . . . . . . . . . . . 97

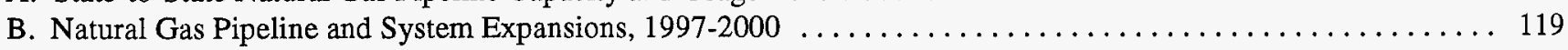

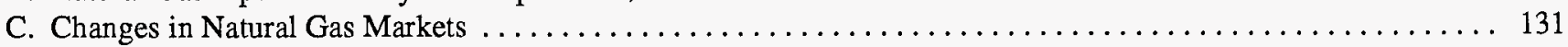

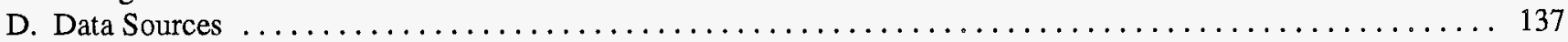

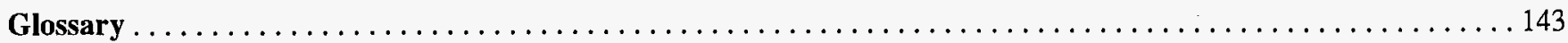




\section{Tables}

1. Forty Largest Interstate Pipeline Companies by Level of Deliverability, $1996 \ldots \ldots \ldots \ldots \ldots \ldots \ldots \ldots$

2. Natural Gas Production and Supplies in the Lower 48 States, by Region, $1990-2000 \ldots \ldots \ldots \ldots \ldots \ldots \ldots 13$

3. Lower 48 Dry Natural Gas Proved Reserves and Reserves-to-Production Ratio, 1990-1996 . . . . . . . . . . 15

4. Central and Western Gulf of Mexico Lease Sales Before and After the Royalty Relief Act $\ldots \ldots \ldots \ldots \ldots 17$

5. Top 10 Fields in the Lower 48 States Ranked by Natural Gas Production, $1996 \ldots \ldots \ldots \ldots \ldots \ldots \ldots \ldots$

6. U.S. Natural Gas Productive Capacity Utilization and Surplus Deliverability by Region, 1990, 1995, and 1996 . 18

7. Interregional Pipeline Export Capacity, Average Daily Flows, and Usage Rates, 1990 and $1996 \ldots \ldots \ldots$

8. Natural Gas Transportation Corridors and Associated Major Pipeline Systems, $1996 \ldots \ldots \ldots \ldots \ldots \ldots \ldots . . .38$

9. Interregional Pipeline Capacity, Average Daily Flows, and Usage Rates, 1990 and $1996 \ldots \ldots \ldots \ldots \ldots \ldots$

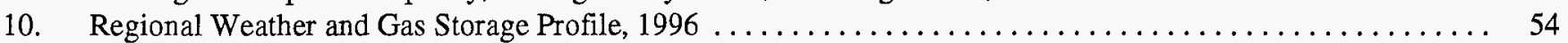

11. Regional Energy Profile Comparison of Annual Average Change, 1990-1995 or 1990-1996 . . . . . . . . . . 54

12. Regional Natural Gas Customer Market Share Changes, $1990-1996$. . . . . . . . . . . . . . . . . . . . . . . . 55

13. Regional Natural Gas Customers, Average Annual Change, $1990-1996$. . . . . . . . . . . . . . . . . . . . . 56

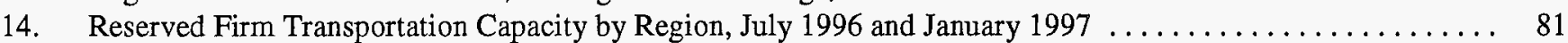

15. Characteristics of Firm Contract Capacity as of April 1, 1997, by Shipper $\ldots \ldots \ldots \ldots \ldots \ldots \ldots \ldots$

\section{Figures}

1. Generalized Schematic of Natural Gas Pipeline Transmission $\ldots \ldots \ldots \ldots \ldots \ldots \ldots \ldots \ldots \ldots \ldots \ldots \ldots . \ldots$

2. Major Natural Gas Producing Basins and Transportation Routes to Market Areas $\ldots \ldots \ldots \ldots \ldots \ldots \ldots \ldots$

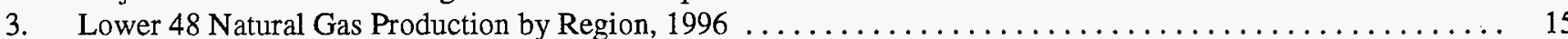

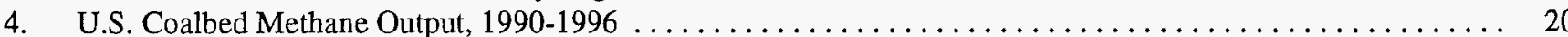

5. Comparison of Average U.S. Natural Gas Wellhead Price and Canadian Natural Gas Import Price, 1990-1996 . 22

6. Canadian Gas Exports to the United States and Total Canadian Gas Production, 1990-1996 ............ 23

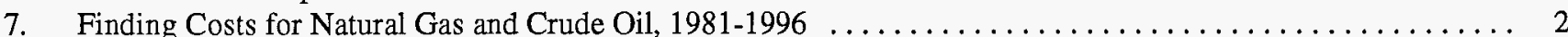

8. Offshore and Onshore Production Costs for Natural Gas and Crude Oil, 1995 and $1996 \ldots \ldots \ldots \ldots \ldots \ldots . \ldots 27$

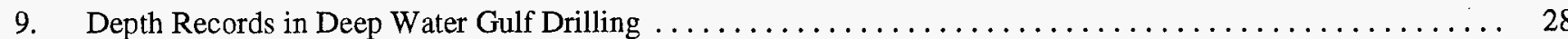

10. Capacity of New Natural Gas Pipeline Systems Placed in Service in the United States Between 1990 and 1997 . 33

11. Region-to-Region Natural Gas Pipeline Capacity, 1990 and $1996 \ldots \ldots \ldots \ldots \ldots \ldots \ldots \ldots \ldots \ldots \ldots \ldots$

12. Major Natural Gas Transportation Corridors in the United States and Canada, $1997 \ldots \ldots \ldots \ldots \ldots \ldots \ldots . . \ldots 6$

13. Net Natural Gas Pipeline Capacity Entering (-Exiting) Each Region, December $1997 \ldots \ldots \ldots \ldots \ldots \ldots \ldots .52$

14. Interstate Natural Gas Capacity Summary for the Central Region, $1996 \ldots \ldots \ldots \ldots \ldots \ldots \ldots \ldots \ldots \ldots$

15. Interstate Natural Gas Capacity Summary for the Midwest Region, $1996 \ldots \ldots \ldots \ldots \ldots \ldots \ldots \ldots \ldots \ldots \ldots$. . . . . 61

16. Interstate Natural Gas Capacity Summary for the Northeast Region, $1996 \ldots \ldots \ldots \ldots \ldots \ldots \ldots \ldots \ldots$. . . . . . . . . 64

17. Interstate Natural Gas Capacity Summary for the Southeast Region, $1996 \ldots \ldots \ldots \ldots \ldots \ldots \ldots \ldots \ldots . \ldots 6$

18. Interstate Natural Gas Capacity Summary for the Southwest Region, $1996 \ldots \ldots \ldots \ldots \ldots \ldots \ldots \ldots \ldots \ldots . \ldots 1$

19. Interstate Natural Gas Capacity Summary for the Western Region, $1996 \ldots \ldots \ldots \ldots \ldots \ldots \ldots \ldots \ldots \ldots$

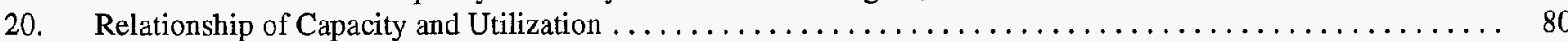

21. Concentration of Reserved Firm Capacity by Region, April 1996 - April 1997 . . . . . . . . . . . . . . . . . 83

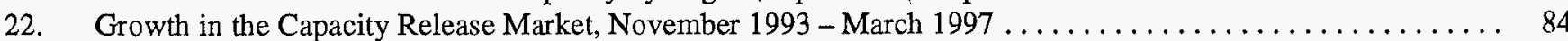

23. Capacity Held by Replacement Shippers, by Region and Heating Years, 1994-95-1996-97 . . . . . . . . . . . . 84

24. Capacity Held by Replacement Shippers During the Nonheating and Heating Seasons, by Region ........ 86

25. Natural Gas Pipeline Throughput Under Firm and Interruptible Service, January 1996 - September $1997 \quad \ldots$.. 86

26. Share of Total Firm Capacity Held on April 1, 1997, by Type of Shipper $\ldots \ldots \ldots \ldots \ldots \ldots \ldots \ldots . . . \ldots 9$

27. Average Length of Long-Term Firm Contracts as of April $1,1997 \ldots \ldots \ldots \ldots \ldots \ldots \ldots \ldots \ldots \ldots \ldots \ldots$

28. Average Length of Short-Term Firm Contracts, January and April $1997 \ldots \ldots \ldots \ldots \ldots \ldots \ldots \ldots \ldots \ldots . \ldots 1$

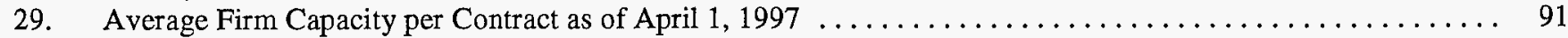

30. Share of Regional Firm Capacity as of April 1, 1997, by Shipper for Selected Regions . ............ 92

31. Capacity Under New and Expiring Firm Contracts, April 1,1996 - April 1, $1997 \ldots \ldots \ldots \ldots \ldots \ldots \ldots . \ldots 3$

32. Reserved, Utilized, and Available Capacity for the $1996-97$ Heating Year $\ldots \ldots \ldots \ldots \ldots \ldots \ldots \ldots . . \ldots 4$ 


\section{Executive Summary}

Deliverability on the Interstate Natural Gas Pipeline System examines the capability of the interstate pipeline network to move natural gas to various markets within the United States, highlighting the changes that have occurred since 1990 . Significant changes have occurred in the natural gas industry since the Energy Information Administration (EIA) published the predecessor to this report in 1992. ${ }^{1}$ Fundamental changes in industry structure were imposed with the issuance of Order 636 in 1992 by the Federal Energy Regulatory Commission that allowed market forces and competition to become the primary factors influencing change in the natural gas marketplace. Several new concepts in natural gas trading and distribution have developed, such as the market center, and changes have been made in how certain network resources are being used in support of these system changes, such as open access to underground storage capacity.

For the most part, these changes have been positive. Total U.S. natural gas consumption has increased by 17 percent since 1990, marketed production has increased by 6 percent, net imports have nearly doubled, and the interstate pipeline system has increased in size and capability. Overall growth in the pipeline network has occurred in both its deliverability and usage levels. For instance, between 1990 and the end of 1996:

- Deliverability (capacity) on the interstate pipeline system increased by more than 15 percent, or 10.9 billion cubic feet per day, at regional borders (Table ES1). The largest increase in interregional deliverability was to the Western Region, with an additional 3.2 billion cubic feet (Bcf) per day, or 45 percent (Figure ES1). The second largest increase was 2.4 Bcf per day, 24 percent, into the Northeast Region. The development of so much capacity in the West led to a surplus of capacity and an overall drop in the pipeline capacity usage rate, whereas in the Northeast, demand growth fully supported the increase. In fact, pipelines into the Northeast saw a substantial increase in average daily usage rates, up 6 percentage points from 1990 levels.

- Pipeline utilization rates also increased, by 7 percentage points, reaching a high of 75 percent (on an average day) in 1996. This increase in interregional pipeline use, occurring simultaneously with a major

\footnotetext{
${ }^{1}$ Energy Information Administration, Capacity and Service on the Interstate Natural Gas Pipeline System 1990: Regional Profiles and Analyses, DOE/EIA-0556 (Washington, DC, June 1992).
}

increase in pipeline capacity, would seem to indicate that demand for natural gas was growing faster than new capacity was being added and that, in some areas, occasional bottlenecks or periodic capacity constraints might have occurred or were developing. In other areas, the increase in pipeline usage rates simply reflected a greater use of existing capacity that had been previously underutilized because of overbuilding or a temporary dropoff in demand.

- Reflecting its growing role in the U.S. natural gas market, Canadian import capacity into the United States increased by 69 percent, or 4.5 billion cubic feet per day. It also represents the largest portion of new interregional pipeline capacity proposed for development during the next several years. Although it is unlikely that all projects will be built, more than $7.7 \mathrm{Bcf}$ per day of import capacity expansion has been proposed, most of it feeding into the U.S. Midwest and Northeast regions. To a great degree, the proposals are driven by producers in Western Canada seeking markets for that region's expanding production capability. Plans to develop fields in the Sable Island area off the east coast of Canada have also triggered a need to find markets for that production as well. (Between 1990 and 1996, Canadian marketed natural gas production increased at an 8-percent annual rate, while natural gas end-use consumption in Canada increased at only a 3.5-percent rate, thus the desire to expand export capabilities.)

Growth and changes in deliverability on the natural gas network have also resulted in some shifts in transportation corridors and access to production areas. Deliverability out of the Rocky Mountain area is increasing as producers there are seeking customers in expanding markets, such as the U.S. Midwest, to supplement their traditional markets in the Western Region. Likewise, producers and pipeline companies in the areas of West Texas and New Mexico have also shifted a larger portion of their capabilities toward Eastern markets.

In 1997, at least 41 natural gas pipeline projects were completed and placed in service in the United States, adding $6.3 \mathrm{Bcf}$ per day of capacity overall, with $0.5 \mathrm{Bcf}$ per day of that representing added interregional deliverability and 3.9 Bcf intraregional deliverability (Table ES1). A major portion of the new pipeline capacity represented increased receipt capability in expanding supply regions. For instance, the largest projects were in the Gulf of Mexico (3.2 Bcf per day) as offshore and deep-water development efforts in the area continue to expand. In addition, several major projects were completed that expanded access to the Wind River and 
Table ES1. Regional Summary of Changes in Interstate Pipeline Capacity, 1990-1996, and Planned Additions, 1997-2000

\begin{tabular}{|c|c|c|c|c|c|c|c|c|c|c|c|c|}
\hline \multirow[b]{2}{*}{ Reglon } & \multicolumn{6}{|c|}{ Entering the Reglon ${ }^{6}$ (MMct/d) } & \multicolumn{6}{|c|}{ Within the Region ${ }^{b}$ (MMct/d) } \\
\hline & $\begin{array}{c}\text { Capaclty } \\
\text { End of } \\
1990\end{array}$ & $\begin{array}{c}\text { Capacity } \\
\text { End of } \\
1996\end{array}$ & $\begin{array}{l}\text { Percent } \\
\text { Change } \\
1990-96\end{array}$ & $\begin{array}{c}\text { Estlmated } \\
\text { Capaclty } \\
\text { Added In } \\
1997\end{array}$ & $\begin{array}{l}\text { Proposed } \\
\text { Additlons } \\
\text { to Capaclty } \\
1998-2000^{\circ}\end{array}$ & $\begin{array}{c}\text { Percent } \\
\text { Change } \\
1996- \\
2000\end{array}$ & $\begin{array}{c}\text { Capacity } \\
\text { End of } \\
1990\end{array}$ & $\begin{array}{c}\text { Capaclity } \\
\text { End of } \\
1996\end{array}$ & $\begin{array}{c}\text { Percent } \\
\text { Change } \\
1990\end{array}$ & $\begin{array}{c}\text { Estlmated } \\
\text { Capaclty } \\
\text { Added In } \\
1997\end{array}$ & $\begin{array}{c}\text { Proposed } \\
\text { Addltlons } \\
\text { to Capaclty } \\
1998-2000\end{array}$ & $\begin{array}{c}\text { Percent } \\
\text { Change } \\
1996- \\
2000\end{array}$ \\
\hline Central & 11,824 & 12,824 & 8 & 3 & 3,012 & 23 & 20,754 & 23,593 & 14 & 1,143 & 1,081 & 9 \\
\hline Midwest & 22,818 & 24,787 & 9 & 306 & 5,306 & 21 & 23,354 & 23,151 & 10 & 820 & 2,721 & 15 \\
\hline Northeast & 10,009 & 12,403 & 24 & 24 & 4,973 & 40 & 29,261 & 32,966 & 13 & 364 & 5,037 & 16 \\
\hline Southeast & 19,914 & 21,393 & 7 & 0 & 438 & 2 & 47,788 & 51,128 & 7 & 436 & 1,999 & 5 \\
\hline Southwest & 2,048 & 2,869 & 40 & 180 & 115 & 10 & 43,583 & 45,072 & 3 & 2,341 & 1,461 & 8 \\
\hline Western ...... & 7,126 & 10,331 & 45 & 0 & 326 & 3 & 9,924 & 15,489 & 56 & 13 & 193 & 1 \\
\hline U.S. Total . . . & 73,739 & 84,606 & 15 & 513 & 14,170 & 17 & 174,664 & 191,399 & 10 & 3,874 & 12,492 & 9 \\
\hline Canada ........ & 1,277 & 2,609 & 104 & 0 & 1,300 & 50 & NA & NA & NA & NA & NA & NA \\
\hline Mexico ........ & 399 & 889 & 123 & 237 & 1,375 & 181 & NA & NA & NA & NA & NA & NA \\
\hline
\end{tabular}

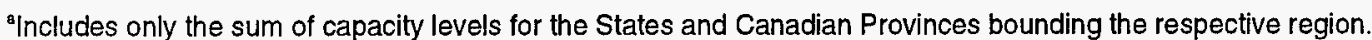

${ }^{b}$ Represents the sum of the interstate pipeline capacity, or planned capacity, on a State-to-State basis as measured at individual State border crossing points, exclusive of capacities "Entering the Region." Does not include projects that are entirely within one State. Gulf of Mexico projects are considered within the Southwest or Southeast region.

'Proposed capacity has been counted in only one region even though some projects may cross regional boundaries. In the case of a new line, the additional capacity has been included within the region in which it terminates. For an expansion project, the added capacity is included in the region where most of the expansion effort is focused.

MMcf/d = Million cubic feet per day. NA = Not available.

D Sources: Capaclty: Energy Information Administration (EIA), EIAGIS-NG Geographic Information System, Natural Gas Pipeline State Border Capacity Database, as of December 1997. Capacity AddItions: EIAGIS-NG Geographic Information System, Natural Gas Pipeline Construction Database, as of March 1998, compiled from Federal Energy Regulatory Commission, Natural Gas Act Section 7(c) Filings, "Application for Certificate of Public Convenience and Necessity," and various natural gas industry news sources.

Figure ES1. Region-to-Region Natural Gas Pipeline Capacity, 1990 and 1996 (Volumes in Million Cubic Feet per Day)
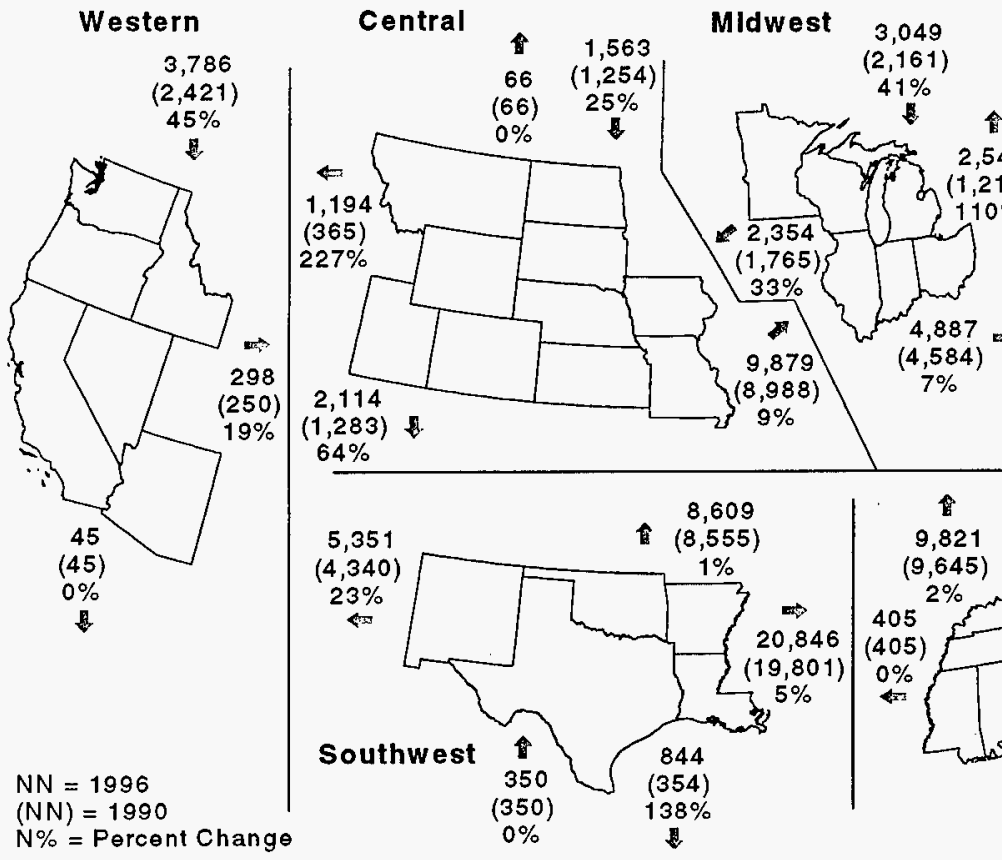

$(4,584)$

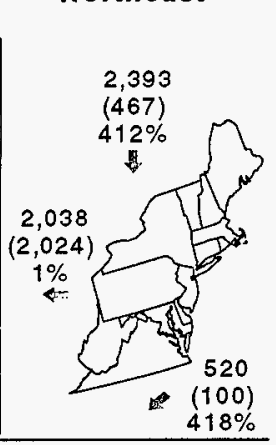

$\mathrm{N} \%=$ Percent Change

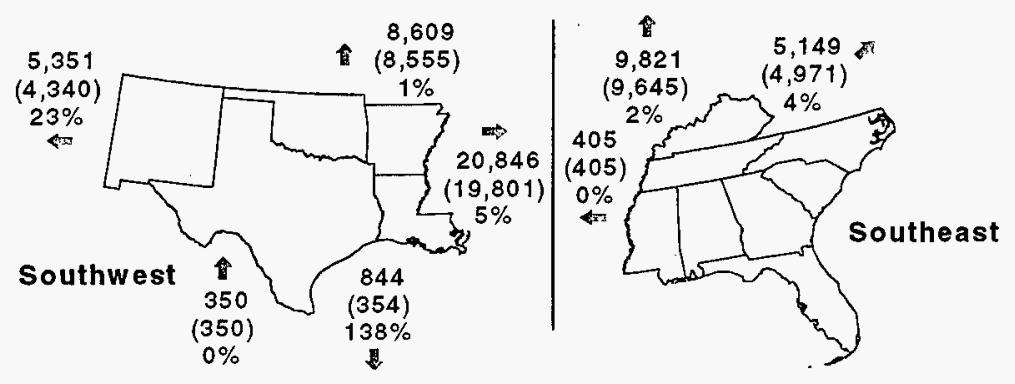

Source: Energy Information Administration (EIA), EIAGIS-NG Geographic Information System, Natural Gas Pipeline State Border Capacity Database, as of December 1997. 
Powder River basins of the Rocky Mountain area by almost $0.7 \mathrm{Bcf}$ per day. The first new export lines to Mexico to be completed in 5 years were also placed in service during 1997. The increase in pipeline utilization levels since 1990 can be attributed in part to new trading and shipping arrangements that evolved with the introduction of pipeline open-access transportation and storage. The increased opportunities for trading, variable routing of gas shipments, and the development of new services to complement and expedite network operations have done much to improve the efficiency and utilization of available capacity. Several factors can be cited as contributing to the improvement, including:

- Development of a release market for pipeline capacity, whereby unused firm capacity can be sublet by other shippers. The pipeline capacity release market reached a level of about 3.6 trillion cubic feet in 1996 (the equivalent of 16 percent of available capacity). Before FERC Order 636, there was only limited experience with capacity brokering, which had been authorized by the Federal Energy Regulatory Commission in 1989.

- Development of market centers. Since 1990, when only one formal market center/hub was operational (the Henry Hub in Louisiana), more than 36 market centers have developed at strategic points within the North American pipeline grid. These centers have contributed significantly to providing shippers greater access to lowest-cost gas supplies. Shippers now use market centers for rerouting gas supplies from one pipeline to another and also for access to services, such as short-term gas loans and parking, that facilitate gas trading and improve pipeline capacity usage. The Henry Hub, the Chicago Center (Illinois), and the Leidy Hub (Pennsylvania) are the three most active market centers in the United States today.

- Improved access to underground storage. Open access to underground storage services, mandated in Order 636, has also played a large role in improving the quality of transacting business on the natural gas pipeline network. The major trend in underground storage growth has been the increasing development of high-deliverability facilities, mostly salt cavern sites, which are designed to permit rapid access and turnover of stored inventory. These types of sites have become closely associated with market centers as they complement the short-term parking and loaning services offered by these centers. Since 1993, daily deliverability from salt cavern and other types of high-deliverability storage facilities has grown to represent more than 15 percent of total underground storage daily withdrawal capability, up from 10 percent. Practically all salt cavern storage sites are accessible from market centers.

- Availability of electronic trading. Another growing feature of the new natural gas marketplace is the increased use of computer-based electronic trading. Although there are only a few dominant systems in this marketplace, the number of trades conducted via electronic trading has grown steadily during the past several years. These systems bring together gas traders, capacity seller/buyers, and others at a number of optional points on the pipeline grid and assist the parties in carrying out their transactions. Most of the major market centers/hubs in North America, as well as a number of the most active spot-market trading points on the pipeline grid, are accessible to traders. Not to be forgotten, however, is trading on the non-electronic spot market, which still accounts for the large majority of trading activity covering short-term buying and selling of natural gas. Currently there are more than 120 trading points within the national pipeline network at which trading is conducted by open-market traders.

In the market for pipeline capacity, shippers prefer long-term contracts (a year or more in length) over short-term contracts and firm rather than interruptible transportation services. During the 12 months ended March 31, 1997, about 78 percent of capacity was reserved under firm transportation contracts. However, not all of that capacity was used by the contract holders and, in addition, substantial firm transportation capacity is unsubscribed and available to shippers (27 trillion Btu per day, or 21 percent of maximum capability in 1997). Although this uncommitted capacity may not suit the needs of a particular shipper because of its location or term etc., it could support additional market growth beyond current levels. Shippers also have access to additional transportation services in which deliveries may not necessarily be guaranteed by the pipeline company. These services include capacity release and interruptible transportation service and are available to shippers depending on the actual use of the pipeline system by firm transportation customers. Marketers are the most active in the short-term and capacity release markets because these markets provide the flexibility to meet varying and unexpected demand levels.

\section{Outlook}

Based upon EIA natural gas consumption projections, the market for natural gas will continue to grow steadily into the next century. EIA forecasts about a 2-percent annual growth rate during the next 10 years (1999-2008). Excluding demand in the supply areas, this translates into a projected increase in consumption of nearly 1.2 trillion cubic feet by the year 2001 . 
In fact, the extensive number of currently planned capacity additions and expansion projects indicates that substantial activity is underway to address these potential increases in demand. If all the projects currently proposed through 2000 were built, interregional capacity would increase by as much as 14.7 billion cubic feet (Bcf) per day, or about 17 percent, from the level in 1996. Additional projects that are limited to providing service within a specific region comprise an additional 15.3 Bcf per day of capacity.

Natural gas consumption is projected to grow at a 5-percent annual rate in the Southeast Region through 2008, supported by anticipated growth in electric utility and industrial markets for natural gas. Markets in the Northeast and Midwest are projected to expand at annual rates of only 3.3 and 1.6 percent, respectively. Current proposals to expand pipeline capacity into these regions between 1998 and 2000 amount to the equivalent of about $10.7 \mathrm{Bcf}$ per day, with $5.3 \mathrm{Bcf}$ per day directed to the Midwest, 5.0 Bcf to the Northeast, and $0.4 \mathrm{Bcf}$ to the Southeast.

Based on current expansion proposals, the most extensive development of new capacity during the next several years will occur along the Canadian corridors. At least four new pipelines and several expansions are planned that will expand deliverability from Canada to the U.S. Midwest and Northeast markets and also to Canadian domestic markets. These lines will improve access to natural gas supplies in Western Canada and also create a new corridor to bring production from the developing fields off the coast of Eastern Canada (Sable Island) to Canadian and U.S. markets. These expansions could add between 5.9 and $7.0 \mathrm{Bcf}$ per day to U.S. import capacity from Canada during the next 3 years along these corridors, an increase of more than 52 percent over 1997 levels.

Current interregional and State-to-State capacity levels, in most instances, appear to be adequate to meet current customer demands, although in a few instances average daily pipeline utilization rates increased significantly between 1990 and 1996. This rise in usage is a strong indicator that instances of peak-period capacity constraint could begin to occur if demand for natural gas in the affected markets were to increase at a faster rate than expected. Also, while the amount of new capacity proposed for the next several years appears to be adequate, and in some instances more than adequate, to meet forecasted demand, there will probably be some local areas with capacity constraints.

The capability of the pipeline network to transport and deliver gas from supply areas to ultimate consumers has grown measurably since 1990 , and the quality and flexibility of service has improved as well. Substantial further growth in system capability is expected in light of the many expansion projects scheduled for completion during the next few years. Further integration, improved services, and more interconnections along the grid should also help accommodate anticipated future demand. 


\section{Introduction}

The United States has an extensive network of pipelines for transporting natural gas from supply areas to all of the lower 48 States. In 1996, this system delivered about 20 trillion cubic feet of natural gas to end users, an average increase of about 5 percent annually since $1990 .{ }^{1}$ This trend is expected to continue, as Energy Information Administration (EIA) projections indicate that demand could be near an all-time high by the turn of the century. ${ }^{2}$ These projections of increasing demand raise important issues for the U.S. pipeline transmission industry concerning the system's capability to move gas, the mechanisms for allocating capacity, and the best way to apportion costs among users to obtain efficient use of the system.

\section{Report Purpose and Structure}

This report primarily examines the capability of the interstate pipeline network to move natural gas to various markets within the United States. The examination evaluates these capabilities from supply areas to end-use markets, looking first at the productive capacity and assets of major production areas and the ability of the pipeline network to handle current and proposed levels of production. It then assesses the ability of the mainline pipeline network to transport and direct supplies to end-use markets and the capabilities of the trunklines and regional pipeline systems to deliver gas to the ultimate consumer. Throughout the report, the data are discussed and analyzed on a regional basis (see Figure ES1) to reflect the significantly different profiles of various production and market areas within North America that are linked by the pipeline network.

The main purposes of this study are to:

- Quantify the capacity levels and usage of capacity on the interstate pipeline network in 1996 between supply areas and major market areas.

- Examine the changes that have occurred on the pipeline network since 1990 , including new pipeline systems and expansions to existing systems.

\footnotetext{
${ }^{1}$ Excludes gas used for pipeline fuel as well as lease (field) and plant processing. Also does not include Alaska and Hawaii. Energy Information Administration, Natural Gas Annual 1996, DOE/EIA-0131(96) (Washington, DC, September 1997), Table 1.

${ }^{2}$ Energy Information Administration, Annual Energy Outlook 1996, DOE/EIA-0383(96) (Washington, DC, January 1998).
}

- Analyze how regulatory change and market forces since 1990 have created new market entities while altering the traditional role of a number of existing ones.

- Characterize and compare the various production and market areas in relationship to the interstate pipeline system.

- Assess shifts in market and end-use consumption patterns within the different markets between 1990 and $1996{ }^{3}$

- Identify and examine recent proposals for new pipeline routes and capacity expansions on existing lines, particularly their effects on capacity levels.

The report does not attempt to identify specific instances of excess pipeline capacity or system bottlenecks. Identification of specific existing capacity constraints or excesses would require modeling and simulation runs using actual daily operational data. Such an endeavor would require more detailed and specific data than were available for this study.

This chapter discusses some of the operational and regulatory features of the U.S. interstate pipeline system: the shipper requirements that affect the overall system design, the design process, the system utilization, and the regulatory procedures for capacity expansion. It also examines the differences between various types of pipeline companies and the importance of underground storage facilities in the design and operation of a pipeline system.

Chapter 2 looks at how the exploration, development, and production of natural gas within North America are linked to the national pipeline grid. The analysis includes a profile of current and, where possible, projected production levels within the major natural gas-producing areas in the United States and Canada. It also examines production levels relative to pipeline capacity on pipeline systems exiting these areas and entering the major natural gas transportation corridors serving markets in North America.

The capability of the interstate natural gas pipeline network to link production areas to market areas is examined in Chapter 3, based on capacity and usage levels along 10 corridors. Each corridor is profiled and analyzed relative

\footnotetext{
${ }^{3}$ Unless otherwise specified, historical or general production and consumption data cited throughout this report are based on the publication, Energy Information Administration, Natural Gas Annual 1996, DOE/EIA0131(96) (Washington, DC, September 1997).
} 
to its combined pipeline capacity and usage levels, especially as to its receipt capability from supply areas and deliverability to market areas. The chapter also examines capacity expansions that have occurred since 1990 along each corridor and the potential impact of proposed new capacity.

Chapter 4 discusses the last step in the transportation chain, that is, deliverability to the ultimate end user. Flow patterns into and out of each market region are discussed, as well as the movement of natural gas between States in each region. The profile of the customer base is addressed to provide some insight into the current operation of pipeline and storage facilities in the market area. The potential impact of announced expansion projects is analyzed relative to current capacity levels and the regional demand profile.

Chapter 5 examines how shippers reserve interstate pipeline capacity in the current transportation marketplace. It looks at how pipeline companies are handling the secondary market for short-term unused capacity that is placed on the market by shippers eager to lower their overall transportation costs. It also analyzes the level of this (capacity release) trading and what current trends might mean for firm and interruptible contract (reservation) levels on pipelines in the future. The report also includes four appendices that provide supporting data and additional detail on the methodology used to estimate capacity.

For the most part, the time series data used in this report cover the years 1990 through 1996. There are a few exceptions worth noting, however. Pipeline projects completed in 1997 are included in the analyses in chapters 3 and 4, although these projects were only in service for a part of the year. Since pipeline flow data for 1997 were not yet available, no attempt was made to integrate the 1997 projects into any discussion of pipeline utilization or specific State-to-State capacity profiles.

Another exception is the energy consumption data in Chapter 4 (and Appendix C, Table C1). As of March 1998, no comparative annual data for 1996 were available concerning total national energy consumption by fuel type. While this limited the data time series to the period 1990 through 1995, the use of average annual (percent) change in the accompanying profile analyses minimized the impact of the 1 year of missing data. It should also be noted that the analysis in Chapter 5 examines firm transportation contract data for the 1997 heating year (the 12 months ended March 31, 1997).

Analyses concerning out-year projections vary with the types of issues being addressed. Projections of pipeline capacity additions through the year 2000 presented in the report are based upon actual proposals currently under active consideration by the pipeline companies and regulatory authorities. Some of these projects may not survive the development process. Projections concerning production (Chapter 2) and future demand levels (Chapter 4), on the other hand, reflect estimates presented in EIA's Annual Energy Outlook 1998 With Projections to 2020 as produced from the EIA's National Energy Modeling System (NEMS).

\section{Defining Deliverability}

"Deliverability" is defined for this report as the maximum volume (capacity) that can be received, delivered, or passed through a specific point during a specified period, e.g., 1 day. Pipeline deliverability, or capacity, can be measured in different ways, resulting in slightly different meanings. For example:

- Systemwide peak-day capacity. Major interstate pipeline companies file an annual capacity report (18 CFR \$284.12) with the Federal Energy Regulatory Commission (FERC) that reports their daily system capacity based on a design estimate of how much their system can deliver for current shippers on a systemwide peak day, otherwise known as the coincidental peak day (Table 1). ${ }^{4}$ The derivation of this figure differs among pipeline companies. Estimates of capacity on grid type (regional) systems (see "Pipeline Utilization" section) often are based upon the sum of system maximum deliverability when the system is in a balanced state (receipts match deliveries). Systemwide capacity on trunkline systems usually represents the sum of capacity at all delivery points.

- Peak-day capacity of each individual receipt, delivery, or interconnection point. This estimate represents the maximum amount of natural gas that can be delivered into or out of the system during a period based on an individual customer's peak needs, although no system is capable of reaching these maximums at all points on the same day. The sum of these capabilities is known as the "noncoincidental peak-day capacity." It is called noncoincidental because the days on which delivery points on a pipeline system experience their peak flow may not coincide.

- Capacity at a specific (strategic) point along the pipeline system, usually at a compressor station or hub interconnection (of several pipelines). Compressor

\footnotetext{
${ }^{4} \mathrm{~A}$ coincidental peak flow is a volume measured at a delivery, receipt, or interconnection point during a specified period (usually a day) when the entire pipeline system operated at its maximum (throughput) for a given year. Thus the day for this measure coincides for all shippers.
} 
Table 1. Forty Largest Interstate Pipeline Companies by Level of Deliverability, 1996

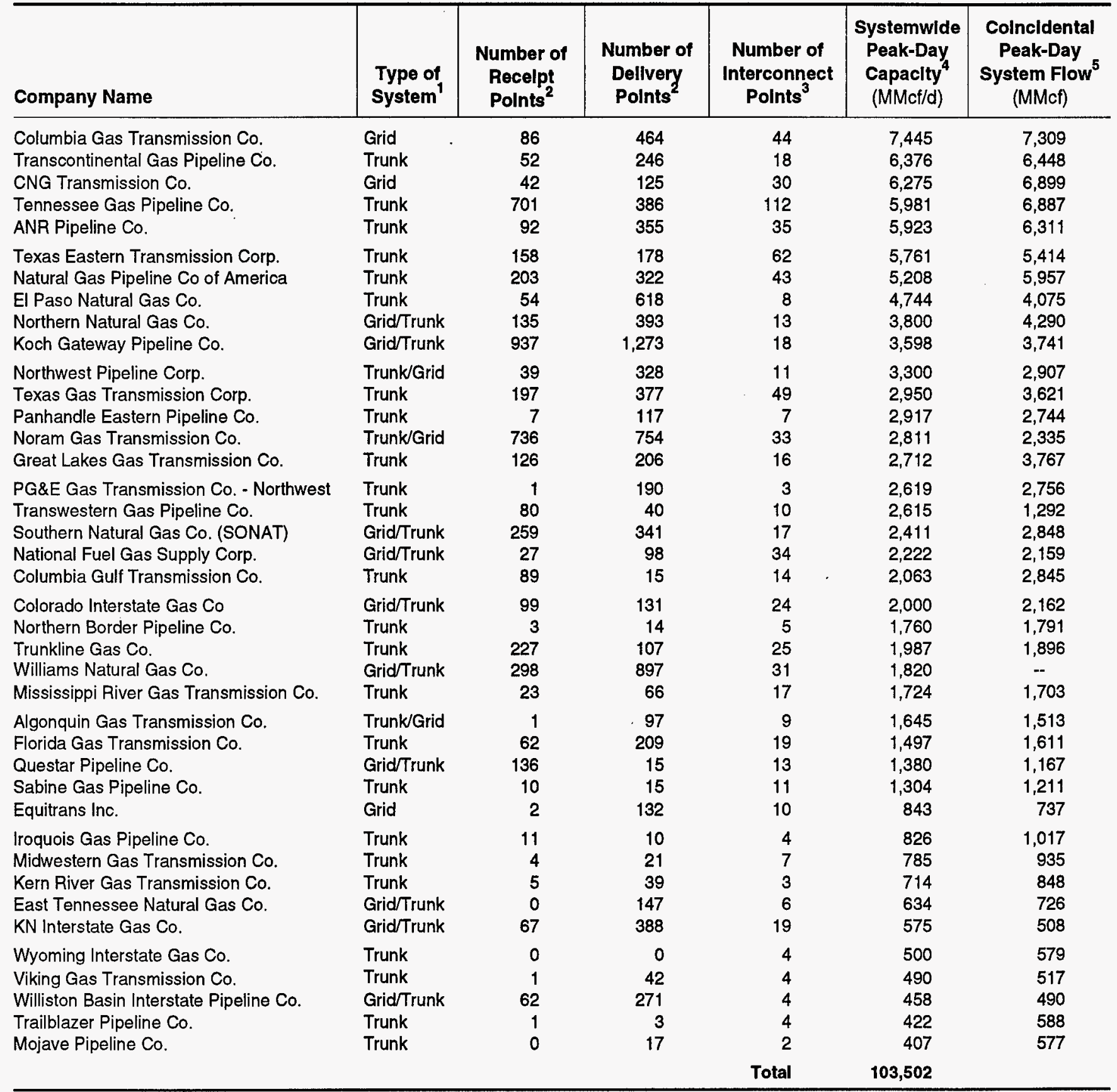

1 "Trunk" systems are long-distance trunklines that generally tie supply areas to market areas. "Grid" systems are usually a network of many interconnection and delivery points that operate in and serve major market areas. Some systems are a combination of the two. Where two are shown, the first represents the predominant system design.

${ }^{2}$ Pipelines with zero receipt and/or delivery points transfer volume via interconnections with other interstate pipelines.

${ }^{3}$ Represents a receipt, delivery, or emergency interconnect with one or more of the other pipeline companies listed in this table.

${ }^{4}$ Some pipeline companies reported their system levels in decaterms per day (Dth/d) rather than in million cubic feet per day (MMcf/d). In those instances, a factor of 1.027 was used for the conversion.

${ }^{5}$ Total volume reported as delivered off the entire pipeline system on its peak-day during the heating year extending from April 1, 1996, through March 31, 1997. All volumes reported in Dth/d and converted to MMcf/d using a 1.027 conversion factor.

$\mathrm{MMcf} / \mathrm{d}=$ Million cubic feet per day.

Source: Federal Energy Regulatory Commission (FERC). Recelpt/Dellvery/lnterconnects: FERC 567 Capacity Report, "System Flow Diagram." Systemwlde Peak-Day Capaclty: FERC Annual Capacity Report (18 CFR §284.12). Peak-Day Flow: FERC Form 2, "Annual Report of Major Natural Gas Companies." 
stations can be viewed as choke points along a system because they are designed to move a limited amount of gas through their location over a period of time. Capacity measures for individual pipelines at a hub are dependent upon the capabilities of the hub itself and operational aspects of other pipelines using the hub during a peak period.

This report primarily uses the "specific point" measure of deliverability, based on an estimated design throughput capability of a pipeline as it crosses State borders. This design capacity estimates the flow that could be obtained along a pipeline segment on a sustained basis under a specific set of conditions and thus provides a measure of comparability across all pipeline systems.

It should be emphasized that the capacity numbers derived for this report are merely "reasonable" estimates based upon design or contractual conditions. Actual capacity at a particular point or system wide is rarely one stable figure. Weather conditions, ambient temperature, elevation, and operational variables, such as short-term line packing ${ }^{5}$ and line pressure shifts, can affect stated capacity levels. In some cases, line packing can increase operational capacity by as much as 20 to 30 percent. Some of this increase is reflected in the differences between system capacity and peak-day flows shown in Table 1. In a number of cases, the peak-day flow is well above the reported overall system capacity.

The pipeline capacity estimates in this report are based primarily upon compressor station data in the Federal Energy Regulatory Commission Format 567, "System Flow Diagrams," filed annually by the major interstate pipeline companies. (See Appendix $\mathrm{C}$ for a detailed discussion of how capacity levels were derived and refined.) Systemwide capacity levels, when used, are based upon data reported to FERC by the major interstate pipeline companies in their annual capacity reports that accompany Format 567 (18 CFR $\$ 284.12$ ) or constructed from pipeline delivery data reported on FERC Form 11, "Natural Gas Pipeline Company Monthly Statement." 6

\section{Shipper Requirements}

Ultimately, the shippers' requirements determine the design capacity of pipeline system facilities. Pipeline companies seek to obtain a mix of shippers and contract types in order to maximize system throughput. Firm service requirements may

\footnotetext{
${ }^{5}$ Line packing is temporary storage of pipeline gas through the use of increased compression.

${ }^{6}$ The FERC Form 11 data used are only through 1995 . The form was revised in 1996 and now is filed only on a quarterly basis.
}

be expressed as a reservation on system capacity for the receipt and delivery of a maximum daily quantity of gas at specific points along the network. Under firm transportation contracts, the pipeline company agrees to reserve capacity on its system to provide a shipper, such as a local distribution company (LDC), industrial user, or electric utility, with up to a specified quantity on any given day. Pipeline companies must stand ready to provide service up to the volume level specified under firm contracts even though their shippers may not need or actually request transport of that gas. (However, in certain instances, pipeline companies have the authority to impose restrictions on the level of service they are obligated to provide (see Box, "Operational Flow Orders")).

LDCs are still the principal providers of supply to the ultimate end user, accounting for about 42 percent of the natural gas sold to end users in 1996 (down from 46 percent in 1993) and 25 percent of the gas transported on their behalf (up from 20 percent in 1993). They typically contract with pipeline companies for firm transportation and storage services to meet the requirements of their high-priority customers and for interruptible service to meet the needs of their lower priority customers. However, in some States where open-access transportation and deregulation are being tested, LDCs are slowly becoming merely deliverers for other sellers. In 1996, nonsales deliveries represented 37 percent $(4.9$ trillion cubic feet) of total LDC deliveries, up from 30 percent in 1993.

Consumers are generally classified into four categories: (1) residential, (2) commercial, (3) industrial, and (4) electric utility. Residential and commercial gas consumers usually have no other alternative for fuel except through the LDCs and thus are considered high-priority users. In contrast, many industrial users and electric utilities do not require firm service because they often have the capability to switch to other fuels. Some electric utility and industrial consumers contract for service on an interruptible basis. Under interruptible contracts, deliveries are subject to curtailments by the pipeline company or local distribution company when necessary to meet the requirements for service under firm contracts. Rates for interruptible service are generally less expensive than for firm service. Service to interruptible shippers is extremely important to the pipeline companies in their efforts to maintain a high level of throughput.

The demand for natural gas is quite diverse regionally. For example, in the northern regions of the country where a high proportion of residential and commercial consumers use natural gas for heating, deliveries under firm service contracts are highly seasonal because of the extreme weather variation. Other more temperate regions, such as the Southwest, may be very dependent on natural gas used in the generation of electricity to meet summer cooling loads. The use of natural gas for industrial purposes also varies substantially from 


\section{Operational Flow Orders}

When FERC Order 636 was instituted in 1993 and open access became the norm, the Federal Energy Regulatory Commission recognized that pipeline operators needed a mechanism in place that would still allow them to maintain the operational integrity of their system during periods of potential flux and when the system is under stress. Conditions such as extreme weather, unscheduled downtime on critical parts of the system, and extreme imbalance situations are some of the reasons pipeline companies cite as the need for such short-term control.

Operational flow orders (OFOs) (also called system emergency orders or critical period measures) are the mechanisms put in place to permit this control. In effect, these orders permit the pipeline operator during emergency situations to restrain shipper activities and to curtail services that could result in imbalances and service interruptions. For instance, OFOs allow the operator to reduce or eliminate flow tolerances and require shippers to maintain a strict daily balance between receipt and delivery volumes. The OFO also may restrict or eliminate such services as intraday nominations, the use of secondary receipt and delivery points, firm storage withdrawals, and interruptible storage services. As an enforcement measure, pipeline companies can exact penalties for violations (pipeline companies do not bear any costs incurred as a result of service restrictions and they get to keep any penalty revenues).

Despite their utility, OFOs are controversial. The direct consequence of measures taken under OFOs is to lessen short-term trading and shipping flexibility on the part of customers. Some maintain that pipeline operators are given too much discretion regarding what constitutes an OFO situation and that operators have incentives for maintaining the OFO for longer than is needed. Critics also argue that the fact that the pipeline company can retain any penalty revenues and place restrictions on nonfirm services and secondary receipt/delivery points is a disincentive to shippers who want these lower-cost services but are unwilling to risk possible interruption of their operational flows during peak periods.

While operating contingencies must be addressed and some form of pipeline system control during stress periods and emergencies will continue to be required, the criteria for OFO implementation may be changed as more experience is gained with emergency situations under open-access conditions. For instance, it has been suggested that the restrictions be imposed in a ratcheted manner, implementing more severe restrictions only if the lesser ones fail to alleviate the situation. Among the other possibilities: limit restrictions only to those parts of the system that are under stress; give shippers more advance notice before issuing the OFO; remove any financial incentives to pipeline companies under the OFO; and clearly define within the pipeline company's tariff the conditions for imposing an OFO and what operational conditions constitute an end to an OFO.

region to region. Some applications use natural gas for feedstocks and require a secure, dedicated supply of natural gas. Other uses are for boiler fuel where the user typically has the capability to burn other fuels in the event that natural gas is not available or is less economic than the alternatives.

\section{Transmission System Design}

The principal requirement of the natural gas transmission system is that it be capable of meeting the peak-day demand of its shippers who have contracts for firm service. To meet this requirement, the principal facilities developed by the natural gas industry are a combination of transmission lines to bring the gas to the market areas and of underground storage and liquefied natural gas (LNG) facilities closer to the market areas to meet surges in demand (Figure 1).
The design of the transmission lines and integrated storage sites represents a balance of the most efficient and economical mix of delivery techniques given the operational requirements facing pipeline companies. The mix varies widely depending on the number and types of shippers and access to supplies, either from production areas or underground storage. Many pipeline systems are configured principally for the longdistance transmission of supplies from production regions to market areas and are characterized as "trunklines" (Table 1). At the other extreme are the "grid". systems, which generally operate in and serve major market areas. Many of the grid systems can be categorized as regional distribution systems. For the most part, they receive their supplies from major trunklines or directly from local production areas and transport gas to local distribution companies and other consumers in more than one State.

Underground storage is an essential component of an efficient and reliable interstate natural gas transmission and 
Figure 1. Generalized Schematic of Natural Gas Pipeline Transmission

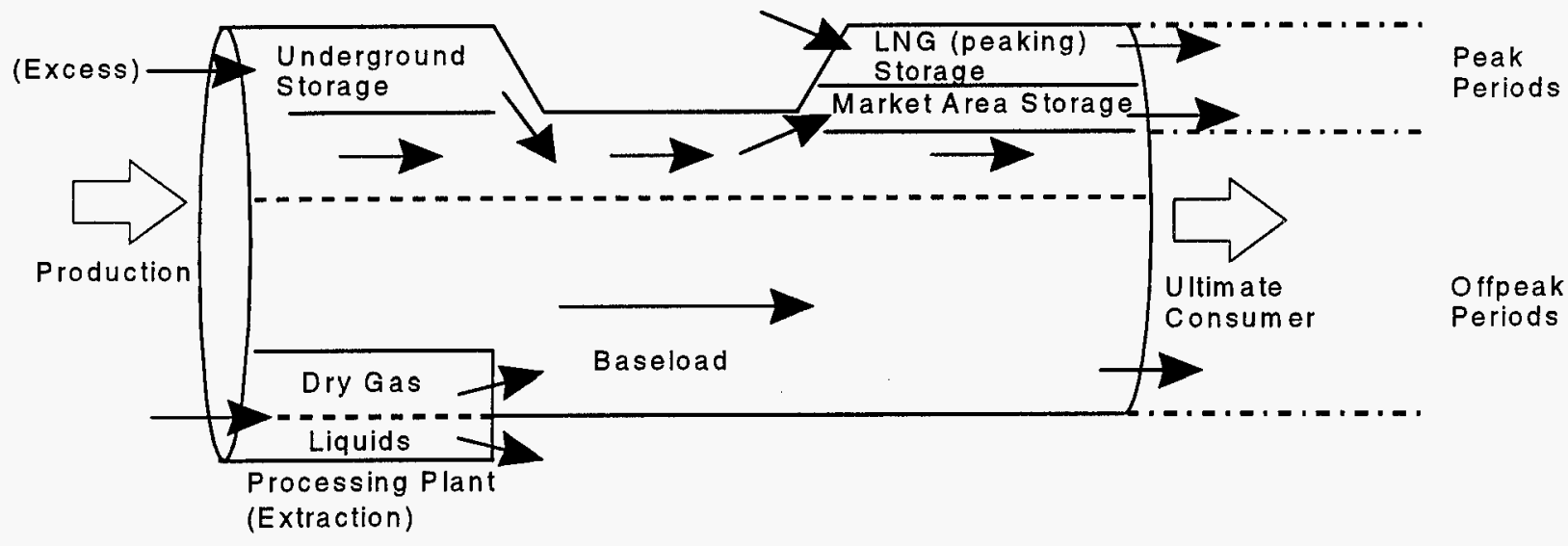

Note: Areas shown are not proportional to actual operational volumes or capacity.

Source: Energy Information Administration, Office of Oil and Gas.

distribution network. The size of the transmission line often depends in large part on the availability of storage. Rather than size a line to meet peak-day volumes, the line need satisfy only the difference between total shipper peak requirements and maximum withdrawal from storage as it enters the market area. In off-peak periods, the line must be able to provide shippers' off-peak needs plus injection to storage. In addition, some storage sites may require that system flow be reversible and that the main transmission line in the vicinity be able to accommodate this capability. The resulting pipeline configuration, including storage, may result in a comparatively low usage level in the off-peak season and a much higher, albeit shorter term, usage level during the peak-demand season.

During the nonheating season, for instance, when shippers do not use all the capacity contracted for, natural gas can be transported and injected into storage at a fairly constant rate. By the beginning of the heating season (November 1), inventory levels are generally at their annual peak. Working gas, that is, the portion of natural gas in storage sites ordinarily available for withdrawal and delivery to markets, ${ }^{7}$ is then withdrawn during periods of peak demand.

In addition, the pipeline company itself can avoid the need to expand transmission capacity from production areas by using existing, or establishing new, storage facilities in market areas

\footnotetext{
${ }^{7}$ In addition to working (top storage) gas, underground storage reservoirs also contain base (cushion) gas and, in the case of depleted oil and/or gas field reservoirs, native gas. Native gas is gas that remains after economic production ceases and before conversion to use as a storage site. Native gas and base gas typically are not withdrawn from the storage facility, as these volumes are necessary to ensure sufficient pressure for the withdrawal of the working gas.
}

where there is a strong seasonal variation to demand and where the system may be subjected to some operational imbalances.

The daily deliverability from storage can also be factored into the design needs of a new pipeline or the expansion needs of an existing one. Some underground storage facilities are located in production areas at the terminus of the pipeline corridor and, in contrast to storage near local markets, can be used to store gas that may not be economically marketable at the time of production. ${ }^{8}$ These sites can be used by shippers to store short-term excess supplies that exceed their reserve capacity on the pipeline system and the reverse when supplies fall below reserved capacity. Thus, the pipeline is relieved of additional demands for capacity brought on by temporary swings in transportation demands.

Often new systems are initially designed to handle volumes beyond the minimum requirement. A number of factors are involved in calculating how much gas a pipeline can carry, the most important being the diameter of the pipe and the pressure pushing the gas along the pipe. ${ }^{9}$ Because of flow dynamics, doubling the diameter of the pipe will increase the

\footnotetext{
${ }^{8}$ For instance, natural gas produced in association with oil production is a function of oil market decisions, which may not coincide with natural gas demand or available pipeline capacity to transport the gas to end-use markets. Another example is the storage of gas from low-pressure wells, where the gas can be injected during the off-peak season and delivered, at high pressure, to the mainline during the peak season.

${ }^{9}$ Standard design codes require that all pipelines passing though populated areas have their maximum operating pressures reduced for safety reasons. It became common practice to maintain nominal diameter but increase wall thickness where a line had to be derated for its surroundings in order to keep the working pressure rating more constant along the line.
} 
capacity more than sixfold at approximately twice the cost. Increasing the pipe wall thickness or strength of the pipe will enable the pipe to withstand a greater pressure. The pressure pushing the gas is usually provided by mechanical compression.

The design process itself includes the development of cost estimates for various possible combinations of pipe size, compression equipment, and interstation distances to find the combination that minimizes transportation cost given the desired flexibility and expandability goals. New trunklines are typically built with larger diameter pipe than needed initially, but only with the currently required compression capacity. Compression can then be added, either in existing or new, intermediate stations, to increase capacity as growth in load occurs.

\section{Pipeline Utilization}

Pipeline companies prefer to operate as close to capacity as possible, thus maximizing revenue; however, the average annual utilization rate usually does not reach 100 percent even in cases of full utilization. Several factors contribute to these lower rates, including the outages resulting from pipeline maintenance. During the summer months, when pipeline capacity demands are lowest, most pipeline companies schedule needed maintenance. As a result, some pipeline segments or compressor facilities may be placed out of service and transportation service suspended temporarily, for a day, a week, or even as long as a month.

Thus, average utilization rates below 100 percent do not necessarily imply that additional capacity is available. A pipeline company that serves primarily a seasonal market may have a relatively low average utilization rate even if there is no unreserved capacity on its system. Yet because of the difficulty in balancing unused commitments for firm service with interruptible service and transportation for others, it may be unable to provide further interruptible service to complement the high level of deliveries required during the peak consumption periods.

Integration of storage capacity into the pipeline network design can increase average-day utilization rates. Storage used for seasonal demand-swings effectively moves demand from one season of the year to another. Trunklines, which are generally upstream of the market storage areas, can be designed for a more constant load than the pipelines on the downstream side of the storage fields. Storage is usually integrated into or available to the system at the production and/or the market end as a means of balancing flow levels throughout the year. Therefore, trunklines serving markets with significant storage capacity have a much greater potential for obtaining a high utilization rate because the load moving on these pipelines can be levelized. Furthermore, to the extent these pipelines serve multiple markets, they can also achieve higher utilization rates because of load diversity across the markets they serve.

In fact, some trunkline systems, especially those reaching high-demand markets, often exhibit peak daily utilization rates greater than 100 percent. For example, the Iroquois Pipeline system, which transports Canadian gas to the U.S. Northeast, showed a peak-period usage rate above 100 percent in 1996, as did the Trailblazer Pipeline system out of the Rocky Mountains area. Several factors contribute to this situation. ${ }^{10}$ First, some trunkline systems are capable of handling much larger volumes than indicated by the operational design level certificated by FERC, which is the level that is used as the denominator when calculating usage rates (based on an annual throughput volume divided by 365 days). Second, as the line can handle more than the certificated capacity and shipper demand is high, maximum usage is made of the pipeline by its owners. In many instances of high demand, pipeline companies also use line packing and/or secondary compression to increase throughput, which was a tactic used by both Iroquois and Trailblazer this past year. When average daily utilization rates exceed stated capacity, it is more appropriate to use the peak-day volume as the actual capacity, or capability, of the system.

Utilization on the grid systems operating closer to the market areas and downstream of the storage fields is more likely to reflect the seasonal load profile of the market being served than utilization on upstream trunklines. The grid-type systems usually operate at lower average utilization levels than the trunklines, although during peak periods, usage levels are generally also at much higher rates. Grid systems usually show a marked variation between high and low flow levels, reflecting their seasonal service and local market characteristics. Storage services are usually highly integrated into the grid network to meet varying local market demands. Because grid systems have numerous interconnections within the network, their overall usage levels depend upon what happens in the various parts of the system. Pipeline segments that show a high degree of utilization are either serving a

\footnotetext{
${ }^{10}$ It should also be noted that in some instances the sum of individual transportation transactions may exceed pipeline capacity even though physically the pipeline may be full. For example, suppose a segment from points $A$ to $D$ (with points $B$ and $C$ between $A$ and $D$ ) has a capacity of 200 million cubic feet (MMcf) per day. Suppose further that this segment handles a $100 \mathrm{MMcf}$ per day transaction from $\mathrm{A}$ to $\mathrm{B}$, a second of $100 \mathrm{MMcf}$ per day from $B$ to $C$, and a third of $100 \mathrm{MMcf}$ per day from $\mathrm{C}$ to $\mathrm{D}$. The pipeline company will report transportation volumes of $300 \mathrm{MMcf}$ per day, even though its capacity is $200 \mathrm{MMcf}$ per day but is only 50 percent utilized on any one segment.
} 
shipper (or group of shippers) with relatively constant demand or have a significant interruptible service market.

The primary measure of pipeline utilization used in this analysis is an estimate of average-day natural gas throughput relative to estimates of system capacity at State and regional boundaries. Another measure used is systemwide pipeline flow rates, which highlight variations in monthly system usage relative to an estimated system peak throughput level (see Box, "Pipeline Utilization Measures"). In some instances, where data were available, pipeline peak-day utilization rates are referenced in this report. System peak-day usage rates, although only a reflection of peak system deliveries versus estimated system capacity, come the closest to showing how well the design of the system matches current shipper peakday needs. For example, when a pipeline shows a comparatively low average usage rate (based on annual or monthly data) yet shows a usage rate approaching 100 percent on its peak day, it indicates that the system is still called upon and is capable of meeting its shipper's maximum daily needs. Nevertheless, a large spread between average usage rates and peak-day usage rates can indicate a need to find better ways to utilize off-peak unused capacity.

\section{Capacity Expansion}

Although pipeline systems have some flexibility in handling changes in demand, sometimes system expansion and new pipeline routes are needed. There was substantial interest in expansion of the national pipeline network during the late 1980 's and early 1990 's and that interest continues today. Two of the largest proposals of the late 1980's to be implemented during the early 1990's were the Iroquois project, built to bring Canadian natural gas into the Northeast, and the Kern River project, which now transports natural gas from supply sources in Wyoming to California. These new lines began service in 1991 and 1992, respectively. A large number of other new systems and expansions are planned or under construction that will bring additional supplies from Canada, as well as from the Rocky Mountains area and the Southwest, to the U.S. Midwest and Northeast regions.

In most cases, interstate pipeline companies are required under Section 7(c) of the Natural Gas Act of 1938 to obtain a certificate of public convenience and necessity before constructing pipeline facilities. Besides review of operational aspects of the system, other legislation requires extensive review of the environmental aspects of the projects. ${ }^{11}$ These requirements have resulted in a very time-consuming, complex, and sometimes controversial process.

Once a project is approved and constructed under a Section 7(c) certificate, the costs of the facilities are eligible for inclusion in the pipeline company rate base (when the company files its next general rate case). ${ }^{12}$ Other options are also available to pipeline companies for capacity expansion, depending on the size of the project and the amount of risk the company is willing to assume. These options include:

- Blanket Certificate. Blanket certification can be used for relatively small projects. A blanket certificate approves a series of similar actions in one authorization. For instance, construction of small additions to a pipeline may be authorized by a blanket certificate, provided the total cost does not exceed some threshold level and other eligibility criteria are met. Similarly, pipeline companies may be allowed to transport gas on a self-implementing basis (without prior FERC approval) for many different shippers on the approval of a single blanket certificate. In recent years, FERC has been using blanket certification more frequently to authorize and facilitate both construction projects and transportation programs.

- Optional Certificate (formerly known as Optional Expedited Certificate). In 1985, under Order 436, FERC introduced optional certificates whereby construction could be approved without assessment of its market need or competitive proposals. In return, the pipeline company agrees to bear the majority of the risk of the project. Furthermore, the pipeline company may not decrease the projected volume of services used to design rates nor shift costs to pre-existing shippers. Because of the "at risk" factor, some optional certificate projects tend to be more adversely affected by procedural delays since changes in market conditions that occur in the meantime may necessitate a re-evaluation of the project's feasibility and its potential success.

- NGPA Section 311. Section 311 of the Natural Gas Policy Act (NGPA) of 1978 allows an interstate pipeline company to sell or transport gas "on behalf of" any

\footnotetext{
${ }^{11}$ These laws include: the National Environmental Policy Act, National Historical Preservation Act, Endangered Species Act, Toxic Substances Control Act, Clean Air Act, Clean Water Act, Coastal Zone Management Act, Wild and Scenic Rivers Act, Wilderness Act, and National Parks and Recreation Act.

${ }^{12}$ In some instances, FERC may also issue a Section 7(c) certificate subject to "at risk" conditions. In such cases, the pipeline companies are not guaranteed authority to include costs in the rate base, and risks borne by the companies are not reduced. Under an "at risk" certificate, a pipeline company's risk is minimized only where it has fully contracted the capacity of a new line.
} 


\section{Pipeline Utilization Measures}

\section{At State Borders}

The State-to-State measure of pipeline utilization used in this analysis is based on estimates of average-day pipeline throughput relative to estimates of system capacity at State boundaries. Average-day throughputs were computed by dividing annual Stateto-State flows in 1990 (reported by pipeline companies) by 365 days and those in 1996 by 366 days. Average-day utilization for the 2 years were then derived by dividing the average-day flow by the estimated capacity level. This measure provided the basis for the analysis pertaining to usage of specific portions of a pipeline system and additionally some insight into the type of service provided in the area.

But, because it uses averaged annual throughput volumes, the measure implies nothing about the availability of capacity during peak periods, except to the extent that the average daily utilization approaches, or exceeds, 100 percent. (Service levels on a pipeline system often vary from month to month, day to day, and even hourly.) As the computed utilization rate approaches 100 percent, it indicates only that the volume of gas moving through a specific geographic area on an average day during the year approximated estimated capacity. When this does occur, however, it is likely that the specific system location experiences some constraints during peak periods. A system that fully utilizes available capacity for short periods and not on a sustained basis throughout the year will show a lower utilization rate based on a daily averaging of annual throughput.

\section{Systemwide}

In order to evaluate operational and utilization levels of the various pipeline systems during the year, several flow-rate derivations were computed. These rates are based on a comparison of 1995 monthly throughput (the latest available monthly data) on the entire pipeline system with the largest throughput (sales, transportation, and intercompany transfers) that occurred in any month over a 15-year period (1980-1995). They were developed to show the degree of difference that occurs on different types of systems over the year as seasons and demand change. In these computations, the highest monthly throughput during the 15-year period is used as the proxy for the systemwide capacity of the pipeline. (This method has its limitations, including the fact that accounting of throughput can vary by pipeline company, leading to the reporting of excess throughput levels.) For 1995, (1) average-month throughput, (2) high-month throughput, and (3) low-month throughput were each divided by the 15-year high-month throughput to derive three flow-rate percentages. In addition, a summer (nonheating season) usage level, using the sum of volumes delivered during the nonshoulder months of May through September divided by 153 days, was also computed. (April and October are considered to be months that "shoulder" the heating season of November through March.)

Another systemwide usage rate was also computed based upon an annual system (deliverability) capacity level reported to the Federal Energy Regulatory Commission (FERC) by the major pipeline companies and the system's yearly peak 1-day volume. This figure provided a snapshot of the system's maximum use level containing a minimum skew caused by downtime and other factors.

An analysis of the peak-day, high month, low month, average monthly, and average summer (off-peak) throughput rates provides some understanding of the load variability on a pipeline system throughout the year. For instance, systems with a high-month rate of 100 percent in 1995 had a record monthly throughput level in 1995 . If these same systems also exhibited high average utilization rates at State border crossings, they may be constrained in their abilities to serve additional shippers without capacity expansion. In contrast, systems having a relatively low peak-month throughput but high average utilization levels at specific points along the network probably are experiencing more localized capacity constraints.

Comparison of the systemwide average-month flow rates with utilization rates at State border crossings can provide insight into how representative the individual utilization rates are of the whole system. For example, if utilization rates are very high at State border crossings but the systemwide average-month rate is significantly lower, then there are likely to be elements of the system, probably wholly contained within a region or State, where utilization is low. Conversely, if utilization rates at State borders are very low but the systemwide average-month rate is significantly higher, then there are likely to be elements of the system where utilization is quite high. These areas are likely to be near supply regions where interstate pipelines interconnect and transfer large volumes of gas from one system to another. 
intrastate pipeline or local distribution company. FERC has exempted the construction of facilities used solely for Section 311 transportation from certificate requirements. Construction is subject to environmental conditions and a 30-day notice to FERC, which requires only information on the delivery point of gas from the interstate pipeline, the total and daily volumes expected to be delivered, and the rate to be charged for transportation or sale.

Planned expansions of the current pipeline system are proposed under each of these options and are detailed in Appendix B. The traditional Section 7(c) application is still the most widely used.

As of March 1998, the Energy Information Administration was tracking more than 100 proposed pipeline expansions and new pipeline projects at various stages of development in the United States, Canada, and Mexico. If all U.S. projects were completed, the amount of new capacity would add more than 29 billion cubic feet of daily deliverability on the national network. The most extensive development is focused on expanding the deliverability of Canadian gas to the U.S. Midwest and Northeast and to Canadian markets. The secondlargest focus is on improving access to the increasing deepwater production in the Gulf of Mexico. Next are those projects whose objective it is to increase the flow of lowercost supplies located in the Central United States to markets located primarily in the Midwest. Currently, the capability to do so is limited. The latter series of expansions will be competing, to some degree, with the projects slated to increase flows of Western Canadian gas to the Midwest marketplace. The potential impact of proposed capacity expansions is discussed in subsequent chapters. 


\section{Access to Supplies and Production Areas}

Natural gas production patterns in the lower 48 States have changed in recent years as new fields have been brought on line and older gas-producing areas have declined in importance. For example, the eighth largest gas field in the United States in 1996 in terms of output, Bob West in southern Texas, was discovered only in 1990 and as late as 1993 did not even figure among the top 30 producers. Also, new technology has rejuvenated older fields and allowed production from fields previously thought uneconomic.

The shifts in regional production will affect existing pipeline routes, reducing flows along some, while increasing flows along others. Some regional production increases from new gas fields in the Rocky Mountain area and New Mexico will require additional capacity to transport the gas to markets. The Gulf Coast region has seen a substantial increase in production over the past several years and, although traditionally served by an extensive pipeline network, will probably require the addition of new capacity. Meanwhile, production in the Anadarko and Arkoma Basins declined during the first half of the 1990s.

This chapter discusses U.S. natural gas deliverability at the wellhead through 2000 and the capability of the pipeline network to receive and export that gas through the national network grid. The analysis focuses on eight producing areas that roughly correspond to major geologic basins in the lower 48 States (Figure 2), as well as imports from Canada. Relatively new producing regions (in terms of average field age) covered in this chapter include the offshore Gulf of Mexico; major fields in the Rocky Mountain States of Utah, Colorado, and Wyoming; and the San Juan Basin of New Mexico. Older producing regions examined include the Permian Basin; the onshore Gulf Coast of Texas and Louisiana; the Anadarko and Arkoma basins in Oklahoma, Kansas, and Arkansas; the fields of East Texas; and the Appalachian Basin. ${ }^{13}$ Although a relatively minor gas producer, the Appalachian Basin region is notable because of its proximity to major markets in the Northeast. Canada has sharply increased gas exports to the United States during the

\footnotetext{
${ }^{13}$ The regional data were aggregated from data by State and sub-State areas. The lack of strict correspondence between the basins and these data means that portions of basins may be excluded, or other lesser basins may be included in the regional estimates. For expository purposes, the regions, in some cases, are treated as equivalent to the major basins within the regions.
}

1990 s, growing as a major source of deliverability in the lower 48 States.

Alaska is not included as a supply area in this study because its natural gas production is not destined for U.S. markets in the lower 48 for some time to come and therefore does not directly affect U.S. gas deliverability within the time frame of the analysis.

\section{U.S. Natural Gas Supplies by Region, 1990-2000}

Total natural gas production in the lower 48 States has shown an upward trend during the 1990 s, rising 5 percent from an average 47.7 billion cubic feet (Bcf) per day (17.4 trillion cubic feet (Tcf) on an annual basis) in 1990 to $50.1 \mathrm{Bcf}$ per day (18.4 Tcf per year) in 1996 (Table 2), its highest level since the early 1980s. Higher gas demand and stable prices are projected to raise production in the lower 48 to about $54 \mathrm{Bcf}$ per day (19.8 Tcf per year) in 2000. The 1.9-percent average annual growth rate forecast for the period 1996 through $\mathbf{2 0 0 0}$ is more than double the production growth rates of the first half of the 1990s. ${ }^{14}$

Lower 48 gas reserves increased to $156 \mathrm{Tcf}$ in 1996, marking the third consecutive year of higher reserve levels although still slightly below the 1990 level of $160 \mathrm{Tcf}$. This recent trend is expected to continue. Various factors, such as improved well completions, advanced stimulation technology, and improved seismic technology, have allowed producers to maximize gas output from existing fields, resulting in a decline in the ratio of reserves to production since 1990. The near-term supply outlook for natural gas shows expanded production through 2000 , reflecting the recent production trends as well as the substantial volume of remaining resources. ${ }^{15}$ One recent study estimated remaining recoverable gas resources at $929 \mathrm{Tcf}$ as of December 31, 1996, suggesting

\footnotetext{
${ }^{14}$ Unless otherwise noted, all forecasts are derived from data in the Energy Information Administration (EIA) publication Annual Energy Outlook 1998 With Projections to 2020, DOE/EIA-0383(98) (Washington, DC, December 1997). Historical data for the lower 48 States are from EIA's Natural Gas Annual 1996, DOE/EIA-0131(96) (Washington, DC, September 1997), and earlier editions of this report. The lower 48 totals are disaggregated to regional estimates, based on relative dry gas production values as reported in the EIA report U.S. Crude Oil Natural Gas, and Natural Gas Liquids Reserves 1996, DOE/EIA-0216(96) (Washington, DC, December 1997), and earlier editions.

${ }^{15}$ Energy Information Administration, Annual Energy Outlook 1998, (Washington, DC, December 1997).
} 
Figure 2. Major Natural Gas Producing Basins and Transportation Routes to Market Areas

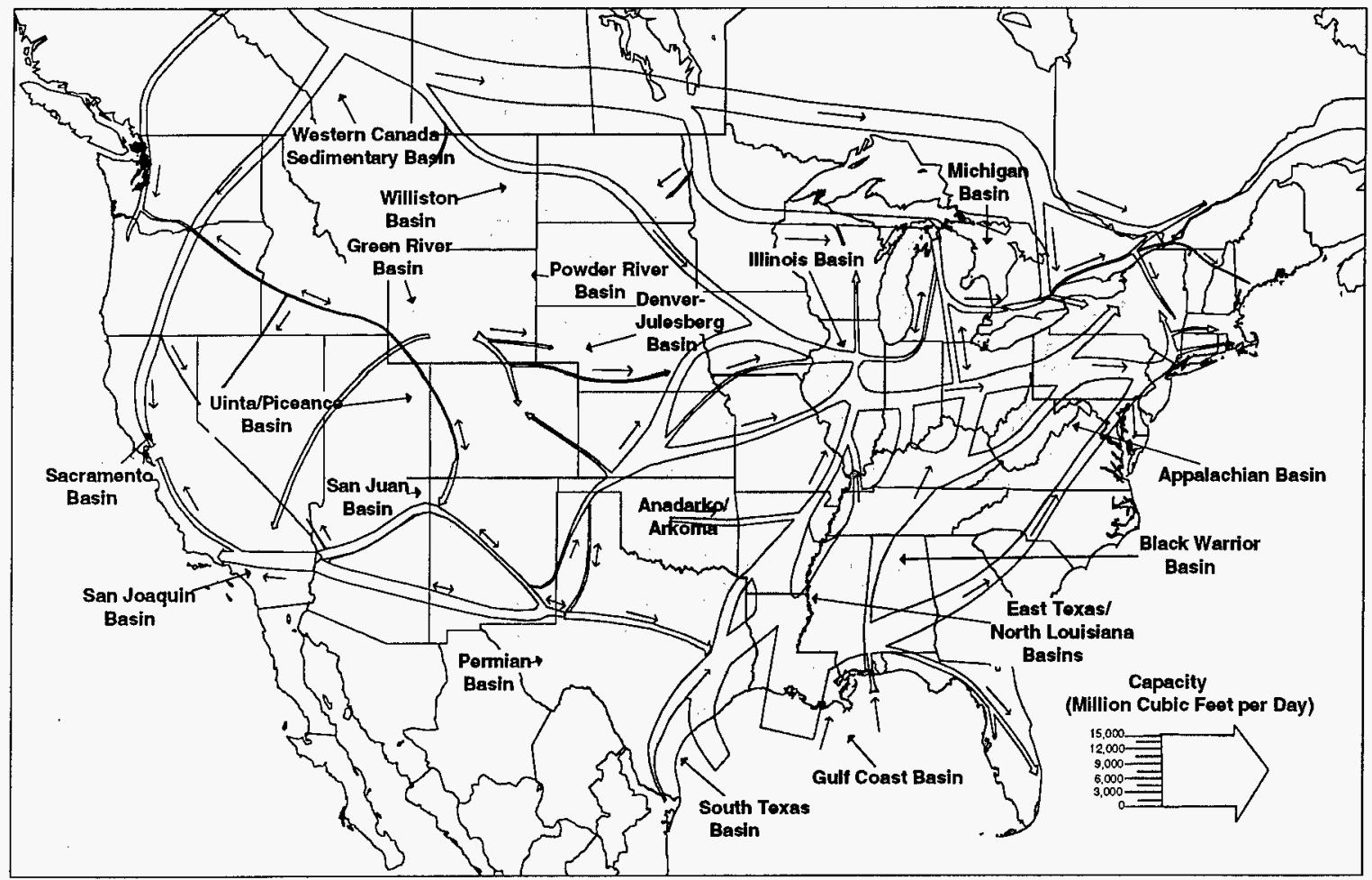

Correspondence to Major Natural Gas Producing Regions

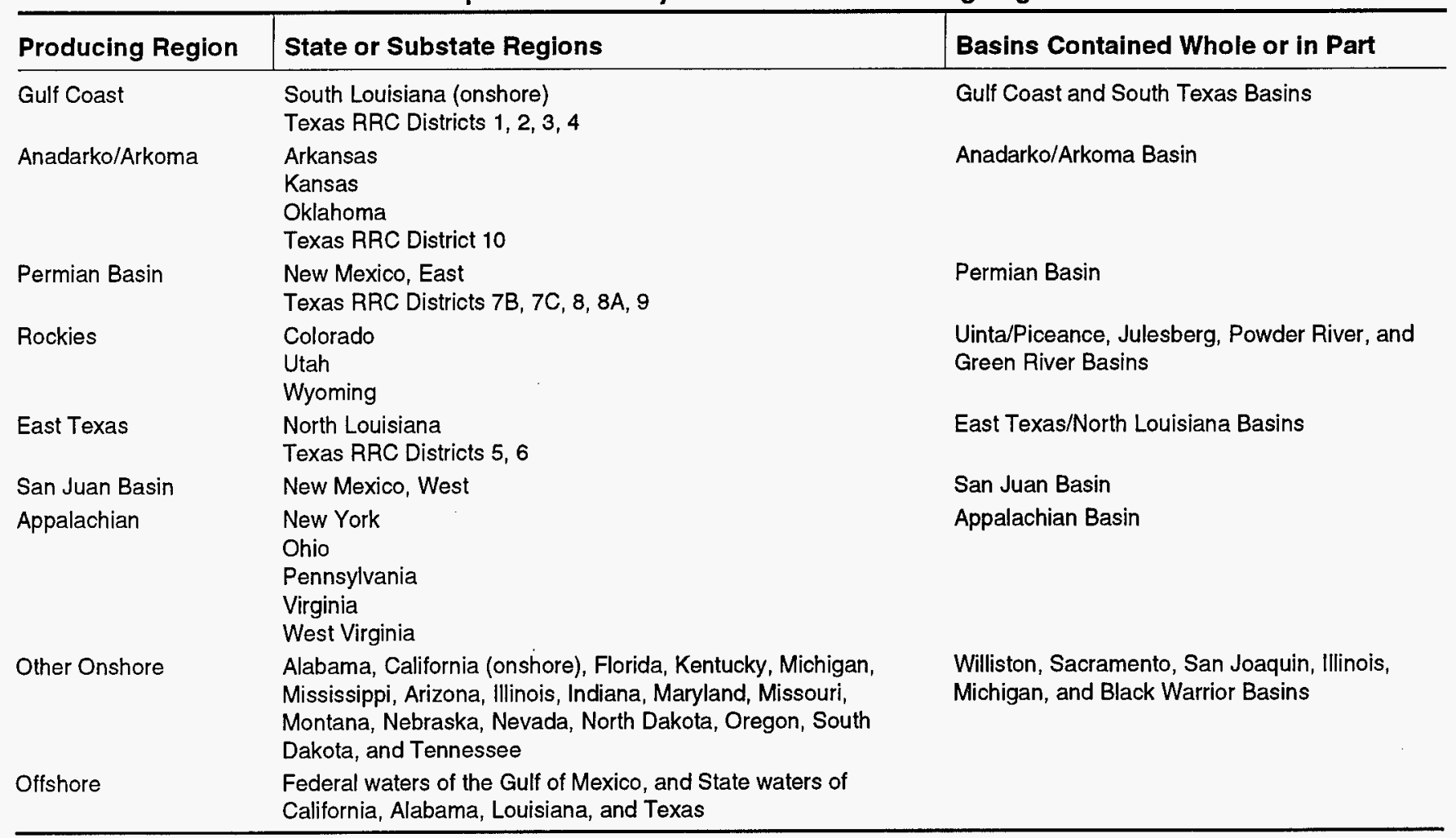

Source: Energy Information Administration, EIAGIS-NG Geographic Information System, Natural Gas Pipeline State Border Capacity Database, as of December 1997. 
Table 2. Natural Gas Production and Supplies in the Lower 48 States, by Region, 1990-2000

\begin{tabular}{|c|c|c|c|c|c|c|c|c|c|c|c|}
\hline \multirow[b]{2}{*}{ Region } & \multicolumn{3}{|c|}{$\begin{array}{l}\text { Annual Gas Supplles } \\
\text { (billion cubic feet per year) }\end{array}$} & \multicolumn{3}{|c|}{$\begin{array}{c}\text { Dally Gas Supplles } \\
\text { (billion cubic feet per day) }\end{array}$} & \multicolumn{2}{|c|}{$\begin{array}{l}\text { Change In Gas Supplles } \\
\text { (percent increase/decrease) }\end{array}$} & \multicolumn{3}{|c|}{$\begin{array}{c}\text { Share of Total Supplles } \\
\text { (percent) }\end{array}$} \\
\hline & 1990 & 1996 & $\begin{array}{c}2000 \\
\text { (forecast) }\end{array}$ & 1990 & 1996 & $\begin{array}{c}2000 \\
\text { (forecast) }\end{array}$ & $1990-96$ & $\begin{array}{l}1996-2000 \\
\text { (forecast) }\end{array}$ & 1990 & 1996 & $\begin{array}{c}2000 \\
\text { (forecast) }\end{array}$ \\
\hline \multicolumn{12}{|l|}{ Lower 48 Production } \\
\hline Gulf Coast & 3,130 & 3,340 & 3,432 & 8.6 & 9.1 & 9.4 & 6.4 & 2.8 & 16.5 & 15.7 & 14.4 \\
\hline Anadarko/Arkoma & 3,339 & 2,929 & 2,967 & 9.1 & 8.0 & 8.1 & -12.5 & 1.3 & 17.6 & 13.8 & 12.4 \\
\hline Permian Basin & 1,663 & 1,621 & 1,890 & 4.6 & 4.4 & 5.2 & -2.8 & 16.6 & 8.8 & 7.6 & 7.9 \\
\hline Rockies & 911 & 1,497 & 1,668 & 2.5 & 4.1 & 4.6 & 63.9 & 11.5 & 4.8 & 7.0 & 7.0 \\
\hline East Texas & 1,109 & 1,153 & 1,185 & 3.0 & 3.2 & 3.2 & 3.7 & 2.8 & 5.8 & 5.4 & 5.0 \\
\hline San Juan Basin & 511 & 988 & 1,101 & 1.4 & 2.7 & 3.0 & 92.9 & 11.5 & 2.7 & 4.6 & 4.6 \\
\hline Appalachian Basin & 496 & 504 & 583 & 1.4 & 1.4 & 1.6 & 1.3 & 15.7 & 2.6 & 2.4 & 2.4 \\
\hline Other Onshore & 844 & 828 & 1,073 & 2.3 & 2.3 & 2.9 & -2.2 & 29.6 & 4.5 & 3.9 & 4.5 \\
\hline Total Onshore & 12,003 & 12,859 & 13,899 & 32.9 & 35.1 & 38.0 & 6.8 & 8.1 & 63.3 & 60.4 & 58.2 \\
\hline Offshore & 5,425 & 5,491 & 5,881 & 14.9 & 15.0 & 16.1 & 0.9 & 7.1 & 28.6 & 25.8 & 24.6 \\
\hline Total Lower 48 & 17,428 & 18,350 & 19,780 & 47.7 & 50.1 & 54.0 & 5.0 & 7.8 & 91.9 & 86.2 & 82.8 \\
\hline \multicolumn{12}{|l|}{ Lower 48 Imports } \\
\hline From Canada & 1,448 & 2,883 & 3,910 & 4.0 & 7.9 & 10.7 & 98.6 & 35.6 & 7.6 & 13.5 & 16.4 \\
\hline Total Lower 48 & 1,532 & 2,937 & 4,120 & 4.2 & 8.0 & 11.3 & 91.2 & 40.3 & 8.1 & 13.8 & 17.2 \\
\hline $\begin{array}{l}\text { Total Lower } 48 \\
\text { Supplles }\end{array}$ & 18,960 & 21,287 & 23,900 & 51.9 & 58.2 & 65.3 & 12.0 & 12.3 & 100.0 & 100.0 & 100.0 \\
\hline
\end{tabular}

Sources: 1990-96 Data: Energy Information Administration (EIA), Natural Gas Annual 1996 (September 1997) and earlier editions. Production volumes by regions were derived based on relative dry gas production values published in U.S. Crude Oil, Natural Gas, and Natural Gas Liquids Reserves 1996 (December 1997) and earlier editions. 2000 Forecasts: ElA, Annual Energy Outlook 1998 (AEO) (December 1997). When regions differed between the Natural Gas Annual and the $A E O$, regional production volumes were projected for 2000 by applying the growth factor for the AEO region between 1996 and 2000.

adequate domestic gas supplies through the near-term perspective of the present analysis. ${ }^{16}$

While higher gas production in the lower 48 States contributed to increased U.S. gas supplies between 1990 and 1996, the source of the largest portion of the increase was imports from Canada. Benefiting from strong U.S. demand and a more open trade environment, Canadian gas exports to the United States nearly doubled between 1990 and 1996 and accounted for about two-fifths of the increase in U.S. gas supplies during this period. By 2000 , imports of natural gas from Canada are projected to account for 16 percent of U.S. gas supplies, more than double their 1990 share.

The concentration of increased gas supplies through 2000 in a small number of areas-Canada, the Rocky Mountain area, the Permian Basin, the San Juan Basin of New Mexico, and the offshore/onshore Gulf-raises concerns about the ability of the pipeline system and other infrastructure to meet

\footnotetext{
${ }^{16}$ Remaining recoverable gas resources are those volumes producible with current recovery technology and efficiency but without reference to economic viability. The estimate of 929 trillion cubic feet of remaining recoverable gas resources is published in the report Potential Supply of Natural Gas in the United States, Potential Gas Agency, Colorado School of Mines (March 1997).
}

increased demand for U.S. gas deliverability through the year 2000 . Of the $7.1 \mathrm{Bcf}$ per day (2.6 Tcf) in additional U.S. gas supplies anticipated between 1996 through 2000, imports from Canada are likely to represent about two-fifths of supply growth. Key domestic regions contributing to the supply rise are the offshore and Permian Basin regions with 15 and 10 percent of the total increase, respectively (Table 2).

In 1996 , the United States had nearly 302,000 producing gas wells and gas-condensate wells, ${ }^{17}$ as well as a very large number of oil wells, yielding approximately $50 \mathrm{Bcf}$ of natural gas per day (18.4 Tcf per year). The largest gas-producing region in the lower 48 States is the offshore region, followed by the onshore Gulf Coast, the Anadarko/Arkoma Basins, the Permian Basin, and the Rockies. Together, these five regions accounted for 81 percent of total U.S. dry gas production in 1996. Eighty-six percent of U.S. consumption is met by domestic producers, while the remainder is imported mostly from Canada. The following sections highlight the contribution of each major supply region to gas supplies and deliverability in the lower 48 States.

\footnotetext{
${ }^{17}$ Energy Information Administration, Natural Gas Annual 1996, DOE/EIA-0137 (Washington, DC, September 1997).
} 


\section{Offshore Gulf of Mexico}

The top gas-producing region in the lower 48 States is the offshore region, where production flows almost exclusively from the Offshore Gulf of Mexico. The Gulf accounted for almost 30 percent of natural gas production (Figure 3 ) and more than one-fifth of proved reserves ${ }^{18}$ (Table 3 ) in the lower 48 in 1996. The recent rebound in offshore exploration and development activity is likely to make the offshore region an important source of increased gas supplies during the late 1990s. Recent changes in the sources of gas production in the Gulf in favor of associated gas and deep water gas have major implications for future gas deliverability from this region and its impact on regional markets.

Major plays in the Gulf of Mexico are found in the Flexure Trend, the Norphlet Trend, the Destin Dome, subsalt, and deep water fields. The Flexure Trend extends from Mobile Bay to Mexico and includes fields in waters deeper than 600 feet; estimated productive capacity in the Flexure Trend was about $1.2 \mathrm{Tcf}$ in $1996 .{ }^{19}$ The Norphlet Trend is an extension of the Flexure Trend stretching from Alabama to Florida containing fields at 600 to 2,000 feet of depth. Production in the Norphlet Trend was about 1 Tcf in 1996. The Destin Dome, a part of the Norphlet Trend located off the coast of the Florida Panhandle, is estimated to contain $3 \mathrm{Tcf}$ of potential reserves. However, significant production here is not likely to begin until around 2000 and will therefore have minimal impact on U.S. gas deliverability in the near term.

The collapse of oil and gas prices in the mid 1980s caused a reduction in overall exploration and development activities in the Gulf that continued into the early 1990 s. As the average U.S. wellhead price fell by more than two-fifths in real terms (1996 dollars) between 1985 and the early 1990 s, $^{20}$ offshore gas production was hit harder than onshore production because of the rapid depletion of known deposits in shallow waters and higher increased risks and costs associated with exploration and development of gas in deep water. Between 1990 and 1992, offshore gas production declined by 8 percent because of the lack of reserves replacement. Total offshore reserves shrank 10 percent between 1990 and 1992.

The large fields in the deep waters, combined with costcutting new technologies, have greatly improved the economics of offshore gas production, raising offshore output

\footnotetext{
${ }^{18}$ Proved reserves of natural gas are the estimated quantities which analysis of geological and engineering data demonstrate with reasonable certainty to be recoverable in future years from known reservoirs under existing economic and operating conditions.

${ }^{19}$ WEFA, Natural Gas Outlook (Spring/Summer 1997), p. 6.9.

${ }^{20}$ Energy Information Administration, U.S. Crude Oil, Natural Gas, and Natural Gas Liquids Reserves, Annual Report 1996, DOE/EIA-0216(96) (Washington, DC, December 1997), p. 10.
}

more than 13.0 percent between 1992 and 1996 to a level of $15.0 \mathrm{Bcf}$ per day (5.5 Tcf per year). A 12-percent increase in average gas wellhead prices over the average from 1990 through 1992 (in constant 1996 dollars), coupled with a onethird decline in finding costs (also in 1996 dollars), contributed to a dramatic improvement in the profitability of offshore gas production. According to one source, ${ }^{21}$ offshore gas production by $1995-96$ was profitable at average wellhead prices of only $\$ 1.75$ per thousand cubic feet, down from a profitability threshold estimated at $\$ 2.50$ per thousand cubic feet (in current dollars) in 1991-92. With 1996 U.S. wellhead prices averaging $\$ 2.17$ per thousand cubic feet, offshore gas production had become profitable after a high degree of unprofitability during the late 1980 s and early 1990 s.

The very high exploration and development (E\&D) expenditures associated with offshore projects, more than $\$ 1$ billion in some cases, are declining generally as companies gain experience with more challenging deep water and subsalt projects. Both project time horizons and platform costs are shrinking dramatically. For example, the capital portion of daily production costs for Shell's Ursa tension leg platform (TLP), due to begin production in 1999 , is projected to be slightly more than half that of Auger, Shell's first TLP installed in $1994 .{ }^{22}$ Offshore projects partially compensate for higher upfront expenditures with faster recovery of reserves through higher flow rates. The faster depletion of offshore wells requires more continuous exploration activity to maintain production levels. The Outer Continental Shelf (OCS) Deep Water Royalty Relief Act (DWRRA), ${ }^{23}$ signed in November 1995, has also improved the economics of offshore production. The DWRRA provides for a waiver of royalty payments for production from new leases and certain other deep water leases. ${ }^{24}$

Overall, offshore gas production is projected to grow 7 percent from 15.0 Bcf per day (5.5 Tcf per year) in 1996 to $16.1 \mathrm{Bcf}$ per day (5.9 Tcf per year) in 2000. A key source of expanded production is likely to be associated-dissolved (AD) gas from crude oil production (accounting for one-fourth of the incremental production), although expanded output of

\footnotetext{
${ }^{21}$ James Dodson and Leonard LeBlanc, "U.S. Gulf Rebound to Continue in 1995," Offshore (January 1995), p. 20.

22،"Deepwater, subsalt projects open new era for Gulf of Mexico actions," Oil and Gas Joumal (January 20, 1997), p. 37.

${ }^{23}$ The law provides royalty relief to oil and gas fields in the Central and Western Gulf of Mexico that would not be economic to produce without royalty relief. In particular, fields that did not produce prior to November 28 , 1995, and meet Minerals Management Service (MMS) economic determinations may receive royalty suspension volumes of at least 17.5 million barrels of oil equivalent (BOE) in 200 to 400 meters of water, 52.5 million BOE in 400 to 800 meters of water, and 87.5 million BOE in more than 800 meters of water.

24،"Deepwater royalty relief product of $31 / 2$ year U.S. political effort," Oil and Gas Joumal (April 1, 1996), pp. 45-56.
} 
Figure 3. Lower 48 Natural Gas Production by Region, 1996 (Share of Total in Percent)

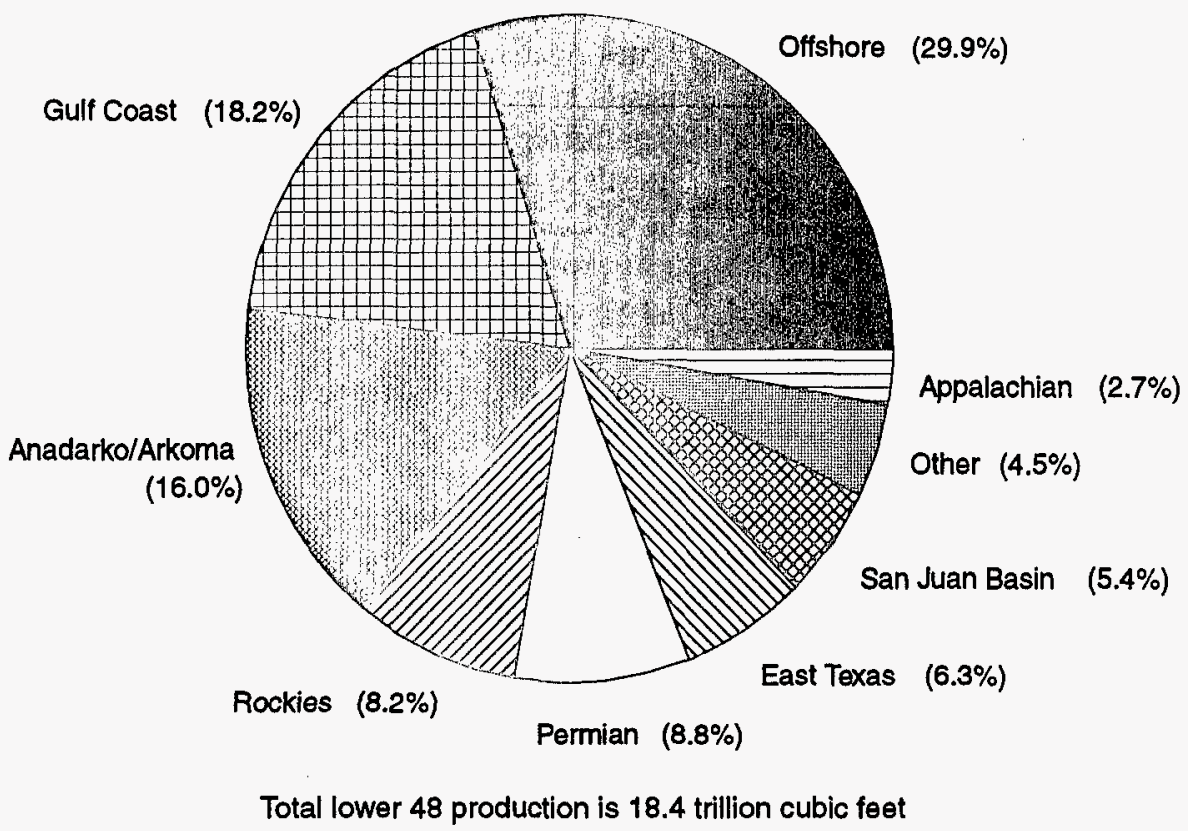

Source: Energy Information Administration. Total 1996 Production: Natural Gas Annual 1996 (September 1997). Shares by Reglon: U.S. Crude Oil, Natural Gas, and Natural Gas Liquids Resenves 1996 (December 1997).

Table 3. Lower 48 Dry Natural Gas Proved Reserves and Reserves-to-Production Ratio, 1990-1996

\begin{tabular}{l|r|r|r|r|r|r}
\hline \multirow{2}{*}{ Region } & \multicolumn{3}{c|}{$\begin{array}{c}\text { Proved Reserves } \\
\text { (billion cubic feet) }\end{array}$} & \multicolumn{3}{c}{$\begin{array}{c}\text { Proved Reserves-to- } \\
\text { Productlon Ratio }\end{array}$} \\
\cline { 2 - 7 } & \multicolumn{1}{|c|}{$\mathbf{1 9 9 0}$} & $\mathbf{1 9 9 5}$ & $\mathbf{1 9 9 6}$ & $\mathbf{1 9 9 0}$ & $\mathbf{1 9 9 5}$ & $\mathbf{1 9 9 6}$ \\
\hline Gulf Coast & 21,325 & 19,186 & 20,050 & 7.0 & 6.1 & 6.0 \\
Anadarko/Arkoma & 31,986 & 28,008 & 26,629 & 9.9 & 9.8 & 9.1 \\
Permian Basin & 15,718 & 13,534 & 14,053 & 9.8 & 8.5 & 8.6 \\
Rockies & 16,009 & 21,002 & 21,663 & 18.1 & 14.1 & 14.4 \\
East Texas & 10,216 & 10,376 & 11,083 & 9.5 & 9.2 & 9.6 \\
San Juan Basin & 14,004 & 14,624 & 13,695 & 28.3 & 14.9 & 13.8 \\
Appalachian Basin & 5,633 & 7,068 & 7,674 & 11.7 & 15.3 & 15.2 \\
Other Onshore & 9,584 & 8,027 & 8,653 & 11.7 & 10.1 & 10.4 \\
Total Onshore & $\mathbf{1 2 4 , 4 7 5}$ & $\mathbf{1 2 1 , 8 2 5}$ & $\mathbf{1 2 3 , 5 0 0}$ & $\mathbf{1 0 . 7}$ & $\mathbf{9 . 8}$ & $\mathbf{9 . 6}$ \\
Offshore & 35,571 & 33,824 & 33,680 & 6.8 & 6.6 & 6.1 \\
Total Lower 48 & $\mathbf{1 6 0 , 0 4 6}$ & $\mathbf{1 5 5 , 6 4 9}$ & $\mathbf{1 5 7 , 1 8 0}$ & $\mathbf{9 . 5}$ & $\mathbf{8 . 9}$ & $\mathbf{8 . 5}$ \\
\hline
\end{tabular}

Source: Energy Information Administration, U.S. Crude Oil, Natural Gas, and Natural Gas Liquids Reserves 1996 (December 1997). 
deep water and subsalt gas also contribute to production gains.

A more than one-third increase in Gulf oil production since 1990 has led to higher output of AD gas, which reached $2.2 \mathrm{Bcf}$ per day ( $0.8 \mathrm{Tcf}$ ), or 15 percent of total offshore gas production in 1996. Based on Energy Information Administration (EIA) projections of Gulf oil output through $2000,{ }^{25} \mathrm{AD}$ gas will rise by another $0.25 \mathrm{Bcf}$ per day. The considerable future potential of $\mathrm{AD}$ gas is demonstrated by its large share of total offshore reserves, which grew from less than 20 percent in 1990 to 22.4 percent in 1996.

The growing influence of $\mathrm{AD}$ gas in the Gulf has provided producers with some logistical challenges and has possible implications for regional gas prices. Because natural gas is consumed in accordance with seasonal market demand, the fairly steady recovery schedule of $A D$ gas from oil projects results in some gas being produced during periods of minimal demand. Such an inelastic production schedule, characteristic of $\mathrm{AD}$ gas, could depress gas prices in the Gulf region during periods of minimal demand.

Expanding production of $\mathrm{AD}$ gas in the Gulf of Mexico has therefore led to increased use of storage along the Gulf Coast, so that producers can better match supplies to seasonal demand. The anticipated increase in $\mathrm{AD}$ gas production through 2000 is being accompanied by underground storage expansions under development in Texas and Louisiana with a combined daily deliverability of 2 Bcf per day. ${ }^{26}$ Underground storage capacity is also being expanded near major market areas in the Northeast and Midwest, where up to $1.5 \mathrm{Bcf}$ per day in daily deliverability could be added in each region by 2000 . However, most likely not all planned capacity additions will be realized.

Other offshore production trends affecting gas deliverability include a movement to the deeper offshore and an emerging interest in subsalt deposits. While wells in water deeper than 1,000 feet (roughly 305 meters) have been producing gas in the Gulf since the late 1970s, their role in offshore gas production was minimal until recent technological advances, such as improved 3-D seismic surveys and floating production systems (see Box, "Technological Improvements"), allowed for the discovery and development of several large deep water deposits. By 1996, 20 new deep water prospects began producing, with a similar number of

\footnotetext{
${ }^{25}$ Energy Information Administration, Annual Energy Outlook 1998 With Projections to 2020, DOE/EIA-0383(98) (Washington, DC, December 1997).

${ }^{26}$ See Energy Information Administration, "U.S. Underground Storage of Natural Gas in 1997: Existing and Proposed," Natural Gas Monthly, DOE/EIA-0130(97/09 (Washington, DC, September 1997), pp xxi-xli.
}

startups expected from 1997 through $2000{ }^{27}$ Activity in the deep waters of the Gulf of Mexico is expected to remain strong as leasing activity has responded to the royalty relief act incentives. The number of blocks receiving bids in the sales since the DWRRA was signed in November 1995 has risen substantially, with blocks in at least 800 meters numbering seven times the earlier count (Table 4). Some of the deep water capacity coming on stream during the $1990 \mathrm{~s}$ is replacing depleted deposits in shallower water. Deep water gas production will contribute to a net increase in offshore production during the latter half of the decade.

Advances in 3-D seismic interpretation and drilling through thick sections of salt have made it possible to develop resources under sheets of salt that are believed to extend under more than half of the Gulf of Mexico. In 1993, the first subsalt find to be commercially developed, Mahogany, was discovered, followed by seven more in 1994 and 1995. Even though some initial successes generated considerable interest in the estimated 15 trillion cubic feet or more of undiscovered subsalt recoverable gas resources, significant exploratory risks remain and subsalt gas supplies are not expected to be as significant in the near term as deep water gas. Less than $1 \mathrm{Bcf}$ per day of total additional production capacity is likely from new subsalt gas through the year 2000. In the longer term, which is beyond the scope of this report, subsalt gas production could have greater impact on offshore gas deliverability.

The steady movement of gas production into deeper, more remote environments further offshore raises several challenges related to delivery of gas from the field. They include building the offshore pipeline network to bring the new deep water gas ashore and expanding existing onshore pipeline capacity to accommodate the additional gas (see Appendix B, "Natural Gas Pipeline and System Expansions, 1997-2000").

\section{Onshore (Texas and Louisiana) Gulf Coast}

The Gulf Coast region, containing the coastal East and Southeast Texas (Railroad Commission Districts 1, 2, 3, and 4), and Southern Louisiana, produced more gas than any other onshore region in the United States in 1996 after trailing the Anadarko and Arkoma Basins in the early 1990s. Gas production grew by roughly 6 percent between 1990 and 1996 and at $9.1 \mathrm{Bcf}$ per day (3.3 Tcf per year) accounted for nearly

\footnotetext{
${ }^{27}$ Chris C. Oynes, Regional Director, Gulf of Mexico Region, Minerals Management Service, presentation at the OCS Workshop, American Association of Professional Landsmen (Houston, TX, January 22, 1998).
} 
Table 4. Central and Western Gulf of Mexico Lease Sales Before and After the Royalty Relief Act

\begin{tabular}{l|r|r|r|r}
\hline \multirow{2}{*}{$\begin{array}{l}\text { Block Water Depth } \\
\text { (meters) }\end{array}$} & \multicolumn{4}{|c}{ Number of Blocks Receiving Bids } \\
\cline { 2 - 5 } & $\mathbf{1 9 9 4}$ & 1995 & $\mathbf{1 9 9 6}$ & $\mathbf{1 9 9 7}$ \\
\hline $0-200$ & 490 & 516 & 637 & 542 \\
$200-400$ & 18 & 50 & 69 & 52 \\
$400-800$ & 28 & 83 & 113 & 104 \\
$800+$ & 49 & 214 & 722 & 1,138 \\
All Depths & 585 & $\mathbf{8 6 3}$ & $\mathbf{1 , 5 4 1}$ & $\mathbf{1 , 8 3 6}$ \\
\hline
\end{tabular}

Note: The Outer Continental Shelf Deep Water Royalty Relief Act was signed in November 1995.

Source: Derived from a speech by Chris C. Oynes, Regional Director, Gulf of Mexico Region, Mineral Management Service, to the OCS Workshop, American Association of Professional Landsmen (Houston, TX, January 22, 1998).

16 percent of U.S. gas supplies in the latter year. The two largest fields in the region, Giddings and Bob West, are located in southern Texas. They produced a daily average of 1.1 and 0.3 Bcf of wet gas, ${ }^{28}$ respectively, in 1996 (Table 5). Most of the onshore Gulf Coast's production is from nonassociated gas, with AD gas accounting for only about one-tenth of regional gas production and reserves.

A high degree of exploration activity, enhanced by the use of horizontal and multilateral drilling, is yielding impressive results, particularly around the Austin Chalk Trend. In March 1997, one well set an onshore U.S. horizontal well record, flowing an average of 84 million cubic feet per day, which was exceeded by another with an average flow of 100 million cubic feet per day in April 1997. Technology has also been employed in the onshore Gulf region to expand flow at producing fields, with a major developer of the Wilcox/Lobo Trend achieving a 75-percent success rate in 1994 using 3-D seismic technology and improved fracturing fluids.

Proved reserves in the onshore Gulf Coast region declined between 1990 and 1996 to the equivalent of 6 years' worth of production, the lowest reserves-to-production ratio among major onshore gas-producing regions (Table 3). Reserves declined by more than 15 percent between 1990 and 1993 but have since partially recovered to $20.1 \mathrm{Tcf}$ in 1996 as increased exploration activity from 1994 through 1996 found increased gas at existing fields and some new finds.

The new Texas finds in the Austin Chalk Trend, along with the potential for additional finds in the Louisiana portion of this trend, suggest further near-term growth potential for onshore Gulf Coast gas output. Between 1996 and 2000, gas production in the onshore Gulf Coast region is forecast to rise almost 3 percent to $9.4 \mathrm{Bcf}$ per day (3.4 Tcf per year). Estimates of productive capacity show that surplus wellhead

\footnotetext{
${ }^{28}$ Wet gas refers to produced natural gas that contains liquid hydrocarbons that are removed at a natural gas plant. Dry gas is the gas remaining after liquids removal.
}

deliverability during January, the peak of the heating season (November 1 through March 31), declined from 23 percent of total deliverability in 1990 to an estimated 14 percent in 1996 (Table 6).

\section{Anadarko and Arkoma Basins}

The Anadarko/Arkoma region comprises Oklahoma, Kansas, Arkansas, and the Texas Panhandle area (Railroad Commission District 10). It was the largest onshore gasproducing region in 1990, when production averaged 9.1 Bcf per day (3.3 Tcf per year) (Table 2). However, a sharp production decline in Oklahoma reduced the region's gas production by more than 12 percent between 1990 and 1996 to a level of $8.0 \mathrm{Bcf}$ per day ( $2.9 \mathrm{Tcf}$ per year). A major factor in declining regional gas output was a nearly 30-percent contraction of productive capacity between 1990 and 1996. By the mid-1990s, Anadarko/Arkoma had fallen to second place behind the Gulf Coast among onshore regions in terms of gas output volumes. It does remain the top onshore region in terms of proved reserves, despite a 17-percent drop in Anadarko/Arkoma proved reserves, from $32.0 \mathrm{Tcf}$ in 1990 to 26.6 Tcf in 1996 (Table 3).

The largest gas field in Anadarko/Arkoma is the giant Hugoton gas field in Kansas, which dates from 1922 (Table 5). Despite its age, Hugoton was the second largest U.S. gas field ranked by annual production in 1996 (1.5 Bcf per day of wet gas) and is the largest U.S. field in terms of cumulative production (about $22 \mathrm{Tcf}$ ). Hugoton, whose production comes from low permeability sandy carbonate reservoir rocks, occupies much of the western half of Kansas and extends south into Oklahoma and the Texas Panhandle.

Hugoton's gas output has been raised in recent years through the practice of more intensive drilling in existing fields and through some new finds, including those along the Eubank channel. This helped to offset significant declines in production at other Anadarko/Arkoma fields, particularly in 
Table 5. Top 10 Fields in the Lower 48 States Ranked by Natural Gas Production, 1996 (Billion Cubic Feet)

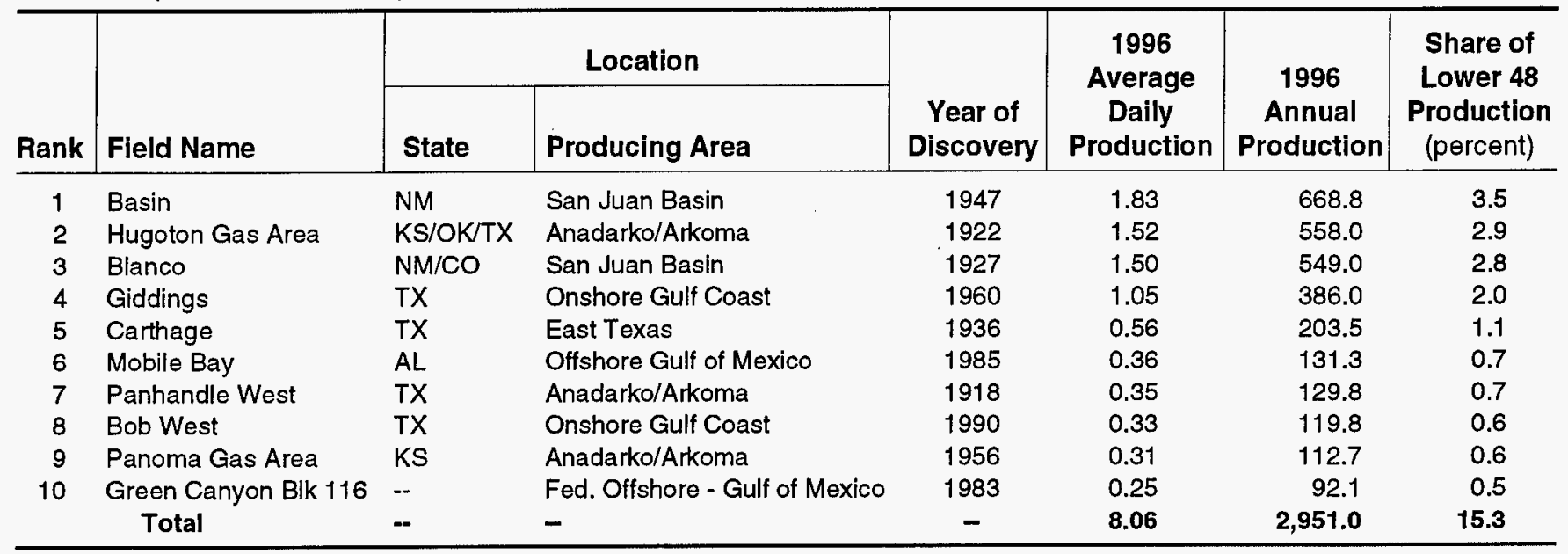

Note: Gas is wet after lease separation.

Source: Energy Information Administration, U.S. Crude Oil, Natural Gas, and Natural Gas Liquids Resenves 1996 (December 1997).

Table 6. U.S. Natural Gas Productive Capacity Utilization and Surplus Deliverability by Region, 1990, 1995, and 1996

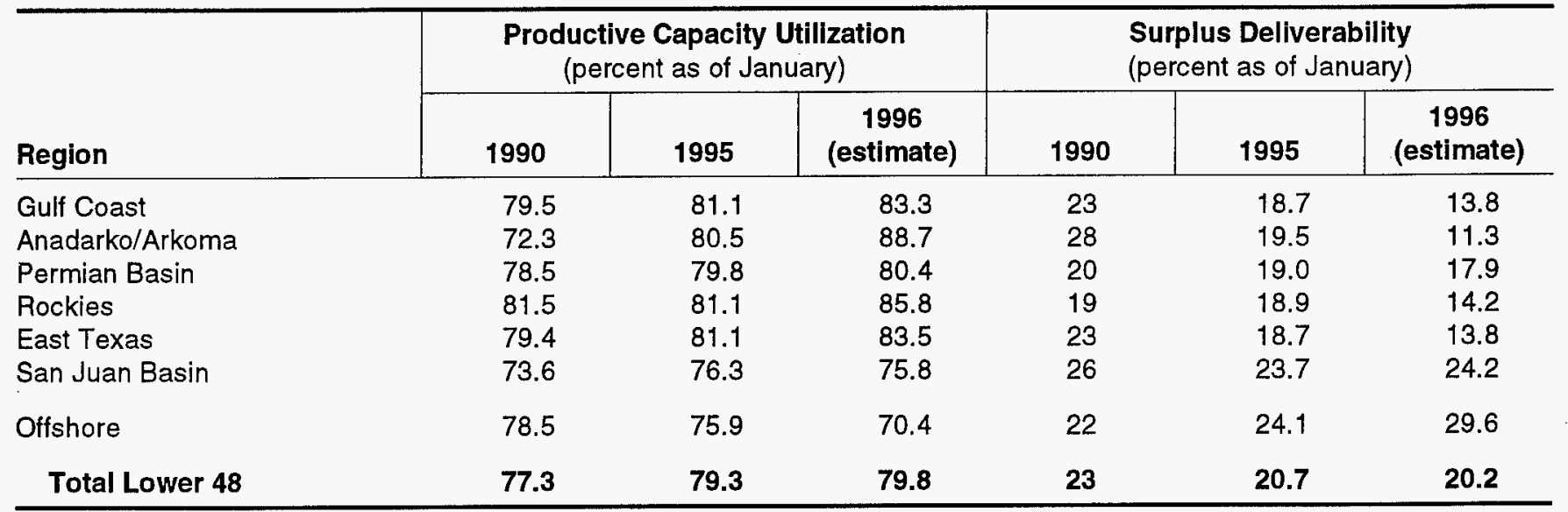

Note: Utilization factors for the Gulf Coast, Permian Basin, and East Texas regions are average factors for the relevant States weighted by the relative dry gas production volumes in the region.

Source: Energy Information Administration, Natural Gas Productive Capacity for the Lower 48 States (December 1996).

Oklahoma. In October 1997, Mobil and Anadarko Petroleum Corp. announced that they would jointly exploit deeper horizons in Hugoton, providing further indication of future potential. Two other Anadarko/Arkoma gas fields rank among the top 10 in the lower 48. Panhandle West in Texas produced a daily average of $0.36 \mathrm{Bcf}$ and the Panoma gas area in Kansas produced another 0.31 Bcf daily on average in 1996.

Contracting productive capacity reduced Anadarko/Arkoma's surplus deliverability from 28 percent in January 1990 to about 11 percent in January 1996 (Table 6). Output gains from infill drilling and some new finds at Hugoton, combined with a stabilization of productive capacity, should keep Anadarko/Arkoma's gas production level at about $8.1 \mathrm{Bcf}$ per day (3.0 Tcf per year) through 2000 (Table 2).

\section{Permian Basin}

The Permian Basin region spans from eastern New Mexico to western Texas (Railroad Commission Districts 7B, 7C, 8, 8A, and 9). Gas production declined between 1990 and 1996, from 4.6 to $4.4 \mathrm{Bcf}$ per day (1.7 to $1.6 \mathrm{Tcf}$ per year), while proved reserves declined by about one-tenth to $14.1 \mathrm{Tcf}$ in 
1996 (Table 3). The top five fields-Gomez, Spraberry Trend Area, Puckett, Sugg Ranch, and Keystone-account for about one-quarter of total Permian Basin gas production and onethird of the region's proved reserves. AD gas accounts for about two-fifths of gas production and reserves in the Permian Basin and is almost as large in absolute terms (about $2 \mathrm{Bcf}$ per day) as offshore $\mathrm{AD}$ gas output.

Improvements in both seismic technology and drilling methods could give the Permian Basin new life during the late 1990s. One play, Texas' Val Verde Basin, a sub-basin within the Permian, may have world-class potential. While Val Verde has yielded finds such as Puckett since the 1950s, improved seismology has shown huge, previously unknown structures in the Ellenburger formation and thrusted rocks extending further east and north in Val Verde than previously realized. Thrusted Shawn reservoirs, limestones that produce either from fractured intervals or reefs, are at 10,000 feet and offer more immediate economic opportunity than deeper plays. In addition, Wolfcamp (also known as Canyon Sand) is a low-risk, limited-potential play that is popular because of success rates of 90 percent in some cases.

The potential from these plays, combined with one of the highest surplus deliverability measures among producing regions (an estimated 18 percent in 1996), should help to raise Permian Basin gas production more than 10 percent between 1996 and 2000 to $5.2 \mathrm{Bcf}$ per day (1.9 Tcf per year) (Table 2).

\section{Rocky Mountain Area}

The Rocky Mountain area, including Colorado, Utah, and Wyoming, was one of the fastest-growing U.S. producing regions between 1990 and 1996 and has the potential for further output gains through 2000 . Gas production increased nearly two-thirds since 1990 from 2.5 Bcf per day ( $0.9 \mathrm{Tcf}$ per year) to $4.1 \mathrm{Bcf}$ per day (1.5 Tcf per year) in 1996 (Table 2). Major plays in the Rockies include the Wind River Basin, the Labarge and Big Piney Projects, the Overthrust Belt, the Green River Basin, and the Powder River Basin.

The Rocky Mountain area is one of the newest major gas producing regions in the United States in terms of average field age, with most of the leading fields dating from the 1960 s or later. The top producing fields in 1996 included Wattenburg in Colorado (0.24 Bcf per day), Anschutz Ranch East in Utah/Wyoming ( 0.23 Bcf per day), Whitney CanyonCarter Creek in Wyoming (0.22 Bcf per day), and Bruff in Wyoming (0.14 Bcf per day). ${ }^{29}$

\footnotetext{
${ }^{29}$ Energy Information Administration U.S. Crude Oil, Natural Gas, and Natural Gas Liquids Reserves, Annual Report 1996 (Washington, DC, December 1997), p. 58.
}

A growing portion of Rockies' natural gas production during the early 1990s came from coalbed methane (Figure 4), spurred by a Federal tax credit for natural gas produced from coal seam wells with initial drilling prior to January 1, 1993. This tax credit extends up to 10 years for any producing well so it will affect production on at least some portion of coalbed production through 2002. Expiration of the qualifying period for the tax credit has reduced drilling activities, which will likely affect the future volume of coalbed methane production in both the Rockies and San Juan Basin, another region which is the leading U.S. producer of coalbed methane. The Rocky Mountain area is also a significant producer of $\mathrm{AD}$ gas, which accounted for 12 to 15 percent of total regional output in the mid-1990s and about one-tenth of reserves.

Proved gas reserves in the Rocky Mountain area grew by onethird from 16.0 trillion cubic feet (Tcf) in 1990 to 21.7 Tcf in 1996 (Table 3). Large recent reserve gains at the Big PineyLaBarge Field have made it the largest field in terms of reserves in Wyoming, while further reserve increases are also likely to come from the Madden Field and Moxa Arch Extension. The Madden Field could become a very profitable play because it might be possible to draw most of its gas out of the formation through just one or two holes drilled at the top of the reservoirs. The Moxa Arch Extension ranks high in terms of gas produced per drilling dollar, but this does not include heavy associated costs of fracturing the tight formations that are common to this play. Other possible sources of increased gas in the near term include coalbed methane in the Powder River play of Wyoming, where productive capacity rose from near zero in 1990 to 28 million cubic feet per day in 1996, with at least another 35 million cubic feet per day waiting for connection and pipeline hookup.

As a result of reserve growth, the 1996 reserve-to-production ratio in the Rocky Mountain area was among the highest in the lower 48 States at 14 (Table 3). Large reserves and output from new finds are expected to contribute to an 11-percent growth in Rockies' gas production between 1996 and 2000 to around $4.6 \mathrm{Bcf}$ per day (1.7 Tcf per year) in the latter year (Table 2). The rate of growth in Rockies' gas output during the latter half of the 1990s is quite impressive given the number of impeding factors. Such factors include the phaseout of the coalbed methane tax credit, saturation of Western markets, and the cost of building additional pipeline capacity to redirect more Rockies' gas eastward towards high-demand markets, rather than due to any shortage of gas supplies.

\section{East Texas}

The East Texas region includes Northeast Texas (Railroad Commission Districts 5 and 6) and northern Louisiana. Its gas 
Figure 4. U.S. Coalbed Methane Output, 1990-1996

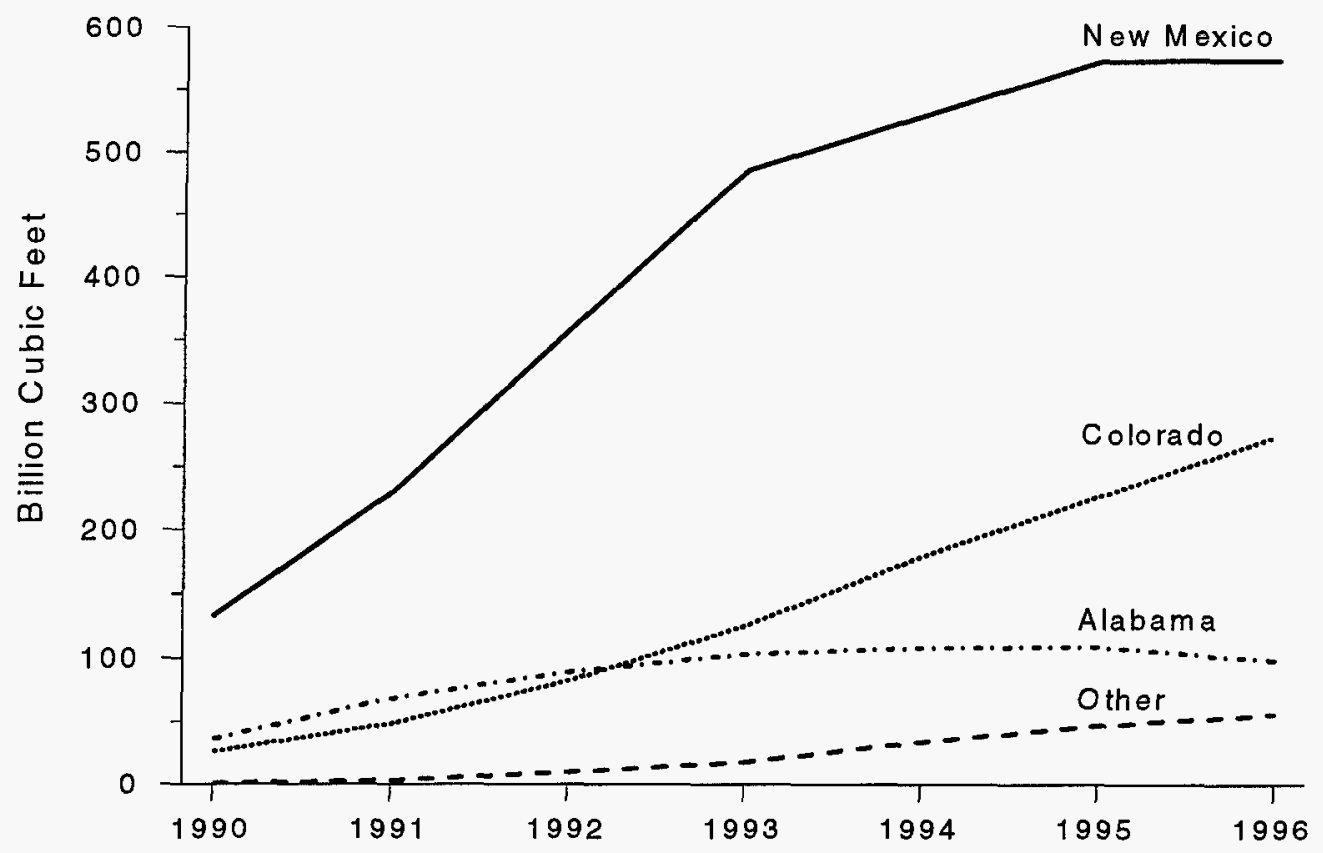

Note: Other includes Kansas, Oklahoma, Pennsylvania, Utah, Virginia, West Virginia, and Wyoming.

Source: Energy Information Administration, U.S. Crude Oil, Natural Gas, and Natural Gas Liquids Reserves 1996 (December 1997).

production increased by one-tenth from $3.0 \mathrm{Bcf}$ per day (1.1 Tcf per year) in 1990 to $3.2 \mathrm{Bcf}$ per day (1.2 Tcf per year) in 1996 (Table 2). Nearly one-half of production and over one-half of reserves in East Texas are accounted for by five fields: Carthage, Oak Hill, Willow Springs, Whelan, and Hawkins. Carthage is the largest among them; in 1996, it produced 203.5 Bcf (wet gas, $0.56 \mathrm{Bcf}$ per day) and was the fifth largest U.S. gas field that year in terms of production.

East Texas is one of the few onshore regions to register substantial new field finds in recent years. Drilling in the Cotton Valley lime reef play resulted in 25 discoveries reported out of 45 wells as of mid-1997 for a 55-percent success rate. At least $550 \mathrm{Bcf}$ of reserves have been found at the Cotton Valley Lime reef play, helping to expand the region's reserves 7 percent to $11.1 \mathrm{Tcf}$ in 1996 after little change between 1990 and 1995. Overall, East Texas gas output is likely to increase moderately by about $0.1 \mathrm{Bcf}$ per day to just under 1.2 Tcf per year in 2000 .

\section{San Juan Basin}

The San Juan Basin in northwestern New Mexico, like the Rockies, has substantially increased production since the late 1980s. Production almost doubled between 1990 and 1996 to $2.7 \mathrm{Bcf}$ per day (1.0 Tef per year) in 1996 (Table 2) and is mainly accounted for by two giant gas fields-Basin and Blanco-that are two of the three largest in the lower 48 States. The Basin Field, first drilled in 1947, was formed in February 1961 by combining several existing fields. The Blanco Field encompasses much of the central San Juan Basin.

Much of the increase in gas production in the San Juan Basin during the 1990s has come from coalbed methane wells. Production gains were strongest until the end of 1992, when phase-out of the coalbed methane tax credit began. Coalbed methane production grew further in the years 1993 through 1996, owing to subsequent completion of wells spudded prior to the tax credit deadline and as these wells proceeded through the dewatering phase early in their production cycle. San Juan Basin production increases were also the result of well recompletions in the basin's deeper tight sands formations as operators employed new technologies to increase gas flow.

Expiration of the coalbed methane tax credit had an immediate impact on San Juan Basin proved reserves, which contracted 13 percent between 1992 and 1996 (in part because of downward revisions as some coalbed fields were considered no longer economical, especially in a pipeline constrained market) after expanding by a similar percentage between 1990 and 1992. This left the region's reserves at 
13.7 trillion cubic feet in 1996, compared with 14.0 in 1990 . Stagnant reserves are not likely to limit the San Juan Basin's gas production in the near term, because its reserves still represent almost 14 years' worth of production (well above the U.S. average). Gas output is projected to increase about 3 percent per year on average during the late $1990 \mathrm{~s}$ to $3.0 \mathrm{Bcf}$ per day (1.1 Tcf per year) in 2000 as a result of reduced coalbed methane activity, well below its double-digit annual growth rate during the early 1990 s.

As with the Rockies region, the major constraints on future growth of gas production in the San Juan Basin are more related to market conditions and infrastructure than to physical output capability. With peak productive capacity utilization in the San Juan Basin running below 80 percent in the mid-1990s, surplus deliverability was the highest of any major gas-producing basin at over 20 percent. Thus, a major determinant of future gas output here is likely to be the pace of expansion of pipeline capacity to carry the gas to major markets in the Northeast and Midwest given the saturation of California and other Western markets.

\section{Appalachian Basin}

The Appalachian Basin extends from the Middle Atlantic to the South Atlantic Census Bureau divisions and is the largest gas-producing basin close to major markets in the Northeast. This region is a minor producer of gas, providing only about 2 percent of total lower 48 gas supplies, but it is a major source of gas for the large urban areas of the Northeast. Pennsylvania and West Virginia account for the majority of the Appalachian Basin's natural gas production, while Virginia has increased production following sizable new finds, including coalbed methane deposits.

A portion of the region's $1.4 \mathrm{Bcf}$ per day gas output comes from unconventional sources, such as Devonian Shale. In December 1992, the National Petroleum Council estimated that the Devonian Shale in this area contains about $27 \mathrm{Tcf}$ that could be produced using known technology. ${ }^{30}$ This compares with proved reserves in 1996 of $7.7 \mathrm{Tcf}$, which is one-third larger than the 1990 level mainly because of the new finds in Virginia.

Higher reserves raised the Appalachian region's ratio of proved reserves to production to 15 in 1996, the highest in the lower 48. Such a ratio indicates high likelihood of production increases during the late 1990s, with Appalachian Basin gas output forecast to grow about 16 percent to $1.6 \mathrm{Bcf}$ per day (0.6 Tcf per year) in 2000. With demand in the Northeast

\footnotetext{
${ }^{30}$ National Petroleum Council, The Potential for Natural Gas in the United States: Source and Supply (1992), p. 111.
}

expected to far exceed the expected modest increment to Appalachian Basin production during the 1997 through 2000 period, attractive opportunities are likely for gas suppliers from other regions of the lower 48 and from Canada.

\section{Canadian Supplies}

Sharp increases in natural gas imports from Canada have made Canada the third most important source of U.S. gas supplies after the offshore and Gulf Coast regions. Various factors have contributed to the strong growth in U.S. natural gas imports from Canada over the past decade, ${ }^{31}$ including:

- The 1985 Agreement on Natural Gas Markets and Prices that changed Canada's pricing policy from governmentadministered to market-oriented pricing

- The "market-based procedure" for determining the surplus Canadian natural gas available for export that replaced the previous reserves-to-production (R/P) ratio procedure in 1987

- The U.S.-Canadian Free Trade Agreement (CFTA) of 1988 that prohibited most trade restrictions on energy products.

Since 1987, U.S. gas imports from Canada have nearly tripled to around 8 Bcf per day (2.9 Tcf per year) in 1996, accounting for 13.5 percent of U.S. gas supplies. Growth was swiftest between 1990 and 1995, when imports of Canadian gas increased at a 14-percent average annual rate. Relative price movements helped to stimulate increased U.S. gas imports from Canada, since the average wellhead price in the lower 48 changed from being 11 percent cheaper than imported Canadian gas in 1990 to being 11 percent more expensive by 1996 (Figure 5).

Canada produced about $5.6 \mathrm{Tcf}$ of gas in 1996, equivalent to about 30 percent of lower 48 production. Canadian gas production is centered in the Western Canada sedimentary basin, 95 percent of which occurs in the western provinces of Alberta (83) and British Columbia (12). Total Canadian gas production was 56 percent higher in 1996 than in 1990, while natural gas end-use consumption in Canada grew by only 23 percent during the same period. ${ }^{32}$ As a result, domestic use of natural gas in Canada ( 47 percent of final gas sales occurs

\footnotetext{
${ }^{31}$ For more detail see Energy Information Administration, Natural Gas 1996 Issues and Trends, DOE/EIA-0560(96) (Washington, DC, December 1996), p. 95.

${ }^{32}$ Canadian Association of Petroleum Producers, CAPP 1996 Statistical Handbook (Calgary, Alberta, Canada, 1997), Tables 3.10a, 6.3a, and 9.1a.
} 
Figure 5. Comparison of Average U.S. Natural Gas Wellhead Price and Canadian Natural Gas import Price, 1990-1996
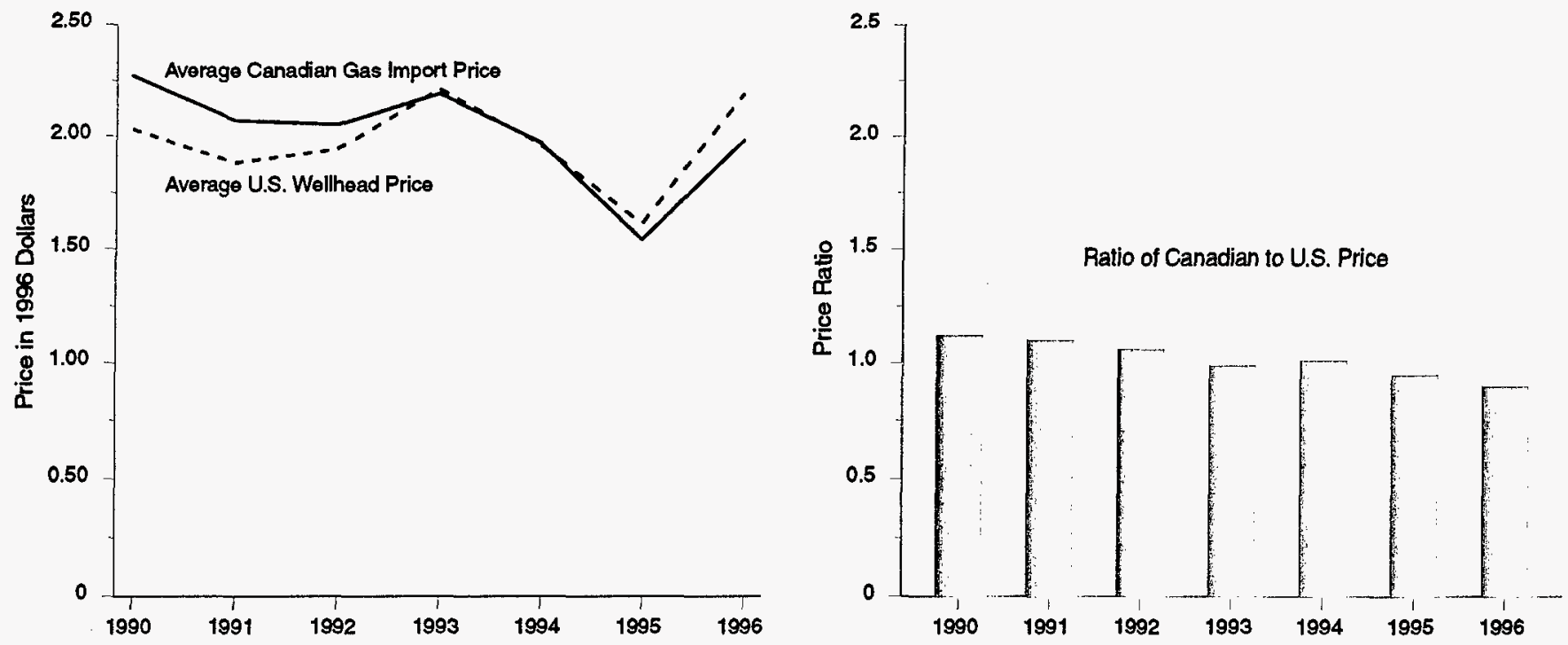

Note: Prices in 1996 dollars based on appropriate gross domestic product (GDP) deflators as published in the Survey of Current Business (August 1997) and distributed on the Internet site www.bea.doc.gov.

Source: Energy Information Administration (EIA), Natural Gas Annual (September 1997).

in the eastern provinces of Ontario and Quebec) fell from representing 60 percent of Canadian production in 1990 to only 49 percent in 1996. Since 1990, the TransCanada Pipeline system has substantially increased its capability to move supplies from the Alberta/Saskatchewan border (currently 7.2 Bcf per day during the winter) but not rapidly enough to meet both the growth in domestic demand and export capacity. As a result, TransCanada Pipeline and several other firms have developed plans to expand domestic and export capability over the next several years to meet the demands of Western producers and customers in Canadian Eastern markets.

While the more than 50-percent growth in Canadian gas production reduced the country's reserves-to-production ratio from almost 26 in 1990 to 12 in 1996, the Canadian Gas Potential Committee has estimated remaining marketable gas, including discovered reserves and undiscovered potential in established exploration plays and coalbed methane, at about 570 trillion cubic feet. ${ }^{33}$ This suggests that Canadian supplies are more than sufficient to meet expected domestic and export demands well past the year 2000. New gas finds off Canada's Atlantic shores are expected to begin

\footnotetext{
33. Where future Canadian gas supply will originate," Oil and Gas Joumal (December 15, 1997), p. 67.
}

commercial production by late 1999 and contribute significantly to North American gas supplies in the longer term, although their impact on U.S. markets through 2000 will be limited.

The rising importance of U.S. export markets to Canadian gas producers is illustrated by the fact that more than half of Canadian gas production by the mid-1990s was destined for export to the United States compared with two-fifths in 1990 (Figure 6). In 1996, growth in Canadian gas exports to the United States slowed to 2.4 percent primarily because of bottlenecks resulting from existing pipeline capacity constraints. Relative price data show that prices for U.S. imports of Canadian gas in 1996 continued to decline relative to the average wellhead price in the lower 48 . The downward movement in the price for Canadian gas relative to the U.S. price was influenced also by a significant shift in the exchange rate, with the Canadian dollar falling from $\$ 0.86$ US in 1990 to $\$ 0.73$ US in $19966^{34}$ Favorable price trends combined with continued demand growth in the lower 48 are likely to raise imports of Canadian gas by over one-third between 1996 and 2000 to about 10.7 Bcf per day (3.9 Tcf per year) in $2000 .^{35}$

\footnotetext{
${ }^{34}$ Canadian Association of Petroleum Producers, CAPP 1996 Statistical Handbook (Calgary, Alberta, Canada, 1997), Table 5.5c.

${ }^{35}$ See Energy Information Administration, Annual Energy Outlook 1998 (December 1997), p. 118
} 
Figure 6. Canadian Gas Exports to the United States and Total Canadian Gas Production, 1990-1996

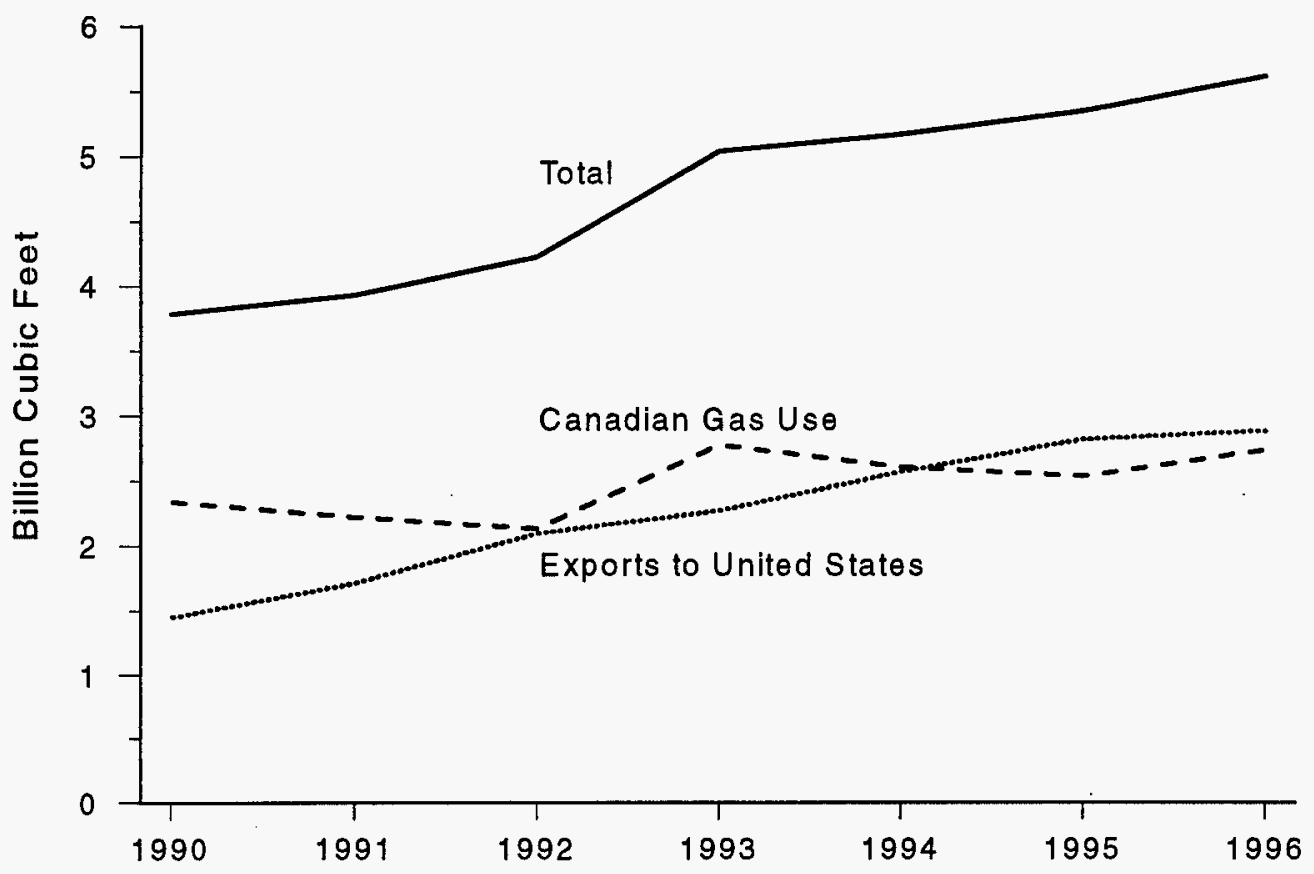

Note: Canadian gas use was calculated by subtracting exports to the United States from total Canadian gas production.

Sources: Canadlan Gas Exports to Unlted States: Energy Information Administration, Natural Gas Annual 1996 (September 1997) and earlier editions. Canadlan Gas Production: Canadian Association of Petroleum Producers (CAPP), Statistical Handbook 1996 (September 1997).

\section{Receipt Capabilities}

Wellhead gas productive capacity is only one of the elements necessary to meet U.S. natural gas demand. Because major market areas are not usually located in close proximity to supply/production areas, moving the gas from the wellhead to market areas via pipeline is an important element of satisfying demand. The first leg of the transportation journey, which is relevant to this chapter, requires adequate pipeline receipt capability to facilitate the movement of the natural gas from producing fields to the interstate pipeline system.

In the United States, natural gas typically moves from major supply areas in Texas, Oklahoma, Louisiana, Wyoming, Kansas, Colorado, New Mexico and the Offshore Gulf of Mexico to the North and East. These routes saw a rise in average daily usage rates between 1990 and 1996, while usage rates fell sharply on pipelines heading westward into markets on the Pacific Coast, which are saturated with gas from Canada. Additionally, the dramatic increase in gas imports from Canada during the past decade has opened up new supply routes from Western Canada to the lower 48 , with the swiftest growth in route volume occurring into the Northeast.
While wellhead gas productive capacity and import capacity were sufficient to meet U.S. demand under normal weather conditions through the end of 1997 , unusually high peak-day or peak-week heating or cooling demand required deliveries from storage or peak-day shaving. Limited pipeline receipt capabilities in key production areas, such as the Gulf of Mexico, the Northern Rocky Mountains, and the San Juan Basin, compromise the ability to meet peak demand. And with total U.S. gas supplies expected to increase by more than 12 percent between 1996 and 2000 , the additional $7 \mathrm{Bcf}$ per day of supplies will require expansion of existing transport and storage capacity. Several projects have been proposed that will expand the receipt capability of the interstate pipelines transporting natural gas from producing to consuming areas in the United States, including gas imports via pipeline from Canada.

\section{Offshore and Onshore Gulf Northward}

The offshore and onshore Gulf region, which together provide almost half of all natural gas produced in the lower 48, supply a large portion of this gas to other regions. These two regions account for a large portion of the $12.6 \mathrm{Bcf}$ per day on average 
transported from the Southeast to the Midwest and Northeast, where rising shipments brought average usage rates to 82 to 86 percent in 1996.

Despite an already well-developed gas infrastructure around the Gulf, the last 6 years have seen an ongoing effort to build sufficient offshore pipeline receipt capacity to support the rapidly increasing wellhead productive capacity, particularly offshore. Offshore pipeline construction increased more than 20 percent between 1990 and 1995, followed by completion of two large expansion projects in 1996-the Shell Gas Pipeline and the Centana Main Pass/Viosca Knoll Gathering System. Several new pipeline projects were completed in 1997, including the Garden Banks Offshore System, the Manta Ray Gathering System, the DIGS Main Pass Gathering System, the Discovery Pipeline, and the Nautilus Pipeline.

As a result of this construction, nearly $20 \mathrm{Bcf}$ per day of pipeline capacity extends onshore from the offshore Gulf region, mostly to Louisiana. Major pipelines that receive onshore and offshore Gulf gas for transportation to markets in the Northeast and Midwest include ANR, Columbia Gulf, Florida Gas, Koch Gateway, Southern Natural Gas, Tennessee Gas, Texas Eastern, Transcontinental, and Trunkline systems. Some of these pipeline systems, notably Tennessee and Texas Eastern, are very large and were operating at nearly full capacity in 1996 during peak periods.

Despite ambitious pipeline expansion plans to bring an additional 3 Bcf per day or more of offshore gas ashore at Alabama, Louisiana, and Mississippi by the year 2000, lack of adequate capacity to transport the gas to markets in the Northeast and Midwest could hamper future gas deliverability from the Gulf. There are 10 proposed projects that would bring more than $1.6 \mathrm{Bcf}$ per day of additional gas ashore at Louisiana and about 1.5 Bcf per day at Mississippi and Alabama (see Appendix B, Table B2). Potential bottlenecks may arise further downstream as existing pipeline capacity into Mississippi and Arkansas is not expected to expand by similar magnitude and could face average usage levels far in excess of 90 percent.

An alternative solution, increased reliance on storage, could allow for increased gas deliveries from the Gulf to the Northeast without adding new pipeline capacity. A number of new storage facilities, including high-deliverability salt cavern storage, are being built both in the Northeast near the consuming markets and on the Gulf coast near offshore production areas. ${ }^{36}$ New salt cavern storage facilities expected to be built during the years 1998 through 2000 could add up

\footnotetext{
${ }^{36}$ Energy Information Administration, "U.S. Underground Storage of Natural Gas in 1997," Natural Gas Monthly, DOE/EIA-0130(97/09) (Washington, DC, September 1997).
}

to $1.5 \mathrm{Bcf}$ of daily deliverability from storage in the Southwest and up to 1 Bcf per day from storage in the Northeast (mainly in New York and Pennsylvania). By moving the gas into markets such as the Northeast during nonpeak periods, natural gas marketers are better able to utilize existing pipelines. Because storage is generally cheaper to build than laying new pipeline, this is an economically attractive option for the short term. In the longer term, however, marginal increases from greater usage of existing pipelines may not be sufficient to accommodate the expected magnitude of produced gas in certain regions.

\section{From the Rockies and San Juan Basin Eastward}

Despite strong growth in production and reserves in the Rocky Mountain area and in the San Juan Basin of New Mexico between 1990 and 1996, only a small portion of that production saw its way to Midwest or Northeast markets. Pipeline capability to move gas eastward from that area has been limited as traditionally the production has been targeted to Western markets. But with Western markets becoming saturated, interest has increased in moving supplies eastward.

While the northern Rocky Mountain area has not experienced receipt constraints for supplies moving westward, it has been unable to gain access to Eastern markets because of limited pipeline receipt capability. This constraint is expected to ease as eastern access via the San Juan Basin has increased and several expansion projects have been planned that will increase pipeline capacity from the Rocky Mountains to hubs serving the Midwest and East. Expansions completed in 1997 included KN Energy's Pony Express line from Wyoming to several long-haul pipelines running from the Permian Basin to the Midwest and expanded capacity from the Overthrust and Green River basins to the eastward-running Trailblazer Line.

Sufficient new pipeline capacity is planned between 1998 and 2000 to accommodate the expected production increases in the Rockies and San Juan Basin areas (almost 0.8 Bcf per day additional) without major bottlenecks. According to 1996 data, the El Paso pipeline from the San Juan Basin of New Mexico into Texas alone had nearly $1 \mathrm{Bcf}$ per day of unused capacity on average. Along with completion of the TransColorado line ( 0.3 Bcf per day) to the San Juan Basin running from Colorado's Piceance Basin, Southwestern Wyoming, and Utah's Paradox and Uinta basins, this suggests adequate receipt capability for the anticipated increase in San Juan Basin output during the next 3 years. The Natural Gas Pipeline Company of America's Amarillo expansion would help move these new supplies to the East through Chicago from the Waha hub in Texas. 


\section{Technological Improvements}

\section{A decade of technological improvements has reduced finding costs, raised the size of finds, and opened new areas of exploration}

The combined application of several new technologies over the last decade has contributed to U.S. gas production gains during the 1990s in a number of ways. These technologies include enhancements to exploratory and developmental activities, such as 3-D seismic and cross-well seismic surveys, improved drilling techniques through the use of horizontal and multi-lateral drilling, and new offshore production systems that include floating and subsea assemblies.

Lower finding costs facilitated by wider use of 3-D seismic surveys and other new technologies have reduced production costs and contributed to higher U.S. gas production during the 1990s.* Over the past decade, onshore finding costs have been cut by more than half, while offshore finding costs have fallen even more sharply. As a result, offshore finding costs converged with onshore finding costs in the mid-1990s after more than a decade of exceeding them by a considerable margin (Figure 7). The nearly two-thirds reduction of offshore finding costs between 1986 and 1996 was a major factor in the increased profitability of offshore gas production because offshore lifting costs are much lower and comprise a smaller share of total production costs than with onshore production (Figure 8).

New technologies have redefined deep water drilling opportunities in the Gulf of Mexico. In 1996, dry gas productive capacity in the Federal Offshore Gulf of Mexico region was nearly 30 percent of the productive capacity for the lower 48 States. The offshore region also had a higher average reserves addition per successful well, averaging more than 16 Bcf from 1992 through 1994. The importance of the offshore portion of total U.S. gas production is expected to rise further through the year 2000 with new capacity due for startup from deep water and subsalt wells as well as continued gains in AD gas output. Because of technological changes, deep water drilling is now taking place at previously impossible water depths-for example, Shell's Mensa at depths of more than 5,300 feet. Future plans call for even deeper drilling, with Shell's Couloumb and BAHA projects planned at 7,500 feet or more (Figure 9).

The technologies contributing to these breakthroughs include:

- 3-D Seismic Surveys - 3D seismic surveys are conducted by use of meticulously spaced vibration-detecting geophones to measure the feedback from a sequence of experimental seismic disturbances. Their use has greatly improved geological interpretations and has led to a much higher rate of successful wildcat drilling. Future innovation may include 4D seismic (essentially time-lapse 3D seismic), which could help improve flow models to optimize recovery.

- Cross-well Seismic Surveys - Cross-well seismic surveys are used to evaluate the geological characteristics of terrain between wells. Cross-well seismic measures the vibrations detected in one or more wells when widespectrum sound is produced at varying intensity in another well. The nature of the vibrations provides important information on the qualities of the intervening region.

- Horizontal Drilling - Originally employed onshore in the 1980s, horizontal drilling angles off the vertical to follow the path of a gas-producing formation. While more costly than vertically completed wells, wells with horizontal completion segments often produce at rates 3 to 5 times that of vertical wells and may reduce the unit costs of production by as much as 50 percent. The first offshore horizontal wells were drilled in 1990 and have played an important role in exploiting gas reserves in the Gulf of Mexico.

*The finding and lifting costs introduced here represent calculations for the major integrated oil- and gas-producing companies and the large independent firms included in the Energy Information Administration's Financial Reporting System (FRS). The FRS companies are 24 major U.S. energy companies that are required to report financial and operating developments annually to the Energy Information Administration on Form EIA-28, "Financial Reporting System," pursuant to Section 205(h) of the Department of Energy Organization Act. 


\section{Technological Improvements (Continued)}

- Multilateral Drilling - This drilling method involves drilling multiple horizontal well completion segments at different depths having varying characteristics (e.g., permeability) and allows for economical recovery of a greater portion of a given well's reserves under certain conditions.

- Subsalt Drilling - Considerable gas deposits are believed to reside beneath large horizontal sheets of salt. While historically the salt sheets blurred seismic images and made it difficult to drill successfully for subsalt gas deposits, new technologies have sharpened seismic images and improved chances of discovery. The first subsalt discovery to be commercially developed was the 1993 Mahogany strike in 370 feet of water off the Louisiana coast. Subsequent discoveries, including the Teak, Agate, Chimichanga, Enchilada, and Gemini wells, suggest high future potential for offshore development of subsalt gas deposits.

- Floating Production Systems - Key to expansion of deep water gas exploration and development, floating production systems include floating platforms or structures tethered to the sea floor. Their advantages over fixed platforms include deeper range in offshore waters, lower average costs over their productive lives because they can be towed to various locations, and greater tolerance of hurricanes and other inclement weather as they move compliantly to waves. Two major types of floating systems are:

- Tension Leg Platform (TLP) - Consisting of a hull with excess buoyancy that maintains tension in a tether mooring system, it behaves like an inverted pendulum that moves compliantly to waves. Because conventional TLPs have encountered problems in waters over 3,000 feet, various modifications have been created for deeper waters that include tension base TLPs, suspended TLPs, tension raft jackets (TRJs), and hybrid compliant platforms (HCPs). The first TLP, Conoco's Jolliet at 1,720 feet of depth, came onstream in 1989.

- Spar Production System - Consisting of a single point buoy tanker loading and mooring platform with a storage tank, the spar's stability is increased because its center of buoyancy is above its center of gravity. In contrast to a TLP, the spar's hull does not support the production risers; instead, two separate floats carry the weight of the risers. Spar technology offers operators a way to reduce deep water production costs while still having surface well completions. The first spar was introduced in 1997 at Oryx's Neptune in nearly 2,000 feet of Gulf water.

- Subsea Production Systems - Subsea production systems have found wider applications in the Gulf of Mexico over the past 2 to 3 years as production moves into deeper water. By tying back subsea wells to either floating production systems or platforms in shallower water, operators are able to develop wells, including smaller ones, that otherwise would not be economic. In deeper waters, some operators are using subsea production systems based on template and well cluster designs. The Gulf's first subsea cluster production system was installed at Popeye Field, which started production in 1996. In an attempt to reduce costs, subsea production systems are becoming smaller, more modular units, and greater emphasis is being placed on retrievable subsea components. 
Figure 7. Finding Costs for Natural Gas and Crude Oil, 1981-1996

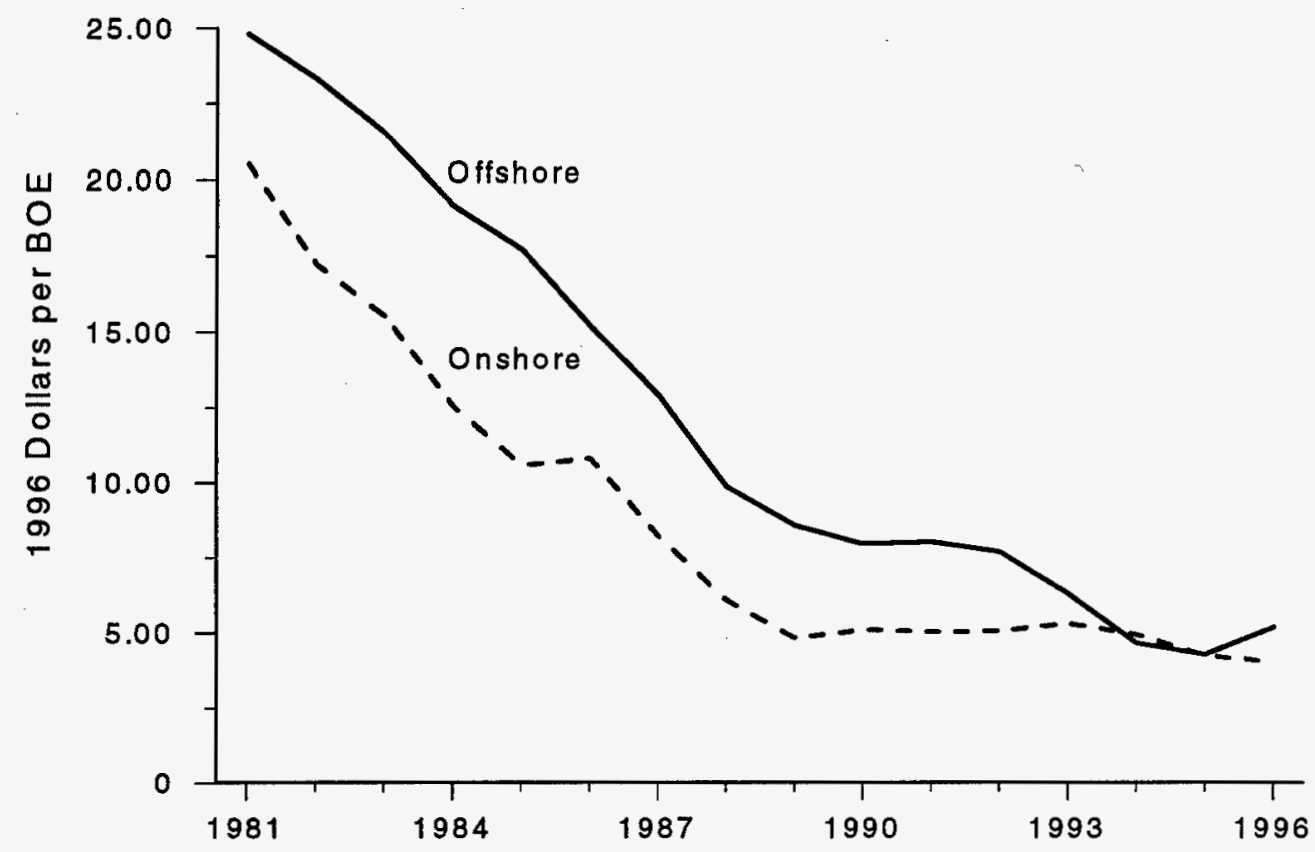

BOE = Barrels of oil equivalent.

Note: Finding costs are 3-year weighted averages of exploration and development expenditures for oil and gas, converted to BOE.

Source: Energy Information Administration, Performance Profiles of Major Energy Producers 1996 (January 1998) and earlier editions.

Figure 8. Offshore and Onshore Production Costs for Natural Gas and Crude Oil, 1995 and 1996

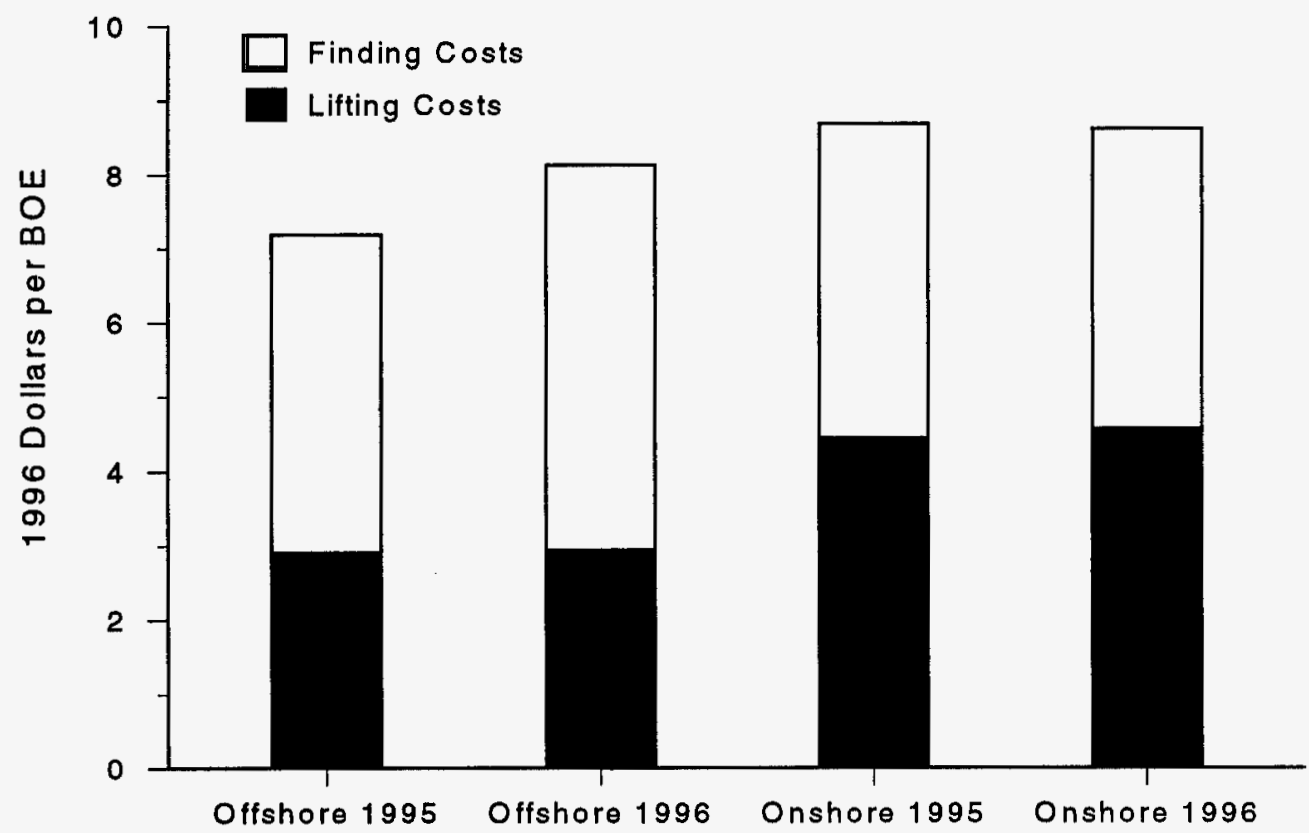

BOE = Barrels of oil equivalent.

Note: Finding costs are 3-year weighted averages of exploration and development expenditures for oil and gas, converted to BOE. Lifting (or production) costs are the out-of-pocket costs of extracting oil and gas and include operating (direct lifting) costs and production taxes.

Source: Energy Information Administration, Performance Profiles of Major Energy Producers 1996 (January 1998). 
Figure 9. Depth Records in Deep Water Gulf Drilling

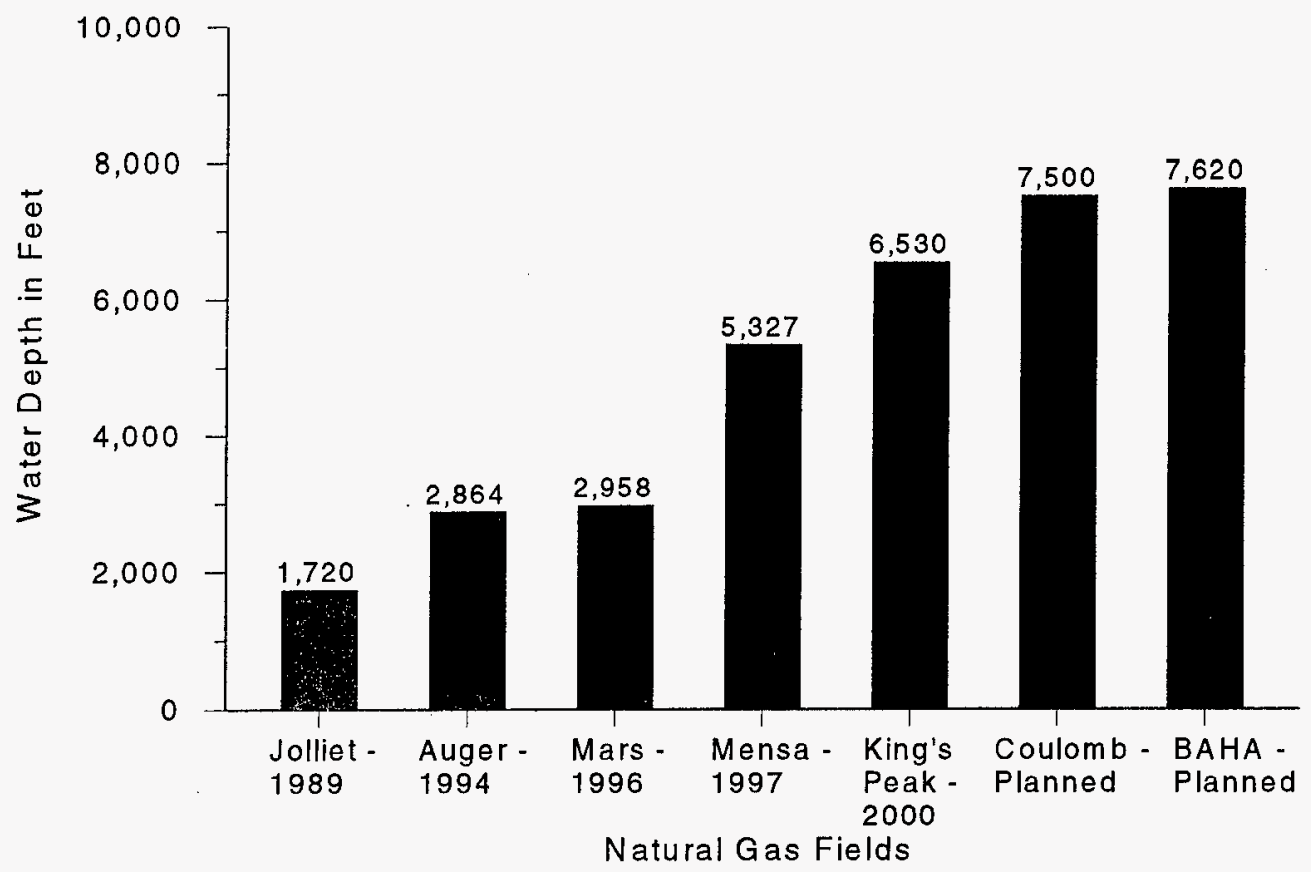

Note: Water depths (in feet) are noted for each project.

Source: "Seventy U.S. Gulf deepwater fields awaiting development, 26 are in production," Offshore (September 1997), p. 39.

\section{Canada Southward}

Canadian gas is imported into four U.S. regions: the Midwest (with a 28-percent share of the total in 1996); the Central States (17 percent) $;{ }^{37}$ Northeast ( 20 percent); and the Pacific Northwest (35 percent). Expansion of Canadian pipeline capacity has not kept up with the rapid U.S. demand growth for Canadian gas, raising the average usage rate on pipelines transporting this gas to the United States from 77 percent in 1990 to 84 percent in 1996. Certain corridors, especially from Canada to the U.S. Northeast and from Canada to the U.S. Midwest, were operating at or close to full operational capacity in 1996 (see Chapter 3), suggesting that Canadian gas imports may be close to maximum flow until additional capacity can be added.

The small growth in U.S. gas imports from Canada in 1996 and 1997 (less than 1 percent) was due largely to deliverability limitations to the TransCanada system and other exporting systems rather than because of Canadian supply limitations. Production capabilities in Western Canada, especially in Alberta, exceed the amount of pipeline capacity now existing on the system in that area (about $10.6 \mathrm{Bcf}$ per

\footnotetext{
${ }^{37}$ Most of the gas imported into the Central Region goes to the Midwest.
}

day, of which 7.1 Bcf is directed toward Eastern Canada and the U.S. Midwest and Northeast). As a result, Canadian shippers have been unable to reach their full potential market to the east.

Proposals to alleviate the situation consist of at least 11 projects within Canada, which would provide an additional 0.3 Bcf per day to Canadian markets and 7.7 Bcf per day to U.S. gas import capacity from Canada from 1998 through 2000. (About $4.5 \mathrm{Bcf}$ per day of import capacity was added from 1990 through 1997.) A number of these projects are competing for the same markets and will not be built in all likelihood. Even if only half of the proposed capacity is completed by 2000 (see Appendix B), it would accommodate the additional $2.8 \mathrm{Bcf}$ per day of projected imports while easing bottlenecks on the pipeline network.

Moreover, on December 30, 1997, the Canada-Nova Scotia Offshore Petroleum Board approved the Sable Offshore Energy project, which is aimed at development of six gas fields containing an estimated 3 trillion cubic feet of gas. In light of these events, sales of Sable Island gas in U.S. markets appear likely before 2000 , but they are unlikely to be large enough to affect gas deliverability to the lower 48 States appreciably during this period. The Maritimes \& Northeast Pipeline (MNE) transportation project will bring gas from the 
Nova Scotian shelf offshore Sable Island to Eastern Canada and the United States. One other transportation project, the Marine Line Subsea proposal, continues to be considered as a possible alternative to move this gas to Canadian and U.S. markets.

\section{Implications for Downstream Markets}

Expanded pipeline capacity should move more gas eastward from the Rocky Mountain area and San Juan Basin of New Mexico to markets in the Northeast and Midwest during the next few years, although increased demand from within the Central Region could absorb some of the additional gas supplies from these two producing areas (see Chapter 4). Even larger increases in supplies are anticipated from Canadian gas imports moving southward and eastward and from Gulf supplies moving northward primarily towards the Northeast and Midwest. Oversupply of the Midwest market is possible, given the large capacity increases planned from all three sources, while increased supplies to the Northeast should help mitigate potential increases in natural gas prices. Increased use of storage, particularly high-deliverability salt cavern storage, is likely to play a role in stabilizing prices by better matching seasonal demand with available gas supplies. In the longer term, increased gas supplies from Nova Scotia are targeted primarily at the Northeast and Eastern Canada, potentially contributing to further leveling of natural gas prices throughout North America.

\section{Summary}

Natural gas production in the lower 48 States is forecast to rise 7.8 percent from an average of 50.1 billion cubic feet per day in 1996 to 54.0 billion cubic feet per day in 2000 , with much of the increase coming from the offshore Gulf of Mexico, the Permian Basin, and the Rocky Mountain area. A technological revolution during the 1990s, led by 3-D seismic surveys, horizontal drilling, and new offshore platform designs, has opened up deeper water frontiers in the Gulf of Mexico while also yielding new opportunities in onshore producing regions. Additional pipeline capacity from producing areas in Western Canada to major markets in the U.S. Northeast and Midwest will allow natural gas imports from Canada to rise, contributing to increased U.S. gas supplies in the near term.

Planned pipeline expansions through 2000 appear generally adequate to accommodate new lower 48 productive capacity and increased Canadian gas imports, although bottlenecks may be caused by lack of sufficient capacity to carry anticipated new offshore gas production beyond onshore Louisiana and the fact that most of the pipeline expansions allowing for increased Canadian imports are not due for completion before 1999 and 2000.

Major expansions of underground storage underway in the Northeast and Midwest as well as along the Texas and Louisiana coasts could help to avoid bottlenecks for gas moving northward from the offshore and onshore Gulf and ensure adequate deliverability to the top U.S. gas markets. 


\section{Deliverability on the Interstate Network}

The United States has a complex, extensive pipeline infrastructure for transporting natural gas from production areas to ultimate consumers. More than 85 U.S. interstate pipeline companies operate almost 200,000 miles of transmission lines, hundreds of compressor stations, and numerous storage facilities, allowing gas delivery throughout the lower 48 States. The importance of the network is reflected in the fact that 27 of the lower 48 States are almost totally dependent upon the interstate system for their gas supplies (Appendix C, Table C2).

Fifty of the interstate pipeline companies are classified as "major" systems by the Federal Energy Regulatory Commission (FERC), in that they each transported more than 50 million dekatherms (equivalent to about 66 billion cubic feet (Bcf)) of natural gas in each of the past 3 years. During January 1996, the month of greatest gas consumption that year, deliveries to end-use customers averaged 77 Bcf per day, with much of the gas moving along these same pipelines. ${ }^{38}$ The smaller interstate pipeline companies and the intrastate network (more than 200 systems) are also important, although their services are regional in nature. In fact, some of the intrastate pipeline systems in Texas and Louisiana rival some of the interstate systems in capacity, volumes transported, and revenue generation.

This chapter examines the capability of the interstate pipeline system to link production and market areas, focusing on pipeline operations along 10 distinct corridors: 5 of which extend from the Southwest, 3 from Canada, and 2 from the Rocky Mountains. It identifies the various pipeline companies operating in each corridor and discusses the changes in capacity and usage that have occurred since 1990 . It also briefly describes how some of the changes that have occurred as a result of industry restructuring have affected the way gas moves along the pipeline network.

The natural gas pipeline network has grown substantially since 1990, with more than 11.4 Bcf per day of interregional capacity (a 15-percent increase) added through the end of 1997. Meanwhile, the network has become more interconnected, its routings more complex, and its business operations more fluid. New types of facilities, such as market centers, and established operations, such as underground storage facilities, have become further interwoven into the

\footnotetext{
${ }^{38} \mathrm{~B}$ ased on total gas delivered to residential, commercial, industrial and electric utility customers in the United States. Energy Information Administration, Natural Gas Monthly, DOE/EIA-0130(97/12) (Washington, DC, December 1997).
}

national pipeline grid, allowing the system to operate in a much smoother manner.

Although a few natural gas transportation corridors are operating at close to full utilization year round, the pipeline network in North America has demonstrated its capability to meet the current level of demand. In addition, several expansions are planned to alleviate those cases where limitations exist, especially along those corridors transporting Canadian gas into the United States. In fact some excess capacity could develop along several corridors, although there probably will be some local areas where available pipeline capacity will not match demand.

\section{Recent Changes Affecting the Pipeline Network}

Pipeline system operations have changed radically during the past 10 years, particularly since 1992 when FERC issued Order 636 . The order formalized the transition of interstate pipeline companies from sellers of natural gas to nondiscriminatory transporters and mandated open access to interstate storage facilities. The resulting restructuring of the industry changed how network resources were being used and caused some shifts in transportation routes and trading and shipping arrangements.

- The increased competitiveness of the marketplace has led to several new pipeline interconnections as end users sought access to the least expensive gas supplies. With pipeline companies no longer owning the gas they transport, end users became responsible for making their own arrangements for purchasing and transporting natural gas. Sometimes the traditional pipeline link could not accommodate the consumers' needs directly and consequently several new transportation relationships (interconnections) developed.

- Storage has become an increasingly important component of overall pipeline and network operations. The interstate pipeline network depends upon a large number of underground storage sites to provide storage services to pipeline shippers and as a means for maintaining system balances and backup. Underground storage provides the mechanism through which a pipeline company can maintain control over its throughput levels in an environment where it no longer has total control over its receipts and deliveries. Of the 410 underground storage sites operating in the United 
States in 1996, almost half (190), representing more than 52 billion cubic feet of peak-day deliverability, were owned by interstate pipeline companies or their affiliates. ${ }^{39}$ Another 39 of the 400 storage sites serve the interstate market although they are owned by independent operators or large local natural gas distribution companies. The majority of sites owned by independent operators are linked to natural gas market centers.

- Market centers have proliferated during the 1990s and are becoming increasingly integrated into the transportation network. Natural gas market centers are a recent development in North America. Prior to 1990, only the Henry Hub site in southern Louisiana loosely fit the current profile of a market center. ${ }^{40}$ Today, at least 38 market centers are operating in the United States and Canada, providing numerous interconnections and routes to enhance transfers and movements of gas from production areas to markets. These centers provide a number of services formerly provided by pipeline companies and also offer many of the new services needed in today's market, such as short-term gas loans or temporary gas parking. The types of flexibility demanded of market center services is predicated upon the use of high-deliverability (mostly salt cavern) underground storage facilities. Practically all of the high-deliverability storage located in North America is accessible through or linked directly to market centers. More than two-thirds of market centers have some form of storage access, accounting for about 47 percent of the working gas in North America, or more than 2 trillion cubic feet. Market centers also offer transportation (wheeling) services, balancing, title transfer, gas trading, electronic trading, and administrative services needed to complete transactions on behalf of the parties.

- The emergence of natural gas trading centers or trading points is also a recent development within the natural gas marketplace. Trading centers, which sometimes represent the same physical points as a market center or hub, have emerged with the growth of electronic gas trading. Many centers also represent trading points that evolved from the natural gas spot market that first arose during the mid-1980's. At first, commercial electronic gas trading systems were associated with and available only through a few market centers, but now their marketability has been expanded as subscribers are being offered the opportunity to enact

\footnotetext{
${ }^{39}$ Energy Information Administration, Form EIA-191, "Underground Gas Storage Report."

${ }^{40}$ Energy Information Administration, Natural Gas 1996: Issues and Trends, DOE/EIA-0560(96) (Washington, DC, December 1996), Chapter 3.
}

trading at strategic points throughout the North American pipeline grid. Most of the points are located in production areas, reflecting the selling of gas by producers at various gathering and pooling points. However, the number of points within market areas is growing as shippers demand more trading flexibility to handle imbalance situations during peak transportation periods. ${ }^{41}$ Currently, there are almost 150 trading points defined on these electronic trading services. In addition, many of these same points, and some others, are tracked in the industry trade press. For instance, Gas Daily, a widely circulated industry newsletter, publishes a daily price index of natural gas trades based upon transactions reported at approximately 120 points in North America.

Market centers and electronic trading centers/points are rapidly becoming vital components in maintaining an efficient and smooth pipeline network operation in North America. The vast majority of market and trading centers are located at either end of most of the transportation corridors discussed in the following sections. Future growth, or lack thereof, within these corridors will become a function of how much activity develops at these sites. Conversely, growth in demand within individual corridors would be necessary to support any additional market and trading centers.

\section{System Growth Since 1990}

The accommodations to change in the restructured industry brought about significant shifts in natural gas receipt, transport, and deliverability along the pipeline network. Since 1990 , several new pipelines have been constructed that have improved customer access to production sources (Figure 10). But, for the most part, much of the new capacity added on the network was an expansion to existing systems in order to increase access to new production sources or to new markets.

Between 1990 and the end of 1997, capacity additions on the long-haul corridors alone, which link production and market areas, totaled approximately 12.4 billion cubic feet per day, an increase of about 17 percent. ${ }^{42}$ Capacity and deliverability additions made during the period fall into several categories:

\footnotetext{
${ }^{41}$ In fact, according to Quicktrade L.L.C., one of the largest of the electronic trading companies in volume traded, the Chicago trading point, in 1996 transacted six times more business than the largest traded production area point, NGPL Texas/Oklahoma.

${ }^{42}$ Energy Information Administration, EIAGIS-NG Geographic Information System, Natural Gas Pipeline State Border Capacity, as of December 1997.
} 
Figure 10. Capacity of New Natural Gas Pipeline Systems Placed in Service in the United States Between 1990 and 1997

(Volumes in Million Cubic Feet per Day)

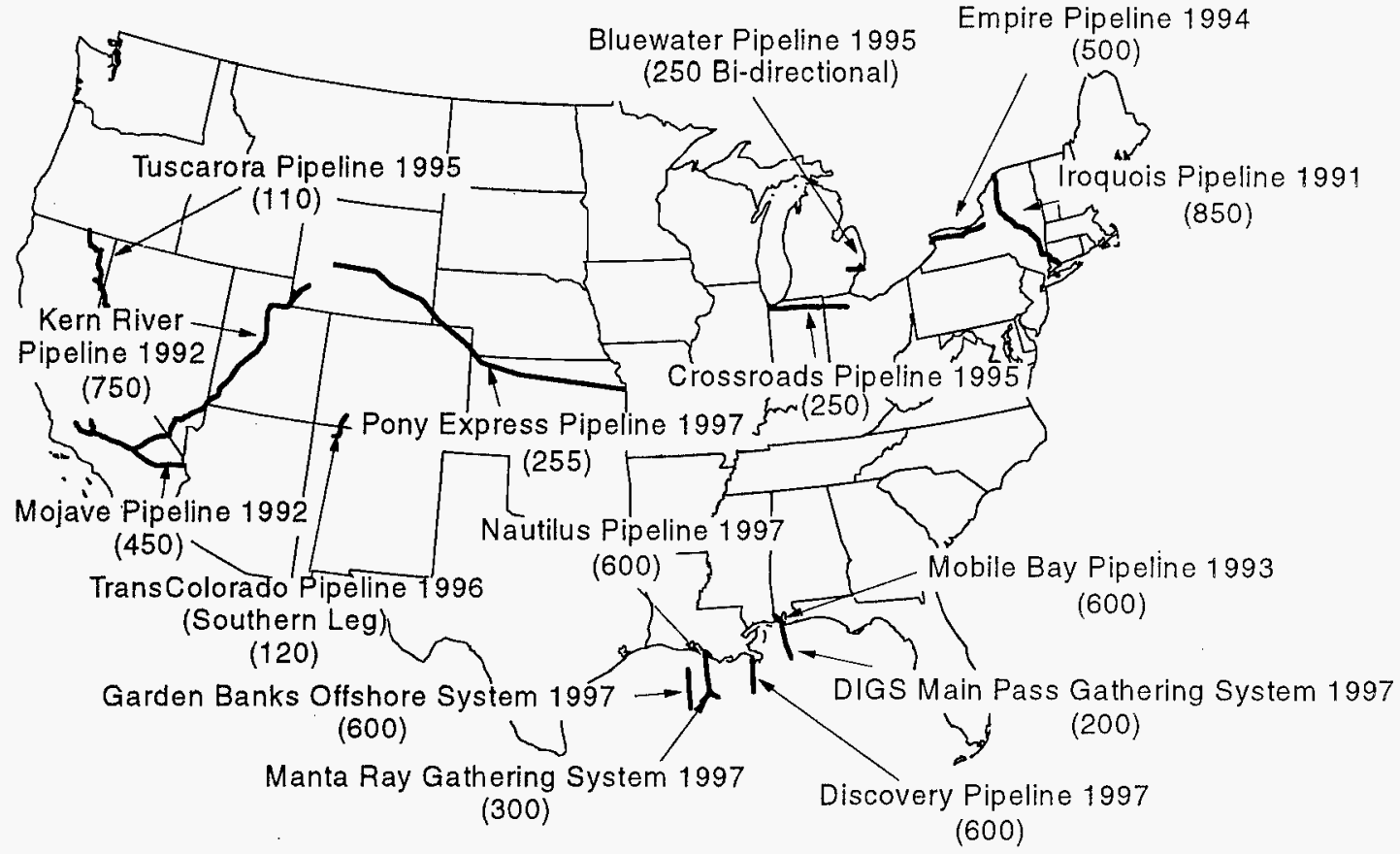

Note: Crossroads and Pony Express pipelines were conversions of existing oil pipelines to natural gas usage.

Source: Energy Information Administration, EIAGIS-NG Geographic Information System, Natural Gas Pipeline State Border Capacity and Natural Gas Proposed Pipeline Construction Database, as of December 1997.

- New pipeline systems built either to transport gas from expanding production areas or to service new market areas

- Expansion of existing systems to accommodate growing customer demand but accessing supplies already linked to the network

- Expansion of an existing system to accommodate shipper supplies transported via other pipeline systems

- Expansions of short-haul local delivery lines to link with new customers who bypass local natural gas distribution companies

- Expansions of pipeline systems in areas where productive capacity was greater than existing transportation capacity.

Most of the pipeline expansions since 1990 took place between 1991 and 1993, when approximately 17.2 billion cubic feet $(\mathrm{Bcf})$ per day of additional interstate pipeline capacity was brought into service. ${ }^{38}$ In 1994,1995 , and 1996, new capacity additions fell off dramatically (totaling only $4.9 \mathrm{Bcf}$ per day over the 3 years). The low level of pipeline expansions in those years reflects decisions made as far back as 1992 and earlier, just as the natural gas marketplace was undergoing a major restructuring and expanding deregulation. Uncertainty about the needs of this new market most likely kept the number of proposed projects to a minimum. In addition, as market conditions changed so did some project plans.

In 1997, more than 40 pipeline projects were completed, the largest number since 1993, adding $6.3 \mathrm{Bcf}$ per day of capacity overall while adding $0.5 \mathrm{Bcf}$ per day to interregional deliverability and $3.9 \mathrm{Bcf}$ to intraregional deliverability. A major portion of the new pipeline capacity represented increased receipt capability in expanding supply areas. For instance, the largest projects were in the Gulf of Mexico (3.2 Bcf per day) as offshore and deep-water development efforts in the area continue to expand. In addition, several

\footnotetext{
${ }^{38}$ The total capacity represented by the major interstate pipeline construction projects during the period tabulated on a per project basis.
} 
major projects were completed that expanded access to the Wind River and Powder River basins of the Rocky Mountain area by more than $0.5 \mathrm{Bcf}$ per day. The first new export lines to Mexico to be completed in 5 years were also placed in service during 1997.

The greatest increase in capacity since 1990 occurred on those routes between Canada and the U.S. Northeast, $1.9 \mathrm{Bcf}$ per day, or 412 percent (Table 7). This was brought about with the completion of several new pipelines and expansions to several import stations, almost exclusively in New York State (Figure 11). The largest increase in domestic capacity was between the Southwestern and Southeastern States, 1.0 Bcf per day. This increase was driven primarily by the growth in electric power and industrial demand for natural gas in the Southeast, particularly in Florida. ${ }^{44}$

The magnitude of pipeline expansion since 1990 can best be illustrated in conjunction with the natural gas pipeline transportation patterns that have emerged in North America over the years (Figure 12). In the early 1990s, three geographic regions were the primary focus of capacity expansion: the Western, Midwest, and Northeast regions. All three regions shared one common element, greater access to Canadian supplies. In addition, the Western Region was the target of expansions out of the Southwest Region, as new production sources were developed in the San Juan Basin of New Mexico and demand for natural gas in California was expected to grow substantially during the decade.

Through the year 2000, U.S. access to Canadian production is expected to continue to expand at a rate never before seen, while major service expansion to the Western Region appears to have ended. During the next several years, the emphasis will shift to expanding natural gas transportation capabilities from the Rocky Mountain, New Mexico, and West Texas areas eastward to link with pipeline systems reaching the Midwest and Northeast markets. With the completion of this effort, the interstate natural gas pipeline network will come closer to being a national grid where production from almost any part of the country can find a route to customers in almost any area. It will fill the gap in the national network that to some extent has left the Rocky Mountain and Western natural gas producers isolated from certain markets (see Chapter 2).

\section{Major Transportation Corridors}

The national natural gas delivery network is quite intricate and expansive, but most of the major transportation routes can be broadly categorized into 10 distinct corridors. Five major routes extend from the producing areas of the Southwest, three routes enter the United States from Canada, and two originate in the Rocky Mountains. For this analysis the 10 corridors have been roughly delineated as follows (Figure 12):

\section{From the Southwest}

(1) Southwest-Southeast: from the area of East Texas, Louisiana, Gulf of Mexico, and Mississippi to the Southeastern States.

(2) Southwest-Northeast: from the area of East Texas, Louisiana, Gulf of Mexico, and Mississippi to the U.S. Northeast (via the Southeast Region).

(3) Southwest-Midwest: from the area of East Texas, Louisiana, Gulf of Mexico, and Arkansas to the Midwest.

(4) Southwest Panhandle-Midwest: from the area of southwestern Texas, the Texas and Oklahoma panhandles, western Arkansas, and southwestern Kansas to the Midwest.

(5) Southwest-Western: from the area of southwestern Texas (Permian Basin) and northern New Mexico (San Juan Basin) to the Western States, primarily California.

\section{From Canada}

(6) Canada-Midwest: from the area of Western Canada to Midwestern markets in the United States.

(7) Canada-Northeast: from the area of Western Canada to Northeastern markets in the United States.

(8) Canada-Western: from the area of Western Canada to Western markets in the United States.

\section{From the Rocky Mountains}

(9) Rocky Mountains-Western: From the Rocky Mountain area of Utah, Colorado, and Wyoming to the Western States, primarily Nevada and California with support for markets in Oregon and Washington.

(10) Rocky Mountains-Midwest: From the Rocky Mountain area to the Midwest, including markets in Iowa, Missouri, and eastern Kansas.

\footnotetext{
${ }^{44}$ Only a small part of this additional capacity, 342 MMcf per day, represented capacity that continued on to the Northeast or Midwest regions.
} 
Table 7. Interregional Pipeline Export Capacity, Average Daily Flows, and Usage Rates, 1990 and 1996

\begin{tabular}{|c|c|c|c|c|c|c|c|c|c|c|}
\hline \multirow{2}{*}{$\begin{array}{l}\text { Sending } \\
\text { Region }\end{array}$} & \multirow{2}{*}{$\begin{array}{c}\text { Receiving } \\
\text { Region }\end{array}$} & \multicolumn{3}{|c|}{$\begin{array}{c}\text { Capacity } \\
\text { (MMcf per Day) }\end{array}$} & \multicolumn{3}{|c|}{$\begin{array}{l}\text { Average Flow } \\
\text { (MMcf per Day) }\end{array}$} & \multicolumn{3}{|c|}{$\begin{array}{c}\text { Usage Rate } \\
\text { (percent) }\end{array}$} \\
\hline & & 1990 & 1996 & $\begin{array}{l}\text { Percent } \\
\text { Change }\end{array}$ & 1990 & 1996 & $\begin{array}{l}\text { Percent } \\
\text { Change }\end{array}$ & 1990 & 1996 & Change \\
\hline \multirow[t]{4}{*}{ Canada } & Central & 1,254 & 1,563 & 25 & 941 & 1,542 & 64 & 75 & 99 & 24 \\
\hline & Midwest & 2,161 & 3,049 & 41 & 1,733 & 2,581 & 49 & 84 & 85 & 1 \\
\hline & Northeast & 467 & 2,393 & 412 & 309 & 1,834 & 494 & 66 & 77 & 11 \\
\hline & Western & 2,421 & 3,786 & 56 & 1,874 & 3,275 & 75 & 78 & 87 & 10 \\
\hline \multicolumn{2}{|c|}{ Total from Region } & 6,303 & 10,791 & 69 & 4,857 & 9,233 & 90 & 78 & 86 & 8 \\
\hline Mexico & Southwest & 350 & 350 & 0 & 0 & 37 & - & 0 & 11 & - \\
\hline \multicolumn{2}{|c|}{ Total from Region } & 350 & 350 & 0 & 0 & 37 & -- & $\mathbf{0}$ & 11 & - \\
\hline \multirow[t]{4}{*}{ Central } & Canada & 66 & 66 & 0 & 44 & 4 & -99 & 67 & 4 & -63 \\
\hline & Midwest & 8,988 & 9,879 & 10 & 5,684 & 7,714 & 36 & 63 & 78 & 15 \\
\hline & Southwest & 1,283 & 2,114 & 64 & 572 & 1,267 & 122 & 68 & 70 & 2 \\
\hline & Western & 365 & 1,194 & 227 & 196 & 713 & 264 & 54 & 95 & 41 \\
\hline \multicolumn{2}{|c|}{ Total from Reglon } & 10,702 & 13,253 & 24 & 6,495 & 9,698 & 49 & 63 & 78 & 15 \\
\hline \multirow[t]{3}{*}{ Midwest } & Canada & 1,211 & 2,543 & 110 & 961 & 1,626 & 69 & 79 & 68 & -11 \\
\hline & Central & 1,765 & 2,354 & 33 & 974 & 1,564 & 61 & 86 & 94 & 8 \\
\hline & Northeast & 4,584 & 4,887 & 7 & 3,474 & 4,220 & 21 & 76 & 86 & 11 \\
\hline \multicolumn{2}{|c|}{ Total from Reglon } & 7,560 & 9,784 & 29 & 5,409 & 7,410 & 37 & 78 & 83 & 5 \\
\hline \multirow[t]{2}{*}{ Northeast } & Midwest & 2,024 & 2,038 & 1 & 714 & 910 & 27 & 45 & 45 & 0 \\
\hline & Southeast & 100 & 520 & 417 & 63 & 15 & -78 & 63 & 60 & -3 \\
\hline \multicolumn{2}{|c|}{ Total from Reglon } & 2,124 & 2,558 & 20 & 777 & 925 & 18 & 46 & 45 & -1 \\
\hline \multirow[t]{3}{*}{ Southeast } & Midwest & 9,645 & 9,821 & 2 & 6,134 & 8,020 & 31 & 64 & 82 & 18 \\
\hline & Northeast & 4,971 & 5,149 & 4 & 4,091 & 4,431 & 8 & 82 & 86 & 4 \\
\hline & Southwest & 405 & 405 & 0 & 75 & 60 & -20 & 79 & 86 & -4 \\
\hline \multicolumn{2}{|c|}{ Total from Reglon } & 15,021 & 15,375 & 2 & 10,300 & 12,511 & 22 & 70 & 83 & 13 \\
\hline \multirow[t]{4}{*}{ Southwest } & Central & 8,555 & 8,609 & 1 & 4,119 & 4,993 & 21 & 49 & 60 & 11 \\
\hline & Mexico & 354 & 844 & 138 & 38 & 83 & 117 & 11 & 10 & -1 \\
\hline & Southeast & 19,801 & 20,846 & 5 & 14,613 & 16,063 & 10 & 74 & 77 & 3 \\
\hline & Western & 4,340 & 5,351 & 23 & 3,910 & 2,415 & -38 & 90 & 45 & -45 \\
\hline \multicolumn{2}{|c|}{ Total from Reglon } & 33,050 & 35,650 & 8 & 22,680 & 23,555 & 4 & 69 & 66 & -3 \\
\hline \multirow[t]{2}{*}{ Western } & Central & 250 & 298 & 19 & 196 & 4 & - & 78 & 0 & - \\
\hline & Mexico & 45 & 45 & 0 & 5 & 9 & 86 & 11 & 21 & 9 \\
\hline \multicolumn{2}{|c|}{ Total from Reglon } & 295 & 343 & 16 & 201 & 13 & -93 & 69 & 29 & -40 \\
\hline
\end{tabular}

'Usage rate shown may not equal the average daily flows divided by capacity because in some cases no throughput volumes were reported for known border crossings. This capacity was not included in the computation of usage rate.

MMcf = Million cubic feet. -- = Not applicable.

Sources: Energy Information Administration (EIA). PIpeline Capaclty: EIAGIS-NG Geographic Information System, Natural Gas Pipeline State Border Capacity Database, as of December 1997. Average Flow: Form EIA-176, "Annual Report of Natural and Supplemental Gas Supply and Disposition." Usage Rate: Office of Oil and Gas, derived from Pipeline Capacity and Average Flow. 
Figure 11. Region-to-Region Natural Gas Pipeline Capacity, 1990 and 1996 (Volumes in Million Cubic Feet per Day)
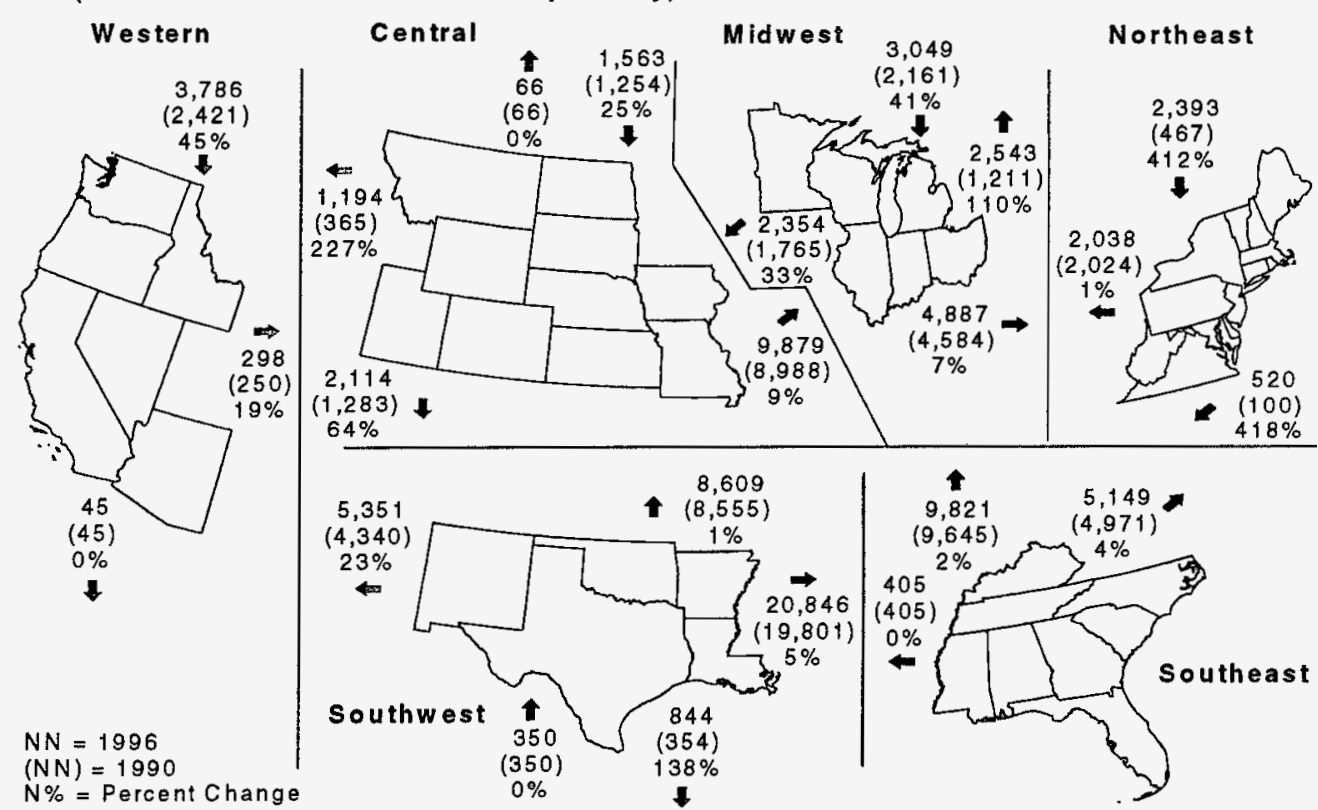

N\% = Percent Change

Source: Energy Information Administration (EIA), EIAGIS-NG Geographic Information System, Natural Gas Pipeline State Border Capacity Database, as of December 1997.

Figure 12. Major Natural Gas Transportation Corridors in the United States and Canada, 1997

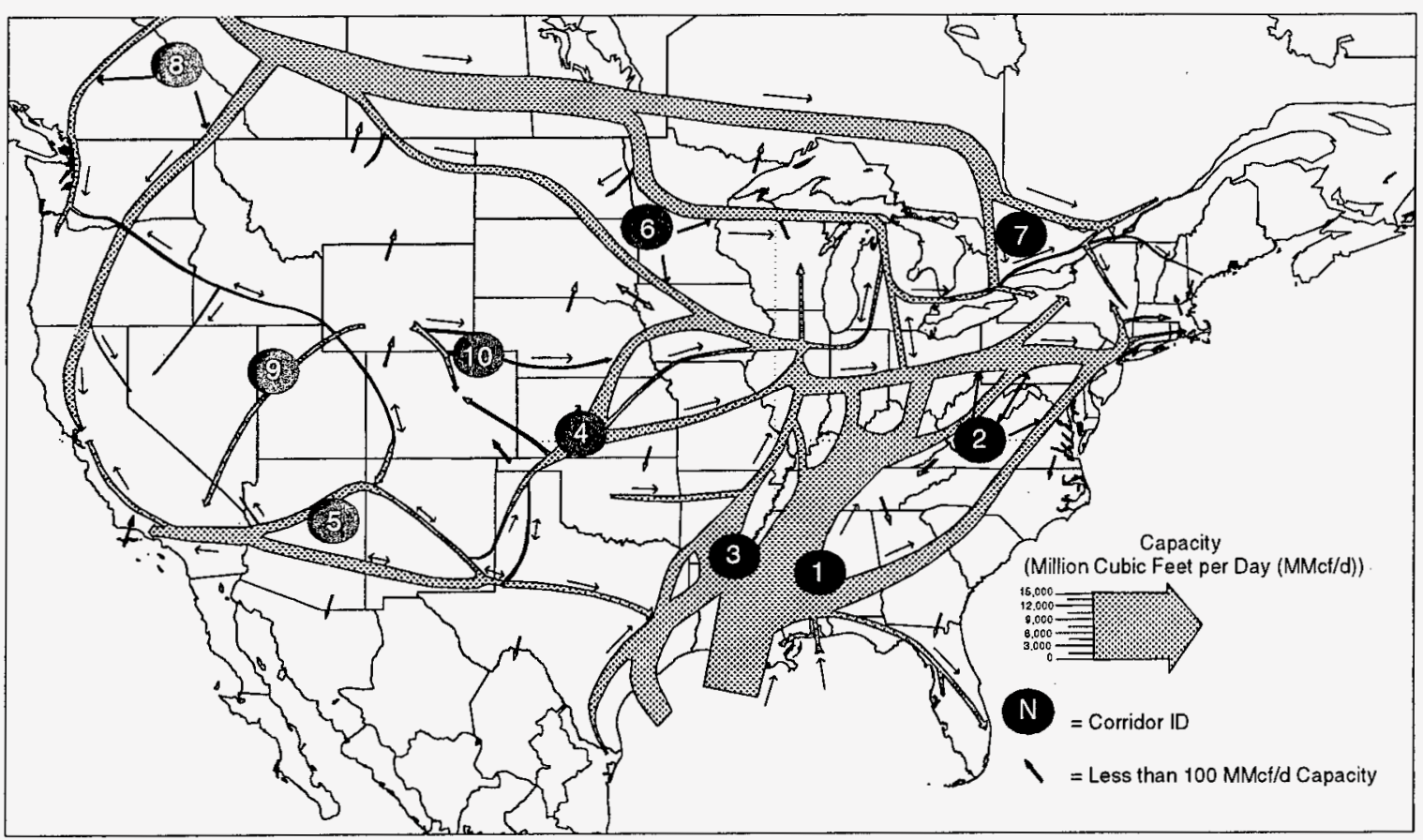

Note: The 10 transportation corridors are: (1) Southwest-Southeast, (2) Southwest-Northeast, (3) Southwest-Midwest, (4) Southwest Panhandle-Midwest, (5) Southwest-Western, (6) Canada-Midwest, (7) Canada-Northeast, (8) Canada-Western, (9) Rocky Mountains-Western, and (10) Rocky Mountains-Midwest.

Source: Energy Information Administration, EIAGIS-NG Geographic Information System, Natural Gas Pipeline State Border Capacily Database, as of December 1997. 
While these 10 corridors constitute the bulk of the longdistance transportation routes, a number of regional pipeline systems also serve markets within either the supply region itself or the major market areas. For instance, one of the largest pipeline systems within the Southwest supply region is NORAM Gas Transmission Company; within the Northeast market region, Columbia Gas Transmission Company is a major interstate transporter/distributor of natural gas (see Chapter 4 for a regional breakout of pipeline service areas).

\section{Originating Regions}

The largest amount of natural gas pipeline capacity exists on those systems that link the production areas of the U.S. Southwest with the other regions of the country. Capacity exiting the region in 1996 was nearly 36 billion cubic feet (Bcf) per day. Between 1990 and the end of 1996, total export capacity from the region grew by 8 percent or $2.6 \mathrm{Bcf}$ per day (Table 7). Export capacity from the Central Region, which includes the Rocky Mountain production areas, was slightly more than 13.3 Bcf per day in 1996, most of which is directed to the U.S. Midwest ( 9.9 Bcf per day). About 86 percent of this latter figure, however, represents capacity that originates outside the region (from the Southwestern States or at the Canadian border) and merely traverses the region. Canadian export capacity into the United States in 1996 stood at about $10.8 \mathrm{Bcf}$ per day. That figure represents a growth of 69 percent (4.5 Bcf per day) since 1990 , with much of the additional export capacity reaching into the U.S. Northeast.

The motivation behind many of the expansion projects completed in these exporting regions from 1991 through 1996 was to improve deliverability from capacity-constrained production areas and/or provide alternative routing opportunities to shippers seeking access to new markets.

More than 20 of the major interstate pipelines originate in the Southwest. Some extend to the Southeast through Louisiana and Mississippi, others to the Central and Midwestern States through Texas, Oklahoma, and Arkansas, and to the Western States through New Mexico. This area of the country exports about 60 percent ( 8.6 trillion cubic feet in 1996) of its production, which is 58 percent of the total natural gas consumed elsewhere in the lower 48 States. ${ }^{45}$ Pipelines exiting the region have the capacity to accommodate as much as 35.7 Bcf per day: 58 percent to the Southeast Region, 24 percent to the Central Region, 15 percent to the Western Region, and the rest to Mexico (Figure 11). Much of the pipeline capacity directed toward the Southeast traverses the region en route to Midwestern and Northeastern markets. To

\footnotetext{
${ }^{45}$ For purposes of this discussion, exports pertain to all volumes leaving a region for another region or country.
}

a lesser degree, this is also true for the pipeline capacity exiting to the midsection of the country, much of which is ultimately destined for the Midwestern States.

The Southwestern States also have a large number of underground storage facilities, most of which were once used to store excess natural gas production during months of low consumption. ${ }^{46}$ While still true, production storage service is now only one of the functions provided by these sites. A growing amount of the storage in the region is highdeliverability (salt dome) storage, which allows a rapid drawdown of inventory (within 10 days or once a month) and quick shifts from injection to withdrawal mode. This type of storage is highly complementary of the needs of shippers, who under today's rules must manage their own accounts and avoid costly pipeline imbalance penalties and the other vagaries of a more competitive marketplace. Total working gas storage capacity in the Southwest (over 982 billion cubic feet) is the second highest of the six regions (Appendix C, Table C1).

In the Central Region, only one major interstate pipeline provides transportation services directly to another region, Kern River Transmission Company. All the others operate primarily within the Central Region itself. Shippers using these lines to move supplies outside the region take advantage of the interconnections these lines have with the interstate pipelines traversing the region, principally those coming out of the Southwest Region.

\section{Transportation Corridors}

\section{(1) Southwest-Southeast}

\section{Two routes extend from the Southwest to the Southeast}

Two fairly distinct subcorridors extend into the Southeast Region from the Southwest: one goes eastward into Mississippi and continues further east, and the second goes northward into Tennessee and Kentucky (Figure 12). Along the first route, there are three major interstate pipeline companies that operate almost exclusively within the Southeast Region-Florida Gas Transmission Company (FGT), Koch Gateway Pipeline Company (Koch), and Southern Natural Gas Company (SONAT) (Table 8). Together they can handle at least 4.9 billion cubic feet (Bcf) per day for shippers in the region.

\footnotetext{
${ }^{46}$ Energy Information Administration, "U.S. Underground Storage of Natural Gas in 1997: Existing and Proposed," Natural Gas Monthly, DOE/EIA-0130(97/09) (Washington, DC, September 1997).
} 
Table 8. Natural Gas Transportation Corridors and Associated Major Pipeline Systems, 1996

\begin{tabular}{|c|c|c|c|c|c|}
\hline Corridor / Pipeline Name & $\begin{array}{l}\text { Other } \\
\text { Regions } \\
\text { Crossed }\end{array}$ & $\begin{array}{l}\text { Number of } \\
\text { Delivery } \\
\text { Points }\end{array}$ & $\begin{array}{l}\text { Number of } \\
\text { Interconnect } \\
\text { Points }\end{array}$ & $\begin{array}{l}\text { Average Day } \\
\text { Utilization } \\
\text { Rate }^{2}\end{array}$ & $\begin{array}{c}\text { Capacity } \\
\text { (MMci/d) }^{3} \\
\text { Wide Point }^{3}\end{array}$ \\
\hline $\begin{array}{l}1 \text { - Southwest-Southeast } \\
\text { Florida Gas Transmission Co } \\
\text { Koch Gateway Pipeline Co } \\
\text { Southern Natural Gas Co } \\
\text { Texas Gas Transmission Corp } \\
\text { Transcontinental Gas Pipeline Co }\end{array}$ & $\begin{array}{l}\text { None } \\
\text { None } \\
\text { None } \\
\text { None } \\
\text { None }\end{array}$ & $\begin{array}{r}181 \\
33 \\
323 \\
215 \\
121\end{array}$ & $\begin{array}{r}3 \\
44 \\
10 \\
8 \\
10\end{array}$ & $\begin{array}{l}71 \\
40 \\
67 \\
81 \\
84\end{array}$ & $\begin{array}{l}1,475 \\
1,134 \\
2,250 \\
2,163 \\
3,467\end{array}$ \\
\hline $\begin{array}{l}2 \text { - Southwest-Northeast } \\
\text { Columbia Gulf Transmission Co } \\
\text { Tennessee Gas Pipeline Co } \\
\text { Texas Eastern Transmission Corp } \\
\text { Transcontinental Gas Pipeline Co }\end{array}$ & $\begin{array}{l}\text { Southeast } \\
\text { Southeast } \\
\text { Southeast } \\
\text { Southeast }\end{array}$ & $\begin{array}{r}0 \\
116 \\
69 \\
124\end{array}$ & $\begin{array}{r}4 \\
61 \\
23 \\
16\end{array}$ & $\begin{array}{l}87 \\
90 \\
84 \\
83\end{array}$ & $\begin{array}{l}2,063 \\
2,671 \\
2,850 \\
2,587\end{array}$ \\
\hline $\begin{array}{l}\text { 3- Southwest-Midwest } \\
\text { ANR Pipeline Co } \\
\text { Midwestern Gas Transmission Co } \\
\text { Natural Gas Pipeline Co of America } \\
\text { Texas Gas Transmission Corp } \\
\text { Texas Eastern Transmission Corp } \\
\text { Trunkline Gas Co }\end{array}$ & $\begin{array}{l}\text { Southeast } \\
\text { Southeast } \\
\text { Central } \\
\text { Southeast } \\
\text { Southeast } \\
\text { Southeast }\end{array}$ & $\begin{array}{r}259 \\
18 \\
165 \\
102 \\
50 \\
53\end{array}$ & $\begin{array}{r}18 \\
10 \\
9 \\
20 \\
13 \\
8\end{array}$ & $\begin{array}{l}70 \\
59 \\
61 \\
79 \\
84 \\
74\end{array}$ & $\begin{array}{r}2,013 \\
665 \\
1,893 \\
1,509 \\
324 \\
1,853\end{array}$ \\
\hline $\begin{array}{l}\text { 4- Southwest Panhandle-Midwest } \\
\text { ANR Pipeline Co } \\
\text { Natural Gas Pipeline Co of America } \\
\text { Northern Natural Gas Co } \\
\text { Panhandle Eastern Pipeline Co }\end{array}$ & $\begin{array}{l}\text { Central } \\
\text { Central } \\
\text { Central } \\
\text { Central }\end{array}$ & $\begin{array}{r}259 \\
165 \\
129 \\
67\end{array}$ & $\begin{array}{r}18 \\
8 \\
4 \\
6\end{array}$ & $\begin{array}{l}70 \\
61 \\
45 \\
78\end{array}$ & $\begin{array}{r}853 \\
1,765 \\
2,500 \\
1,573\end{array}$ \\
\hline $\begin{array}{l}\text { 5 - Southwest-Western } \\
\text { El Paso Natural Gas Co } \\
\text { Transwestern Gas Pipeline Co }\end{array}$ & $\begin{array}{l}\text { None } \\
\text { None }\end{array}$ & $\begin{array}{r}339 \\
6\end{array}$ & $\begin{array}{l}2 \\
1\end{array}$ & $\begin{array}{l}51 \\
36\end{array}$ & $\begin{array}{l}4,261 \\
1,225\end{array}$ \\
\hline $\begin{array}{l}\text { 6- Canada-Midwest } \\
\text { Foothills Pipeline Co LTD (Canada) } \\
\text { Great Lakes Gas Transmission Co (U.S.) } \\
\text { Northern Border Pipeline Co (U.S.) } \\
\text { TransCanada Pipeline LTD (Canada) } \\
\text { Viking Gas Transmission Co (U.S.) }\end{array}$ & $\begin{array}{l}\text { None } \\
\text { None } \\
\text { Central } \\
\text { None } \\
\text { None }\end{array}$ & $\begin{array}{r}0 \\
206 \\
2 \\
0 \\
42\end{array}$ & $\begin{array}{r}1 \\
30 \\
2 \\
2 \\
7\end{array}$ & $\begin{array}{r}\text { NA } \\
88 \\
102 \\
\text { NA } \\
45\end{array}$ & $\begin{array}{r}1,675 \\
2,286 \\
1,675 \\
7,100 \\
425\end{array}$ \\
\hline $\begin{array}{l}7 \text { - Canada-Northeast } \\
\text { Empire Pipeline Co (U.S.) } \\
\text { Granite State Gas Transmission Co (U.S.) } \\
\text { Iroquois Gas Pipeline Co (U.S.) } \\
\text { Tennessee Gas Pipeline Co (U.S.) } \\
\text { TransCanada Pipeline LTD (Canada) }\end{array}$ & $\begin{array}{l}\text { None } \\
\text { None } \\
\text { None } \\
\text { None } \\
\text { None }\end{array}$ & $\begin{array}{r}\text { NA } \\
\text { NA } \\
10 \\
31 \\
4\end{array}$ & $\begin{array}{r}\text { NA } \\
\text { NA } \\
8 \\
25 \\
3\end{array}$ & $\begin{array}{l}\text { NA } \\
52 \\
90 \\
90 \\
\text { NA }\end{array}$ & $\begin{array}{r}500 \\
62 \\
858 \\
843 \\
3,950\end{array}$ \\
\hline $\begin{array}{l}8 \text { - Canada-Western } \\
\text { Alberta Natural Gas LTD (Canada) } \\
\text { Foothills Pipeline Co LTD (Canada) } \\
\text { Northwest Pipeline Corp (U.S.) } \\
\text { Pacific Gas Transmission Co (U.S.) } \\
\text { Tuscarora Gas Transmission Co. (U.S.) } \\
\text { Westcoast Gas Transmission LTD }\end{array}$ & $\begin{array}{l}\text { None } \\
\text { None } \\
\text { None } \\
\text { None } \\
\text { None } \\
\text { None }\end{array}$ & $\begin{array}{r}0 \\
0 \\
282 \\
190 \\
5 \\
1\end{array}$ & $\begin{array}{l}1 \\
1 \\
4 \\
2 \\
1 \\
1\end{array}$ & $\begin{array}{c}\text { NA } \\
\text { NA } \\
56 \\
93 \\
\text { NA } \\
\text { NA }\end{array}$ & $\begin{array}{r}1,360 \\
1,094 \\
1,289 \\
2,454 \\
110 \\
1,066\end{array}$ \\
\hline $\begin{array}{l}9 \text { - Rocky Mountains-Western } \\
\text { Kern River Gas Transmission Co }\end{array}$ & None & 30 & 1 & 95 & 750 \\
\hline $\begin{array}{l}\text { 10 - Rocky Mountains-Midwest } \\
\text { Trailblazer Pipeline System } \\
\text { KN Interstate Gas Co } \\
\text { Williams Natural Gas Co }\end{array}$ & $\begin{array}{l}\text { None } \\
\text { None } \\
\text { None }\end{array}$ & $\begin{array}{l}0 \\
0 \\
0\end{array}$ & $\begin{array}{r}4 \\
12 \\
24\end{array}$ & $\begin{array}{r}127 \\
32 \\
47\end{array}$ & $\begin{array}{l}411 \\
120 \\
186\end{array}$ \\
\hline
\end{tabular}

'Represents the number of delivery points or major pipeline interconnections along the section(s) of the pipeline systems associated with and within the respective corridor.

${ }^{2}$ Based on the sum of the State crossing point capacities of the respective pipeline divided by the sum of average daily flows at the same points.

${ }^{3}$ Represents the capacity (throughput capability) of the pipeline system at its maximum within the corridor.

$\mathrm{NA}=$ Not available. MMcf $/ \mathrm{d}=$ Million cubic feet per day.

Sources: Federal Energy Regulatory Commission, FERC 567 Capacity Report, "System Flow Diagram." Energy Information Administration (EIA), EIAGIS-NG Geographic Information System, Natural Gas Pipeline State Border Capacity Database, as of December 1997. 
Varying amounts of capacity on several other large interstate pipelines that follow this subcorridor also serve limited markets in the region. For instance, Transcontinental Gas Pipeline Company (Transco) serves customers in Georgia, South Carolina, and North Carolina as it continues along its route up the east coast (Appendix A, Figure A4). However, this service only represents about 1.1 Bcf per day, or 30 percent, of the $3.5 \mathrm{Bcf}$ per day found on the Transco system as it enters the region. Yet, in North Carolina it is essentially the only source of natural gas supplies to the State.

Along the second subcorridor, one pipeline company predominates, at least in terms of delivery points, Texas Gas Transmission Company (TGT). While this system extends into the Midwest Region, more than 70 percent of its delivery points are located in the States of Kentucky and Tennessee. TGT provides substantial deliveries to underground storage facilities in northern Kentucky that supplement supplies to the local market and to the Midwest Region during the heating season.

Tennessee Gas Pipeline Company (Tenneco) and Texas Eastern Transmission Company (TETCO) are two additional systems operating along this subcorridor, but most of their delivery points are outside the Southeast Region. Tenneco, however, is the principal supplier of gas to two regional interstate pipelines: MidCoast Pipeline (formerly the Alabama-Tennessee Natural Gas Company) mostly operating in northern Alabama, and the East Tennessee Gas Company (Tennessee and Virginia). Nevertheless, these deliveries represent only about $0.6 \mathrm{Bcf}$ (peak-day) out of a total $2.3 \mathrm{Bcf}$ deliverability available per day on the Tenneco system.

Capacity along the eastern subcorridor increased by about 5 percent between 1991 and 1996, primarily because of a substantial expansion on a major part of the Florida Gas Transmission system (up to 80 percent). In addition, while the Transcontinental Gas Pipeline system is not primarily a regional supplier, a major portion of its expansions during this period were directed toward service along this corridor rather than on its Northeast regional section. Transco's expansion during the period included a large capacity addition $(0.4 \mathrm{Bcf}$ per day) to new customers in northern North Carolina. The addition actually brought service southward, out of Virginia, from Transco's northbound mainline.

One new pipeline, the Mobile Bay Pipeline system (600 million cubic feet (MMcf) per day), was added within this corridor in 1993. It was only the second pipeline built in the Gulf of Mexico that terminates in the Southeast Region (the first being the Chandeleur Pipeline, $275 \mathrm{MMcf}$ per day). The system interconnects with both the Transcontinental Gas Pipeline (Transco) and Florida Gas Transmission (FGT) systems located in Alabama. The completion of this pipeline coincided with the $655 \mathrm{MMcf}$ per day expansion of the FGT system and the multi-phased expansion on the southern portion of the Transco system, totaling $220 \mathrm{MMcf}$ per day.

FGT expanded its system to provide additional service to the State's electric power generation sector and to a growing industrial sector; natural gas use in these sectors grew at an annual rate of 9.8 and 8.7 percent, respectively, between 1990 and 1996. Capacity utilization on the FGT system on its peak day in 1995 was 102 percent (Figure 17, Chapter 4). During its month of greatest throughput (July), average utilization was 97 percent, while during its lowest month (February) it fell to only 66 percent. FGT is unique in that its highest usage rates occur during the summer months, reflecting the strong electric generation (for air conditioning) needs within this warm region.

Tennessee Gas Pipeline Company (Tenneco) added capacity within this corridor to improve its overall capability to serve customers in the Northeast. While its several mainlines were already quite large in 1990, the added capacity represented a sizeable percentage increase to overall capacity along the corridor. Tenneco increased its capacity on the route by 19 percent (126 MMcf per day) leaving the production area of the Southwest (Appendix A, Table A4).

Average daily utilization rates on other pipelines in this corridor in 1995 ranged between 40 and 84 percent. The most highly utilized was the FGT system, which had a 66-percent usage rate during the off-peak periods and close to full capacity during its peak service period. The Transco system operated at about 83 percent on average, while during its peak periods operated at about 99 percent and 81 percent during the summer off-peak period (see Chapter 4).

The underground storage facilities located along this corridor are defined by their location. Those facilities at the corridor's southern end in Louisiana, Mississippi, and Alabama are mainly high-deliverability salt storage sites to support shippers and traders who want to acquire supplies for shipment to market (Appendix C, Table C1). Of the 9.3 Bcf of daily storage deliverability (withdrawal) available in the area, 46 percent is from salt cavern sites. This feature provides shippers using these corridors access to very flexible storage, which can be used to enhance their deliverability schedule, avoid transportation imbalances, and support any gas trading or hedging activities they may wish to engage in.

In northwestern Kentucky, along the western subcorridor, storage facilities are devoted primarily to providing seasonal supplies. They are supported, for the most part, by deliveries from the Texas Gas Transmission system. The majority of the storage in Mississippi and Alabama is available to shippers using either subcorridor. 
The principal pipeline expansions proposed along, or within, this corridor through 2000 represent greater access to Gulf of Mexico supplies and improvements to service within the Southeast Region (Appendix B, Table B2). Projects slated to provide new or improved access to Gulf of Mexico supplies amount to about 1.7 Bcf per day or 54 percent of the regional projects currently proposed. Strictly onshore, the SONAT system will add $141 \mathrm{MMcf}$ per day to its northern section, while Transco will upgrade its system with a short-haul 400 MMcf per day pipeline link to a new liquefied natural gas facility in North Carolina. In addition, Transco plans to update its facilities along this route to support the development of two new regional pipeline systems, the Cardinal Pipeline in North Carolina (140 MMcf per day) and Cumberland Pipeline serving Tennessee and Georgia (200 MMcf per day).

\section{(2) Southwest-Northeast}

\section{The main flow of U.S. gas is toward the Northeast}

The Southwest-to-Northeast corridor consists of two routes. The first extends from East Texas and Louisiana northeastward through Mississippi, Tennessee, Kentucky, and parts of Ohio to enter the Northeast Region via West Virginia or Pennsylvania (Figure 12). The second route begins as the first but then extends northeastward from Mississippi via the east coast States and enters Virginia from the south.

The principal interstate pipeline systems operating along the corridor include Tennessee Gas, Columbia Gulf Transmission, and Texas Eastern Transmission on the western segment, and Transcontinental Gas Pipeline on the eastern segment. These four pipeline companies represent approximately $9.3 \mathrm{Bcf}$ per day of total capacity, making this corridor the largest of the major transportation corridors in North America.

Since 1990, capacity on this corridor increased only slightly, about 500 MMcf per day. Most of that, $300 \mathrm{MMcf}$ per day, occurred on the Texas Eastern Transmission system as improvements were made to the links between its eastern seaboard network and its Midwest interconnections. Transcontinental Gas Pipeline system increased its capacity by $310 \mathrm{MMcf}$ per day, but little of this expansion affected its system north of Virginia.

The average utilization rates for the pipelines operating along this corridor ranged from 73 to 86 percent in 1996, for an overall average rate of 82 percent (Appendix A). That overall rate was the same as in 1990 . With the exception of Transcontinental Gas Pipeline system, which had a slight drop in utilization between the two comparison years, usage on each of the pipeline systems increased marginally. The largest increase was on the Tennessee Gas Pipeline system, which rose from 80 to 86 percent.

During wintertime peak periods, each of the systems are almost fully utilized. During the summer months, however, usage rates for the pipeline systems operating along this corridor tend to drop substantially. Except for the Columbia Gulf Transmission system, which operated at close to 100 percent year-round during 1995, the summertime (system wide) usage rates ranged from 49 percent for Texas Eastern's system to 81 percent for Transco's system. The principal factor affecting summertime usage rates on several of these pipeline systems is the demand for gas to refill underground storage sites in the States of West Virginia and Pennsylvania, and, to some degree, Ohio and New York as well. During the past several years, the refill rate and level of total (storage) working gas inventory prior to the heating season has fallen as inventory management practices have changed. This trend is reflected in the lower off-peak usage rates on some of the affected pipeline systems.

The majority of the more than 190 underground storage sites located along this corridor are accessible to shippers. At the southwestern terminus of the corridor, more than 30 sites with a working gas capacity of at least 624 billion cubic feet and a daily withdrawal capability of $13 \mathrm{Bcf}$ per day are located within 20 miles of the subject pipeline systems. Most of this capacity is used by producers, who use it to store short-term excess production, and by market centers.

Most of the same Southwestern market centers and associated storage discussed previously are also used by shippers on this corridor. ${ }^{47}$ But, in addition, this corridor links with some of the most active market centers located outside the Southwestern production area. One of the most significant is the Ellisburg-Leidy center in Pennsylvania, which provides interconnections and transportation services between the pipelines comprising this corridor and the other major interstate pipelines operating primarily within the Northeast States. Shippers using the corridor may also utilize the services of the CNG/Sabine, Columbia Gas, and New York (Brooklyn Union Gas Company) market centers to expand their marketing and transportation options further.

Several expansions have been proposed that could affect the northwestern portion of this corridor, although they would originate in other areas. For the most part they focus upon expansions that could tranship some of the vast amount of proposed new Canadian import capacity slated for the Midwest to the Northeast Region (Appendix B, Table B2). For instance, ANR Pipeline Company and Transcontinental

\footnotetext{
${ }^{47}$ Storage capacity within each of the 10 corridors should not be summed to get a U.S. total because it would result in double counting.
} 
Gas Pipeline Company have proposed the jointly owned Independence project, which could carry $1 \mathrm{Bcf}$ per day from ANR's line in northwestern Ohio to a major interconnection with Transcontinental's line in Leidy, Pennsylvania. The new line would also be attractive to Canadian shippers seeking an alternative route to Northeast markets. It could also provide an alternative route and opportunity for shippers now moving gas from the Southwestern to the Midwestern areas of the country to reach customers in the Northeast.

Other projects that would affect this portion of the corridor and direct some of the new Midwestern pipeline supplies eastward include Tennessee Gas Pipeline Company's proposed Eastern Express project and Duke Energy Corporation's Spectrum project. These two projects alone represent a total of $1.2 \mathrm{Bcf}$ per day of new capacity into the Northeastern United States.

The Spectrum project ( 0.5 Bcf per day) would extend from the Chicago, Illinois, area to New York and New England, mostly by using expanded facilities along Duke Energy's affiliated pipelines: Panhandle Eastern, Texas Eastern, and Algonquin Gas Transmission systems (west to east). In addition, an interconnection with another affiliate, Trunkline Gas Company, could be upgraded to improve gas supply transshipments from the Southwest Region, if appropriate (as could the Panhandle Eastern Pipeline system). The Eastern Express project (0.7 Bcf per day) would utilize Midwestern Gas Transmission Company (an affiliate of Tennessee Gas Pipeline Company) to ship supplies southward (or though exchanges of gas) to Tennessee Gas's interconnection in northern Tennessee and then, through expanded facilities on its existing system, transport supplies from the Midwest to the east coast. ${ }^{48}$

\section{(3) Southwest-Midwest}

\section{Corridor has significant off-peak capacity}

The Southwest-to-Midwest corridor extends northward out of East Texas, Louisiana, and Arkansas (Arkoma Basin production) and generally through Tennessee/Kentucky into the Midwest Region, although a part of it also travels through Missouri (Figure 12). The principal interstate pipeline systems operating along this corridor are: ANR Pipeline Company (ANR), Midwestern Gas Transmission Company (via Tennessee Gas Pipeline Company), Natural Gas Pipeline Company of America (NGPL), Texas Gas Transmission

\footnotetext{
${ }^{48}$ In addition, the Eastern Express project would include expansion of Tennessee Gas's pipeline ( 0.2 Bcf per day) between its Niagara, New York, import point and its interconnections near Leidy, Pennsylvania, and its northern line extending directly to New England.
}

Company (TGT), Texas Eastern Transmission Company (TETCO), and Trunkline Gas Company. ${ }^{49}$

These systems represent approximately $7.3 \mathrm{Bcf}$ per day, or 29 percent of the total pipeline capacity feeding into the Midwest Region (24.8 Bcf per day). They also account for more than 30 percent of the total pipeline capacity exiting this area of the Southwest.

Several of the major pipeline projects that were planned for development between 1991 and 1996, in large part to provide shippers on this corridor greater access to supplies from the Arkoma Basin in Arkansas/Oklahoma to the Northeast and Midwest markets, were not built. Part of the reason may have been the competing plans for Canadian import expansions and the low utilization rates on the existing lines extending to the Midwest Region.

Very little underground storage is located along the midsection of this corridor. However, shippers have access to significant amounts of storage at either end. This corridor also links together two major gas trading centers: the Henry Hub in Louisiana and the Chicago Center in northern Illinois. In addition, the corridor also includes several natural gas trading (and price discovery) locations accessible to shippers and traders via the several major commercial electronic trading systems set up in the United States and Canada. During the heating season, these markets are actively used by shippers and other market participants as a way to balance their receipts/deliveries, for arbitrage between the two markets, and to smooth market and price fluctuations through hedging.

Pipeline utilization rates on the corridor during peak periods of the heating season are generally in the 90 to 100 percent range, but during the nonheating season, usage rates range between 50 and 70 percent per average day. These figures indicate that a significant amount of capacity is available during off-peak periods, even though at the northern end of the corridor there is a large amount of underground storage capacity to refill. At the end of the 1995-96 heating season, for instance, the amount of working gas capacity to be refilled in the three States at the terminus of this corridor-Illinois, Indiana, and Kentucky-was approximately 287 billion cubic feet (Bcf), ${ }^{50}$ or the equivalent daily refill requirements of $1.4 \mathrm{Bcf}$ per day (210 days in the nonheating season). On this basis, deliveries to storage would need only about 18 percent of the daily pipeline capacity available on this route.

\footnotetext{
${ }^{49}$ Mississippi River Gas Transmission Pipeline Company (0.7 Bcf per day) also transports gas along this corridor but it terminates in the St Louis, Missouri, area. Its operations in Illinois are confined to the area east of St Louis.

${ }^{50} \mathrm{Based}$ on an average 35 percent working gas capacity remaining at the end of March 1996 in all sites located in the three States.
} 
In addition, during August 1996 total natural gas consumption in these three States was only 26 percent as much as that in January, the month of highest consumption. At this level, and assuming that deliveries to these three States were only from this corridor, capacity requirements would be only about $1.9 \mathrm{Bcf}$ per day during this off-peak month. Even with the deliveries to storage considered, pipeline capacity needed to meet the needs of the area is less than $\mathbf{5 0}$ percent of what is already available. Perhaps because of this situation, no additional capacity is currently planned along this corridor.

\section{(4) Southwest Panhandle-Midwest}

\section{Route is a major link between Waha Hub and Chicago}

This corridor extends from the West Texas and Oklahoma Panhandle areas northward through the major gas production fields (Hugoton, Panhandle, etc.) located in southwestern Kansas, and then northeastward toward the Midwest marketplace (Figure 12). Midway on its course, in Nebraska, it links with another corridor (see Rocky Mountain-Midwest section) bringing supplies in from the Rocky Mountain areas of Wyoming, Utah, and Colorado.

There are four major interstate pipelines that run along this corridor: ANR Pipeline Company, Panhandle Eastern Pipeline Company, Northern Natural Gas Company, and Natural Gas Pipeline Company of America. These four pipelines alone constitute 67 percent of total pipeline capacity exiting this area. These pipeline routes, however, represent only about 17 percent of the total capacity into the Midwest Region. The Trailblazer Pipeline system (average flow of $0.5 \mathrm{Bcf}$ per day in 1996) ties in Rocky Mountain supplies with an interconnection to Natural Gas Pipeline Company of America in Nebraska.

Several of the pipeline companies operating within this corridor have completed system expansions since 1990, although the additions were relatively small in comparison with additions in other corridors. For instance, in 1992, Natural Gas Pipeline Company of America (NGPL) added about 90 MMcf per day on the portion of its Amarillo line coming into Illinois and also improved capacity on its system coming out of the production areas of West Texas by about 245 MMcf per day. In 1996, Northern Natural Gas Company (NNG) completed an expansion of $351 \mathrm{MMcf}$ per day on its west-to-east route, improving service in the area and extending north to southern Wisconsin. At its terminus, it also improved its transmission facilities and transport capabilities in the Texas and Oklahoma panhandles by 310 MMcf per day in 1991 through 1993. The ANR Pipeline system increased capacity by 16 percent in this corridor, although this represented an increase of only about $83 \mathrm{MMcf}$ per day:
Capacity levels on the Panhandle Eastern Pipeline system did not increase at all.

Market centers located in the Waha and Panhandle area of West Texas serve this transportation corridor at its apex. At its terminus, shippers and traders can link their Texas trading with the Chicago market center. ${ }^{51}$ In addition, the Midcontinent market center, located in southcentral Kansas, provides shippers with the opportunity to do business with traders in the other two areas. All four pipelines operating in the corridor have direct or indirect links with each of the market centers.

Traders and transporters using this corridor can also tie their business and trading activities in with futures market trading. Both the New York Mercantile Exchange (NYMEX) and the Kansas City Board of Trade (KCBOT) have operated futures trading markets in the West Texas area for several years. These markets provide traders with the opportunity to hedge their trading activities and avoid price volatility risks. ${ }^{52}$ Of the two markets, the KCBOT has generated the most interest since its operational debut in 1995.

Also, because of its links to West Texas and the Oklahoma Panhandle area, many (spot market) trading points have become associated with this corridor. Some of the most active natural gas trading points (on a volume basis) have developed along it.

Only a limited amount of underground storage capacity is available to transporters through markets centers located along this route. Only the Mid-Continent and Chicago market centers offer any applicable access to storage services for shippers. However, during the nonheating season a sizeable amount of capacity on these systems is used to transport supplies for injection into storage facilities in Illinois, Indiana, and Michigan. The ANR Pipeline system in particular has a number of open-access sites located at the northern end of its system in Michigan. NGPL has a number of storage sites located in Illinois.

Very little expansion along this corridor is planned over the next several years. The only significant projects slated for development are the NGPL Amarillo expansion between Iowa and Illinois (110 MMcf per day), scheduled for completion in 1998, and the Northern Natural Gas Company's East Leg 2000 expansion, which will increase service capacity in its Central and Midwest markets by as much as $450 \mathrm{MMcf}$ per

\footnotetext{
${ }^{51}$ Energy Information Administration, Natural Gas 1996: Issues and Trends, DOE/EIA-0560(96) (Washington, DC, December 1996), Chapter 3.

${ }^{52}$ The locations of these futures markets in the Waha area of West Texas also enables their services to be available to shippers operating in East Texas moving supplies through the Texas intrastate system.
} 
day. ${ }^{53}$ The fact that these two projects are focused in the northern tier of this corridor while the southern section is not slated for significant expansion reflects primarily the ripple effect of proposed expansions to Canadian import capabilities.

\section{(5) Southwest-Western}

\section{Westward corridor is overbuilt}

The Southwest-Western corridor is used to transport supplies from the Permian Basin area of West Texas, through New Mexico (where the northern route taps into the San Juan Basin production area), and westward primarily to California (Figure 12). Two major interstate pipelines, El Paso Natural Gas Company and Transwestern Pipeline Company, operate along this corridor (Table 8). Both of these pipelines end at the California or Nevada State borders, where they deliver supplies to Southwest Gas Company (Nevada), Southern California Gas Company, and Pacific Gas \& Electric Company, the largest pipelines serving the California marketplace. In addition, Transwestern Gas Pipeline Company links with the Mojave Pipeline Company, an interstate pipeline placed in service in 1992 to transport natural gas supplies to the enhanced oil recovery (EOR) and cogeneration customers located in Kern County, California.

During the first part of this decade, these two pipeline systems expanded considerably: El Paso Natural Gas Company by 19 percent and Transwestern Pipeline by 41 percent. However, these expansions added capacity into California just when it was least needed and, as a result, a competitive situation developed between lower-cost Canadian supplies and Southwestern regional production. An additional impact was that unused capacity on these systems not only brought about a significant drop in load, but in several instances customers actually turned back contracted capacity, opting instead to satisfy their needs through the capacity release market. Compared with 1990, when average daily utilization levels on the El Paso and Transwestern systems were above 90 percent, in 1995 average-day utilization levels for the two pipelines were below 60 percent. Indeed, on its system peak day in 1995, El Paso Natural Gas had only a 66-percent load factor overall. Transwestern Pipeline's load factor on its peak day was 60 percent (Appendix A, Table A5).

The lower section of the long-delayed TransColorado pipeline system was completed in 1996 . The southern 25 -mile section of this 266-mile proposed pipeline system is currently moving about $120 \mathrm{MMcf}$ per day from the Ignacio area of the southern Colorado San Juan Basin to the Blanco hub in northern New Mexico. While this is less than half of its

\footnotetext{
${ }^{53}$ This expansion will accommodate shippers on the expanded Northern Border Pipeline system.
}

design capability of about $300 \mathrm{MMcf}$ per day, when the northern section of the system ${ }^{54}$ is completed (proposed late 1998), this recently completed section is expected to operate at close to its full capability.

Finally, the completion of Transwestern Pipeline Company's San Juan Basin expansion (255 MMcf per day) in 1996 expanded capacity on the New Mexico side of the San Juan Basin and partially relieved a production constraint situation that has hindered the flow of production out of the area for several years. While some of this improved capability will go to the Western marketplace, a major objective of this project has been to improve producer access to customers in the U.S. Northeast and Midwest.

The Blanco (hub) market center, operated by Transwestern Pipeline Company and located on the New Mexico portion of the San Juan Basin, has become a major pooling point for producers in the area and for shippers, especially those wanting to forward their supplies eastward to the market centers in West Texas (Waha area) and for transhipment on the Northern Natural Gas system (an affiliate of Transwestern), located to the northeast via the Texas and Oklahoma panhandles (see corridor (4)).

Nevertheless, a significant amount of West Texas and New Mexico gas supplies still are transported along this corridor to Arizona, California, and Nevada. In 1996, more than half of the natural gas consumed in those States (approximately 994 billion cubic feet) was transported via this route.

There is very little underground natural gas storage capacity associated with this corridor. At the extreme eastern end of the corridor, only one site, the Washington Ranch facility operated by El Paso Natural Gas Company, is reserved primarily for system support services and is not available for customer use. At its western end, in southern California, a limited amount of storage capacity is available to shippers at five sites operated by Southern California Gas Company (SoCal). While about 60 percent of this capacity is reserved for the company's own use, shippers can access what is available, as well as such storage-related services as shortterm gas loaning and parking, through the California Energy market center, which is also operated by SoCal.

Although some of the natural gas injected into these storage sites comes from producing fields in southern California, a significant amount of the working gas stored at these sites

\footnotetext{
${ }^{54}$ The TransColorado Pipeline was originally slated for completion in mid1992 but changing market conditions and other factors delayed construction until recently. The northern section will run from the Big Hole area of Rio Blanco County in northwest Colorado to the Ignacio area in southern La Plata County, Colorado.
} 
comes out of this corridor. The combined injection rate capability of the five sites is 1.1 billion cubic feet (Bcf) per day, while their total working gas capacity is $115 \mathrm{Bcf}$. This translates into roughly 104 days needed to fill these sites from scratch. But working gas levels at these sites rarely fall below 30 percent, ${ }^{55}$ which means that the equivalent of approximately 83 days per year of about 1 Bcf capacity service on the corridor could be said to be carried by storage service operations, or only about 4 percent on an annual basis.

Because of the excess capacity along this corridor, those projects that have been proposed are intended primarily to support expanded service to the eastern end of this corridor. Nevertheless, the end result of completing these projects will be to improve and expand service to the western end as well. For instance, Transwestern Pipeline Company has proposed further expansion of its San Juan facilities by up to $245 \mathrm{MMcf}$ per day in 1998, while El Paso Natural Gas Company has submitted plans for a compression enhancement project in the same area, which would improve its capacity by $116 \mathrm{MMcf}$ per day. The location of the facilities that are part of these projects, that is, the San Juan Basin triangle, is such that service benefits will affect area producers and shippers transporting to either end of the corridor.

\section{(6) Canada-Midwest}

\section{Corridor is major import route for Canadian gas}

This transportation corridor lies between Western Canadian supply areas and the U.S. Midwest and links two Canadian systems, TransCanada Pipeline Ltd. and Foothills Pipeline Company, with three United States pipeline systems, Great Lakes Gas Transmission Company, Northern Border Pipeline Company $^{56}$ and Viking Gas Transmission Company (Figure 13). This tie-in represents about $4.4 \mathrm{Bcf}$ per day of pipeline capacity, or about 41 percent of total U.S. natural gas import capacity in 1997. Since 1990, capacity on this route has increased by more than 40 percent.

Also, another pipeline, the Bluewater system, located at the eastern end of the corridor and placed in service in 1995, can transport up to $250 \mathrm{MMcf}$ per day on a bi-directional basis between the United States (Michigan) and Canada (Ontario). It was developed primarily to support regional storage services and business at the regional Grand Lacs natural gas

\footnotetext{
${ }^{55}$ Energy Information Administration, Form EIA-191, "Underground Natural Gas Storage Report."

${ }^{56}$ Northern Border currently serves the Midwest Region with deliveries to Northern Natural Gas Company and Natural Gas Pipeline Company of America. The pipeline receives large amounts of gas from Canada at Monchy near the Saskatchewan and Montana borders. Monchy is the second largest of the nine entry points for natural gas imports from Canada.
}

market center; thus it is strategically located. It lies along a route that will be expanding to accommodate increasing amounts of Western Canadian gas being transported to Northeast markets via a southern Canadian/U.S. alternative (see below).

A large number of underground storage facilities are located in proximity to several of the pipeline systems operating in this corridor, although not all of them are directly accessible to shippers. For instance, nine sites (1 Bcf per day injection, 1.8 Bcf per day withdrawal capability) are directly accessible to shippers using the Great Lakes Gas Transmission system, while the storage facilities located in Illinois and operated by Northern Illinois Gas Company (eight sites, 3.4 Bcf working gas capacity) are available only through the Chicago Market Center, which is affiliated with the company, or through the company itself. ${ }^{57}$ Altogether, the daily injection capability at storage facilities linked to the receiving end of this corridor represents the potential use of about $5 \mathrm{Bcf}$ per day of pipeline capacity during the storage refill period from April through October. If the proposed development of additional pipeline capacity along this corridor for extension to the Northeast Region is completed, shippers will have access to storage facilities and local distribution companies located in Pennsylvania and New York as well. Indeed, some proposals to expand storage availability in the Northeast to accommodate this capacity growth are already being put on the table. ${ }^{58}$

Expansions have occurred on two of the corridor's pipeline systems since 1990: Great Lakes Gas Transmission (GLT) and Northern Border Pipeline. Capacity on GLT increased significantly, 620 MMcf per day or 37 percent since 1990. Increasing imports, nevertheless, kept this corridor operating at or near capacity during most of the heating season and at about 90 percent on average throughout 1996 (based on annual flow). In 1995, the summer load factor averaged about 72 percent. Currently, GLT actually returns about 68 percent of the gas it imports at Noyes, Minnesota, to Canada via its St. Clair, Michigan, export point to customers in Ontario or transshipment to New York State through Ontario. GLT, with its access to its underground storage sites located in Michigan, can provide its customers with a seasonal supply backup depository and a peaking source.

The Northern Border Pipeline (NBP) system expanded by 0.4 Bcf per day, or 39 percent from 1991 through 1993. The pipeline is currently running at or above capacity throughout

\footnotetext{
${ }^{57}$ The Chicago Center is only indirectly accessible to shippers using this corridor.

${ }^{58}$ Energy Information Administration, "Underground Storage of Natural Gas in 1997: Existing and Proposed," Natural Gas Monthly, DOE/EIA0130(97/09) (Washington, DC, September 1997).
} 
most of the year; its lowest monthly daily average load factor in $1995 \mathrm{ran}$ in the neighborhood of 96 percent. Utilization levels on the system currently are higher than they were in 1990.

The growth in natural gas demand in Midwestern markets and the competitive pricing of Canadian natural gas over the past decade spurred most of the expansion activity that has occurred on this corridor since 1990. However, some of it has also been production driven, with Western Canadian producers being the initiators. In fact, most of the expansion projects recently proposed for development over the next several years along this corridor fall into this category. The northeastern section of British Columbia and northern Alberta have developed into enormous gas-producing areas and, as a result, markets are being aggressively sought for this gas, with the United States being the obvious and major target.

A very good example of such a project is the Alliance project, which would bring gas from British Columbia to the Chicago, Illinois, area along the right-of-way of an existing oil pipeline. The project was initiated by a consortium of Western Canadian producers dissatisfied with the limited service offered by the single NOVA(Alberta)-TransCanada system route currently available to them. If completed, the proposed Alliance project alone would increase area service along the corridor by $1.3 \mathrm{Bcf}$ per day. ${ }^{59}$ Coupled with the extension of the Northern Border Pipeline (in 1998 and 2000) ${ }^{60}$ and the Viking Voyageur project (2000), capacity on this part of the corridor could increase by more than 172 percent ( $3.8 \mathrm{Bcf}$ per day) from 1996 levels (2.2 Bcf per day). ${ }^{61}$

Partly in response to producer demands for additional exit capacity from Alberta and partly because of the potential competition from proposals such as the Alliance project, TransCanada has tendered its own expansion plans (1.4 Bcf per day) to feed into the proposed Viking Voyageur project. Several U.S. pipeline companies have developed expansion plans of their own that would tie in with TransCanada's additional system expansion plans for 1998 and 1999. These projects would also increase support to shippers wanting to transport gas to Ontario, Canada, via an alternative to the

\footnotetext{
${ }^{59}$ The proposed border-crossing site for the pipeline is slated to be able to move up to $1.6 \mathrm{Bcf}$ per day of gas if necessary.

${ }^{60}$ In August 1996, the Federal Energy Regulatory Commission approved construction of the Northern Border Pipeline Company expansion project which would add $700 \mathrm{MMcf}$ per day to import capacity at the Montana border. Correspondingly, Foothill Pipe Line Ltd. of Canada, which interconnects with Northern Border Pipeline at Monchy, Montana, would expand its eastern leg by the same amount. In February 1997, Foothills Pipeline Ltd., proposed to expand its system further and conducted an open season to gauge shipper demand.

${ }^{61}$ Energy Information Administration, Energy Policy Act Transportation Study: Interim Report on Natural Gas Flows and Rates, DOE/EIA-0602 (Washington, DC, October 1995), Table 5, p. 32.
}

northern TransCanada route and provide an integral link in support of Columbia Gas Transmission Company's Millennium project (see next section).

If all of the current proposals associated with this corridor are actually completed, capacity could increase by as much as 4.2 Bcf per day over the next several years. This level of increase is second only to that proposed for development into the Northeast Region. However, what really distinguishes the growth along this corridor is that the vast majority of new capacity would be on newly built trunklines bringing supplies in from Canada.

\section{(7) Canada-Northeast}

\section{Corridor is target of major expansion proposals}

The Canada-Northeast corridor links the eastern portion of the TransCanada Pipeline system (and Western Canadian gas production) to six pipeline companies in the Northeastern United States (Figure 12). The six are: Iroquois Pipeline Company, Granite State Transmission Company, Tennessee Gas Pipeline Company, Empire Pipeline Company, Vermont Gas Company, and St. Lawrence Gas Company. Indirectly, the corridor supplies gas to the National Fuel Gas Supply Company and CNG Transmission Company. The six systems transport gas primarily into New York and the New England States at a total capacity level of $2.4 \mathrm{Bcf}$ per day. While the vast majority of the Canadian capacity that comes into the U.S. Northeast is off the northern tier of the TransCanada system, about 5 percent represents capacity that traverses the U.S. Midwest (on the Great Lakes Transmission system), crosses back into Canada through Ontario, and is imported once again at Niagara, New York.

Two of the major pipeline systems along the Canada-toNortheast corridor were constructed during the 1990s: the Iroquois (850 MMcf per day) and Empire (500 MMcf per day) (Figure 10). Both systems serve primarily customers in New York State, although the Iroquois system also serves customers in Connecticut and Massachusetts (Appendix A, Table A3). These two new lines, plus the smaller North Country Pipeline also added between 1990 and 1996, alone increased import capacity to the Northeastern United States by nearly 300 percent. In addition, Tennessee Gas Pipeline system more than doubled its import capacity at Niagara, New York, adding $476 \mathrm{MMcf}$ per day, or about 129 percent to its 1990 level.

The increasing demand for Canadian gas in the Northeastern United States has been responsible for the very high utilization rates on the systems operating on this corridor. Annual average-day usage rates on these pipelines ran about 85 to 90 percent during 1996. During peak periods, the 
principal importing pipeline, Iroquois Gas Transmission Company, was operating about 22 percent above its certificated capacity. Even during the summer months, daily capacity utilization levels were in the 90 to 100 percent range. Iroquois often uses line packing on its system to handle heavy demands of shippers.

Several natural gas market centers are intricately tied to this corridor. At its western end, five market centers are located in Alberta, Canada. One of these, the AECO-C hub, is a key trading point on several commercial electronic trading systems and is also the point of trade for NYMEX futures contracts transacted for Western Canadian gas. In addition, several U.S. natural gas trading centers are located at the eastern end of the corridor, such as the Iroquois, CNG/Sabine, and Ellisburg-Liedy market centers. These centers provide customers with interconnections to at least 10 interstate pipeline systems and 4 intrastate systems serving shippers throughout the Northeast. The availability of such active trading centers at both ends of the corridor provides shippers with the transportation tools to transact their business efficiently.

Most of the market centers in this corridor offer customers access to underground storage services, such as gas loaning, temporary gas parking, and load balancing. In Canada, at the western end of this corridor, approximately $21 \mathrm{Bcf}$ per day of daily storage deliverability is available at eight sites. In the U.S. Northeast, storage deliverability of up to $4.6 \mathrm{Bcf}$ per day is available to shippers through market centers. In addition, several storage sites located in Ontario, Canada, are available to shippers transporting supplies to the area via the Great Lakes Transmission system.

This corridor is slated to undergo a major expansion over the next several years. If all the current expansion proposals were implemented, total direct Canadian import capacity into the U.S. Northeast could approach 5.0 Bcf per day by the end of the century, a 110-percent increase over 1997 levels. An already-approved TransCanada Pipeline Ltd. expansion project, slated for 1998 with further additions being considered for 1999 and 2000, would result in expansions at several import points into the U.S. Northeast and development of at least one new import point for Columbia Gas Transmission's Millennium project.

The Millennium project is projected to start deliveries in the fall of 1999 to customers in the U.S. Northeast. The proposed Vector Pipeline, which is a partner with Columbia and TransCanada in the Millennium project, will tranship supplies through Canada via TransCanada from its St. Clair, Michigan, export point to the Millennium pipeline at Niagara, New York.
Combined with the Millennium import level of $700 \mathrm{MMcf}$ per day and several import expansions related to other projects, such as the Portland Natural Gas Pipeline system, ${ }^{62}$ TransCanada's export capacity to the U.S. Northeast could increase by 0.9 Bcf per day by the end of 1999, a 53-percent increase over 1996 levels. In conjunction with TransCanada's multi-year expansion plans, Iroquois Pipeline Company has proposed an expansion of its import capabilities by $160 \mathrm{MMcf}$ per day.

In addition, several new pipelines have been proposed to move gas supplies being developed off the Canadian Atlantic coast near Sable Island to markets in Canada and the United States. The Maritimes \& Northeast pipeline project is slated to transport gas from the Sable Island Offshore project. Its route will take it directly into the State of Maine and through New Hampshire to interconnections with the Tennessee Gas Pipeline system in Massachusetts.

While this northern tier corridor has been the principal route used by shippers to import Canadian supplies into the Northeastern United States, the large number of projects recently proposed to bring Canadian supplies into the Midwestern marketplace (see earlier section) has spurred several major pipeline companies to plan large-scale projects that would extend some of this new capacity further eastward to Northeastern markets. If fully implemented, these projects would greatly expand the southern tier corridor, which in the past has seen only limited use as a route for imported supplies.

\section{(8) Canada-Western}

\section{Demand for Canadian gas has increased in Western markets}

The Canada-Western route brings natural gas from Alberta and British Columbia, Canada, through the States of Washington, Idaho and Oregon, with terminating points in Nevada and California (Figure 12). While much of the gas moving on this corridor reaches California at its northern border, some of the supplies also reach California by way of Arizona, being moved south and west via the States of Utah, Wyoming, and Colorado.

In Canada, Westcoast Gas Transmission Ltd. and Alberta Natural Gas Ltd. (in association with Foothills Pipeline Ltd.) receive gas from the NOVA Gas Transmission Ltd. (the

\footnotetext{
${ }^{62}$ The Portland Natural Gas Pipeline system (PNGT) (178 MMcf per day) will replace and expand upon the Granite State Pipeline Company's 31-MMcfper-day import pipeline that brings Canadian natural gas to Maine via Vermont and New Hampshire. The PNGT system may also be supplemented by LNG facilities that would be built in Maine.
} 
principal pipeline system in the region linked into the major production areas in Alberta and British Columbia) and transport that gas to the U.S. border (Table 8). There the supplies are received by Northwest Pipeline Company (from Westcoast Gas Transmission) and PG\&E Transmission -Northwest (PG\&E-NW), formerly Pacific Gas Transmission (PGT) (from Alberta Natural Gas). The two pipelines have a combined capacity of $3.5 \mathrm{Bcf}$ per day, 99 percent of import capacity in the area. This route represents one-third of the total capacity reaching the United States from Canada.

While PG\&E-NW transports most of its gas (about 82 percent in 1996) directly southward to California, the Northwest Pipeline system extends south and eastward from its border receipt point, operating on a bidirectional basis along much of the eastern section. At the northern Nevada State line, Northwest Pipeline Company links with the Paiute Pipeline Company, which until recently was the only gas supplier to the Reno, Nevada, area. Only one new pipeline has been added to the corridor since 1990, the Tuscarora Pipeline Company (113 MMcf per day) in 1995. This pipeline interconnects with the PG\&E-NW system at the northern California border and transports gas to the Reno, Nevada, area.

Between 1991 and 1996, capacity within this corridor grew by more than 48 percent (1.2 Bcf per day at the Canadian border) as capabilities were increased to meet expected growth in the regional natural gas market (Table 7). While the downturn in the regional economy during the period led to some excess capacity, usage levels for 1996 indicate the trend has turned around slightly, with average utilization levels along some portions of the corridor actually higher than they were in 1990 (Appendix A, Table A6).

Shippers using this corridor have access to the services of several market centers, although the types of available services are somewhat limited. For instance, within the California marketplace, the Golden Gate market center, which is affiliated with the Pacific Gas and Electric Company, limits its offerings mainly to parking and loaning services and interconnections with six of the principal pipeline system located at the southern end of this corridor. The Sumas market center, which operates in the Washington State/Canadian border area, provides shippers, primarily marketers and producers, with a pooling and aggregation point for export trading. At the apex of the corridor are the AECO-C, Alberta, Intra-Alberta and Crossfield hubs. These centers are tied closely to the NOVA pipeline system, which is the exclusive gas transporter in Alberta. The Intra-Alberta hub, which is primarily an electronic trading operation, is linked closely with trading and business conducted at the Sumas market center. This arrangement allows Alberta producers, shippers, and/or traders to coordinate trading with the pooling and aggregation services offered at Sumas.

Access to underground storage for shippers along this corridor is limited. Much of the storage capacity on the southern portion is owned and operated by local distribution companies and is used exclusively to support their own seasonal storage needs. Nevertheless, shippers can acquire access to storage services on an as-available basis through some of the market center operations. The Pacific Gas and Electric Company, through its Golden Gate market center, provides limited access to its three storage sites in northern California (the center also utilizes PG\&E system line packing to support its storage parking and loaning services). At the Canadian end of the corridor, much of the available storage is intricately linked with market center operations, providing parking and loaning services primarily to producers shipping gas to the United States. These Canadian sites are capable of handling up to $6 \mathrm{Bcf}$ per day deliverability and have a working gas capacity level of about 412 Bcf.

\section{(9) Rocky Mountains-Western}

\section{A new westward corridor was built in 1992}

This corridor did not exist until 1992, which was the year the Kern River Pipeline system was completed. This system extends from the Opal, Wyoming, area southwestward through Nevada, just north of Las Vegas, to Kern County, California (Figure 12) ${ }^{63}$ Its capacity is approximately 750 million cubic feet per day.

The Kern River Pipeline system was developed primarily to carry gas to the enhanced oil recovery market in southern California, which has been a substantive natural gas market. In 1996 its average day utilization rate was 95 percent, while on its system peak day it operated at 102 percent. In 1997 its service was extended to the Las Vegas electric power generation market with the opening of an expanded metering facility with Southwest Gas Company, the major natural gas distributor in the Las Vegas area.

Underground storage facilities, although available at the apex of this corridor in Wyoming and Utah, do not play a major role in the operations of the Kern River Pipeline system. Although six sites are in the vicinity, with a combined daily deliverability of $0.6 \mathrm{Bcf}$ per day and $66 \mathrm{Bcf}$ of working gas capacity, only one, Questar Pipeline Company's Clay Basin

\footnotetext{
${ }^{63}$ In California, the Kern River Pipeline system physically merges with the Mojave Pipeline system (400 MMcf per day) to form one line serving customers primarily in Kern County, California. Mojave receives its supplies from Transwestern Gas Pipeline Company and El Paso Natural Gas Company at the Arizona-California border.
} 
facility (0.4 Bcf per day, $51 \mathrm{Bcf}$ ), is accessible to shippers. The Western market center, located at the upper end of the system, provides customers with access to the Kern River Pipeline system and to the Clay Basin site. At the southern end of the corridor shippers have access to the services of two more natural gas market centers, the California Market Center (operated by Southern California Gas Company/Enerchange Inc.) and the Golden Gate Market Center (Pacific Gas \& Electric Company).

Only one expansion along this corridor has been proposed; the Colorado Intrastate Pipeline is assessing the feasibility of expanding its system to serve customers in Nevada along a new 360 -mile route ( 250 million cubic feet per day). This line would open a new market for new production out of the Powder River Basin in Wyoming.

During the early part of the decade, when the proposed Altamont Pipeline system was under serious consideration as a supplier of Canadian gas to California, the Kern River Pipeline Company had a proposal on the table to expand its system correspondingly. However, as a surplus of interstate natural gas pipeline capacity developed in the Western Region and the proponents of the Altamont system directed their target market eastward, those plans were set aside.

\section{(10) Rocky Mountains-Midwest}

\section{Corridor is expected to become more important as transportation capacity expands}

This corridor links Rocky Mountain natural gas supplies from Utah, Wyoming, and Colorado with markets in the Midwestern United States and with several sizable metropolitan markets in eastern Kansas and Missouri (Figure 13). While the corridor itself does not extend into the Midwest, the several pipelines operating along this route interconnect with major trunklines bringing supplies from the Southwest to Midwestern markets (see (3)).

The Trailblazer System, which is a contiguous linkup of the Overthrust, Wyoming Interstate, and Trailblazer pipelines, operates from western Wyoming to eastern Nebraska, where it offloads to the Natural Gas Pipeline Company of America pipeline. The Williams Natural Gas Company and the $\mathrm{KN}$ Interstate Pipeline Company also operate along this corridor, but these two pipelines serve primarily local regional markets (Table 8).

In late 1997, the KN Interstate Pipeline Company completed its Pony Express Pipeline ( 255 million cubic feet per day). This line is the first new long-distance line completed in this corridor since the Trailblazer Pipeline was installed during the early 1980's. The line runs from central Wyoming to south of
Kansas City, Missouri. Currently the new line does not provide any interconnections with the two major interstate pipelines connecting this corridor to Midwestern markets; rather, its full capacity is committed to customers located in the Kansas City area.

Several market centers are available to shippers using this corridor. Located at the western end is the Western market center and at the eastern end the Chicago market center. The Mid-Continent market center, located in southcentral Kansas and with access to the Natural Gas Pipeline Company of America's system, has become a key natural gas trading center for customers along this corridor. The market center in Wyoming currently has limited business with shippers using the corridor, primarily because available capacity is fully booked on a long-term basis and shippers have little need for transportation, title transfers/tracking, buyer/seller matching, and trade administration services. It remains to be seen if planned expansions along this corridor will increase market center activity, as what capacity is coming in service is already fully subscribed.

Customers using this corridor have a limited number of underground storage facilities available for their use. At the terminus of the corridor in Wyoming and Colorado are 18 sites that customers may access. Much of the storage located at this end, however, is used to support local producers and distribution companies. In the Chicago area corridor, shippers have access to storage facilities associated with the Chicago market center.

Compared with most of the other corridors, this particular one is relatively small. Its importance, however, lies in its future. Currently the Trailblazer system is fully utilized throughout most of the year as the demand for lower priced Rocky Mountain supplies grows among Midwestern shippers. In the past, Wyoming and Utah supplies generally moved to a strong southern California gas market, but that market has developed an excess of pipeline capacity during the past several years and is currently considered a soft market for natural gas. With the emphasis on the Western market, development of eastward bound pipeline capacity has been limited in the past.

\section{Summary}

During the past 50 years, the natural gas pipeline network in the United States and Canada has developed into an expansive and highly integrated transmission and distribution system. The 10 major natural gas transportation corridors examined in this chapter reflect only that portion of the network which involves long-haul operations. At the regional level, many other smaller interstate, intrastate, and local distribution systems have the responsibility of delivering gas to the 
ultimate consumer (see Chapter 4). In addition, there are numerous natural gas gathering systems that carry out the task of feeding supplies to the long-haul segment of the network (see Chapter 2).

Between 1990 and the end of 1997 , capacity additions on these long-haul corridors totaled more than 12.4 billion cubic feet (Bcf) per day, an increase of about 17 percent. Most of this construction entailed expansions to existing mainline systems, although some new, small-to-intermediate-size pipelines were also built. The largest combined increase in new or expansion capacity, 27 percent of the total, occurred along those corridors transporting supplies from Canada (1.2 Bcf per day), the Rocky Mountains ( 0.8 Bcf per day) and the Southwest (1.0 Bcf per day) to the Western Region of the United States. On a singular basis, the largest increase in capacity occurred on the corridor leading from Canada to the Northeastern United States, which grew by $1.9 \mathrm{Bcf}$ per day, or over 400 percent.

No matter how it is viewed, the corridors with the largest growth in deliverability since 1990 have been those coming into the United States from Canada. These corridors have also maintained the largest sustained utilization rates, with most of the pipelines in these corridors operating above 90 percent throughout most of the year. The comparatively lower cost of Canadian supplies over the past several years has been a key factor in maintaining these high utilization levels.

Based on current expansion proposals, the most extensive development of new capacity over the next several years will occur along these same corridors, except for the one directed toward the Western States. At least four new pipelines and several expansions are planned that will expand deliverability not only to the U.S. Midwest and Northeast markets but also to Canadian domestic markets. These projects will improve access to natural gas supplies in Western Canada and also create a new corridor that will bring production from the developing fields off the coast of Eastern Canada (Sable Island) to Canadian and U.S. markets. These expansions could add as much as $5.0 \mathrm{Bcf}$ per day to U.S. import capacity from Canada along these corridors, a 45-percent increase over 1997 levels. ${ }^{64}$ This anticipated growth reflects the continuing U.S. demand for Canadian natural gas, especially in the Midwest and Northeast regions, and the desire on the part of Western Canadian producers to expand further into these markets.

While the northern corridors predominate in respect to future expansions, it must be kept in mind that a great deal of natural gas productive capacity is also currently being developed in the Gulf of Mexico. The logical markets for this natural gas are in the Midwest and Northeast United States, the same markets slated for the Canadian expansions (as well as the expanding Rocky Mountain corridor). Yet, no major expansions along the corridors linking the Gulf of Mexico to these marketplaces have been announced. During the summer months, even with market storage refill supplies using significant levels of available capacity, a number of the pipelines along these corridors still have significant amounts of unused capacity available. This available capacity could absorb much of the Gulf's new-found production during offpeak periods, but during the heating season when many of these same pipelines are fully utilized, future capacity constraints could develop. If deep-water development continues over the next decade, most likely some complementary onshore expansions would occur along these corridors.

Although there are a few natural gas transportation corridors that are capacity constrained and/or are operating at close to full utilization throughout the year, the current capabilities of the pipeline network in North America are sufficient to meet the current level of demand. And, project proposals are on the table which will alleviate those few exceptions where limitations exist. In fact, on the surface it appears that an excess in pipeline capacity could develop along several corridors, especially if anticipated demand does not live up to expectations.

\footnotetext{
6The volume increase would be 37 percent more than the total Canadian import capacity added from 1991 through 1996, 4.3 Bcf per day.
} 


\section{Deliverability to Markets}

Each regional market in the United States has widely varying patterns of energy use and natural gas requirements. Different regional demographics, weather patterns, and distinct natural gas customer profiles result in different market needs and consumption levels. The numerous natural gas pipeline systems that have evolved over time to provide transportation services to and within these end-use markets are designed to accommodate these variations. For instance, in the colder, seasonal markets, regional natural gas distribution systems are designed to meet space-heating demands by residential and commercial customers and are interlaced with wintertime backup (underground storage) and peaking facilities. In less weather-sensitive markets where natural gas demand is mainly for electric power generation and/or industrial usage, storage is needed less for backup and more to support some short-term fluctuations in demand and pipeline transportation system balancing.

Except for those markets in the vicinity of major natural gas production areas, shippers depend upon major longhaul pipeline systems to provide their link between suppliers and the regional pipeline network that directs the natural gas to the eventual consumer. The capability of the longhaul "trunkline" usually reflects the needs of regional "grid" pipeline distributors, which sometimes are other major interstate companies but most often are local distribution companies.

This chapter discusses natural gas deliverability to end users in six U.S. geographic market areas: the Central, Midwest, Northeast, Southeast, Southwest, and Western regions. The emphasis is upon the capabilities, that is, the capacity and utilization, of the interstate natural gas pipelines supplying natural gas to and within each region (see Appendix A for a detailed listing of the pipeline companies serving individual States). Changes in deliverability since 1990 and planned expansions through 2000 are also highlighted.

The profile of the customer base is addressed to provide some insight into the current operation of pipeline and storage facilities in the market area. Each regional market is unique.

- Central: This market is the largest in area but is the least populated and produces more natural gas than it consumes, despite having the coldest weather (on average) of the regions. As a result, it is a net export market (Figure 13). Most of the capacity entering the region from Canada and the Southwest actually ends in the Midwest market.

- Midwest: More natural gas pipeline capacity enters this market than any other, 24.8 million cubic feet per day
(Table 9). It is the second coldest region (Table 10) and has a substantial spaceheating market. Residential and industrial customers in the Midwest consume more natural gas as a percentage of total energy (25 percent) than any other regional market except the major production area of the Southwest (Table 11).

- Northeast: This region is the most heavily populated and is the largest consumer of energy. Yet natural gas represents only 21 percent of all energy consumed, a comparatively low percentage (Table 11), especially since the region has very cold winters. However, natural gas use has increased at an annual rate of 4.9 percent since 1990. Coincidently, this market is a principal target for Canadian import expansions during the next several years (Appendix B).

- Southeast: This region has some of the warmest States in the Nation and consumes the second smallest amount of natural gas behind the Central Region (Table 11). However, almost all of the pipeline systems coming out of the Southwest (Texas and Louisiana) en route to Midwest and Northeast markets travel through the Southeast Region. Industrial use of natural gas is the largest consuming sector in this region, with 44 percent of the market (Table 12).

- Southwest: This region not only produces the most natural gas but also consumes the most. The industrial sector's share of the natural gas market is 53 percent, eight times that of the residential (Table 12). Export pipeline capacity exceeds incoming by a factor of 12 to 1 , with 16 major interstate pipeline companies beginning in the region (Appendix A, Table A5). Much of the deliverability within the market is handled by a large network of intrastate pipeline companies.

- Western: The Western Region is served by the least number of interstate pipeline companies (seven) and has the least amount of pipeline capacity entering the region, 10.1 million cubic feet per day. However, almost all natural gas coming into the region is consumed there. The market is a large consumer of Canadian natural gas.

\section{Major Market Changes, 1990-1996}

From 1990 through 1996, natural gas pipeline deliverability to the major U.S. markets increased significantly. On the interstate pipeline system alone, deliverability increased by 
Figure 13. Net Natural Gas Pipeline Capacity Entering (-Exiting) Each Region, December 1997

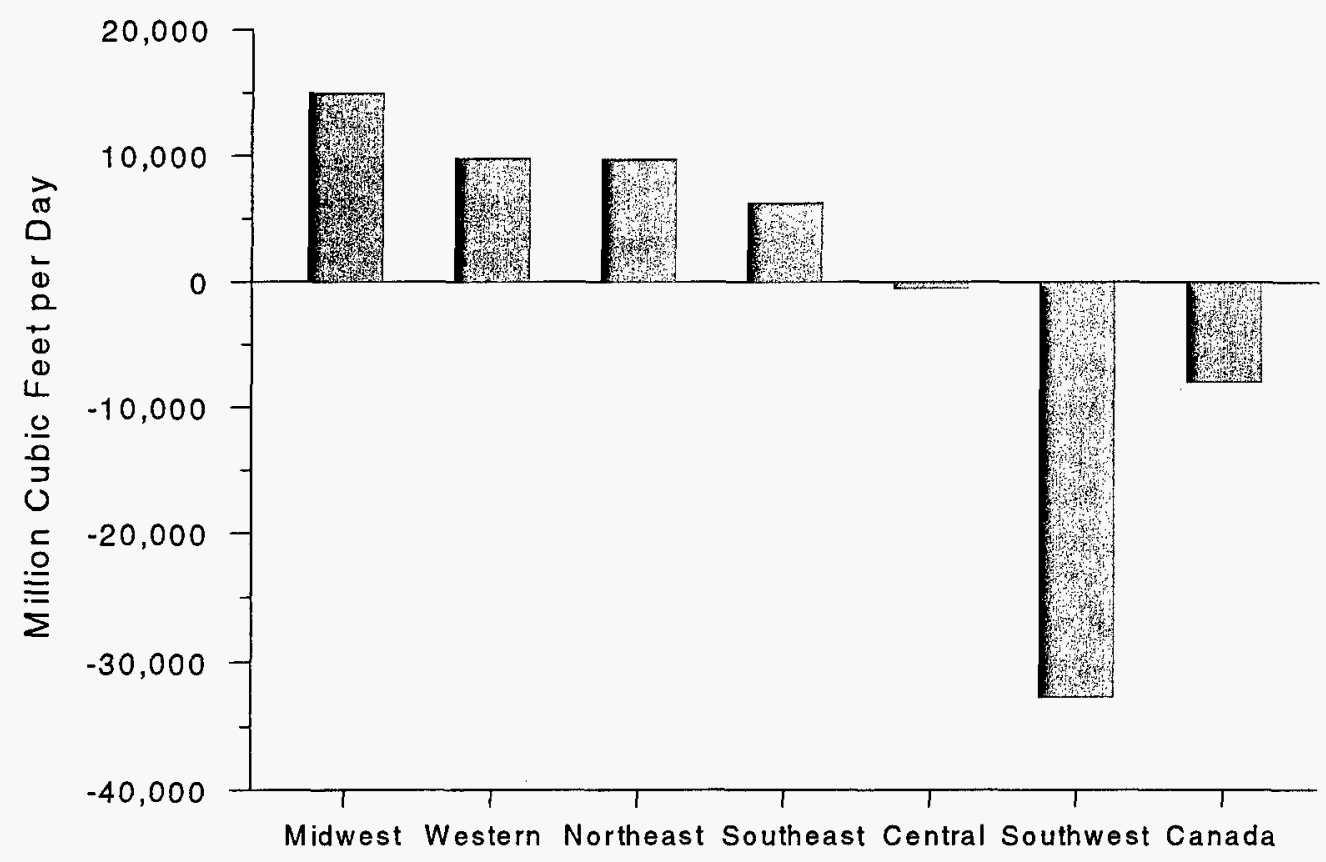

Source: Energy Information Administration, EIAGIS-NG Geographic Information System, Natural Gas Pipeline Capacity Database, as of December 1997.

more than 15 percent, or 10.9 billion cubic feet per day (Table 9), about the same rate as overall growth in natural gas consumption, 3.0 percent per year (Table 11). This increase reflects the growing demand for natural gas and its increasing contribution to the total national energy consumption picture. Some of the major changes include:

- Expansion of pipeline capacity to high demand markets. The largest increase in interregional capacity during the 6 years was in deliverability to the Western Region, 3.2 billion cubic feet per day or 45 percent. Second largest was a 24-percent increase into the Northeast Region, or 2.4 billion cubic feet per day (Table 9). The development of so much capacity in the West led to a surplus of capacity and an overall drop in the pipeline capacity usage rate, whereas in the Northeast, demand growth fully supported the increase. In fact, pipelines into the Northeast saw a substantial increase in average daily usage rates, up 6 percentage points from 1990 levels.

- Higher pipeline utilization rates. During the period, interregional usage rates increased by 7 percentage points, reaching a high of 75 percent (on an average day) in 1996. Pipeline usage rates within several major market areas also grew significantly. For instance, usage rates into the Midwest rose 14 percentage points to an average of 78 percent, ${ }^{65}$ while into the Central Region, rates rose 13 points. The overall rate fell only along routes into the Western and Southwest regions. In some areas of only limited capacity expansion, the increase in pipeline usage rates reflects a greater use of existing capacity that had been previously underutilized because of previous overbuilding or a temporary drop in demand.

- Elimination of some previous deliverability bottlenecks. Although average usage rates have increased, the reported occurrence of market area deliverability constraint is rare. ${ }^{66}$ In fact, many of the capacity additions in recent years have been to improve the capability of the regional pipeline systems and their service to local markets. In 1997 alone, excluding the exporting Southwest Region, 19 of the 31 completed expansion projects affected service totally within the market area. The Northeast had the highest, with 11 of 12 projects fitting into this category. Currently, capacity

\footnotetext{
${ }^{65} \mathrm{~B}$ ased only upon pipelines for which some flow was reported for a known State-to-State capability.

${ }^{66}$ The number and instances of pipeline service curtailments have decreased in recent years because of improved deliverability and system efficiencies, but serious system instabilities still occur that limit, and sometimes restrict, the free flow of natural gas to customers. When system instabilities do occur, pipeline operators have the option of executing what are known as operational flow orders (see Box, "Operational Flow Orders" in Chapter 1).
} 
Table 9. Interregional Pipeline Import Capacity, Average Daily Flows, and Usage Rates, 1990 and 1996

\begin{tabular}{|c|c|c|c|c|c|c|c|c|c|c|}
\hline \multirow{2}{*}{$\begin{array}{l}\text { Receiving } \\
\text { Region }\end{array}$} & \multirow{2}{*}{$\begin{array}{l}\text { Sending } \\
\text { Region }\end{array}$} & \multicolumn{3}{|c|}{$\begin{array}{c}\text { Capacity } \\
\text { (MMcf per Day) }\end{array}$} & \multicolumn{3}{|c|}{$\begin{array}{l}\text { Average Flow } \\
\text { (MMcf per Day) }\end{array}$} & \multicolumn{3}{|c|}{$\begin{array}{l}\text { Usage Rate }^{1} \\
\text { (percent) }\end{array}$} \\
\hline & & 1990 & 1996 & $\begin{array}{l}\text { Percent } \\
\text { Change }\end{array}$ & 1990 & 1996 & $\begin{array}{l}\text { Percent } \\
\text { Change }\end{array}$ & 1990 & 1996 & Change \\
\hline $\begin{array}{l}\text { Canada } \\
\text { Total Into Reglon }\end{array}$ & $\begin{array}{l}\text { Central } \\
\text { Midwest }\end{array}$ & $\begin{array}{r}66 \\
1,211 \\
1,277\end{array}$ & $\begin{array}{r}66 \\
2,543 \\
2,609\end{array}$ & $\begin{array}{r}0 \\
110 \\
104\end{array}$ & $\begin{array}{r}44 \\
961 \\
1,005\end{array}$ & $\begin{array}{r}4 \\
1,626 \\
1,630\end{array}$ & $\begin{array}{r}-99 \\
69 \\
62\end{array}$ & $\begin{array}{l}67 \\
79 \\
79\end{array}$ & $\begin{array}{r}4 \\
68 \\
68\end{array}$ & $\begin{array}{l}-63 \\
-11 \\
-11\end{array}$ \\
\hline $\begin{array}{l}\text { Mexico } \\
\text { Total into Reglon }\end{array}$ & $\begin{array}{l}\text { Southwest } \\
\text { Western }\end{array}$ & $\begin{array}{r}354 \\
45 \\
399\end{array}$ & $\begin{array}{r}844 \\
45 \\
889\end{array}$ & $\begin{array}{r}138 \\
0 \\
123\end{array}$ & $\begin{array}{r}38 \\
5 \\
43\end{array}$ & $\begin{array}{r}83 \\
9 \\
92\end{array}$ & $\begin{array}{r}117 \\
86 \\
113\end{array}$ & $\begin{array}{l}11 \\
11 \\
11\end{array}$ & $\begin{array}{l}10 \\
21 \\
10\end{array}$ & $\begin{array}{r}-1 \\
9 \\
-1\end{array}$ \\
\hline Total Into Reglon & $\begin{array}{l}\text { Canada } \\
\text { Midwest } \\
\text { Southwest } \\
\text { Western }\end{array}$ & $\begin{array}{r}1,254 \\
1,765 \\
8,555 \\
250 \\
11,824\end{array}$ & $\begin{array}{r}1,563 \\
2,354 \\
8,609 \\
298 \\
12,824\end{array}$ & $\begin{array}{r}25 \\
33 \\
1 \\
19 \\
8\end{array}$ & $\begin{array}{r}941 \\
974 \\
4,119 \\
196 \\
6,230\end{array}$ & $\begin{array}{r}1,542 \\
1,564 \\
4,993 \\
4 \\
8,099\end{array}$ & $\begin{array}{r}64 \\
61 \\
21 \\
-. \\
30\end{array}$ & $\begin{array}{l}75 \\
86 \\
49 \\
78 \\
57\end{array}$ & $\begin{array}{r}99 \\
94 \\
60 \\
0 \\
70\end{array}$ & $\begin{array}{r}24 \\
8 \\
11 \\
-- \\
13\end{array}$ \\
\hline Total Into Reglon & $\begin{array}{l}\text { Canada } \\
\text { Central } \\
\text { Northeast } \\
\text { Southeast }\end{array}$ & $\begin{array}{r}2,161 \\
8,988 \\
2,024 \\
9,645 \\
22,818\end{array}$ & $\begin{array}{r}3,049 \\
9,879 \\
2,038 \\
9,821 \\
24,787\end{array}$ & $\begin{array}{r}41 \\
10 \\
1 \\
2 \\
9\end{array}$ & $\begin{array}{r}1,733 \\
5,684 \\
714 \\
6,134 \\
14,265\end{array}$ & $\begin{array}{r}2,581 \\
7,714 \\
910 \\
8,020 \\
19,224\end{array}$ & $\begin{array}{l}49 \\
36 \\
27 \\
31 \\
35\end{array}$ & $\begin{array}{l}84 \\
63 \\
45 \\
64 \\
64\end{array}$ & $\begin{array}{l}85 \\
78 \\
45 \\
82 \\
78\end{array}$ & $\begin{array}{r}1 \\
15 \\
0 \\
18 \\
14\end{array}$ \\
\hline Total Into Reglon & $\begin{array}{l}\text { Canada } \\
\text { Midwest } \\
\text { Southeast }\end{array}$ & $\begin{array}{r}467 \\
4,584 \\
4,971 \\
10,022\end{array}$ & $\begin{array}{r}2,393 \\
4,887 \\
5,149 \\
12,429\end{array}$ & $\begin{array}{r}412 \\
7 \\
4 \\
24\end{array}$ & $\begin{array}{r}309 \\
3,474 \\
4,091 \\
7,874\end{array}$ & $\begin{array}{r}1,834 \\
4,220 \\
4,431 \\
10,485\end{array}$ & $\begin{array}{r}494 \\
21 \\
8 \\
33\end{array}$ & $\begin{array}{l}66 \\
76 \\
82 \\
79\end{array}$ & $\begin{array}{l}77 \\
86 \\
86 \\
85\end{array}$ & $\begin{array}{r}11 \\
11 \\
4 \\
6\end{array}$ \\
\hline $\begin{array}{l}\text { Southeast } \\
\text { Total into Reglon }\end{array}$ & $\begin{array}{l}\text { Northeast } \\
\text { Southwest }\end{array}$ & $\begin{array}{r}100 \\
19,801 \\
19,901\end{array}$ & $\begin{array}{r}520 \\
20,846 \\
21,366\end{array}$ & $\begin{array}{r}417 \\
5 \\
7\end{array}$ & $\begin{array}{r}63 \\
14,613 \\
14,676\end{array}$ & $\begin{array}{r}15 \\
16,063 \\
16,078\end{array}$ & $\begin{array}{r}-78 \\
10 \\
10\end{array}$ & $\begin{array}{l}63 \\
74 \\
74\end{array}$ & $\begin{array}{l}60 \\
77 \\
77\end{array}$ & $\begin{array}{r}-3 \\
3 \\
3\end{array}$ \\
\hline Total Into Reglon & $\begin{array}{l}\text { Central } \\
\text { Mexico } \\
\text { Southeast }\end{array}$ & $\begin{array}{r}1,283 \\
350 \\
405 \\
2,048\end{array}$ & $\begin{array}{r}2,114 \\
350 \\
405 \\
2,869\end{array}$ & $\begin{array}{r}64 \\
0 \\
0 \\
40\end{array}$ & $\begin{array}{r}572 \\
0 \\
75 \\
647\end{array}$ & $\begin{array}{r}1,267 \\
37 \\
60 \\
1,364\end{array}$ & $\begin{array}{r}122 \\
-. \\
-20 \\
111\end{array}$ & $\begin{array}{r}68 \\
0 \\
79 \\
69\end{array}$ & $\begin{array}{l}70 \\
11 \\
86 \\
61\end{array}$ & $\begin{array}{r}2 \\
- \\
7 \\
-8\end{array}$ \\
\hline Total Into Reglon & $\begin{array}{l}\text { Canada } \\
\text { Central } \\
\text { Southwest }\end{array}$ & $\begin{array}{r}2,421 \\
365 \\
4,340 \\
7,126\end{array}$ & $\begin{array}{r}3,786 \\
1,194 \\
5,351 \\
10,331\end{array}$ & $\begin{array}{r}56 \\
227 \\
23 \\
45\end{array}$ & $\begin{array}{r}1,874 \\
196 \\
3,910 \\
5,980\end{array}$ & $\begin{array}{r}3,275 \\
713 \\
2,415 \\
6,403\end{array}$ & $\begin{array}{r}75 \\
264 \\
-38 \\
7\end{array}$ & $\begin{array}{l}77 \\
54 \\
90 \\
84\end{array}$ & $\begin{array}{l}87 \\
95 \\
45 \\
62\end{array}$ & $\begin{array}{r}10 \\
41 \\
-45 \\
-22\end{array}$ \\
\hline Total Within Lower & 48 States & 73,739 & 84,606 & 15 & 49,672 & 61,655 & 24 & 68 & 75 & 7 \\
\hline
\end{tabular}

'Usage Rate shown may not equal the average daily flows divided by capacity because in some cases no throughput volumes were reported for known border crossings. This capacity was not included in the computation of usage rate.

MMcf = Million cubic feet. $--=$ Not applicable.

Sources: Energy Information Administration (EIA). Pipeline Capaclty: EIAGIS-NG Geographic Information System, Natural Gas Pipeline State Border Capacity Database, as of December 1997. Average Flow: Form ElA-176, "Annual Report of Natural and Supplemental Gas Supply and Disposition." Usage Rate: Office of Oil and Gas, derived from Pipeline Capacity and Average Flow.

constraints appear to be limited mainly to production areas, a fact that is reflected in the number of planned expansions through 2000 that address this problem.

- Larger natural gas share of energy market. On an annual percentage change basis, the increase in natural gas consumption is larger than the growth in total energy use in the United States. The increase has been especially noticeable in the Northeast market, where natural gas use grew at an annual rate of 4.9 percent while overall energy use increased at a rate of only 1.2 percent (Table 11). The difference is even more dramatic in the Western Region, 
Table 10. Regional Weather and Gas Storage Profile, 1996

\begin{tabular}{|c|c|c|c|c|c|c|c|c|c|c|c|c|}
\hline \multirow[b]{3}{*}{ Region } & \multirow[b]{3}{*}{$\begin{array}{c}\text { Number of } \\
\text { Interstate } \\
\text { Pipelines } \\
\text { Operating } \\
\text { in } \\
\text { Region }\end{array}$} & \multirow[b]{3}{*}{$\begin{array}{c}\text { Normal } \\
\text { Heating } \\
\text { Degree } \\
\text { Days } \\
(1960- \\
1990)\end{array}$} & \multirow[b]{3}{*}{$\begin{array}{l}\text { Weather } \\
\text { Ranking } \\
\text { Among } \\
\text { States } \\
(1= \\
\text { Coldest) }\end{array}$} & \multicolumn{7}{|c|}{ Natural Gas Underground Storage } & \multirow{2}{*}{\multicolumn{2}{|c|}{$\begin{array}{l}\text { LNG Peaking } \\
\text { Supplies }\end{array}$}} \\
\hline & & & & \multicolumn{7}{|c|}{ Peak-Day Withdrawal Capability (Deliverability) } & & \\
\hline & & & & \begin{tabular}{|} 
Working \\
Gas \\
Capaclty \\
(MMcf)
\end{tabular} & Total & $\begin{array}{c}\text { From } \\
\text { Convent- } \\
\text { Ional } \\
\text { Storage } \\
\text { (percent) }\end{array}$ & \begin{tabular}{|c|} 
From \\
High- \\
Deliverability \\
Storage \\
(percent)
\end{tabular} & $\begin{array}{c}\text { Percent } \\
\text { Operated } \\
\text { by } \\
\text { Interstate } \\
\text { Pipeline }\end{array}$ & \begin{tabular}{|} 
Percent \\
Operated \\
by \\
Independents
\end{tabular} & $\begin{array}{c}\text { Percent } \\
\text { LDC } \\
\text { Owned } \\
\text { and } \\
\text { Operated }\end{array}$ & $\begin{array}{c}\text { Capacity } \\
\text { (MMcf) }\end{array}$ & $\begin{array}{l}\text { Peak-Day } \\
\text { Support } \\
\text { (MMcf/d) }\end{array}$ \\
\hline Central & 21 & 7,061 & 1 & 565,894 & 6,037 & 97 & 3 & 81 & 3 & 16 & 4,921 & 416 \\
\hline Midwest & 17 & 6,867 & 2 & $1,130,475$ & 24,000 & 99 & 1 & 33 & 6 & 61 & 17,722 & 2,685 \\
\hline Northeast & 15 & 6,029 & 3 & 669,842 & 11,701 & 98 & 2 & 94 & 0 & 6 & 31,765 & 3,759 \\
\hline Southeast & 18 & 2,946 & 6 & 173,717 & 5,220 & 53 & 47 & 70 & 13 & 17 & 25,044 & 2,841 \\
\hline Southwest & 35 & 3,096 & 5 & 982,532 & 20,500 & 59 & 41 & 38 & 29 & 33 & 6,588 & 669 \\
\hline Western & 10 & 4,517 & 4 & 244,206 & 7,120 & 100 & 0 & 0 & 0 & 100 & 6,780 & 811 \\
\hline U.S. Total & - & - & - & $3,766,666$ & 74,578 & 85 & 15 & 70 & 13 & 17 & 92,820 & 11,181 \\
\hline
\end{tabular}

MMcf/d = Million cubic feet per day. LDC = Local distribution company. LNG = Liquefied natural gas. -- Not applicable.

Sources: Normal Heatlng Degree Days: U.S. Department of Commerce, National Oceanic and Atmospheric Administration, "State Regional, and National Monthly and Seasonal Heating Degree Days Weighted by Population." Natural Gas Underground Storage: Energy Information Administration (EIA), Form EIA-191, "Underground Gas Storage Report." Llquefled Natural Gas: EIAGIS-NG Geographic Information System, LNG Database, as of December 1997.

Table 11. Regional Energy Profile Comparison of Annual Average Change, 1990-1995 or 1990-1996

\begin{tabular}{|c|c|c|c|c|c|c|c|c|c|c|}
\hline \multirow[b]{2}{*}{ Reglon } & \multicolumn{2}{|c|}{ Population } & \multicolumn{3}{|c|}{ Overall Energy Consumption } & \multicolumn{4}{|c|}{ Natural Gas Consumption } & \multirow[b]{2}{*}{$\begin{array}{l}\text { Ratio of } \\
\text { Natural Gas } \\
\text { Production } \\
\text { (1996) to } \\
\text { Consumption }\end{array}$} \\
\hline & $\begin{array}{c}1996 \\
\text { Estimated } \\
\text { (millions) }\end{array}$ & $\begin{array}{l}1990-96 \\
\text { Percent } \\
\text { Annual } \\
\text { Change }\end{array}$ & $\begin{array}{c}\text { Quantity } \\
1995 \\
\text { (trillion Btu) }\end{array}$ & $\begin{array}{c}\text { U.S. } \\
\text { RankIng } \\
1995\end{array}$ & $\begin{array}{l}\text { 1990-95 } \\
\text { Percent } \\
\text { Annual } \\
\text { Change }\end{array}$ & $\begin{array}{l}\text { As Percent } \\
\text { of Total } \\
\text { Energy } \\
\text { Consumed }\end{array}$ & $\begin{array}{c}\text { Quantlty } \\
1995 \\
\text { (trillion Btu) }\end{array}$ & $\begin{array}{c}\text { U.S. } \\
\text { Ranking } \\
\text { (Natural Gas } \\
\text { Consumption) }\end{array}$ & $\begin{array}{l}1990-95 \\
\text { Percent } \\
\text { Annual } \\
\text { Change }\end{array}$ & \\
\hline Central & 20,995 & 2.1 & 7,435 & 6 & 2.1 & 24 & 1,749 & 6 & 3.8 & 1.39 \\
\hline Southeast & 48,967 & 2.7 & 16,497 & 4 & 2.2 & 15 & 2,415 & 5 & 2.9 & 0.28 \\
\hline Southwest & 31,003 & 2.9 & 17,258 & 2 & 1.3 & 39 & 6,797 & 1 & 0.2 & 2.25 \\
\hline Western & 47,835 & 2.9 & 12,836 & 5 & 0.3 & 21 & 2,642 & 4 & 4.0 & 0.11 \\
\hline U.S. Total & 263,493 & 1.9 & 89,422 & - & 1.3 & 24 & 21,753 & - & 3.0 & 0.88 \\
\hline
\end{tabular}

-- Not applicable.

Sources: Natural Gas Productlon and Consumption: Energy Information Administration (EIA), Form ElA-176, "Annual Report of Natural and Supplemental Gas Supply and Disposition." Energy Consumptlon: EIA, State Energy Data Report, Consumption Estimates 1980-1995 (December 1997). Population: U.S. Department of Commerce, Bureau of the Census.

where natural gas use increased annually by 4.0 percent while total energy grew by only 0.3 percent. California experienced a 0.4 percent drop per year in overall energy production during its economic slowdown of the early 1990 s, a drop that brought down the regional average (Appendix C, Table C2). But as a percentage of total energy consumption, natural gas still retained its 21percent share of the Western regional energy market, the same as in 1990.

- Decrease in natural gas use by electric utilities. The electric utility sector's share of the U.S. natural gas market fell 2 percentage points between 1990 and 1996, with the largest decreases occurring in the Western (6 points) and Northeast (5 points) marketplaces (Table 12), usually heavy markets for electric power generation. Actual natural gas consumption by electric utilities also decreased nationally but only slightly, at an annual average rate of 0.4 percent during the same period. The only markets to show a gain in electric utility consumption were the Southeast and Midwest regions, 8 and 10 percent per year, respectively. Only in the 
Table 12. Regional Natural Gas Customer Market Share Changes, 1990-1996 (1996 Volumes Consumed -- Billion Cubic Feet)

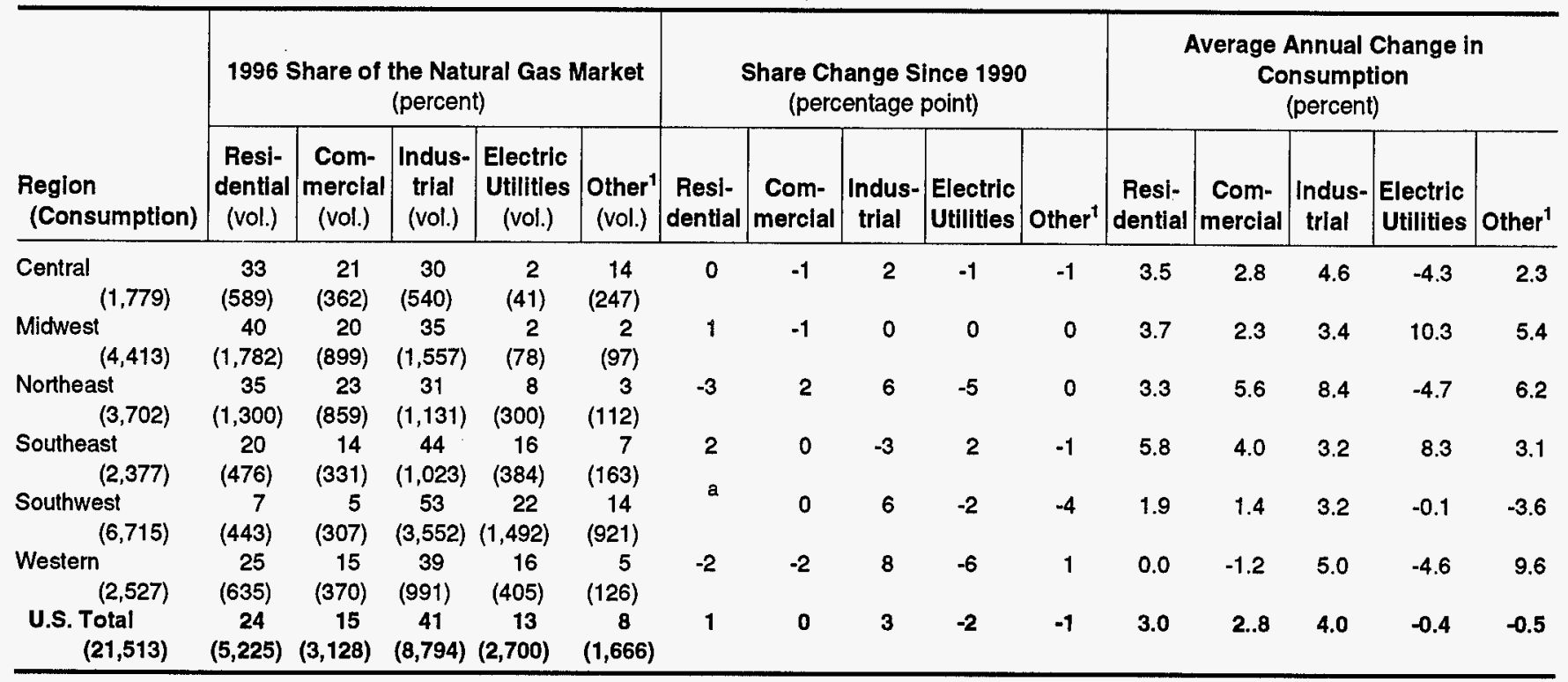

'Includes natural gas used as a vehicle fuel, in pipeline and natural gas plant operations, and in association with production and gathering facilities.

Between plus 0.5 percent and minus 0.5 percent.

Note: Totals may not equal sum of components because of independent rounding.

Source: Energy Information Administration, Form EIA-176, "Annual Report of Natural and Supplemental Gas Supply and Disposition."

Southeast Region did the electric utility sector increase its share of the natural gas market.

- Substantial growth in industrial gas consumption, especially for electricity cogeneration ${ }^{67}$ The industrial sector's use of natural gas increased substantially in several markets, ${ }^{68}$ principally because of significant growth in electricity cogeneration, which is primatily natural-gas based, and also because of the relatively low natural gas prices in comparison with other fuels. ${ }^{69}$ In the Northeastern States of New Jersey, New York, and Massachusetts, which have a large number of

\footnotetext{
${ }^{67}$ Natural gas used in cogeneration facilities is categorized and included in the industrial sector rather than the electric utility sector, because cogeneration represents electricity generated as a byproduct of industrial/commercial processes.

${ }^{68}$ While the number of natural gas industrial customers has declined since 1990 by about 1.0 percent per year, this sector's consumption of natural gas rose by more than 3 percent per year between 1990 and 1996 as average usage per customer rose 5.1 percent per year (Table 13).

${ }^{69}$ In 1995, nonutilities (cogenerators) accounted for 13 percent of all electric power generated in the United States, up from 7 percent in 1990. In 1996, 60 percent of cogenerated power was created by burning natural gas. Derived from Energy Information Administration, Form EIA-867, "Annual Nonutility Power Producer Report."
}

cogeneration facilities, ${ }^{70}$ the industrial sector's share of the natural gas market increased to 33,29 , and 28 percent, respectively (Appendix C, Table C3). The average use per industrial customer increased the most in the Southwest Region, at an average annual rate of 16.0 percent (Table 13). Average industrial consumption per customer in the Western and Northeast regions increased at an annual rate of 8.4 and 9.7 percent, respectively, yet the number of industrial customers in these markets actually fell. The number of industrial consumers increased in the other regions.

- Increased deliverability from storage. A major increase in deliverability from underground storage facilities since 1990 has complemented pipeline expansions in several markets. Since 1993 alone, daily deliverability from storage increased by 12 percent, with the largest increase occurring in the Southwest, most of it high-deliverability storage. $^{71}$ This type of storage is used extensively in the

\footnotetext{
${ }^{70}$ More than 600 nonutility generating facilities are currently operating in the Northeast Region, up about 12 percent since 1992-New York has 183; New Jersey, 61; and Massachusetts, 68.

${ }^{71}$ See, Energy Information Administration, "U.S. Underground Storage of Natural Gas in 1997: Existing and Proposed," Natural Gas Monthly, DOE/EIA-0130(97)/9) (Washington, DC, September 1997).
} 
Table 13. Regional Natural Gas Customers, Average Annual Change, 1990-1996

\begin{tabular}{|c|c|c|c|c|c|c|c|c|c|c|c|c|c|}
\hline \multirow[b]{3}{*}{ Reglon } & \multicolumn{3}{|c|}{ Residentlal Customers } & \multicolumn{3}{|c|}{ Commerclal Firms } & \multicolumn{3}{|c|}{ Industrial Firms } & \multirow{2}{*}{\multicolumn{4}{|c|}{$\begin{array}{c}\text { Electrlc Utilitles } \\
\begin{array}{c}\text { Annual Change } \\
\text { (percent) }\end{array}\end{array}$}} \\
\hline & \multirow[b]{2}{*}{$\begin{array}{c}\text { Number } \\
\text { In } \\
1996\end{array}$} & \multicolumn{2}{|c|}{$\begin{array}{l}\text { Annual Change } \\
\text { (percent) }\end{array}$} & \multirow[b]{2}{*}{$\begin{array}{c}\text { Number } \\
\text { In } \\
1996\end{array}$} & \multicolumn{2}{|c|}{$\begin{array}{c}\text { Annual Change } \\
\text { (percent) }\end{array}$} & \multirow[b]{2}{*}{$\begin{array}{c}\text { Number } \\
\text { In } \\
1996\end{array}$} & \multicolumn{2}{|c|}{$\begin{array}{c}\text { Annual Change } \\
\text { (percent) }\end{array}$} & & & & \\
\hline & & $\begin{array}{c}\text { In } \\
\text { Number } \\
\text { of Users }\end{array}$ & $\begin{array}{c}\text { In } \\
\text { Average } \\
\text { Use }\end{array}$ & & $\begin{array}{c}\text { In } \\
\text { Number } \\
\text { of Users }\end{array}$ & $\begin{array}{c}\text { In } \\
\text { Average } \\
\text { Use }\end{array}$ & & $\begin{array}{c}\text { In } \\
\text { Number } \\
\text { of Users }\end{array}$ & $\begin{array}{c}\text { In } \\
\text { Average } \\
\text { Use }\end{array}$ & $\begin{array}{c}\text { In } \\
\text { Number } \\
\text { of All } \\
\text { Type } \\
\text { Units }\end{array}$ & $\begin{array}{c}\text { In } \\
\text { Number } \\
\text { of Gas- } \\
\text { Fired } \\
\text { Unlts }\end{array}$ & $\begin{array}{l}\text { In Total } \\
\text { Summer } \\
\text { Capacity }\end{array}$ & $\begin{array}{l}\text { In Gas- } \\
\text { FIred } \\
\text { Capaclty }\end{array}$ \\
\hline Central & $5,562,943$ & 1.8 & 1.5 & 608,800 & 1.9 & 0.8 & 15,004 & 1.5 & 3.2 & -1.3 & -1.0 & -0.5 & 1.2 \\
\hline Midwest & $13,220,238$ & 1.6 & 2.0 & $1,113,287$ & 1.6 & 0.7 & 65,024 & 0.8 & 2.6 & -0.6 & 0.3 & 0.3 & 8.0 \\
\hline Northeast & $12,829,400$ & 1.1 & 2.1 & $1,154,093$ & 1.8 & 3.8 & 50,795 & -1.5 & 9.7 & -1.1 & 0.4 & 0.1 & 4.4 \\
\hline Southeast & $5,908,364$ & 2.9 & 2.7 & 600,971 & 2.6 & 1.3 & 17,251 & 1.9 & 1.4 & 0.1 & 3.2 & 1.2 & 4.2 \\
\hline Southwest & $6,282,924$ & 1.2 & 0.6 & 586,329 & 2.2 & -0.9 & 15,936 & -7.8 & 11.0 & 0.1 & -0.1 & 0.5 & 1.4 \\
\hline Western & $11,347,439$ & 1.7 & -1.7 & 641,192 & 0.9 & -2.1 & 41,837 & -3.4 & 8.4 & 0.3 & 0.9 & 0.1 & 0.3 \\
\hline U.S. Total & $55,151,308$ & 1.6 & 1.4 & $4,704,672$ & 1.8 & 1.0 & 205,845 & -1.0 & 5.1 & -0.5 & 0.3 & 0.3 & 2.5 \\
\hline
\end{tabular}

'Includes both primary and secondary generating units.

Source: Natural Gas Usage: Energy Information Administration (EIA), Form ElA-176, "Annual Report of Natural and Supplemental Gas Supply and Disposition." Electrlc Generatlon Capacity: EIA, Form EIA-860, "Annual Electric Generation Report" (1990-1996).

region not only to support the swing demands of local industrial and electric utility customers but also to support short-term transportation-balancing needs and provide incremental peaking supply for customers in distant markets, such as the Northeast and Midwest. In the Northeast market, where open-access interstate storage deliverability represents 94 percent of all available, several of the largest proposed pipeline expansion projects include improved access to existing storage sites and expansion of their deliverability (Table 10).

\section{Regional Overviews}

The natural gas pipeline capacity profile of each region in the country has evolved over time to meet its particular requirements. Each region differs in climate, underground storage capacity, number of pipeline companies, and availability of local production. Additionally, the varying demographics of each region dictate different patterns of gas use and potential for growth.

\section{Central Regional Market}

The Central Region produces more gas than it consumes and therefore is a net exporter of natural gas. ${ }^{72}$ Its 1996 natural gas

\footnotetext{
${ }^{72}$ Still, 4 of the 10 States in the region, Iowa, Missouri, Nebraska, and South Dakota, are almost totally dependent on the interstate pipeline network for their supplies of natural gas (Appendix C, Table C2).
}

production of about 2.3 trillion cubic feet accounted for approximately 11 percent of the total gas consumed in the Nation. ${ }^{73}$ Its exported production represented about 2 percent of the natural gas consumed elsewhere in the country. This region had the largest production increase in the Nation between 1990 and $1996-0.5$ trillion cubic feet, or 30 percent.

The region is the largest in area and the least populated. The total volume of gas consumed in the region in 1996, 1.8 billion cubic feet, was also the least consumed in the six regions. Much of this gas is consumed for space heating, as it has the second highest percentage of households using natural gas.

The region's cold winters, combined with the lowest residential prices for natural gas of any region, help make the residential sector a very large consumer of natural gas. The residential sector accounted for 33 percent of all natural gas consumed in the region in 1996 (Table 12). Plentiful supplies from production and storage sites within the region and adequate capacity on local transmission and distribution lines ensure that peak demands of residential customers are met during the winter.

The industrial sector is also a large consumer of natural gas (30 percent), while natural gas use for electric power generation in the region constitutes only 2 percent of natural gas usage, one of the lowest rates among the six regions. Because it is a major producer of natural gas, almost 14 percent of gas consumption in the region in 1996 was

\footnotetext{
${ }^{73}$ See, Energy Information Administration, Natural Gas Annual 1996, DOE/EIA-0131 (Washington, DC, September 1997) and previous editions.
} 
devoted to natural gas production and transportation-related activities (Table 12).

Although it is not as highly populated as the other regions, the Central Region has several large metropolitan markets, which are major customers of the interstate pipeline network. To name the largest: Denver, Colorado; Salt Lake City, Utah; Kansas City, Kansas and Missouri; and St. Louis, Missouri. Large underground natural gas storage facilities are located in proximity to these areas The local distribution companies (LDCs) serving these markets account for about 16 percent of the total storage deliverability in the region (Table 10). LNG peaking supplies are found only in Iowa and Nebraska, two States with limited underground storage capacity and no local production capabilities (Appendix C, Table C1).

\section{Entering/Exiting Capacity}

In 1996, approximately 12.8 billion cubic feet (Bcf) per day of pipeline capacity entered the Central Region (Figure 14), 8 percent above the 1990 level (Table 9). Only about 10 percent of that capacity was destined for markets within the region. Twelve pipeline systems enter the region from the south and east, while four enter from the north carrying Canadian supplies (Appendix A, Figure A1). The average utilization rates for pipelines transporting Canadian gas tend to be higher than those carrying domestic supply, 99 percent versus about 60 percent from the Southwest and 94 percent from the Midwest (Table 9). Nevertheless, because of an increase in regional production and in natural gas demand in both the Midwest and Central regions during the past 5 years, capacity usage on lines transporting domestic supply from the south and east also increased substantially, about 10 percentage points since 1990 . Another factor in the increased pipeline usage rates has been the more efficient use of capacity during off-peak periods via the capacity release market.

Most of the capacity exiting the region (52 percent) flows to Illinois in the Midwest Region, with the pipeline systems involved operating at average utilization rates of 83 percent in 1996 (Appendix A, Table A1). Since 1993, Central Region supplies have also flowed into the Western Region to serve markets in California and Nevada, with the pipelines serving these markets operating at average utilization rates of nearly 95 percent.

\section{Deliverability Within the Region}

Eight of the interstate pipeline companies traversing the Central Region also have major service commitments within the region (Figure 14), accounting for 80 percent of their peak-day deliveries. In 1996, these pipeline systems operated at an average utilization rate of about 80 percent, delivering
10.3 Bcf on their individual system peak days at 1,742 delivery and/or pipeline interconnect points. In addition, a number of intrastate pipeline companies provide deliveries and/or interconnections with the interstate system to support local markets. ${ }^{74}$ The largest service commitments of the interstate pipeline companies are for deliveries to other interstate pipelines within the region rather than to LDCs. For instance, Northern Border Pipeline Company delivers more than two-thirds of its shipped volumes to other interstate pipeline companies, while the rest is delivered to small customers in the region.

Of the regional interstate pipeline companies, the largest State-to-State capacity is 972 million cubic feet per day on Williams Natural Gas Company's line from Kansas to Missouri (Appendix A, Table A1). However, the average usage rate on this and similar service lines in the area is low, primarily because of the seasonal nature of the service; low summertime flows tend to offset the high winter flows. In 1996 , for instance, capacity utilization on Williams' line from Kansas to Missouri was only 27 percent. Of all the interstate pipeline companies serving the region, Northern Natural Gas Company has the largest State-to-State pipeline capacity, 2.1 Bcf per day from Kansas to Nebraska.

Kansas Power \& Light Company is the largest LDC in the region and the 13th largest $\mathrm{LDC}$, in terms of sales, in the United States. It serves primarily the Kansas City, Missouri, area and has demands on interstate pipeline capacity of up to 1.5 Bcf per day, mostly supplied by Williams Natural Gas Company. Kansas Power \& Light also accounts for two-thirds of the reserved capacity on the interstate system in Kansas and one-third of the total in Missouri.

A major LDC in the western part of this region is Mountain Fuel Supply Company, which serves the Salt Lake City area and accounts for 99 percent of the total shipments on interstate natural gas pipelines operating in Utah. Questar Pipeline Company, an affiliate, supplies the needs of this distribution company. The Public Service Company of Colorado is the major distributor of gas in Colorado, with more single-State end-use customers than any other company in the region. Colorado Interstate Gas Company provides nearly all of the gas to this LDC.

\section{Storage Deliverability}

Underground natural gas storage in the Central Region is notable for several reasons. First, most of the storage facilities are used to store excess production rather than to serve as a supply source for local markets. Second, the region has the

\footnotetext{
${ }^{74}$ Energy Information Administration, Form EIA-176, "Annual Report of Natural and Supplemental Gas Supply and Disposition."
} 
Figure 14. Interstate Natural Gas Capacity Summary for the Central Region, 1996 (Volumes in Million Cubic Feet per Day)

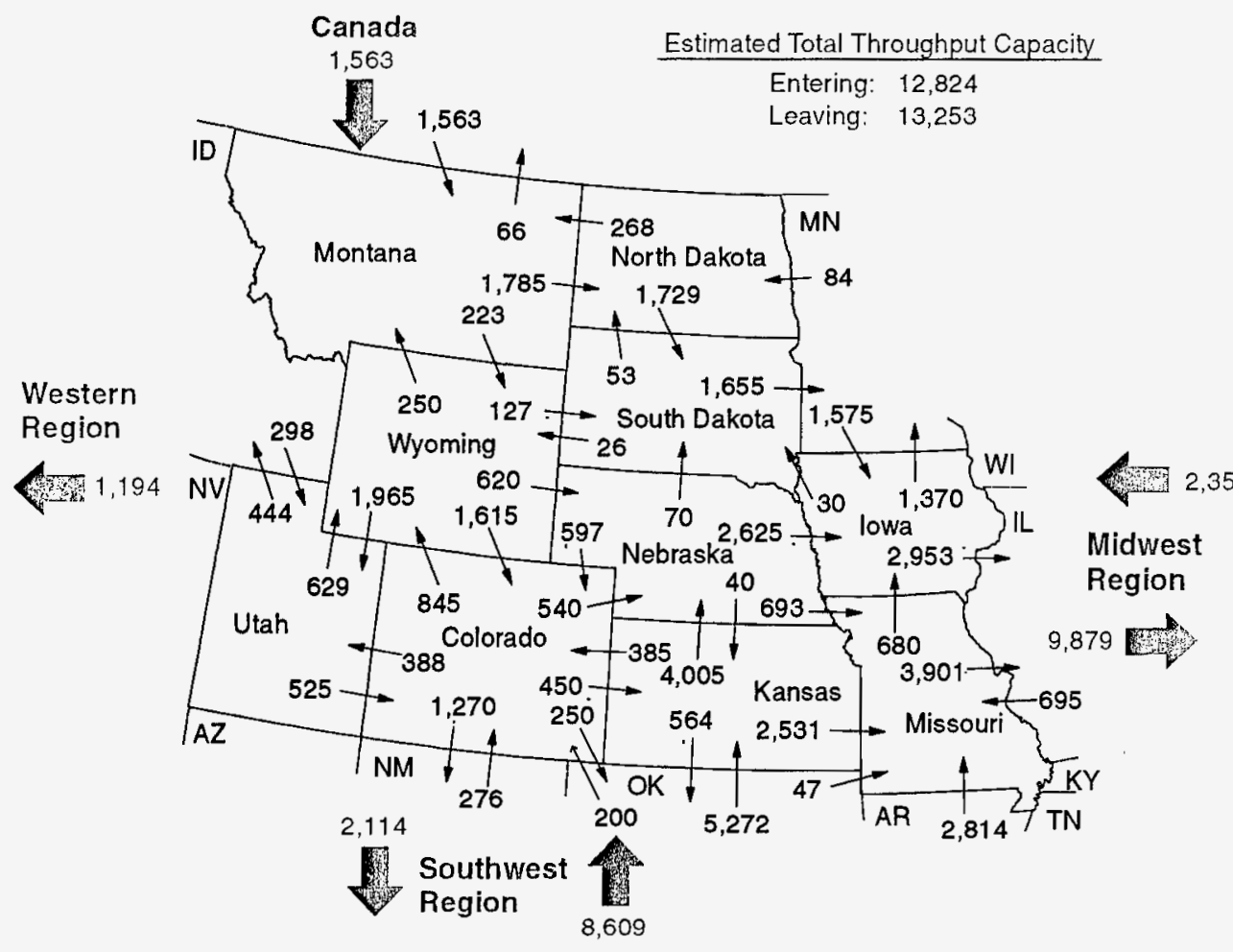

Principal Interstate Natural Gas Pipeline Companies Operating in the Central Region

\begin{tabular}{|c|c|c|c|c|c|c|c|c|}
\hline \multirow[b]{2}{*}{ Plpellne Name } & \multirow[b]{2}{*}{$\begin{array}{l}\text { Reglonal } \\
\text { Supply } \\
\text { Source(s) }\end{array}$} & \multirow[b]{2}{*}{$\begin{array}{c}\text { Primaryl } \\
\text { Secondary } \\
\text { System } \\
\text { Conflguration } 2\end{array}$} & \multicolumn{3}{|c|}{ Reglonal Service Level } & \multicolumn{3}{|c|}{ Systemwlde Utllization Rates ${ }^{1} \%$} \\
\hline & & & $\begin{array}{l}\text { Percent of } \\
\text { System } \\
\text { Peak-day } \\
\text { Dellverles }^{3}\end{array}$ & $\begin{array}{c}\text { Number } \\
\text { of } \\
\text { Dellvery } \\
\text { Polnts }\end{array}$ & $\begin{array}{l}\text { Number } \\
\text { of } \\
\text { Intercon- } \\
\text { nects }\end{array}$ & $\begin{array}{l}\text { 12-Month } \\
\text { Average }^{4}\end{array}$ & $\begin{array}{l}\text { Peak } \\
\text { Day }^{5}\end{array}$ & $\begin{array}{l}\text { Summer } \\
\text { Offpeak }^{6}\end{array}$ \\
\hline \multicolumn{9}{|l|}{ Reglonal PIpellnes } \\
\hline Colorado Interstate Gas Co & CE, SW & Trunk/Grid & 94 & 120 & 17 & 82 & 104 & 76 \\
\hline KN Interstate Gas Co & $C E, S W$ & Trunk/Grid & 80 & 381 & 13 & 79 & 91 & 69 \\
\hline Mississippi River Transmission Corp. & SW & Trunk/Grid & 16 & 21 & 0 & 85 & 92 & 59 \\
\hline Northern Border Pipeline Co & Canada & Trunk & 90 & 12 & 3 & 98 & 105 & 96 \\
\hline Northern Natural Gas Co & sw & Trunk/Grid & 41 & 219 & 3 & 92 & 107 & 80 \\
\hline Questar Pipeline Co & $\mathrm{CE}$ & Grid/Trunk & 100 & 29 & 13 & 79 & 81 & 62 \\
\hline Trailblazer Pipeline Co & CE & Trunk & 100 & 3 & 3 & 97 & 132 & 89 \\
\hline Williams Natural Gas Co & SW, CE & Grid & 96 & 811 & 16 & 75 & 82 & 42 \\
\hline Williston Basin Interstate PL Co & CE & Grid/Trunk & 100 & 271 & 4 & 83 & 98 & 40 \\
\hline Wyoming Interstate Gas Co & CE & Trunk & 100 & 0 & 3 & 93 & 107 & 86 \\
\hline \multicolumn{9}{|l|}{ Supplemental Plpeline Servlce } \\
\hline ANR Pipeline Co & sw & Trunk/Grid & 1 & 69 & 2 & 70 & 100 & 66 \\
\hline Kern River Gas Transmission Co & CE & Trunk & 1 & 9 & $\overline{0}$ & 98 & 109 & 96 \\
\hline Natural Gas Pipeline Co of America & CE, SW & Trunk/Grid & 7 & 74 & 13 & 84 & 96 & 80 \\
\hline Noram Gas Transmission Co & SW & Grid/Trunk & 1 & 3 & 1 & 56 & 86 & 61 \\
\hline Northwest Pipeline Co & Canada & Trunk/Grid & 34 & 46 & 9 & 90 & 94 & 54 \\
\hline Panhandle Eastern Pipeline Co & SW & Trunk & 11 & 41 & 4 & 78 & 98 & 58 \\
\hline Texas Eastern Transmission Co & SW & Trunk & 1 & 10 & 0 & 84 & 109 & 49 \\
\hline Viking Gas Transmission Co & Canada & Trunk & 3 & 3 & 0 & 85 & 105 & 82 \\
\hline
\end{tabular}

${ }^{1}$ Usage rates are based upon capacity and transportation volumes for the whole system and do not represent regional service only.

"Trunk" systems are long-distance trunklines that generally tie supply areas to market areas. "Grid" systems are usually a network of many interconnections and delivery points that operate in and serve major market areas. Some systems are a combination of the two.

${ }^{3}$ Represents the percent of total pipeline system volume delivered within the region on the system peak-day occurring in the $1996-97$ heating year.

${ }^{4}$ Represents total system capacity divided by the total annual volumes (divided by 366 days) delivered in 1996 as reported in FERC Form 2.

${ }^{5}$ Represents total system capacity divided by the single peak-day volumes delivered in the 1996-97 heating year as reported in FERC Form 2.

Represents a summer (nonheating season) usage level, using the sum of volumes delivered during the nonshoulder months of May through September (based on FERC Form 11 gas delivery data for 1995) divided by 153 days. April and October are considered to be months that "shoulder" the heating season of November-March.

Sources: Capaclty: Federal Energy Regulatory Commission, FERC 567 Capacity Report, "System Flow Diagram" and Annual Capacity Report (18 CFR \$284.12); Energy Information Administration, EIAGIS-NG Geographic Information System, Natural Gas Pipeline State Border Capacity, as of December 1997. Dellvery and Transport Volumes: Federal Energy Regulatory Commission, FERC Form 11, "Natural Gas Pipeline Company Monthly Statement" and FERC Form 2, "Annual Report of Major Natural Gas Companies." 
Nation's largest storage site, the Baker/Cedar Creek Field in Montana, with a working gas capacity of $164 \mathrm{Bcf}$. However, the total regional working gas storage capacity (approximately $566 \mathrm{Bcf}$ ) is only 15 percent of the U.S. total (Table 10), while daily deliverability from storage is only 6 Bcf per day, or 8 percent of the U.S. total.

Storage facilities in Kansas provide a major service to the interstate pipeline systems that move natural gas to the Midwest Region, but they are also integral to regional requirements. For example, about 35 percent of the State's working gas storage capacity of approximately $109 \mathrm{Bcf}$ is owned and operated by Williams Natural Gas Company, which is primarily a regional pipeline system. About 96 percent of the State's storage capacity is available to customers and shippers on other interstate trunklines, while the remaining 4 percent is devoted to local distribution and production field service (Appendix C, Table $\mathrm{C} 1$ ). About 41 percent of the daily peakday storage deliverability in the State, or 960 million cubic feet per day, is available to the two interstate pipeline companies traversing the region, Northern Natural Gas and Panhandle Eastern Pipe Line Company.

Storage facilities in the rest of the region serve primarily as seasonal supply sources for local markets. Storage fields in Utah provide service to shippers using the Questar Pipeline system as well as to the Salt Lake City area. The storage fields in Colorado and portions of Wyoming serve the Denver area through the Colorado Interstate Gas Company system.

\section{End-Use Consumption}

Within the region, natural gas has gained a slightly larger share of the energy marketplace since 1990, rising 1 percentage point to 24 percent (Table 11). Consumption increased at an annual rate of 3.8 percent from 1990 through 1996, while total energy production rose at a 2.1 percent rate. In every State in the region, natural gas experienced a growth in market share, with North and South Dakota and Utah having the largest increase. ${ }^{75}$ In each of these States, access to greater local production was a major contributing factor. Also, the ratio of State production to consumption at least doubled in each State compared with that in 1990 (Appendix C, Table C2). Greater consumption of local supplies was supported in part by low prices ${ }^{76}$ brought on by an inability by producers to ship their gas elsewhere because of capacity limitations on several of the longhaul trunklines exiting the region.

\footnotetext{
${ }^{75}$ Energy Information Administration, Capacity and Service on the Interstate Natural Gas Pipeline System, 1990: Profiles and Analyses, DOE/EIA-0556 (Washington, DC, June 1992), Table 16, p. 47.

${ }^{76}$ Energy Information Administration, Natural Gas 1996: Issues and Trends, DOE/EIA-0560(96) (Washington, DC, December 1996), Chapter 5.
}

In all States in the region, the number of residential and commercial customers increased, whereas in three States the number of industrial customers dropped by more than 6 percent per year (Appendix C, Table C4). Yet, the average use by industrial customers increased at an annual rate of 3.2 percent and total use increased at an annual rate of 4.6 percent (Table 12). Reflecting this, the industrial sector's share of the regional market increased from 28 percent in 1990 to 30 percent in 1996.

Natural gas use still remains only a very small percentage of the total energy used for electricity generation. While the installation of gas-fired generating capacity at utilities within the region increased at an annual rate of 1.2 percent during the first part of the decade, its share of the natural gas market fell 1 percentage point and actual consumption fell by 4.3 percent per year (Table 12). One reason is that utilities in this region depend primarily on coal, which is generally available at a relatively low cost. However, local environmental needs, linked with technological constraints, could have an impact on future development planning. Montana, North Dakota, and Utah have some of the major coal basins in the United States.

Although the industrial sector has gained a larger share of overall natural gas use in the region, the residential sector still represents the major share of gas use. The overall growth of natural gas consumption in the region, about 3.8 percent annually from 1990 through 1995, along with the growth in regional pipeline average utilization rates, from 57 percent in 1990 to 70 percent in 1996 (Table 9), would seem to indicate the need for some expansion in the near future. There are signs that some actions are already being taken in this regard.

\section{Recent and Proposed Expansions}

In 1997, eight pipeline expansion projects were completed in the Central Region, the largest of which was the new Pony Express line owned and operated by KN Interstate Pipeline Company (Appendix B, Table B1). The new line runs from southern Wyoming to the Kansas City, Missouri, area and helps alleviate some of the capacity restraint problems experienced by Rocky Mountain producers in recent years. Also completed were the Trailblazer system expansion and several area expansions by Colorado Interstate Pipeline Company that addressed the same constraint problems and expanded the flow of area gas toward the Midwest.

While completion of these projects helped resolve some production-side demands for capacity, consumer demands in the area have spurred several additional expansion proposals (Appendix B, Table B2). Growth in the Denver, Colorado, metropolitan area, for instance, has generated similar proposals from two of the area's largest systems: $\mathrm{KN}$ 
Interstate Pipeline Company and Public Service Company of Colorado. The proposals call for developing new lines and expanding old ones to bring expanding northern Wyoming gas production to the Denver area. The principal question is whether both projects, as currently designed, will be competitive and nonduplicative enough to be built.

\section{Midwestern Regional Market}

The Midwest Region is the Nation's second largest market for natural gas and is served by an extensive regional pipeline network (Table 11). The region is weather-sensitive, with cold winters and moderate summers. Minnesota and Wisconsin are among the coldest States in the Nation, while the other four States in the region are colder than the national average (Table 10). The region also has a number of major population centers and is the third largest of the six regions in population.

The large number of residential space-heating customers, combined with the cold winters, result in large residential requirements for natural gas. Yet, the region's geographic position between the Central and Northeast regions has resulted in a significant portion of the region's pipeline system capabilities being reserved for deliveries beyond its borders.

The region's two northernmost States, Wisconsin and Minnesota, as well as portions of Michigan, are served by pipelines importing Canadian supplies, while the southern portion of the region is served primarily by major trunklines coming from the Southwest. Regional production, principally from Ohio and Michigan, provides a little more than 8 percent of the gas consumed in the region (Table 11).

The Midwest Region also has the largest amount of underground storage capacity and daily deliverability from storage of any region, more than 30 percent each of the U.S. total. Regional LDCs control about 61 percent of daily deliverability, more than any region but the Western.

\section{Entering/Exiting Capacity}

Today 18 interstate pipeline companies have the capacity to move $24.8 \mathrm{Bcf}$ of gas into the Midwest per day (Appendix A, Table A2). The total capacity of the interstate pipeline companies entering the region is more than for any other region. Of that amount, 35 percent enters through Illinois, 26 percent through Ohio, 23 percent through Minnesota, and the remainder through Indiana (Figure 15).

Capacity additions into the Midwest Region from 1991 through 1996 totaled $2.0 \mathrm{Bcf}$ per day, an increase of 9 percent over 1990 levels (Table 9). Two new major interstate pipelines (Crossroads and Bluewater) were constructed in the region (Figure 10, Chapter 3 ), and a number of expansion projects were completed. The primary expansions included additions to the Great Lakes Transmission System (a 41percent increase in capacity), the Northern Border Pipeline (36 percent), and ANR Pipeline Company (18 percent in Michigan and Indiana).

Regional peak-day deliveries by the interstate pipelines on behalf of shippers approximated $19.8 \mathrm{Bcf}$ per day during the 1996-97 heating season, which is equivalent to about 80 percent of the capacity into the region (Figure 15). When deliveries to other interconnecting interstate pipelines are included, the peak-day total is equivalent to 99 percent of capacity. Although some demand is satisfied through intraregional production and deliveries, the vast majority of natural gas service in the region is dependent on the interstate system.

In 1996, utilization of total capacity entering the region was 78 percent (Table 9), the second highest of the gas-importing regions. This is a dramatic change from 1990, when the utilization rate was the second lowest. Natural Gas Pipeline Company of America has about 14 percent of the total throughput capacity into the Midwest, primarily with connections into Illinois (Appendix A, Table A2). Other major players are: Texas Eastern Transmission Corporation with 10 percent, and ANR Pipeline Company and Trunkline Pipeline Company with 8 percent each. Texas Eastern Transmission Corporation moves most of its gas through to markets in the Northeast. On the other hand, almost all of the contract commitments of the other companies represent commitments for deliveries within the Midwest market only.

On pipelines entering the region from Canada, the average daily utilization rate in 1996 was 85 percent (Table 9). Average utilization levels on lines entering from the Southeast Region (into Illinois, Indiana, and Ohio) and from the Central Region (into Minnesota and Illinois) were somewhat lower: 82 percent and 78 percent, respectively. Many of the pipelines with the highest utilization rates into the Midwest from the Southeast Region are heavily involved in transporting gas to the Northeast Region or to storage sites during the nonheating season and for meeting system-load balancing need.

\section{Deliverability Within the Region}

Nine of the interstate pipeline companies entering the Midwest terminate and deliver most of their gas for shippers within the region (Figure 15). For instance, ANR Pipeline Company operates in all States in the region except Minnesota and can import 2.0 Bcf per day into the region. In 1996, it had a systemwide average flow rate of about 70 percent. But the largest regional pipeline is Natural Gas 
Figure 15. Interstate Natural Gas Capacity Summary for the Midwest Region, 1996 (Volumes in Million Cubic Feet per Day)

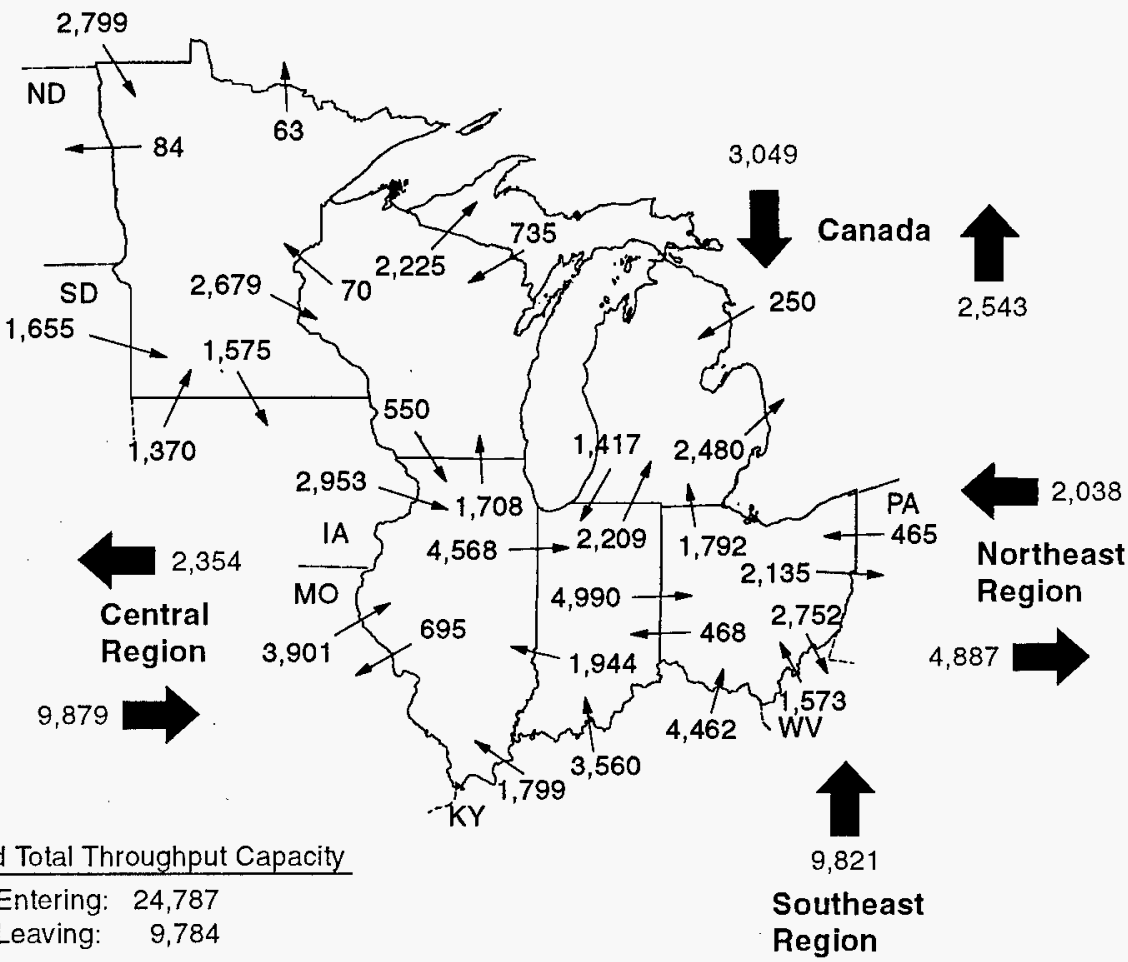

Principal Interstate Natural Gas Pipeline Companies Operating in the Midwest Region

\begin{tabular}{|c|c|c|c|c|c|c|c|c|}
\hline \multirow[b]{2}{*}{$\begin{array}{l}\text { Princlpal Market Region / } \\
\text { Pipellne Name }\end{array}$} & \multirow[b]{2}{*}{$\begin{array}{c}\text { Reglonal } \\
\text { Supply } \\
\text { Source(s) }\end{array}$} & \multirow[b]{2}{*}{$\begin{array}{c}\text { Primary/ } \\
\text { Secondary } \\
\text { System } \\
\text { Configuratlon } 2\end{array}$} & \multicolumn{3}{|c|}{ Reglonal Servlce Level } & \multicolumn{3}{|c|}{ Systemwlde Utillzation Rates ${ }^{1} \%$} \\
\hline & & & $\begin{array}{l}\text { Percent of } \\
\text { System } \\
\text { Peak-day } \\
\text { Dellverles }\end{array}$ & $\begin{array}{c}\text { Number } \\
\text { of } \\
\text { Dellvery } \\
\text { Polnts }\end{array}$ & $\begin{array}{l}\text { Number } \\
\text { of } \\
\text { Intercon- } \\
\text { nects }\end{array}$ & $\begin{array}{l}\text { 12-Month } \\
\text { Average }^{4}\end{array}$ & $\begin{array}{l}\text { Peak } \\
\text { Day }\end{array}$ & $\begin{array}{l}\text { Summer } \\
\text { Offpeak }^{6}\end{array}$ \\
\hline \multicolumn{9}{|l|}{ Reglonal Pipelines } \\
\hline $\begin{array}{l}\text { ANR Pipeline Co } \\
\text { Crossroads Pipeline Co }\end{array}$ & $\begin{array}{l}\text { SW } \\
\text { SW }\end{array}$ & $\begin{array}{l}\text { Trunk } \\
\text { Trunk }\end{array}$ & $\begin{array}{r}79 \\
100\end{array}$ & $\begin{array}{r}259 \\
\text { NA }\end{array}$ & $\begin{array}{r}10 \\
1\end{array}$ & $\begin{array}{r}70 \\
\mathrm{NA}\end{array}$ & $\begin{array}{l}100 \\
\text { NA }\end{array}$ & $\begin{array}{r}66 \\
\text { NA }\end{array}$ \\
\hline Greal Lakes Gas Transmission Co & Canada & Trunk & 100 & 206 & 14 & 94 & 132 & 59 \\
\hline Midwestern Gas Transmissions Co & SW & Trunk & 94 & 18 & 6 & 89 & 104 & 80 \\
\hline Natural Gas Pipeline Co of America & SW & Trunk & 75 & 165 & 4 & 84 & 96 & 80 \\
\hline Panhandle Eastern Pipeline Co & SW & Trunk & 88 & 67 & 3 & 78 & 98 & 58 \\
\hline Texas Gas Transmission Corp & SW & Trunk & 28 & 103 & 5 & 79 & 111 & 58 \\
\hline Trunkline Gas Co & SW & Trunk & 67 & 53 & 6 & 74 & 90 & 66 \\
\hline Viking Gas Transmission Co & Canada & Trunk & 97 & 39 & 4 & 94 & 105 & 82 \\
\hline \multicolumn{9}{|l|}{ Supplemental PIpellne Servlce } \\
\hline Columbia Gas Transmission Corp & SW, NE & Grid & 38 & 121 & 1 & 73 & 98 & 26 \\
\hline CNG Transmission Corp & SW, NE & Grid & 13 & 15 & 0 & 80 & 92 & 25 \\
\hline Mississippi River Transmission Co & sW & Trunk & 39 & 13 & 0 & 85 & 92 & 59 \\
\hline Northern Natural Gas Co & SW, Canada & Trunk/Grid & 56 & 129 & 2 & 92 & 107 & 80 \\
\hline Tennessee Gas Pipeline Co & SW & Trunk & 4 & 6 & 7 & 90 & 111 & 70 \\
\hline Texas Eastern Transmission Co & SW & Trunk & 1 & 50 & 12 & 84 & 109 & 49 \\
\hline
\end{tabular}

'Usage rates are based upon capacity and transportation volumes for the whole system and do not represent regional service only.

"'Trunk" systems are long-distance trunklines that generally tie supply areas to market areas. "Grid" systems are usually a network of many interconnections and delivery points that operate in and serve major market areas. Some systems are a combination of the two.

${ }^{3}$ Represents the percent of total pipeline system volume delivered within the region on the system peak-day occurring in the $1996-97$ heating year.

${ }^{4}$ Represents total system capacity divided by the total annual volumes (divided by 366 days) delivered in 1996 as reported in FERC Form 2.

${ }^{5}$ Represents total system capacity divided by the single peak-day volumes delivered in the 1996-97 heating year as reported in FERC Form 2.

"Represents a summer (nonheating season) usage level, using the sum of volumes delivered during the nonshoulder months of May through September (based on FERC Form 11 gas delivery data for 1995) divided by 153 days. April and October are considered to be months that "shoulder" the heating season of November-March. NA = Not available.

Sources: Capaclty: Federal Energy Regulatory Commission, FERC 567 Capacity Report, "System Flow Diagram" and Annual Capacity Report (18 CFR §284.12); Energy Information Administration, ElAGIS-NG Geographic Information System, Natural Gas Pipeline State Border Capacity, as of December 1997. Dellvery and Transport Volumes: Federal Energy Regulatory Commission, FERC Form 11, "Natural Gas Pipeline Company Monthly Statement" and FERC Form 2, "Annual Report of Major Naturat Gas Companies." 
Pipeline Company of America, with 3.3 Bcf per day. In 1996, its average daily usage rate within the region was 84 percent. However, Natural Gas Pipeline Company of America is second to ANR Pipeline in the amount of regional peak deliveries (almost all in Illinois).

Those pipeline systems involved in extensive trade with Canada had some of the highest systemwide average flow rates in the region (Appendix A, Table A2). In 1996, the average flow rates for both the Great Lakes Gas Transmission and the Viking Transmission pipelines were 94 percent.

In contrast to utilization rates on lines entering the region or moving gas to the Northeast, intraregional utilization rates averaged only 53 percent in 1996. This is the combined average utilization of all flows from one State within the region to another. This statistic, combined with the generally low systemwide flow rates for the pipelines serving the Midwest in 1990, seems to indicate that most pipeline companies have sufficient throughput capacity to accommodate any additional demand for natural gas in the near term.

A relatively few large shippers account for the bulk of the gas delivered by interstate pipeline companies within the region. In Illinois and Ohio, the demands of the two largest LDCs represent 47 and 55 percent, respectively, of the total interstate system volumes delivered in each State and the equivalent of 25 and 30 percent, respectively, of the total capacity entering those States. ${ }^{77}$

In Illinois and Indiana, the largest LDCs each interconnect with at least three major pipeline systems, providing flexibility in their purchase and transportation strategies. On the other hand, in Minnesota, the major LDCs acquire gas from only one interstate pipeline company, Northern Natural Gas.

\section{Storage Deliverability}

The Midwest has the highest level of working gas storage capacity of any region, 1.1 trillion cubic feet (Table 10). During the 1996-97 heating season, storage withdrawals in this region averaged $2.0 \mathrm{Bcf}$ per day, with much greater levels on peak days (approximately $3.8 \mathrm{Bcf}$ ). ${ }^{78}$

\footnotetext{
${ }^{n}$ Derived from data reported to the Energy Information Administration on Form EIA-176, "Annual Report of Natural and Supplemental Gas Supply and Disposition," and the EIAGIS-NG Geographic Information System, Natural Gas Pipeline State Border Capacity, as of December 1997.

${ }^{78}$ Energy Information Administration, Form EIA-191, "Monthly Underground Gas Storage Report."
}

Michigan and Illinois have the largest number of gas storage facilities in the region. Their combined working gas storage capacity in 1996 was approximately 0.9 trillion cubic feet, or 78 percent of the total regional storage capacity (Appendix $C$, Table C1). This represents a peak-day deliverability rate of $18 \mathrm{Bcf}$, or 77 percent of the area's capability. In Illinois, 71 percent of the daily deliverability from storage is held by three large LDCs: Northern Illinois Gas Company, Illinois Power Company, and Central Illinois Public Service Company. Northern Illinois Gas Company also uses part of its working gas storage (the excess) to support shippers using its Chicago market center.

Great Lakes Gas Transmission and ANR Pipeline companies use Michigan storage facilities extensively to support their shippers needs. In the first case, the Great Lakes system transports most of its volumes eventually to markets in Ontario, Canada, but uses Michigan storage sites to store supplies shipped for Canadian customers during the summer for redelivery during winter peak periods. ANR provides essentially the same service but for domestic shippers who need to supply customers throughout the Midwest during peak periods. These activities help maintain high load factors on these systems during the summer months.

Because of the region's relatively cold and volatile weather, LDCs in this market also have come to rely on LNG peaking facilities to supplement or substitute for unavailable local underground storage capacity. The Midwest is the third largest source of LNG storage, with about $18 \mathrm{Bcf}$ of storage capacity and 2.7 Bcf of peak-day deliverability.

\section{End-Use Consumption}

Natural gas usage accounts for about 25 percent of overall energy consumption in the Midwest, which is second only to the 39 percent level in the Southwest Region, the major U.S. production area (Table 11). Since 1990, the natural gas share in the region increased by 1 percent. The levels in the individual States of the region range from 21 percent to as high as 31 percent of overall consumption (Appendix C, Table C2).

Natural gas consumption in the region increased at an annual rate of 2.9 percent from 1990 through 1995. All customer sectors showed an increase, but a major contributor to this gain has been the growth in the use of natural gas by electric utilities within the region (Table 12). Although electric utilities account for only 2 percent of regional natural gas consumption, the amount of electric generating capacity fired by natural gas grew at an annual rate of 8 percent, while the number of gas-fired units increased at an annual rate of 0.3 percent during the period (Table 13). 
Although the region's population base grew by only 3 percent during the 1980s (the smallest increase of the six regions) and 1.2 percent annually in the early 1990s (Table 11), residential consumption of natural gas in the region increased at an annual rate of 3.7 percent between 1990 and 1996. This growth was second only to the increase in this sector in the Southeast Region (Table 12). The cold winters in the Midwest account for the residential sector using 40 percent of the natural gas delivered to the region each year (up 1 percentage point since 1990). The number of residential customers in the region increased during the period as did the average use per customer (Table 13).

Industrial sector consumption increased at a 3.4 percent annual rate as well, although its share of the regional natural gas market fell slightly (Table 12). There had been some speculation that industrial gas demand in the Midwest would decrease because of a trend toward greater service industry development, displacing heavy industries that tend to be greater users of natural gas, but the average use per industrial customer actually increased at an annual rate of 2.6 percent. The number of industrial customers grew slightly during the period.

Recent market patterns suggest that natural gas demand in the Midwest will continue to increase into the next century but probably at a slower rate than demand growth in some of the regions. Although major plans are underway to increase deliverability to the Chicago market area, it is likely that much of that capacity will be forwarded to the Northeast.

\section{Recent and Proposed Expansions}

Three pipeline expansion projects into the Midwest Region were completed during 1997, providing 441 million cubic feet per day of additional interstate service (Appendix B). Only one of these projects, the ANR Michigan Leg expansion, affected the major Chicago market. The other two provide additional service to growing markets in Wisconsin and Minnesota.

Several large new pipelines and major expansion projects into the region have been proposed, primarily to transport Canadian natural gas from expanding production fields in Alberta and British Columbia to the Chicago area. What is noteworthy about this effort is that the ultimate market for much of this new capacity will be beyond the region, in eastern Canada and the U.S. Northeast. Indeed, if these projects were targeted only toward gaining market share within the Midwest Region, an excess of capacity would develop over the next several years. Planned capacity expansion from the Southwest, which remains the largest source of Midwest market gas supply, is minimal.

\section{Northeast Regional Market}

The Northeast consumes more energy than any other region, although only 21 percent (up 3 percent since 1990) is in the form of natural gas (Table 11). It is the most heavily and densely populated of the six regions. At one time, the Northeast was a major source of natural gas and, as a result, a large distribution network of pipelines has been in place for many years. Similarly, the region has considerable access to underground storage since gas storage fields were first developed and used commercially in the area. Still, the New England States have only truly had access to natural gas supplies since the 1950 s.

The region has large swings in gas demand because of weather. Overall, it is the third coldest of the regions (Table 10), with some of the coldest States in the Nation at its northern limits. Withdrawals from storage are necessary to meet peak demand, as total capacity entering the region plus regional gas production are only about two-thirds of the region's peak demand.

Residential and commercial natural gas consumption (mostly space-heating demand) accounts for the largest share of the regional natural gas market although the industrial and electric utility sectors also represent large users of natural gas, with 31 and 8 percent, respectively (Table 12). The major markets in the region are the metropolitan areas of Boston, Massachusetts; New York City; Philadelphia/Trenton; Baltimore/Washington; Richmond, Virginia; and the corridor from Erie, Pennsylvania, to Buffalo, New York.

\section{Entering/Exiting Capacity}

Today the interstate pipeline companies serving the Northeast have access to supplies from all major domestic gas-producing areas and from Canada. The two main flows of gas into the region are from the Southeast into Virginia and West Virginia, and from the Midwest into West Virginia and Pennsylvania (Figure 16). Much of this capacity moves within the region toward New York City and Boston. In 1996, the interstate pipeline system had the capacity to move approximately $5 \mathrm{Bcf}$ per day along routes coming out of both the Southeast and Midwest regions. In addition, limited amounts of liquefied natural gas (LNG) is imported into Massachusetts from the Middle East.

Transportation capacity into the Northeast increased by more than 2.4 Bcf per day (24 percent) between 1990 and 1996 (Table 9), second only to the increase in the Western Region. Most of this new capacity provided greater access to Canadian supplies. Some of the larger projects included completion of the Empire Pipeline (0.5 Bcf per day), which 
Figure 16. Interstate Natural Gas Capacity Summary for the Northeast Region, 1996 (Volumes in Million Cubic Feet per Day)

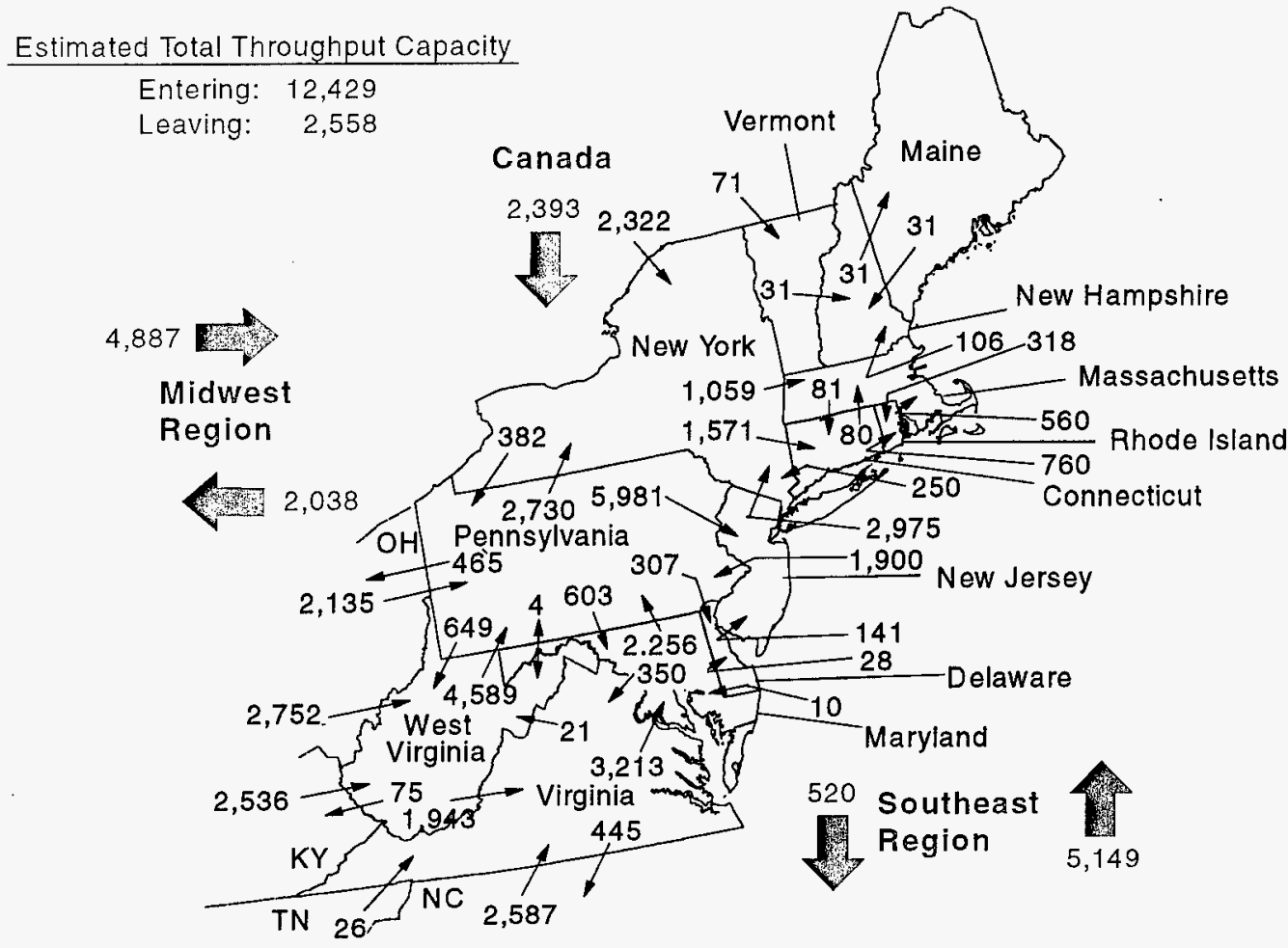

Principal Interstate Natural Gas Pipeline Companies Operating in the Northeast Region

\begin{tabular}{|c|c|c|c|c|c|c|c|c|}
\hline \multirow[b]{2}{*}{$\begin{array}{l}\text { PrInclpal Market Reglon / } \\
\text { PIpellne Name }\end{array}$} & \multirow[b]{2}{*}{$\begin{array}{c}\text { Reglonal } \\
\text { Supply } \\
\text { Source(s) }\end{array}$} & \multirow[b]{2}{*}{$\begin{array}{c}\text { Primaryl } \\
\text { Secondary } \\
\text { System } \\
\text { Conflguration }\end{array}$} & \multicolumn{3}{|c|}{ Regional Servlce Level } & \multicolumn{3}{|c|}{ Systemwide Utillzation Rates ${ }^{\top} \%$} \\
\hline & & & $\begin{array}{l}\text { Percent of } \\
\text { System } \\
\text { Peak-day } \\
\text { Dellverles }^{3}\end{array}$ & $\begin{array}{c}\text { Number } \\
\text { of } \\
\text { Dellvery } \\
\text { Polnts }\end{array}$ & $\begin{array}{l}\text { Number } \\
\text { of } \\
\text { Intercon- } \\
\text { nects }\end{array}$ & $\begin{array}{l}\text { 12-Month } \\
\text { Average }^{4}\end{array}$ & $\begin{array}{l}\text { Peak } \\
\text { Day }^{5}\end{array}$ & $\begin{array}{l}\text { Summer } \\
\text { Offpeak }\end{array}$ \\
\hline \multicolumn{9}{|l|}{ Regional Pipelines } \\
\hline Algonquin Gas Transmission Co & SW & Trunk/Grid & 100 & 97 & 5 & 72 & 89 & 45 \\
\hline CNG Transmission Corp & SW, NE & Grid & 87 & 110 & 25 & 80 & 92 & 25 \\
\hline Columbia Gas Transmission Co & SW, NE & Grid & 51 & 293 & 16 & 73 & 98 & 26 \\
\hline Eastern Shore Natural Gas Co & SW & Grid/Trunk & 100 & NA & NA & NA & NA & NA \\
\hline Equitrans Inc & SW, NE & Grid & 100 & 132 & 10 & 70 & 78 & 23 \\
\hline Granite State Gas Transmission Co & Canada & Grid/Trunk & 100 & NA & NA & NA & NA & NA \\
\hline Iroquois Gas Transmission Co & Canada & Trunk & 100 & 10 & 4 & 102 & 122 & 99 \\
\hline National Fuel Gas Supply Corp & SW, Canada & Grid/Trunk & 100 & 98 & 3 & 75 & 92 & 29 \\
\hline Tennessee Gas Pipeline Co & SW, Canada & Trunk & 55 & 116 & 51 & 90 & 111 & 70 \\
\hline Texas Eastern Transmission Corp & SW & Trunk & 88 & 69 & 18 & 84 & 109 & 49 \\
\hline Transcontinental Gas Pipeline Co & SW & Trunk & 69 & 124 & 10 & 83 & 99 & 81 \\
\hline Vermont Gas Systems Inc & Canada & Trunk & 100 & NA & NA & NA & NA & NA \\
\hline \multicolumn{9}{|l|}{ Supplemental Pipeline Service } \\
\hline East Tennessee Natural Gas Co & SW & Trunk/Grid & 8 & 25 & 0 & 84 & 88 & 37 \\
\hline
\end{tabular}

${ }^{1}$ Usage rates are based upon capacity and transportation volumes for the whole system and do not represent regional service only.

"Trunk" systems are long-distance trunklines that generally tie supply areas to market areas. "Grid" systems are usually a network of many interconnections and delivery points that operate in and serve major market areas. Some systems are a combination of the two.

${ }^{3}$ Represents the percent of total pipeline system volume delivered within the region on the system peak-day occurring in the $1996-97$ heating year.

${ }^{4}$ Represents total system capacity divided by the total annual volumes (divided by 366 days) delivered in 1996 as reported in FERC Form 2.

${ }^{5}$ Represents total system capacity divided by the single peak-day volumes delivered in the 1996-97 heating year as reported in FERC Form 2

Represents a summer (nonheating season) usage level, using the sum of volumes delivered during the nonshoulder months of May through September (based on FERC Form 11 gas delivery data for 1995) divided by 153 days. April and October are considered to be months that "shoulder" the heating season of November-March.

NA = Not available.

Sources: Capaclty: Federal Energy Regulatory Commission, FERC 567 Capacity Report, "System Flow Diagram" and Annual Capacity Report (18 CFR §284.12); Energy Information Administration, EIAGIS-NG Geographic Information System, Natural Gas Pipeline State Border Capacity, as of December 1997. Dellvery and Transport Volumes: Federal Energy Regulatory Commission, FERC Form 11, "Natural Gas Pipeline Company Monthly Statement" and FERC Form 2, "Annual Report of Major Natural Gas Companies." 
is an intrastate affiliated with ANR Pipeline Company, the Iroquois Pipeline (0.9 Bcf per day), and Tennessee Gas Pipeline Company's expansion of its Niagara import facilities (by 0.5 Bcf per day).

In addition, several interstate pipelines serving the region were significantly expanded. The largest expansion was on the Texas Eastern Pipeline system (0.5 Bcf per day) serving Pennsylvania, New York, and New Jersey, as well as southern New England through service to its affiliate, Algonquin Gas Transmission Company (which itself added about 122 million cubic feet (MMcf) per day of capacity). Transcontinental Gas Pipeline Company, a major supplier to the region, added approximately $165 \mathrm{MMcf}$ per day in the Pennsylvania/New York area to improve its local capabilities. Its larger contribution to regional service, however, was a major expansion in the Virginia/North Carolina area where more than $420 \mathrm{MMcf}$ per day was added (1993). The latter project coincided with improvements along much of the Transco system extending from Louisiana to Virginia.

About three-quarters of the capacity into the region is supplied somewhat equally by three trunkline systems: Transcontinental Gas Pipe Line Corporation, Texas Eastern Transmission Corporation, and Tennessee Gas Pipeline Company. In 1996, the utilization rates on these pipeline systems as they entered the region averaged 80 percent. Tennessee Gas Pipeline had the highest utilization (90 percent) and the highest actual volume (2.8 Bcf per day) into the region (Appendix A, Table A3).

\section{Deliverability Within the Region}

Almost all of the interstate pipelines entering or operating within the Northeast Region terminate there; all have major delivery commitments in the region (Figure 16). The largest systems target the New York City area as their primary market. The States of Pennsylvania and New York are the key transit points for gas deliveries within the region. These States, along with West Virginia, have the largest underground storage capacity in the region (Appendix C, Table C1), as well as some of the largest entering and exiting capacities and annual flow rates (Appendix A, Table A3). More pipeline capacity exits these States than enters, reflecting their major storage capability as a seasonal supply source for the States north and east.

The largest major regional pipeline companies, CNG Transmission and Columbia Gas Transmission, have an extensive infrastructure and network of local delivery points and pipeline interconnections. They also have a number of receipt points, where they bring in local production sources to augment supplies from the Southwest and Canada. In addition, each company has access to numerous underground storage facilities, allowing their shipper/customers to develop inventories of seasonal gas supplies for winter use.

Both companies are also the major suppliers of some of the largest LDCs in the region, many of which are affiliates. From 1990 through 1996, Columbia added between 150 to 200 MMcf per day of capacity and CNG added about $100 \mathrm{MMcf}$ to their systems. The primary expansion motivation in these two cases was to attract additional customers and improve overall service in the region.

Utilization rates tend to be much lower on the more disperse, grid-type pipeline systems, such as CNG and Columbia Gas Transmission. Grid systems function as distribution companies to the LDCs as well as transmission companies. The capacity to supply gas in one portion of the grid depends upon how much is being supplied out of the system by other portions of the grid. Both CNG and Columbia Gas Transmission have multiple lines crossing the State borders within the region, allowing gas to flow in both directions at the same time. The only high average-day utilization rate on Columbia Gas Transmission's system is at the Kentucky border, where it receives Gulf-of-Mexico gas from its major trunkline transporter, Columbia Gulf Transmission Company. CNG Transmission's lines serving the region, however, are part of the grid and operated at an average utilization rate of about 31 percent in 1996.

The flow of gas out of the region is almost exclusively to the Midwest (although some lines have bidirectional service) over the many lines that were built around the turn of the century to move local production. West Virginia, western Pennsylvania, and southwestern New York were once the region's and the Nation's largest producing areas and, consequently, have many local gathering, distribution, and storage interconnections. These areas also have many interconnections with operations in Ohio, which is the reason for the $2.0 \mathrm{Bcf}$ per day of capacity exiting the region to the Midwest.

In addition to the interstate pipeline companies that bring gas into the region from the Midwest and Southeast, several smaller interstate pipeline companies operate totally within the region (Figure 16). Foremost among these is Algonquin Gas Transmission Company, which has the capacity to move 1.2 Bcf per day from New Jersey into New York (Appendix A, Table A3). During the 1996-97 heating season, peak-day deliveries for its entire system totaled about 1.5 million cubic feet. Algonquin, with 1,056 miles of trunk transmission lines, distributes the gas received in New Jersey to New York, Connecticut, Rhode Island, and Massachusetts. 
The remaining small interstate pipeline companies averaged only $32 \mathrm{MMcf}$ per day of interstate transmission in $1996 .{ }^{79}$

\section{Storage Deliverability}

Many of the depleted gas fields in New York, Pennsylvania, and West Virginia are now used for storage, which is essential for balancing gas supplies for the region (Table 10). Interstate capacity into the region, $12.4 \mathrm{Bcf}$ per day, combined with local production (approximately $1 \mathrm{Bcf}$ per day on average in 1996) is the equivalent of only about two-thirds of the peakday requirements within the region. The difference between this available system capacity and shipper and consumer demand is designed to be met by withdrawals from storage. During the 1996-97 heating season, average daily withdrawals in the region were about $4.9 \mathrm{Bcf}$; during January 1997, the month with the highest average, storage deliverability averaged $7.7 \mathrm{Bcf}$ per day. ${ }^{80}$

The growth in the Northeast market has also spurred numerous storage projects. Plans are underway to increase storage deliverability in the region 17 percent by 2000 ; this would include new installations or expansions at 37 or more of the 121 storage sites in the region. ${ }^{81}$ Almost all of the expansions would be at 35 sites owned and operated by Columbia Gas Transmission Company. LNG storage is also being increased in the New England market to provide peaking support to those LDCs that will be receiving supplies along new pipeline routes which are not convenient to underground storage facilities.

Compared with other market areas, the Northeast makes the most extensive use of LNG (Table 10). The peak-day deliverability from LNG in the region, 3.8 Bcf per day, is 32 percent as large as the total daily deliverability from underground storage facilities. This backup capability has been included in the overall design of the regional network and is necessary to meet the rapid increases in demand that can occur because of sudden temperature changes.

\section{End-Use Consumption}

Although the Northeast has the highest energy consumption of the regions, natural gas is a relatively low proportion of total energy consumed: 21 percent versus a national average of about 24 percent (Table 11). Yet, since 1990, the average

\footnotetext{
${ }^{75}$ Federal Energy Regulatory Commission, FERC Form 2 and 2A, "Annual Report of Natural Gas Companies," 1996.

${ }^{80}$ Energy Information Administration, Form EIA-191, "Underground Gas Storage Report."

${ }^{81}$ Energy Information Administration, "U.S. Underground Storage of Natural Gas in 1997: Existing and Proposed," Natural Gas Monthly, DOE/EIA-0130(97)/9) (Washington, DC, September 1997)
}

annual growth in natural gas demand in the region grew at a faster rate than the growth in overall energy use, 4.9 percent versus 1.2 percent (Table 11). This average annual growth in natural gas demand, as well as the spread between natural gas and overall energy use, was among the highest of the six regions examined.

Most of this growth can be attributed to the industrial sector, where natural gas consumption grew at an annual rate of 8.3 percent (Table 12) while per-customer usage grew at a 9.7 percent rate (Table 13). Reflected in these rates were large increases in industrial use in New York and New Jersey (Appendix C, Table C3). The increase in industrial gas use came despite a 1.5 percent per annum drop in the industrial customer base during the period.

Electric utilities in the region had a decrease in natural gas use, which declined at an average annual rate of 4.7 percent during the period. This occurred in spite of a growth in gaspowered generating capacity in the region. While the number of gas-fired electric generating units in the Northeast (excluding industrial cogeneration capacity) increased by only 0.4 percent per annum, generating capacity grew at a 4.4 percent annual rate (Table 13). Currently, about 14 percent of the generating capacity in the region is gas-fired and, coincidently, gas-fired generating capacity in the region also represents 14 percent of total U.S. gas-fired generating capacity. ${ }^{82}$

Although industrial use of natural gas continues to grow, residential customers in the region still remain the primary users of natural gas. They accounted for 35 percent of the gas consumed in the region in 1996, in contrast to the national average of 24 percent. Although the population of the region is estimated to have increased by only 0.7 percent per annum (Table 11) between 1990 and 1996, total gas consumption in the region increased at a 4.9 percent rate. Space-heating gas demand in the region is driven by the growing, highly populated urban corridor that stretches from Boston, Massachusetts, to Richmond, Virginia.

\section{Recent and Proposed Expansions}

In 1997, 12 expansion projects were completed in the Northeast, increasing overall deliverability within the region by more than 772 million cubic feet per day (Appendix B, Table B1). Only one project brought additional gas into the region; the rest were implemented to improve local deliverability to expanding markets within the region. Numerous other projects have been proposed for the Northeast market that could increase capacity by more than

\footnotetext{
${ }^{82}$ Derived from: Energy Information Administration, Form EIA-860, "Annual Electric Generator Report" (1990-1996).
} 
7 Bcf per day. Planned expansions into the region would total 4.0 Bcf per day, or 32 percent above the 1996 level. Increasing demand for natural gas service in the region and the readiness of Canadian producers to meet the need underlie the bulk of the expansions. Long dependent on fuel oil, the Northeast has seen a steady increase in the availability of natural gas in recent years.

While a large portion of the anticipated growth in natural gas demand is expected to come from increased usage by the industrial sector, the major growth market is expected to be the electric utility sector. Several nuclear generating stations in the region are slated for retirement during the next several years and will be replaced by nonnuclear plants. The natural gas pipeline industry believes that many of these replacement facilities, as well as a number of new conventional power plants, will be built during the next decade and will use high-efficiency natural-gas-turbine technology more widely. At the same time electricity demand in the region is expected to grow as the effects of electric industry deregulation widen competition in the market.

\section{Southeast Regional Market}

The Southeast Region is the least developed market for natural gas in terms of per-capita consumption. In fact, natural gas accounts for only a small percentage of the total energy consumed in the region (Table 11). However, because of its proximity to major producing areas in the Southwest, numerous interstate natural gas pipeline companies operate throughout the region (Appendix A, Figure A4), transporting significant volumes via the region to the Northeast and Midwest markets.

Although the region has only limited storage capacity, numerous high-deliverability storage sites exist in the southern part of the region, many of which have been developed since 1990. Four such sites were added in Mississippi, which has several major interstate pipelines traversing the State en route to Northeast markets. The availability of these sites has made the State a prime market for the type of storage services needed by shippers with high upstream demand swings and load balancing requirements.

\section{Entering/Exiting Capacity}

During peak periods, the interstate pipeline system has the capacity to move up to $21.4 \mathrm{Bcf}$ into the Southeast Region, principally from the Southwest (Figure 17). This is the second-largest capacity level into any region. More than 70 percent of this capacity is redirected out of the region, with 9.8 Bcf per day into the Midwest and 5.1 Bcf per day into the Northeast Region.
Capacity into the Southeast Region grew by slightly more than 7 percent between 1990 and 1996 (Table 9). Most capacity additions occurred within the region. The major projects completed were the Florida Gas Transmission expansion, the Mobile Bay Pipeline, and the Transcontinental Gas Pipeline southern expansion. Noteworthy were the additional pipeline expansions serving the northern North Carolina market. Several pipelines from the Northeast Region (Columbia Gas Transmission and Transcontinental Gas Pipeline Company) extended their systems into the Southeast market in 1993.

More natural gas pipeline capacity (excluding offshore-toonshore) enters and exits Mississippi than any other State in the Nation (Appendix A, Table A4). It is the hub State for capacity into the region, with $21.3 \mathrm{Bcf}$ per day coming into the State and $20.5 \mathrm{Bcf}$ per day leaving the State. While several routes flow southward toward Florida, most are directed to the Northeast and Midwest regions (Appendix A, Figure A4).

Fifteen interstate pipeline companies operate within the region, with all but four transporting gas from the Southwest. By capacity level, the largest transporters are Tennessee Gas Pipeline Company, Transcontinental Gas Pipe Line Corporation, Texas Eastern Transmission Corporation, and Texas Gas Transmission Corporation. These same four are also the largest exporters.

On its system peak day in 1995, Tennessee Gas Pipeline transported only about 30 percent of its volumes to delivery and interconnection points in the Southeast Region. ${ }^{83}$ Likewise, Transcontinental Gas Pipe Line, which traverses the region via the Carolinas, delivered only 33 percent of its peak-day volumes in the Southeast. In 1996, average utilization rates on Transcontinental's lines en route to the weather-sensitive Northeast were 83 percent in Mississippi and 79 percent out of Virginia (Appendix A, Table A4). The average daily flow of natural gas into Mississippi in 1996 averaged 16.1 Bcf: 10.9 Bcf from Louisiana, at 79 percent of capacity, and 5.1 Bcf from Arkansas at 73 percent of capacity. The combined utilization on lines entering Mississippi in 1996 was 77 percent.

Major shippers on the major interstate pipeline systems serving the region have peak-day demands of approximately $9.4 \mathrm{Bcf}$ per day. Within the region, demand requirements are the largest in Tennessee, primarily because of the interconnections and service provided among several interstate pipeline companies rather than service to LDCs.

\footnotetext{
${ }^{83}$ Based on coincidental peak-day deliveries reported on the annual FERC System Flow Format 567 report.
} 
Figure 17. Interstate Natural Gas Capacity Summary for the Southeast Region, 1996 (Volumes in Million Cubic Feet per Day)

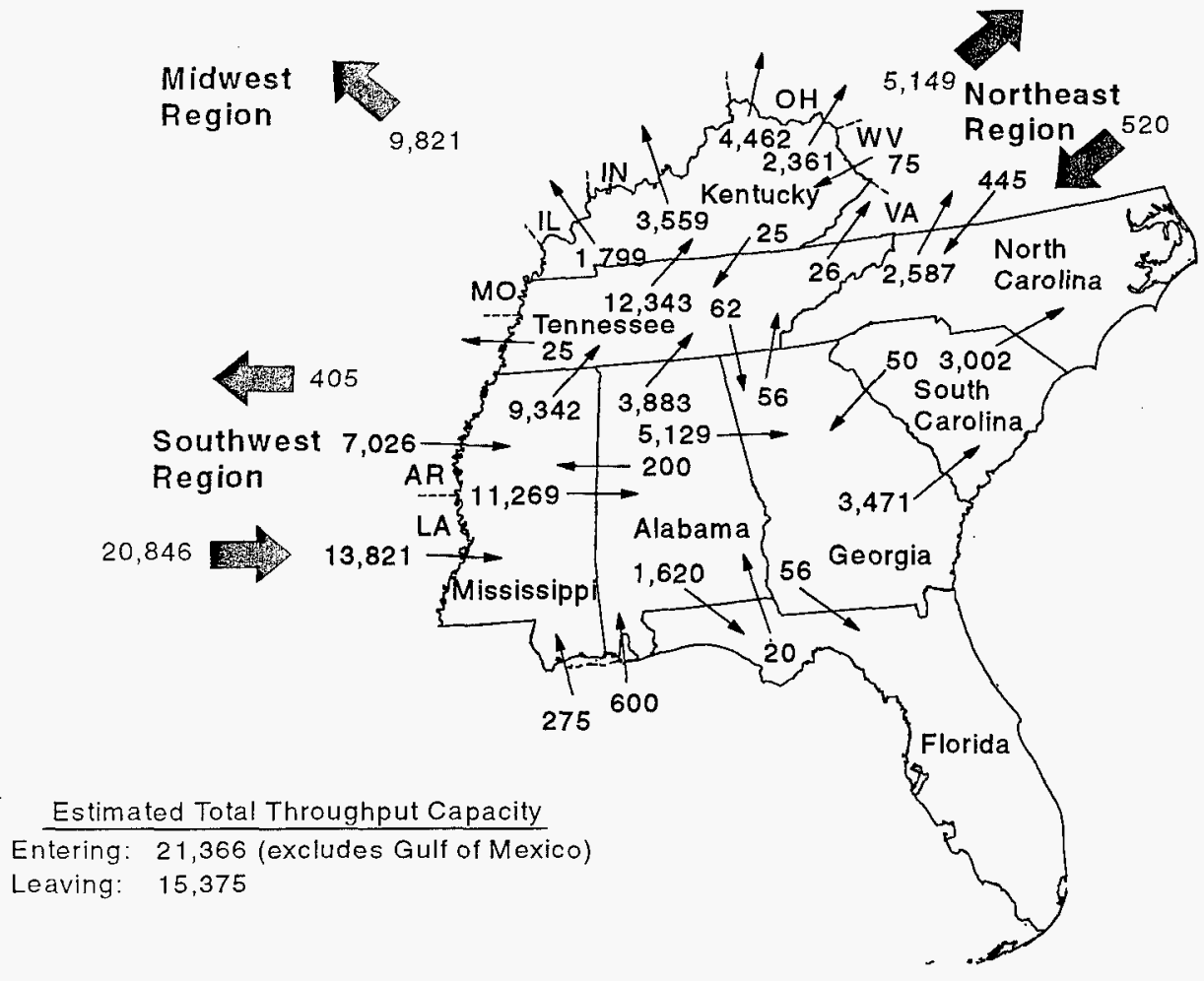

Princlpal Interstate Natural Gas Pipeline Companies Operating in the Southeast Region

\begin{tabular}{|c|c|c|c|c|c|c|c|c|}
\hline \multirow[b]{2}{*}{$\begin{array}{l}\text { Princlpal Market Reglon I } \\
\text { Plpeline Name }\end{array}$} & \multirow[b]{2}{*}{$\begin{array}{l}\text { Reglonal } \\
\text { Supply } \\
\text { Source(s) }\end{array}$} & \multirow[b]{2}{*}{$\begin{array}{l}\text { Prlmaryl } \\
\text { Secondary } \\
\text { System } \\
\text { Configuration }{ }^{2}\end{array}$} & \multicolumn{3}{|c|}{ Reglonal Servlce Level } & \multicolumn{3}{|c|}{ Systemwlde Utilizatlon Rates ${ }^{7} \%$} \\
\hline & & & $\begin{array}{l}\text { Percent of } \\
\text { System } \\
\text { Peak-day } \\
\text { Dellverles }\end{array}$ & $\begin{array}{c}\text { Number } \\
\text { of } \\
\text { Dellvery } \\
\text { Points } \\
\end{array}$ & $\begin{array}{c}\text { Number } \\
\text { of } \\
\text { Intercon- } \\
\text { nects }\end{array}$ & $\begin{array}{l}\text { 12-Month } \\
\text { Average }^{4}\end{array}$ & $\begin{array}{l}\text { Peak } \\
\text { Day }\end{array}$ & $\begin{array}{l}\text { Summer } \\
\text { Offpeak }^{6}\end{array}$ \\
\hline \multicolumn{9}{|l|}{ Regional Plpellnes } \\
\hline Columbia Gulf Transmission Co & SW & Trunk & 98 & 5 & 3 & 98 & 101 & 96 \\
\hline East Tennessee Natural Gas Co & sW & Grid/Trunk & 92 & 122 & 2 & 84 & 88 & 37 \\
\hline Florida Gas Transmission Co & sw & Trunk & 92 & 181 & 3 & 71 & 102 & 66 \\
\hline Midcoast Pipeline Co & sw & Trunk/Grid & 100 & NA & NA & NA & NA & NA \\
\hline South Georgia Natural Gas Co & sW & Grid & 100 & 68 & 1 & $\mathrm{NA}$ & NA & NA \\
\hline Southern Natural Gas Co & sw & Grid/Trunk & 93 & 323 & 7 & 66 & 100 & 88 \\
\hline Texas Gas Transmission Co & sw & Trunk & 55 & 215 & 2 & 79 & 111 & 58 \\
\hline \multicolumn{9}{|l|}{ Supplemental Pipellne Service } \\
\hline ANR Pipeline Co & sW & Trunk/Grid & 1 & 6 & 1 & 70 & 100 & 66 \\
\hline Columbia Gas Transmission Corp & SW, NE & Grid & 11 & 50 & 2 & 73 & 98 & 26 \\
\hline Koch Gateway Pipeline Co & SW, SE & Grid/Trunk & 25 & 365 & 4 & 57 & 100 & 59 \\
\hline Midwestern Gas Transmission Co & sw & Trunk & 6 & 3 & 1 & 89 & 104 & 80 \\
\hline Tennessee Gas Pipeline Co & sw, Canada & Trunk & 30 & 117 & 22 & 90 & 111 & 70 \\
\hline Texas Eastern Transmission Corp & sw & Trunk & 4 & 37 & 3 & 84 & 109 & 49 \\
\hline Transcontinental Gas Pipeline Co ${ }^{8}$ & sw & Trunk & 33 & 117 & 2 & 83 & 99 & 81 \\
\hline Trunkline Gas Co & sw & Trunk & 12 & 24 & 3 & 74 & 90 & 66 \\
\hline \multicolumn{9}{|c|}{ 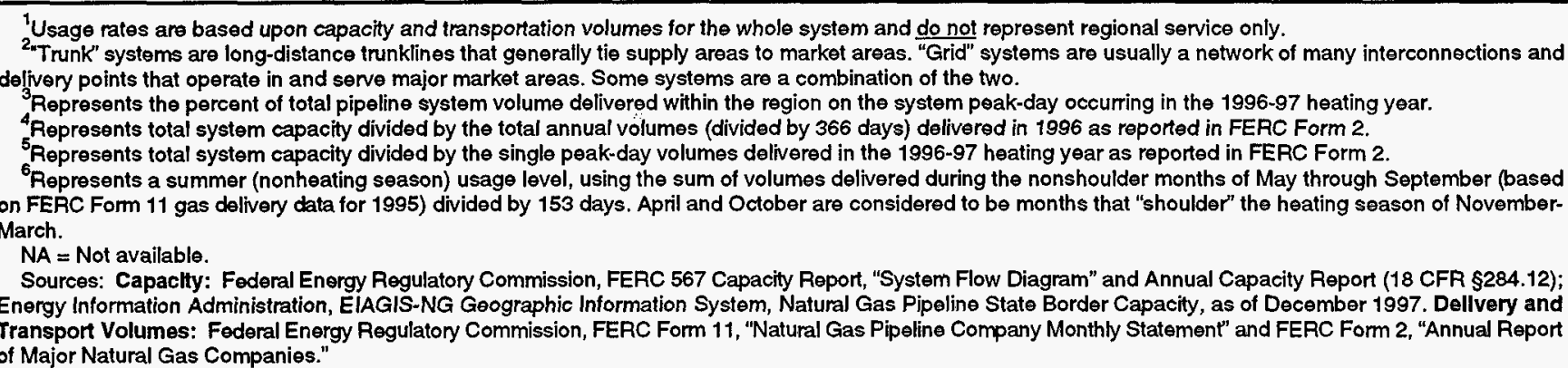 } \\
\hline
\end{tabular}




\section{Deliverability Within the Region}

Local gas service within the region, for the most part, is characterized by the presence of a large number of distributors per State, although in most States only one or two large companies predominate. For example, while Georgia has 90 LDCs, the largest one, Atlanta Gas Light Company, represents nearly three-quarters of the total commitments on interstate pipeline capacity in the State. Southern Natural Gas Company provides most of the gas sold by Atlanta Gas Light.

The States of North and South Carolina are exceptions to this regional pattern of having many different pipeline customers. Each of these States has fewer than 25 LDCs, most of which are quite small-representing less than 15 percent of peak-day deliveries on the interstate systems serving the respective States. The Carolinas were not served by any interstate natural gas pipeline until after World War II. Most of the interstate pipeline service (more than two-thirds) in North Carolina and South Carolina is from Transcontinental Gas Pipe Line Corporation. Southern Natural Gas Company also supplies customers in South Carolina.

The largest peak-day delivery volume in the region is $1.7 \mathrm{Bcf}$ per day by Columbia Gulf Transmission Corporation to its affiliate, Columbia Gas Transmission Company, in Kentucky. Columbia Gas of Kentucky, an LDC, in turn receives about 0.2 Bcf per day of that total from Columbia Gas Transmission Corporation. Louisville Gas \& Electric Company and Western Kentucky Gas Company are the largest LDCs in Kentucky. Their shipments with Texas Gas Transmission Corporation account for about three-quarters of the pipeline company's total deliverability within the State.

\section{Storage Deliverability}

Although the Southeast has the least underground storage capacity of the regions, it has the largest percentage of its daily deliverability ( 47 percent) from high-deliverability storage sites (Table 10), which are mainly located in Mississippi and Alabama. These facilities are used primarily by shippers on the interstate pipeline system to balance their loads on lines crossing into Alabama and points north and east and to accommodate the periodic swings in demand that are characteristic of some industrial and electric utility users. In Mississippi, interstate shippers and local consumers have access to a delivery (withdrawal) capability equivalent to 2.2 Bcf per day from salt dome storage sites (Appendix C, Table C1).

In the northwestern part of the region, in Kentucky, all of the storage sites are conventional depleted reservoirs, which are used primarily for seasonal supply and backup. About 32 percent of this underground storage capacity is owned by
LDCs that serve local markets in Louisville, Kentucky, and Evansville, Indiana. Nevertheless, while most of the remaining storage in Kentucky (representing about 67 percent of the daily peak-day withdrawal capability in the State) is owned by interstate operators, the bulk of its working gas capacity and deliverability service is reserved by LDCs in northern Kentucky, southern Ohio, Indiana, and Illinois.

Four-fifths of the storage capacity in Kentucky is owned by one interstate pipeline company, Texas Gas Transmission Corporation. The company's storage facilities have a total estimated peak-day delivery rate of about 1.2 Bcf per day, about 70 percent of the total within the State. This level is equivalent to about 80 percent of the total daily capacity of Texas Gas Transmission's lines moving north into Indiana. These storage facilities are also in close proximity to the ANR Pipeline Company system, which traverses the State to Indiana and Michigan. Combined, Texas Gas Transmission and ANR Pipeline have the capacity to move 2.9 Bcf per day north to Indiana (Appendix A, Table A2); Texas Gas Transmission's peak-day storage delivery level is the equivalent of about 42 percent of that figure.

\section{End-Use Consumption}

Economic growth in recent years has led to increased natural gas use in the Southeast marketplace. Natural gas increased its share of the energy market, outpacing the growth in total energy usage, 2.9 percent per year versus 2.2 percent (Table 11). Reflecting this growth, in 1995, natural gas use in the region stood at 15 percent of total energy used, 2 percent greater than in 1990. Still, the Southeast remains the smallest consumer of natural gas of all the regions.

Temperate weather, abundant regional coal reserves, and the long history of electricity use fostered by the Tennessee Valley Authority (TVA) have combined to keep residential use of natural gas relatively low. The residential share of natural gas in the region is less than half that of the industrial share, although the residential share has increased 2 percentage points since 1990 because of an increased number of customers during the period (Table 12). The States with the largest residential natural gas markets in the region are Georgia (33 percent) and Kentucky (30 percent) (Appendix C, Table C3).

While the industrial sector increased its consumption of natural gas at an annual rate of 3.2 percent between 1990 and 1996, its share within the natural gas market fell several percentage points (Appendix C, Table C3). Nevertheless, this sector currently represents 44 percent of the natural gas usage within the region, the highest share for the industrial sector in any region except the Southwest (Table 12). Average use by industrial customers increased at an average annual rate of 
almost 1.4 percent in the early 1990s (Table 13) after declining throughout the latter part of the 1980s.

The electric utility sector share also grew during the early 1990s as more gas-fired units were installed at electric generating plants in the region. From 1990 through 1996, gasfired generating capacity grew at an annual rate of 4.2 percent compared with a 1.2 percent growth rate in total generating capacity installed. In 1996, gas-fired generating capacity accounted for 10 percent of the total, compared with only 4 percent in 1990. Currently, this sector represents 16 percent of the natural gas market in the region, up 1 percentage point since 1990 . Its share can be expected to increase during the next several years, even if the annual growth rate slows from the 8.3 percent pace during the period from 1990 through 1996.

\section{Recent and Proposed Expansions}

The continuing decline in deliverability from the western Gulf of Mexico and the increasing development of deep water production in the eastern part of the Gulf (see Chapter 2) is expected to result in greater capacity utilization on the major trunklines traversing the Southeast Region. New capacity could be needed in the near future, but, as of March 1998, no major expansions have been submitted to FERC for approval. Only Columbia Gulf Transmission Company (0.2 Bcf per day) and Tennessee Gas Pipeline Company (0.2 Bcf per day) have announced proposals that would address this issue (Appendix B).

Most of the expansion proposals into and within the region are targeted toward improving deliverability to regional customers and expanding into new market areas. In 1997, five projects were completed, accounting for only $0.4 \mathrm{Bcf}$ per day of new capacity (Table ES1). This is equivalent to only about 0.5 percent of existing interstate pipeline capacity in the region (Appendix B).

More than 3.2 Bcf of new capacity has been proposed within the region for completion between 1998 and 2000 (Appendix B, Table B2). About 54 percent of this capacity is to bring in supplies from the Gulf of Mexico. While almost all of the onshore projects are regional, and for the most part support the area's expanding electric utility and industrial sectors, the offshore projects are designed to support the interstate pipeline network as well.

Demand for natural gas is still growing within the region. More natural gas is being used by all customer groups, including electric utilities (Table 12). In fact, natural gas demand in the region grew at an annual average rate of 3 percent between 1990 and 1995, with each customer category showing an increase. With pipeline utilization rates within the region also showing an increase over the past several years (about 8 percentage points), increased expansion planning in the region can be expected.

\section{Southwest Regional Market}

Even though large volumes of natural gas leave the Southwest Region for other regional markets, significant volumes still remain in the region to fulfill a high level of industrial demand encouraged over the years by the proximity to production areas. In 1996, the Southwest Region consumed more natural gas than any other region, one-half more than the next largest consuming region, the Midwest. About onethird of the Nation's gas is consumed in the Southwest.

The region also has numerous underground storage reservoirs, most of which are used to store excess natural gas production during months of low consumption (Table 10). In recent years, however, more storage in the region is being devoted to supporting the needs of customers using natural gas market centers in the area. Total working gas storage capacity (983 Bcf) is the second highest of the regions. The region has temperate winters and long, hot summers. Louisiana and Texas are the second- and third-warmest States in the lower 48 States, which accounts for large electricity loads for air-conditioning services.

\section{Entering/Exiting Capacity}

Because the Southwest Region has many of the largest gasproducing areas in North America, a huge amount of natural gas pipeline capacity in the region represents export capability. More than $35.7 \mathrm{Bcf}$ per day of capacity exits the region (Figure 18) on at least 20 interstate pipelines (Appendix A, Figure A5), directed toward markets in all other regions of the country, as well as Mexico. This represents an 8-percent increase since 1990 (Table 7, Chapter 3), most of which was evenly distributed on pipelines extending to the Western and Southeast regions (Appendix A, Table A5). From 1990 to 1996, average daily pipeline utilization rates increased along each of the exiting corridors except into the Western Region (and Mexico). The installation of excess interstate pipeline capacity, coupled with an economic downturn in that region, brought on a sizable drop in usage rates along the Western corridor.

Only about 2.9 Bcf per day of capacity enters the Southwest Region. Much of this capacity is on pipeline systems whose flows are directed toward interconnections with other interstate systems for transshipment to markets outside the Southwest Region. The remainder represents flows to local regional markets that are close to the borders of the region, 
Figure 18. Interstate Natural Gas Capacity Summary for the Southwest Region, 1996 (Volumes in Million Cubic Feet per Day)

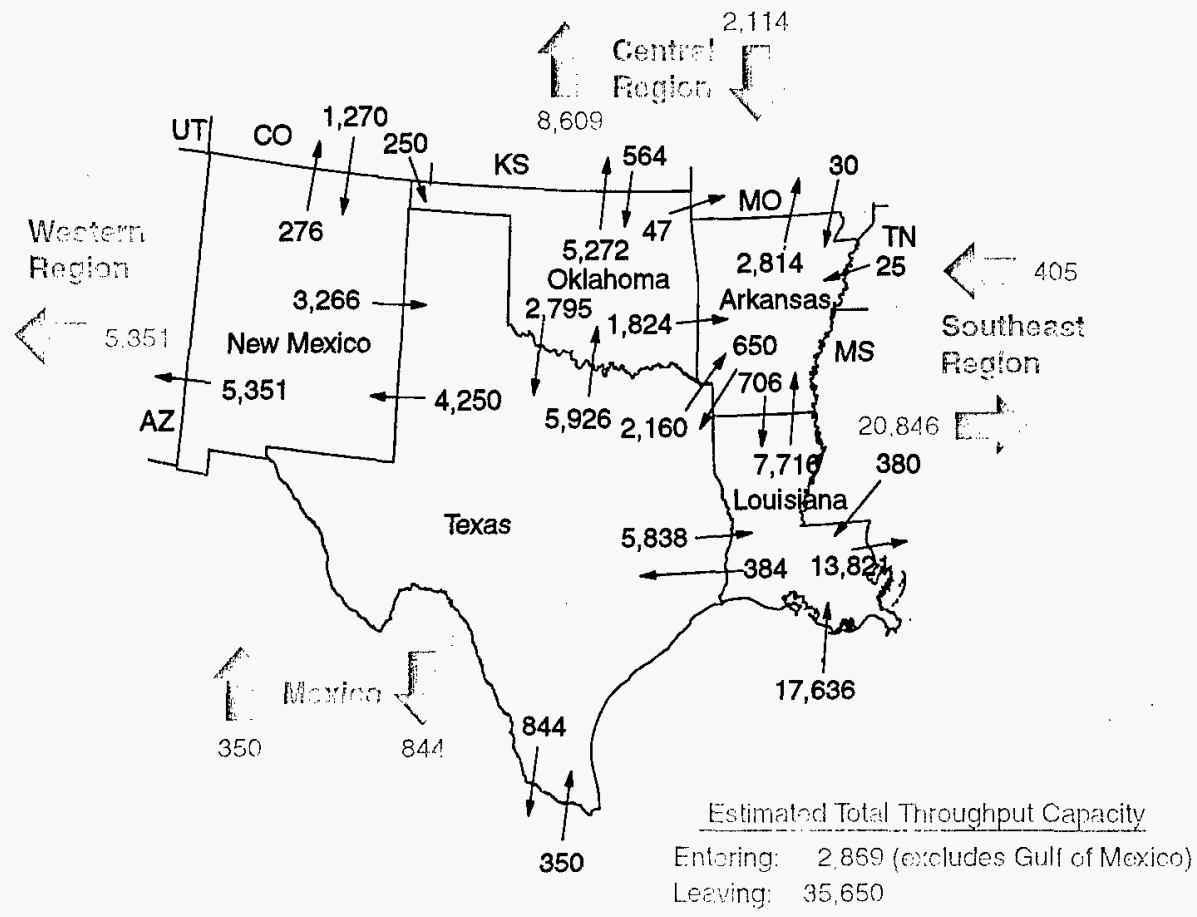

Principal Interstate Natural Gas Pipeline Companies Operating in the Southwest Region

\begin{tabular}{|c|c|c|c|c|c|c|c|c|}
\hline \multirow[b]{2}{*}{$\begin{array}{l}\text { Principal Market Region / } \\
\text { PIpellne Name }\end{array}$} & \multirow[b]{2}{*}{$\begin{array}{l}\text { Reglonal } \\
\text { Supply } \\
\text { Source(s) }\end{array}$} & \multirow[b]{2}{*}{$\begin{array}{c}\text { Primaryl } \\
\text { Secondary } \\
\text { System } \\
\text { Configuratlon }{ }^{2}\end{array}$} & \multicolumn{3}{|c|}{ Regional Servlce Level } & \multicolumn{3}{|c|}{ Systemwide Utilizatlon Pates ${ }^{1} \%$} \\
\hline & & & $\begin{array}{l}\text { Percent of } \\
\text { System } \\
\text { Peak-day } \\
\text { Dellverles }^{3} \\
\end{array}$ & $\begin{array}{c}\text { Number } \\
\text { of } \\
\text { Dellvery } \\
\text { Points }\end{array}$ & $\begin{array}{l}\text { Number } \\
\text { of } \\
\text { Intercon- } \\
\text { nects }\end{array}$ & $\begin{array}{l}\text { 12-Month } \\
\text { Average }^{4}\end{array}$ & $\begin{array}{l}\text { Peak } \\
\text { Day }\end{array}$ & $\begin{array}{l}\text { Summer } \\
\text { Otfpeak }\end{array}$ \\
\hline $\begin{array}{l}\text { Regional Plpelines } \\
\text { Koch Gateway Pipeline Co } \\
\text { Noram Gas Transmission Co } \\
\text { Mid-Louisiana Gas Co } \\
\text { Ozark Gas Transmission Co } \\
\text { Valero Interstate Transmission Co }\end{array}$ & $\begin{array}{l}\text { SW } \\
\text { SW } \\
\text { SW } \\
\text { SW } \\
\text { SW }\end{array}$ & $\begin{array}{l}\text { Trunk/Grid } \\
\text { Trunk/Grid } \\
\text { Trunk } \\
\text { Trunk } \\
\text { Trunk/Grid }\end{array}$ & $\begin{array}{r}75 \\
99 \\
100 \\
100 \\
100\end{array}$ & $\begin{array}{r}907 \\
751 \\
7 \\
\text { NA } \\
\text { NA }\end{array}$ & $\begin{array}{r}13 \\
32 \\
3 \\
\mathrm{NA} \\
\mathrm{NA}\end{array}$ & $\begin{array}{l}57 \\
56 \\
\text { NA } \\
\text { NA } \\
\text { NA }\end{array}$ & $\begin{array}{r}100 \\
86 \\
\text { NA } \\
\text { NA } \\
\text { NA }\end{array}$ & $\begin{array}{l}59 \\
61 \\
\text { NA } \\
\text { NA } \\
\text { NA }\end{array}$ \\
\hline $\begin{array}{l}\text { Supplemental Plpeline Servlce } \\
\text { ANA Pipeline Co } \\
\text { Colorado Interstate Gas Co } \\
\text { Columbia Gulf Transmission Co } \\
\text { El Paso Natural Gas Co } \\
\text { Florida Gas Transmission Co } \\
\text { Mississippi River Transmission Co } \\
\text { Natural Gas Pipeline of America } \\
\text { Northern Natural Gas Co } \\
\text { Pannandle Eastern Transmission Co } \\
\text { Southern Natural Gas Co } \\
\text { Tennessee Gas Pipeline Co } \\
\text { Texas Eastern Transmission Corp } \\
\text { Texas Gas Transmission Corp } \\
\text { Transcontinental Gas Pipeline Co } \\
\text { Trunkline Gas Co } \\
\text { Transwestern Gas Pipeline Co } \\
\text { Williams Natural Gas Co }\end{array}$ & $\begin{array}{l}\text { SW } \\
\text { SW, CE } \\
\text { SW } \\
\text { SW } \\
\text { SW } \\
\text { SW } \\
\text { SW, CE } \\
\text { SW } \\
\text { SW } \\
\text { SW } \\
\text { SW, Canada } \\
\text { SW } \\
\text { SW } \\
\text { SW } \\
\text { SW, CE } \\
\text { SW, CE } \\
\text { SW, CE }\end{array}$ & $\begin{array}{l}\text { Trunk/Grid } \\
\text { Trunk/Grid } \\
\text { Trunk } \\
\text { Trunk } \\
\text { Trunk } \\
\text { Trunk } \\
\text { Trunk } \\
\text { Trunk/Grid } \\
\text { Trunk } \\
\text { Grid/Trunk } \\
\text { Trunk } \\
\text { Trunk } \\
\text { Trunk } \\
\text { Trunk } \\
\text { Trunk } \\
\text { Trunk } \\
\text { Grid/Trunk }\end{array}$ & $\begin{array}{r}17 \\
5 \\
2 \\
3 \\
8 \\
41 \\
7 \\
4 \\
1 \\
2 \\
11 \\
7 \\
17 \\
1 \\
1 \\
67 \\
4 \\
\end{array}$ & $\begin{array}{r}21 \\
11 \\
10 \\
288 \\
25 \\
32 \\
83 \\
45 \\
9 \\
18 \\
141 \\
12 \\
12 \\
58 \\
5 \\
30 \\
34 \\
86 \\
\end{array}$ & $\begin{array}{r}22 \\
7 \\
11 \\
6 \\
1 \\
8 \\
25 \\
8 \\
0 \\
10 \\
29 \\
29 \\
21 \\
4 \\
16 \\
8 \\
1 \\
\end{array}$ & $\begin{array}{l}70 \\
82 \\
98 \\
71 \\
71 \\
85 \\
84 \\
92 \\
78 \\
66 \\
90 \\
84 \\
79 \\
83 \\
74 \\
60 \\
75 \\
\end{array}$ & $\begin{array}{r}100 \\
104 \\
101 \\
78 \\
102 \\
92 \\
96 \\
107 \\
98 \\
100 \\
111 \\
109 \\
111 \\
99 \\
90 \\
62 \\
82 \\
\end{array}$ & $\begin{array}{l}66 \\
76 \\
96 \\
73 \\
66 \\
59 \\
80 \\
80 \\
58 \\
88 \\
70 \\
49 \\
58 \\
81 \\
66 \\
61 \\
42 \\
\end{array}$ \\
\hline \multicolumn{9}{|c|}{$\begin{array}{l}\text { 1Usage rates are based upon capacity and transportation volumes for the whole system and do not represent regional service only. } \\
2^{2} \text { "Trunk" systems are long-distance trunklines that generally tie supply areas to market areas. "Grid" systems are usually a network of many interconnections and } \\
\text { delivery points that operate in and serve major market areas. Some systems are a combination of the two. } \\
3 \text { Represents the percent of total pipeline system volume delivered within the region on the system peak-day occurring in the } 1996-97 \text { heating year. } \\
{ }^{4} \text { Represents total system capacity divided by the total annual volumes (divided by } 366 \text { days) delivered in } 1996 \text { as reported in FERC Form } 2 \text {. } \\
5 \text { Represents total system capacity divided by the single peak-day volumes delivered in the } 1996-97 \text { heating year as reported in FERC Form } 2 \text {. } \\
\text { Represents a summer (nonheating season) usage level, using the sum of volumes delivered during the nonshoulder months of May through September (based } \\
\text { on FERC Form } 11 \text { gas delivery data for 1995) divided by } 153 \text { days. April and October are considered to be months that "shoulder" the heating season of November- } \\
\text { March. } \\
\text { NA = Not available. } \\
\text { Sources: Capaclty: Federal Energy Regulatory Commission, FERC 567 Capacity Report, "System Flow Diagram" and Annual Capacity Report (18 CFR \$284.12); } \\
\text { Energy Information Administration, EIAGIS-NG Geographic Information System, Natural Gas Pipeline State Border Capacity, as of December 1997. Delivery and } \\
\text { Transport Volumes: Federal Energy Regulatory Commission, FERC Form 11, "Natural Gas Pipeline Company Monthly Statement" and FERC Form 2, "Annual Report } \\
\text { of Major Natural Gas Companies." }\end{array}$} \\
\hline
\end{tabular}


for example, Associated Natural Gas Company's $30 \mathrm{MMcf}$ per day from Missouri into Arkansas.

About 45 percent ( $1.3 \mathrm{Bcf}$ per day) of the total entering capacity represents pipeline capacity from Colorado (Central Region) to New Mexico on three pipelines (Appendix A, Table A5). Part of this capacity (about 60 percent) is redirected toward traditional Western Region markets, although in recent years a greater poriion of this capacity is being directed to interstate interconnections and market centers that serve the Midwest marketplace. The average daily utilization rates on these three pipelines ranged from 55 to 88 percent in 1996, the lowest being on the Transwestern Pipeline system, which was affected by unusual maintenance needs and construction during off-peak periods.

\section{Deliverability Within the Region}

Several of the 22 or more interstate pipeline companies operating within the Southwest Region primarily serve customers in the region (Figure 18). Three of the larger ones, Noram Gas Transmission Company, Ozark Gas Transmission Company, and Valero Interstate Pipeline Company, have commitments within the region of close to 100 percent of their total transportation service levels. In addition, several of the major trunklines exiting the region also maintain sizeable deliverability levels within the region itself. For instance, in 1995, El Paso Natural Gas, Koch Gateway Pipeline, and Transwestern Pipeline companies delivered 54, 63, and 53 percent, respectively, of total throughput to points within the region on their system peak day. ${ }^{84}$ Several of the other major exporting pipeline system delivered 25 to 30 percent of their peak-day volumes within the region.

In 1996, the average daily utilization rates on the interstate pipelines within the region ranged from 42 to 98 percent. In general, the average rate within the region was higher in 1996 than in 1990, 57 versus 49 percent. This rate is lower than the 66-percent average utilization for lines exiting the region (Appendix A, Table A5), but reflects some of the gathering and intermediate storage operations within the region performed in conjunction with production-features that affect trunkline operations to a lesser degree. Also, trunkline usage rates often are more a reflection of the downstream demands of other regional markets rather than of demands within the Southwest.

The regional interstate pipeline companies, that is, those with the majority of their deliveries within the region, together account for about one-quarter of the regional deliveries. Most

\footnotetext{
${ }^{84}$ Energy Information Administration, EIAGIS-NG Geographic Information System, Natural Gas Pipeline Deliverability Database, as of December 1995.
}

of the regional consumption is supplied by local intrastate pipeline companies for which data are unavailable. As the largest consuming region in the United States, the Southwest has many large intrastate pipeline companies and LDCs supplying natural gas to consumers. For example, Lone Star Gas Company is the eighth largest LDC in the United States (in terms of total deliveries), with more than 1.2 million customers in Texas. The only States in which LDCs are among the largest customers of the interstate pipeline companies are Louisiana, where Koch Gateway Pipeline Company supplies New Orleans Public Service Inc., and New Mexico, where El Paso Natural Gas Company supplies three LDCs.

\section{Storage Deliverability}

Underground natural gas storage plays a vital role in the efficient export and transmission of natural gas from the Southwest to other regions, as well as in supplementing regional needs. These underground storage facilities represent over 982 Bcf of working gas capacity (Table 10) and an estimated daily deliverability level of over 20.5 million cubic feet. A large portion of this storage is near production fields and is used to balance production flows and fluctuating market demand.

About 38 percent of the region's daily deliverability from storage is owned by interstate pipeline companies, 29 percent by independent operators, and 33 percent by LDCs or intrastate pipeline companies. All of the interstate pipelineowned storage, and most of the independently owned, is open access, that is, working gas storage capacity can be available to shipper/customers on a first-come, first-served basis at nondiscriminatory rates. This means that only a limited amount of the pipeline storage is for system or pipeline use (for load-balancing operations). Most shippers are now responsible for making their own arrangements with storage operators to ensure that they comply with the receipt/delivery balancing requirements of the system on which they are shipping.

As a result, a growing amount of regional storage is also linked to the many natural gas market centers in the region that have become operational during the past 5 years. ${ }^{85}$ These centers, often themselves owners of independent storage, assist shippers in making short-term arrangements to store excess load or to borrow gas when receipt volumes do not match delivery requirements or vice-versa, a situation that can result in imbalance penalties being levied by the transporting pipeline.

\footnotetext{
${ }^{85}$ See, Energy Information Administration, Natural Gas 1996: Issues and Trends, DOE/EIA-0560(96) (Washington, DC, December 1996), Table 8, Chapter 3.
} 
The overall peak-day withdrawal capability from storage into the interstate system is approximately $13.7 \mathrm{Bcf}$ per day (Table 10), the equivalent of about 39 percent of the total capacity exiting the region. In Louisiana, almost all of the underground storage service is available to the interstate system, whereas in Oklahoma, 56 percent is operated as part of the interstate system (Appendix C, Table C1) ${ }^{86}$ Industrial and electric utility customers in the region, with variable load demands and high swing requirements, are major users of high-deliverability, salt cavern storage, most of which is operated by interstate pipeline companies or independents.

Only about a third of the region's storage capacity is owned by LDCs and used exclusively for local service (Table 10), but regional distributors also have access to and use interstate and independent storage facilities. Most of the LDC-owned storage is near major industrial and population centers and has little impact upon the interstate pipeline network in the area. In Texas and Oklahoma, approximately 40 percent of underground storage capacity is at facilities operated by LDCs or intrastate pipeline companies, whereas in Arkansas all of the storage capacity is controlled by local operators (Appendix C, Table C1).

\section{End-Use Consumption}

The Southwest is the only regional marketplace where natural gas use grew at a slower rate than total energy demand (Table 11). Since 1990, natural gas consumption in the region grew at an annual rate of 0.2 percent, while total energy grew at a 1.3 percent rate. In fact, the use of natural gas as a percentage of total energy consumed dropped from 40 percent in 1990 to 39 percent in 1995. Part of this drop can be attributed to an annual growth rate of only 1.9 percent in residential consumption and 3.2 percent in the industrial sector (Table 12).

Although electric utility use of natural gas showed a slight annual decrease ( 0.1 percent) during the period (Table 12), gas-fired generating capability increased at a 1.4 percent rate. Gas-fired generating capacity grew to 57 percent of total electric generating capacity in the region by 1996, the highest rate among regions. Louisiana had the highest percentage, 71 percent, with Texas second at 61 percent. ${ }^{87}$ Total electricity generating capacity in the region increased by only 2 percent from 1990 through 1996, at about the same level as installed gas-fired units (Table 13). On the other hand, nonutility generating capability, although accounting for only about 1 percent of electric power generated in the region in 1996, grew by 14 percent during the same period.

\footnotetext{
${ }^{86}$ Includes supply to the interstate system.

${ }^{87}$ Derived from: Energy Information Administration, Form EIA-860, “Annual Electric Generator Report” (1990-1996).
}

In 1990 , natural gas provided 40 percent of the total energy input to electric utilities in the region. ${ }^{88}$ By 1996 , this proportion had fallen to 36 percent. In addition, the total volume of gas consumed within the region by electric utilities declined by 7 percent during the same period. ${ }^{89}$ In spite of this regional decline, natural gas use by electric utilities in Texas increased slightly and in 1996 still accounted for 40 percent of all gas purchases by utilities in the Nation.

Despite a slight loss in energy share, regional consumption of natural gas is the highest in the Nation. Louisiana, Oklahoma, New Mexico, and then Texas, respectively, use natural gas as an energy source to a greater degree than any other States in the Nation (Appendix C, Table C2). This high level is due to the availability of gas in the region, where the overall ratio of natural gas production to consumption is 2.25 (Table 11), and the use of natural gas by industries and electric utilities in the region is still the highest compared with use in the rest of the Nation (Table 12).

The industrial sector dominates the regional market, consuming 53 percent of the natural gas delivered within the Southwest Region. The industrial share of natural gas consumption is highest in Louisiana (63 percent) because of its large petrochemical industry. From 1990 to 1996, industrial customers in all States in the region increased average natural gas use at an annual rate of 11 percent, with New Mexico (where industrial sector represents the smallest market share) and Texas showing the largest increases (Appendix C, Table C4). While natural gas lost in terms of overall industrial gas users, its share of the regional natural gas market still grew by 6 percentage points between 1990 and 1996 (Table 12).

The residential and commercial use of natural gas remains relatively low in the region, representing only about 11 percent of natural gas consumption in the region, virtually unchanged from the 1990 level. The Southwest is only fourth of the six regions in the proportion of the total population that uses natural gas, and also fourth in terms of average gas use per residential customer. ${ }^{90}$ Since 1990 , the number of residential and commercial gas customers increased somewhat, 1.2 and 2.2 percent per year, respectively, but not enough to affect their respective markets (Table 13).

\footnotetext{
${ }^{88}$ During the 1980 s, the proportion of natural gas consumed by electric utilities in the region dropped from 66 percent in 1980 to 41 percent in 1989 primarily because of high gas prices that developed in the early part of the decade.

${ }^{89}$ Energy Information Administration, Natural Gas Annual 1996, DOE/EIA-0131 (Washington, DC, September 1997) and previous editions.

${ }^{90}$ See, Energy Information Administration, Natural Gas Annual 1996, and previous editions.
} 


\section{Recent and Proposed Expansions}

The principal arena for pipeline capacity expansions in the Southwest Region during the next several years will be in the intrastate market, mostly to expand access to new production areas and improve deliverability to local markets and links with the interstate system. In particular, producers in southern Texas and the Cotton Valley Trend area of eastern Texas will be seeking greater access to the interstate transmission network. In the interstate market, the primary effort will be to forge greater access to deep water developments in the Gulf of Mexico and to improve service at the several market centers in the region.

In 1997, 10 expansion projects were completed within the region, adding more than $3.7 \mathrm{Bcf}$ to regional pipeline capacity. Six of these projects were designed to bring additional supplies onshore from the Gulf of Mexico: three major gathering systems (1.1 Bcf per day) and three pipelines (2.1 Bcf per day) coming onshore to Louisiana (Appendix B). The remaining projects were designed principally to expand interstate access to production in West Texas and New Mexico. Fourteen additional projects are scheduled for completion in 1998 and two in 1999, which would add 3.7 Bcf to regional capacity. Currently, no projects have been announced that would go beyond 1999 .

\section{Western Regional Market}

The Western Region has some of the strongest environmental initiatives in the Nation, many of which call specifically for greater use of natural gas. For instance, regulatory agencies in California have mandated reductions in consumption of residual fuel oil as a boiler fuel, resulting in increased use of natural gas in this area. Even before passage of the Clean Air Act Amendments of 1990, the South Coast Air Quality Management District issued rules that prohibit price-induced burning of fuel in dual-fired utility boilers. The Southern California Edison Company and the Los Angeles Department of Water and Power also adopted plans that would eliminate the use of fuel oil at all their power plants in order to reduce emissions.

This projected preference for gas because of environmental concerns was a primary force behind the 42-percent increase in pipeline capacity into the Western Region between 1990 and 1996. However, the expected growth in the natural gas market did not materialize as an economic slowdown resulted in underutilization of this new capacity.

California dominates the regional natural gas market because of its large population, the highest in the Nation, and because of its relatively high gas use. California customers account for about 59 percent of the energy consumed in the region and 74 percent of the natural gas use (Appendix C, Table C2). One utility, Pacific Gas and Electric, distributed almost 5 percent of the natural gas delivered to end-use customers in the United States in 1996. Another, Southern California Gas Company, is the largest gas distributor in the United States and perhaps in the world.

\section{Entering/Exiting Capacity}

Eight interstate pipeline companies provide service to and within the Western Region, the fewest number serving any region (Figure 19). Capacity entering the region is also the lowest of all gas-importing regions, approximately $10.1 \mathrm{Bcf}$ per day. Slightly more than half of this capacity is on pipeline systems that carry gas from the Rocky Mountains area and the Permian and San Juan Basins (Appendix A, Figure A5). These systems enter the region at the New Mexico-Arizona and Nevada-Utah State lines. The rest arrive on pipeline systems that access Canadian supplies at the British Columbia-Idaho and Washington State border crossings.

Capacity into the Western Region increased overall by 42 percent, or 3.0 Bcf per day, between 1990 and 1996 (Table 9). The majority of this increase occurred on routes transporting gas from Canada, where 48 percent more capacity was implemented. PG\&E Transmission-Northwest (formerly Pacific Gas Transmission Company) and Northwest Pipeline Company accounted for all of these capacity additions. In spite of a general economic downturn in the region during the early 1990s, particularly in California, average capacity usage rates on these routes recovered in 1996 (after falling between 1993 and 1995) to reach or exceed their 1990 average rates.

Three new interstate natural gas pipeline systems were placed in service between 1991 and 1995 in the region and four existing systems underwent major expansions. While they were being built, however, the regional marketplace, especially in California, saw an overall decrease in economic activity and a slowdown in the growth of natural gas demand. A casualty of the slowdown has been the repeated postponement of the Altamont Pipeline project (737 MMcf per day), which was slated to serve the California market with gas transported from western Canada. ${ }^{91}$ Currently, the project is being marketed as a potential route for transporting Canadian supplies eastward via the expanding Trailblazer system (which transports gas to Midwestern markets).

\footnotetext{
${ }^{91}$ The Altamont system, as originally proposed, would flow southward from Alberta, Canada, through Montana and feed into the Kern River pipeline system at Opal, Wyoming.
} 
Figure 19. Interstate Natural Gas Capacity Summary for the Western Region, 1996 (Volumes in Million Cubic Feet per Day)

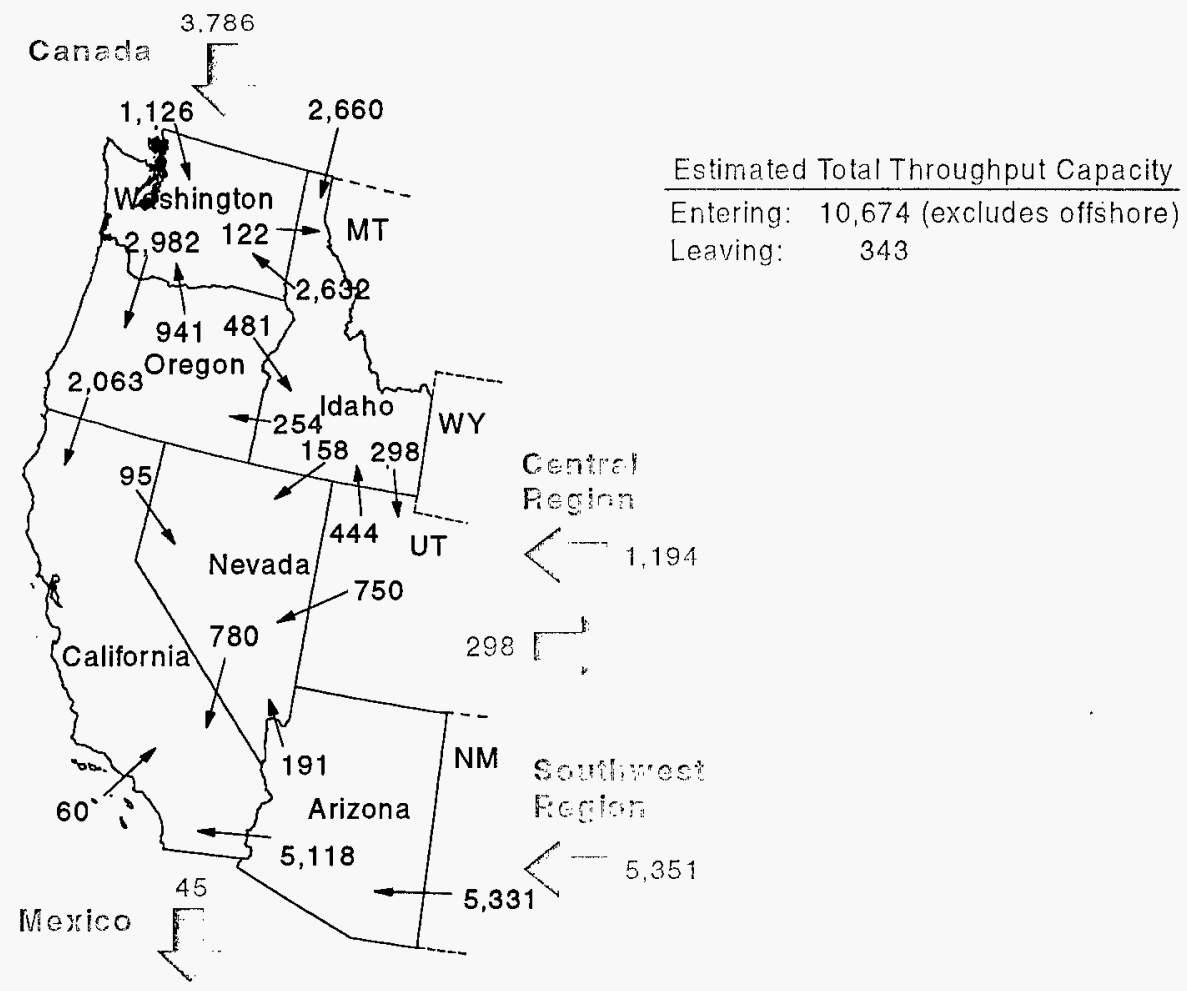

Principal Interstate Natural Gas Pipeline Companies Operating in the Western Region

\begin{tabular}{|c|c|c|c|c|c|c|c|c|}
\hline \multirow[b]{2}{*}{$\begin{array}{l}\text { Princlpal Market Reglon / } \\
\text { PIpeline Name }\end{array}$} & \multirow[b]{2}{*}{$\begin{array}{l}\text { Reglonal } \\
\text { Supply } \\
\text { Source(s) }\end{array}$} & \multirow[b]{2}{*}{$\begin{array}{c}\text { Primary/ } \\
\text { Secondary } \\
\text { System } \\
\text { Conflguration }\end{array}$} & \multicolumn{3}{|c|}{ Reglonal Servlce Level } & \multicolumn{3}{|c|}{ Systemwlde Utillzation Rates ${ }^{\top} \%$} \\
\hline & & & $\begin{array}{l}\text { Percent of } \\
\text { System } \\
\text { Peak-day } \\
\text { Dellverles }^{3}\end{array}$ & $\begin{array}{c}\text { Number } \\
\text { of } \\
\text { Dellivery } \\
\text { Polnts }\end{array}$ & $\begin{array}{c}\text { Number } \\
\text { of } \\
\text { Intercon- } \\
\text { nects }\end{array}$ & $\begin{array}{l}\text { 12-Month } \\
\text { Average }^{4}\end{array}$ & $\begin{array}{l}\text { Peak } \\
\text { Day }\end{array}$ & $\begin{array}{l}\text { Summer } \\
\text { Offpeak }^{6}\end{array}$ \\
\hline \multicolumn{9}{|l|}{ Regional Pipelines } \\
\hline El Paso Natural Gas Co. & W & None & 76 & 330 & 2 & 71 & 78 & 73 \\
\hline & & & 99 & 30 & 0 & & 109 & \\
\hline & & Trunk & 100 & 17 & 2 & 7 & 119 & 95 \\
\hline & nada & nk/Grid & 64 & 282 & 1 & & 94 & 54 \\
\hline n co & a & Tru & 109 & & 3 & & 96 & 85 \\
\hline Transco & & Trunk & 100 & NA & NA & NA & NA & NA \\
\hline & & nk & 31 & 6 & 1 & & & \\
\hline Tuscarora Gas Transmission co & Canada & Trunk & 109 & 4 & 1 & & NA & NA \\
\hline \multicolumn{9}{|c|}{ 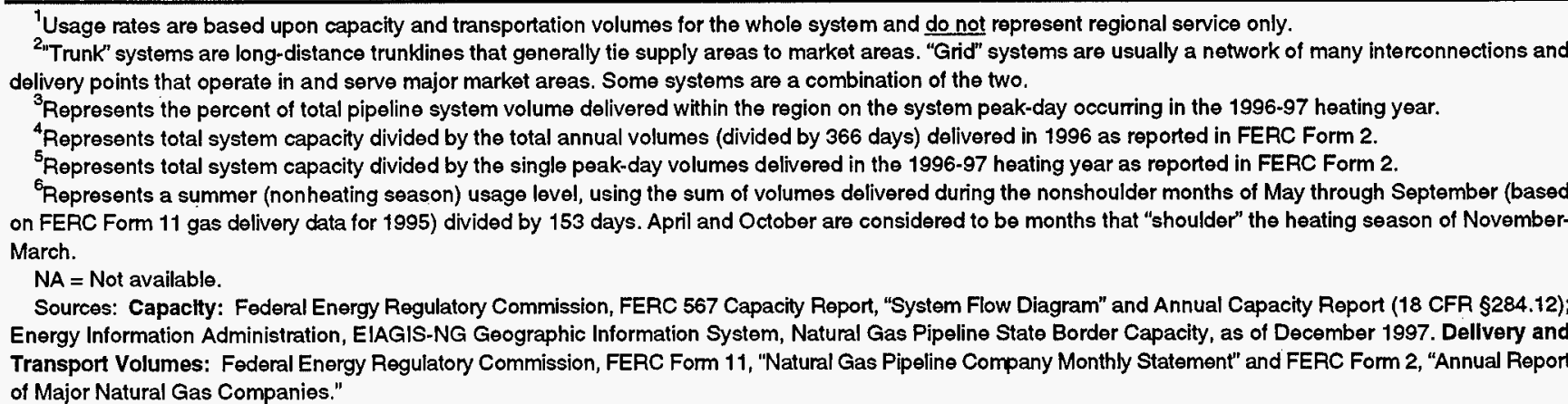 } \\
\hline
\end{tabular}


The new pipeline systems constructed during the period include: (1) the Kern River Pipeline ( $750 \mathrm{MMcf}$ per day) from Opal, Wyoming, to Kern County, California, currently operating at about 100 percent utilization during peak periods and 93 percent during baseload periods; (2) Mojave Pipeline (450 MMcf per day) from the Arizona/California border to Kern County, merging with the Kern River system, currently operating at about full capacity during peak periods but as low as 40 percent during other periods; and (3) Tuscarora Pipeline (110 MMcf per day) from the northern California Border to Reno, Nevada, which began operations in 1995 (load factors are unavailable).

PG\&E Transmission-Northwest had the largest expansion during the period, adding more than $870 \mathrm{MMcf}$ per day to its system from the Canada/Idaho border to the northern California border, a 55-percent increase. While the system currently operates at about 90 to 95 percent capacity during peak periods (compared with 100 percent in 1990), the range between high and low is only about 8 percentage points. Northwest Pipeline Company (NWPL), which also brings Canadian supplies into the region, increased its capacity by more than $240 \mathrm{MMcf}$ per day, adding greater bidirectional flexibility and redirecting some of its flows to growing markets within its operational territory. NWPL's overall utilization level is higher than it was in 1990. The system operates at about full capacity during peak periods, although rates fell as low as 54 percent during off-peak periods.

Expansions of the El Paso Natural Gas Company and Transwestern Pipeline Company systems during 1992 and 1993 provided greater access to San Juan Basin production. The El Paso system experienced an increase of 371 MMcf per day, or 17 percent, while Transwestern's system increased by $680 \mathrm{MMcf}$ per day. ${ }^{92}$

\section{Deliverability Within the Region}

The States within the Western Region are almost totally dependent upon the interstate pipeline network for their gas supplies (Table 11). California is the only one that produces any substantial quantity, about 15 percent of its annual consumption level (Appendix C, Table C2). Another important characteristic of the region is that local gas distribution services are dominated by a few large companies. Other than some small municipal gas distributors, Idaho, Washington, and Nevada have only three LDCs, Oregon and

\footnotetext{
${ }^{92}$ Transwestern completed its San Juan expansion project in 1996 and increased capacity further in the area in 1997. Its completion expanded capacity on the New Mexico side of the basin, thus relieving a production constraint situation that has hindered the flow of production out of the area for several years. The Transwestern system expansion prior to 1996 coincided with the construction of the Mojave Pipeline system, the two interconnecting at the Arizona/California border.
}

Arizona two, and California five. In addition, a company such as Washington Water Power operates in more than one State, providing service in Oregon, Washington, and California.

Until the early 1990s no interstate pipeline companies operated within California; all supplies were received from the interstate companies at the State border. That changed with the completion of the Kern River and Mojave Pipeline system into southern California in 1993 and the Tuscarora Pipeline system into northern California in 1995. However, even today, most service within California is provided by Pacific Gas and Electric Company and Southern California Gas Company, the two largest LDCs in the Nation. The two companies play dual roles as LDCs for their core customers and open-access transporters for major shippers, such as industrial users and electric utilities, within their respective service territories. They also serve as intrastate pipelines with interconnections to the other LDCs serving the State. Southern California Gas Company provides distribution service in southern California. Pacific Gas and Electric claims northern California as its service territory but also serves as a vehicle to move some Canadian gas supplies to southern California.

All of the pipelines entering the region, with the exception of Northwest Pipeline Company, terminate there as well. Each also has major commitments in the region. For instance, of the 645 delivery and interconnection points on the El Paso Natural Gas system, 341 are within the region and represented 76 percent of the peak-day volumes delivered off its system in 1995 (Figure 19). All of Pacific Gas Transmission's 192 delivery points are within the region, with the system transporting $2.7 \mathrm{Bcf}$ on its peak day in 1996 (Table 1).

The interstate pipeline companies within the region operated at an average utilization rate of about 66 percent in $1996 .^{93}$ That was down from an 84-percent level in 1990. The difference reflects, to a large degree, the drop in capacity utilization on those pipelines bringing Southwest Region gas into California: Transwestern Pipeline Company and El Paso Natural Gas Company. However, even during the summer months, these systems operate within a narrow range of capacity utilization.

\section{Storage Deliverability}

Most of the underground storage facilities in the Western Region, especially in California which has 91 percent of the region's working gas capacity, are used as market area supply reservoirs to store Canadian gas supplies, which flow and are

\footnotetext{
${ }^{93}$ Energy Information Administration, EIAGIS-NG Geographic Information System, Natural Gas Pipeline State Border Capacity Database, as of December 1997.
} 
received at a rather constant rate (Appendix $\mathrm{C}$, Table $\mathrm{C} 1$ ). The California storage fields are more like production (area) storage located at the market end of the supply corridor. The availability of this storage is one of the reasons why the pipelines entering the region operate at such high and sustained utilization rates. This storage allows the California operators to address the varying needs of their local customers and shippers while maintaining a steady flow on their systems.

All the underground storage sites in the region are conventional reservoir storage, owned and operated by LDCs (Table 10). Most of the storage is owned by the two largest California intrastate systems, PG\&E and SoCal Gas. The rest is located in Washington State and Oregon and is used for seasonal storage and as peaking facilities.

Despite the region's relatively temperate climate, LNG storage is also used by LDCs in the market, especially in the northern States of Washington and Oregon (Appendix C, Table C1). LNG as a peaking fuel is very compatible with the need for occasional supplemental supply support, especially because the geologic makeup of the region precludes much further development of underground storage facilities. Installation of LNG facilities under these conditions also lessens the need for additional and expensive pipeline capacity when incremental supplies are needed only for the short term.

\section{End-Use Consumption}

Natural gas consumption in the Western Region increased at an average annual rate of about 4 percent between 1990 and 1996, whereas overall energy output increased at only a 0.3 percent rate (Table 11 ). The slowdown in the regional economy during the early 1990 s was the main factor in the decreased energy growth. The higher growth in natural gas consumption can be attributed to its use as a substitute for hydropower when water levels were low and to its increased use for enhanced-oil-recovery operations in California. Environmental dictates also brought about increased substitution of natural gas for less clean-burning fuels. ${ }^{94}$

Consumption by California customers accounts for 59 percent of the energy consumed in the region and 74 percent of the natural gas. In 1995, 26 percent of the total energy consumed in California was natural gas (Appendix C, Table C2). The industrial sector dominates the California gas market

\footnotetext{
${ }^{94}$ Coincidently, Federal and State environmental regulations are encouraging more natural gas use, particularly in applications where petroleum products and coal dominate the market. In some parts of the region, regulations to limit atmospheric emissions may make natural gas the only fossil fuel that can be used for electric power and steam generation.
}

(38 percent in 1996), particularly because of the enhanced oil recovery (EOR) industry in southern California. The EOR market, which uses natural gas to generate steam for injection onto heavy-oil fields, accounts for about $200 \mathrm{Bcf}$ of the natural gas entering the State during the year. The EOR market is the primary reason for the 3.6 percent annual growth in the industrial sector in California since 1993, when the Kern River and Mojave pipelines first entered this market. Another factor in the growth in the industrial sector is the large number of cogeneration sites (more than 450 ) in the State. Natural gas accounted for more than 57 percent of the power generated from these facilities in 1996 and constituted about 12 percent of all electric power generated in the State.

Residential customers have a 26-percent share of the California natural gas market, electric utilities 18 percent, and commercial customers only 13 percent (Appendix C, Table C3). Hydropower electric generation is the major competitor of natural gas in the State. In past years, for instance, when severe drought conditions developed that restricted hydro-power generation, natural gas saw a major gain in its use for electric generation. As water levels improved, however, natural gas lost its market advantage and, as a result, the use of natural gas for this purpose dropped by 7.4 percent per year in the State from 1990 through 1996.

Nonetheless, the electric utility industry remains a significant user of natural gas. In three of the six States in the region (Arizona, Nevada, and California), the electric utility industry accounts for 16 to 38 percent of total natural gas deliveries to consumers (Appendix C, Table C3). From 1990 through 1996, gas-fired electric generation capacity in the region grew at an annual rate of only 0.3 percent, 5.6 percent in Oregon and 3 percent in Nevada.

In the northern States of the region-Idaho, Oregon, and Washington - the industrial segment is the predominant user of natural gas, accounting for more than 48 percent of the natural gas market in each State. Average annual industrial consumption of gas in these States increased by about 6.9 percent between 1990 and 1996, while the commercial and electric utility sectors saw a decrease in natural gas market share. These three States also showed some of the largest gains in overall energy consumption throughout the period. The low usage of natural gas in these States for electricity generation is primarily because of their extensive hydroelectric capacity.

\section{Recent and Proposed Expansions}

In 1997, two projects were completed in the region-a 25 MMcf-per-day export crossing with Mexico and a 12-MMcfper-day pipeline expansion from Nevada to California. No new capacity has been built into the region since 1993 . 
However, the growing economies of the northern States in the region-Idaho, Oregon, and Washington-may increase capacity needs. The two major interstate pipeline companies serving these States, Pacific Gas Transmission and Northwest Pipeline, have announced plans to add additional deliverability during the next several years, although the final levels have yet to be determined.

\section{Outlook}

It appears that most, if not all, natural gas consumer markets in the United States have adequate service to meet their unique needs. Interstate pipeline capacity into each of the six regional markets has increased since 1990 at a pace consistent with the growth in demand. Furthermore, proposals for expanding the network are in line with current projections for regional natural gas demand growth during the next several years. ${ }^{95}$

Open-season exercises conducted by the initiators of the current inventory of expansion proposals have resulted in bids for future capacity sometimes in excess of what had been initially offered as a project expansion estimate. This would seem to indicate that bidders/planners within local markets also believe that demand will grow substantially during the next several years. Planners at the local level usually possess better knowledge of the customer profiles within their own areas and, therefore, their bids for future pipeline capacity can be viewed as relatively firm support for the expansions.

In some cases, however, these bids for capacity are being made by marketers and other parties who are not that intimately involved in the local market but want to ensure their access to new capacity in the future. This new capacity would provide them with alternative routes to meet their customers' desires for access to least cost supplies rather than to address demand growth.
If all the projects currently proposed were built-and that is highly unlikely since several have targeted the same markets-interregional capacity would increase by as much as $14.7 \mathrm{Bcf}$ per day, or about 17 percent, from the 1996 level. Additional projects that are limited to providing service within a specific region comprise another $15.3 \mathrm{Bcf}$ per day of capacity.

Underground storage operations, which facilitate both market center services and efficient pipeline operations, will also be expanding significantly over the next several years, many in support of market center or pipeline expansion..$^{96}$ For instance, the implementation of the proposed Vector pipeline, from Chicago to Dawn, Ontario, via the U.S. Midwest, will require the expansion of several storage facilities in Ontario and in Michigan to serve its shippers. Likewise, in the southern States of Texas, Louisiana, and Mississippi, where a number of market centers are located, including the Henry Hub, a number of high-deliverability salt cavern storage facilities are being built or expanded to handle growing production out of the Gulf of Mexico and increasing business between regional hubs such as those located in the Midwest (Chicago) and the Northeast (Pennsylvania and New York). In these States alone, proposed (through 2001) increases in daily deliverability from storage sites that directly or indirectly support market or trading centers amount to $2.2 \mathrm{Bcf}$ per day, or 5 percent more than current levels.

The services and flexibility offered at natural gas market centers can be expected to be expanded and improved. The Chicago market center, for example, should grow as Canadian import and Southwest supplies (via the Henry Hub) expand into the area and much of this gas is redirected to the Northeast Region. The Leidy hub in Pennsylvania is the transaction and transfer point for several market centers serving the Northeast and can be expected to become key to moving gas from the Midwest to New England markets and other parts of the Northeast.

\footnotetext{
${ }^{95}$ Nevertheless, close scrutiny and detailed economic analyses by regulatory authorities will result in some projects being deemed unnecessary and thus not approved. The analyses are done in an effort to avoid, as much as possible, the burden of costs to future ratepayers that are associated with underutilized or uncompleted projects.
}

\footnotetext{
${ }^{96}$ Energy Information Administration, "U.S. Underground Storage of Natural Gas in 1997: Existing and Proposed," Natural Gas Monthly, DOE/EIA-0130(97/09) (Washington, DC, September 1997).
} 


\section{Access to Transportation Markets}

The physical capability of the U.S. natural gas pipeline network is only one part of transportation deliverability. Just as important is the contractual structure governing the flow of gas along the network and the shipper's access to pipeline capacity. Under Federal Energy Regulatory Commission (FERC) Order 636, which was implemented in November 1993, market participants must make their own arrangements for shipping gas. The contract serves as the service agreement for the level, quality, location (e.g., receipt and delivery points), and price for the transportation service.

Shippers can contract for several types of transportation services, including high-quality firm services, such as firm transportation and no-notice service, ${ }^{97}$ and those services subject to disruption, such as interruptible transportation and released capacity subject to recall. ${ }^{98}$ The types of services selected depend on the purpose for which the gas is being moved. For example, a local distribution company responsible for supplying the gas needs of residential and commercial customers is likely to have a greater share of its transportation under firm contracts than an industrial shipper that can use interruptible service or easily switch to an alternative fuel.

The value of a particular type of transportation service to a shipper will depend on where and when it is available, its cost, and how it fits into the shipper's overall portfolio of services. If a shipper needs to have natural gas delivered to a particular point next week, it would contract for service along a line that has the capacity and services available to make that delivery. Similar services along a pipeline segment in another area or for a different time period would not have the same value to the shipper. The availability of each type of transportation service depends on the physical capability of the pipeline network, how much of that capacity is reserved by shippers, the terms and types of the contracts in place, and the extent to which current contract holders use the system. ${ }^{99}$ All of these factors must be considered when assessing the overall deliverability of the pipeline transportation system.

\footnotetext{
${ }^{97}$ No-notice service is generally a combination of firm transportation and storage services used to re-create the quality of service that customers previously received through pipeline company sales service (see Glossary). It allows shippers to use their full capacity commitment without advanced scheduling.

${ }^{98} \mathrm{About} 40$ and 35 percent of the released capacity during the 1996 nonheating season and 1996-97 heating season, respectively, were not subject to recall and thus may be considered high-quality firm service.

${ }^{99}$ If current capacity holders do not nominate to the pipeline to use their capacity (see p. 81), the pipeline company may offer the unused capacity to other shippers.
}

This chapter provides a general picture of how shippers use the interstate transportation system and estimates the unused capability of the system, on the basis of data for a sample of 46 interstate pipeline companies that accounted for 97 percent of interstate transportation deliveries in 1996. The chapter examines how shippers reserve interstate pipeline capacity in today's marketplace and identifies how much capacity is controlled by primary shippers holding firm contracts. It also calculates capacity release levels to identify the portion of reserved capacity that may be accessed on the release market. Since the ownership of system capability does not necessarily indicate utilization, the volume of gas transported under firm and interruptible services is also studied to complete the picture of transportation market accessibility.

Other parts of the interstate natural gas delivery system can also influence the level of a customer's reliance on the transportation market, such as the type and availability of storage and hub services. While these services may supplement transportation services, they cannot fully substitute for supply-to-market transportation of natural gas. Therefore, the focus of this chapter is on the services used for long-haul transportation. In the chapter, capacity and capacity trading are measured on a heat content or Btu basis to be consistent with the units generally used in natural gas contracts.

\section{Estimating Capacity Availability}

A question that is often raised is how much of the existing pipeline transmission capacity is available to meet additional firm service demand. In this analysis, the estimated available capacity (unused firm service capability) of the current system to transport natural gas is considered the sum of the amounts of unreserved capacity, unused released capacity, and unused firm contracted capacity. The total capability of the system can be divided between the reserved or committed capacity and the unsubscribed capacity. A subset of the reserved capacity can be identified as capacity released to other shippers. Although a significant amount of pipeline capacity is used throughout the year, some remains unused. The relationship between capability and utilization is illustrated in Figure 20. This particular example is not derived from actual information and may not resemble the scale of services, capacity, and utilization on any specific pipeline system. However, the chapter uses the concepts displayed in Figure 20 to analyze shippers' ability to access transportation services on a regional and systemwide basis. 
Figure 20. Relationship of Capacity and Utilization

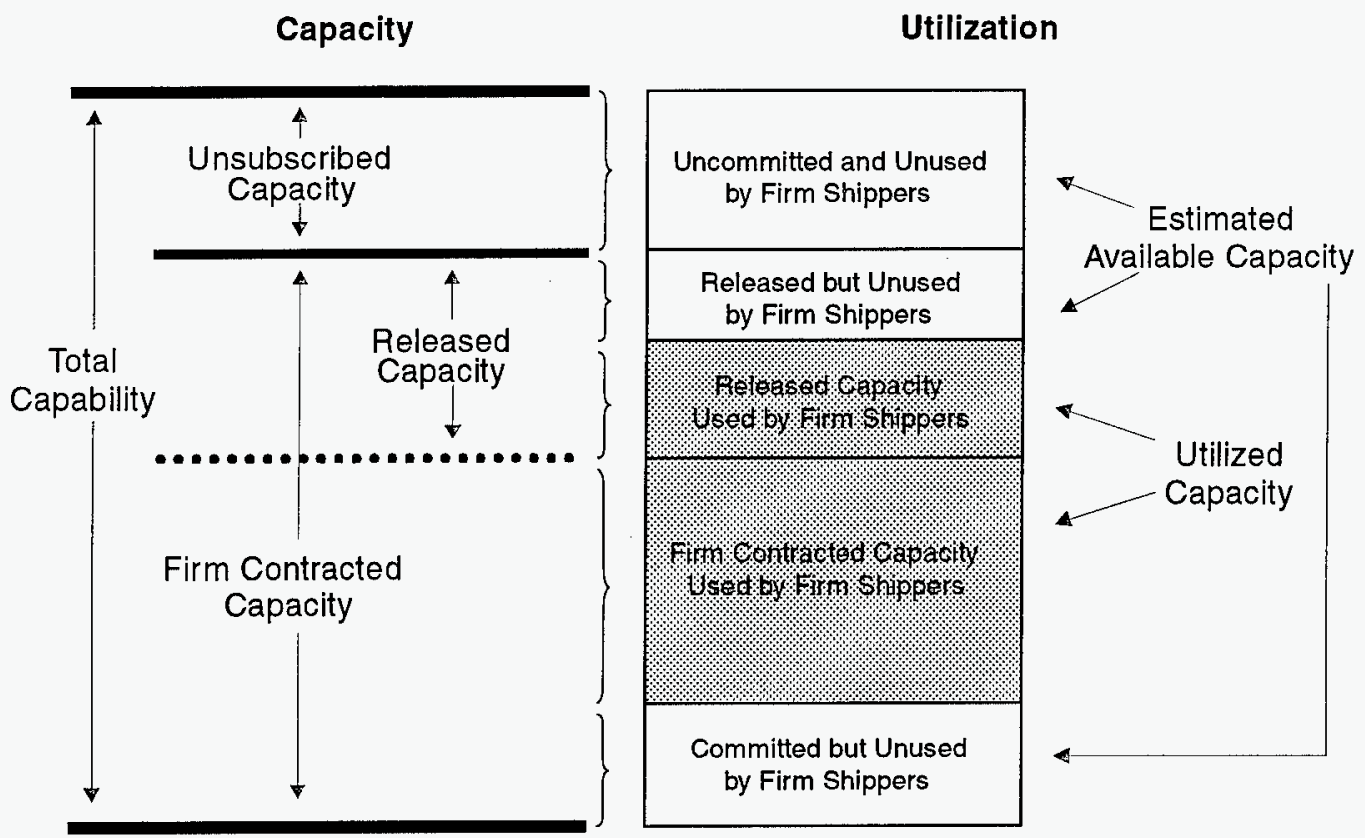

Note: A firm shipper is one using firm transportation services.

Source: Energy Information Administration, Office of Oil and Gas.

The maximum capability of the pipeline system is used in this analysis as the basis against which all other variables are measured to determine accessibility. The analysis uses a slightly different approach to determine maximum capability than that of Chapter 3, which estimates pipeline capacity on the basis of design throughput capability at State border crossings. ${ }^{100}$ This chapter considers maximum capability to be the ability of the system to satisfy the maximum market demands at the pipeline system delivery points. This measurement assumes that if a demand can be met at the delivery point, then the transportation system can move that volume of gas. ${ }^{101}$

In the analysis, the maximum transportation capability of the interstate pipeline system is estimated on the basis of capacity data for a sample of 46 major pipeline companies that accounted for 97 percent of interstate transportation deliveries in 1996. The sample was selected to ensure that adequate and

\footnotetext{
${ }^{100}$ Chapter 3 discusses the capability of pipeline systems to move gas from production to market areas. Therefore, system capability is estimated by measuring the amount of natural gas that can flow across State borders in a given day to determine the utilization of interregional transportation. It includes data only for those pipeline segments that reported gas flow.

${ }^{101}$ It should be noted that most pipeline companies' systems handle loads through a series of receipt and delivery points and that all gas received by the pipeline does not enter at a single point. Nor does a pipeline company deliver all its customers' maximum demands on the same day.
}

uniform data on peak-day and monthly transportation were available for each company. The estimated maximum capacity of each company was determined by choosing the largest reported.amount from the group of four sources of capacity information used in this analysis (see "Transportation System Access," Appendix D). ${ }^{102}$ A pipeline company was considered to be located in the region in which it delivered the most gas.

The sample pipeline companies have a total maximum capability of 127 trillion Btu per day (Table 14). Thus, theoretically, they could deliver more than 46 quadrillion Btu of gas annually, or almost 1.6 times the total gas transported by major interstate pipeline companies in 1996 . While this figure may provide a relatively good estimate for maximum capability, the extent to which shippers reserve and use this capacity provides a better indication of its availability.

\footnotetext{
${ }^{102}$ Several sources of information are used to develop a picture of transportation capability and use, including: annual capacity reports and accompanying Format 567, "System Flow Diagrams," filed annually with the Federal Energy Regulatory Commission (FERC) by major interstate pipeline companies under $18 \mathrm{CFR} \$ 284.12$ and $\$ 260.8$; FERC Index of Customers filing; FERC Form 2, "Annual Report of Major Natural Gas Companies"; FERC Form 11, "Natural Gas Pipeline Company Quarterly Statement of Monthly Data"; and Energy Information Administration, Office of Oil and Gas, Capacity Release Awards dataset. See Appendix D for more detailed information on data sources.
} 
Table 14. Reserved Firm Transportation Capacity by Region, July 1996 and January 1997

\begin{tabular}{l|c|c|c|c|c}
\hline \multirow{2}{*}{} & & \multicolumn{4}{|c}{ Firm Transportation Contracts } \\
\cline { 3 - 6 } & & \multicolumn{2}{|c|}{ As of July 1, 1996 } & \multicolumn{2}{c}{ As of January 1, 1997 } \\
\cline { 3 - 6 } Region & $\begin{array}{c}\text { Maximum Capability } \\
\text { (trillion Btu per day) }\end{array}$ & $\begin{array}{c}\text { Capacity } \\
\text { (trillion Btu per day) }\end{array}$ & $\begin{array}{c}\text { Concentration } \\
\text { Ratio } \\
\text { (percent) }\end{array}$ & $\begin{array}{c}\text { Capacity } \\
\text { (trillion Btu per day) }\end{array}$ & $\begin{array}{c}\text { Concentration } \\
\text { Ratio } \\
\text { (percent) }\end{array}$ \\
\hline Central & 16.6 & 13.7 & 82 & 16.0 & 96 \\
Midwest & 31.1 & 24.2 & 78 & 28.4 & 91 \\
Northeast & 44.2 & 33.4 & 76 & 37.1 & 84 \\
Southeast & 6.0 & 5.1 & 85 & 4.9 & 81 \\
Southwest & 12.6 & 5.9 & 47 & 6.2 & 49 \\
Western & 16.6 & 14.3 & 86 & 14.0 & 84 \\
$\quad$ U.S. Total & 127.0 & 96.6 & 76 & 106.6 & $\mathbf{8 4}$ \\
\hline
\end{tabular}

Note: Totals may not equal sum of components because of independent rounding.

Sources: Energy Information Administration (EIA), Office of Oil and Gas, derived from pipeline company reports filed with the Federal Energy Regulatory Commission (FERC): 1996 Peak-Day Capacity Report (18 CFR §284.12); Index of Customers (April 1, 1996-April 1, 1997); Format FERC 567, "System Flow Diagrams" (1995); and FERC Form 2, "Annual Report of Major Natural Gas Companies" (1996).

\section{Transportation Market Activity}

Shippers must first obtain capacity to effectuate movement of gas on a pipeline system. Therefore, all shippers must have access to the firm or interruptible capacity markets to meet their needs. There are three ways in which a shipper can obtain pipeline transportation service:

- Contract for firm transportation service. ${ }^{103}$ The shipper reserves a specific amount of capacity via a contract with the pipeline company.

- Contract for interruptible transportation service. Capacity that is not committed to firm transportation service or capacity that remains unused by the holder of firm transportation capacity may be offered by the pipeline as interruptible service. These contracts are typically for short periods of time. Changes in market conditions affect the size and availability of interruptible service.

- Obtain capacity via the capacity release market. A shipper with unused capacity for firm transportation service may choose to trade that capacity on the release market. The releasing shipper may or may not subject the capacity to recall, thereby making the service quality similar to interruptible or firm transportation service.

Once a shipper has a right to use capacity, it nominates, in writing or electronic form, the daily amount of gas it wants to be received, delivered, or stored by the pipeline company. The shipper nominates capacity at specific receipt and delivery points along the pipeline system. The nomination of daily volumes may be renewed or changed on a monthly, daily, or intraday basis and may be for any quantity up to the maximum daily quantity (MDQ) specified in the contract.

Next, the pipeline company confirms each shipper's nomination and inquires into any needed changes. Because there are many shippers making nominations, the pipeline company must look at the aggregate quantities and determine whether the pipeline system can tolerate the overall level of nominations during the confirmation process.

Once the pipeline company ascertains that the system can handle all shipper nominations, it schedules the gas, specifying gas flows in and out of each receipt and delivery point. The pipeline company determines priorities based upon type of service. For example, firm service will be scheduled ahead of interruptible service.

During the 1996-97 heating year (the 12 months ended March 31, 1997), on average 78 percent of physical capacity was committed to firm transportation contracts, according to pipeline company information filed with the Federal Energy Regulatory Commission. Although the amount of reserved capacity changes over time, particularly as the seasons change, the share of physical capacity committed to firm transportation service remained fairly constant during 1996 and 1997. A portion of the firm capacity, approximately 20 percent, was traded during the year to replacement

${ }^{103}$ Includes firm transportation service and no-notice service. 
shippers via the capacity release market. ${ }^{104}$ Interruptible service accounted for 16 percent of transportation throughput during the 1996-97 heating year. ${ }^{105}$

Activity in primary firm capacity markets, ${ }^{106}$ which include firm transportation, no-notice service, and sales service, ${ }^{107}$ has generally increased during the years since industry restructuring under FERC Order $636 .{ }^{108}$ Since 1992, the volume of gas transported using firm services has grown at an average rate of 9 percent per year. Transportation under firm services increased from 11.5 quadrillion Btu in 1992 to 16 quadrillion Btu in 1996. Since its inception in 1993, the capacity release market has also grown dramatically. Although release activity declined slightly in 1996, it still represented 16 percent of the gas delivered for market at 3.6 quadrillion Btu. Unlike the firm and release markets, the interruptible transportation market has consistently declined since 1992 . In 1996 only 2.9 quadrillion Btu was moved by interruptible transportation compared with 8.3 quadrillion Btu in 1992.

On the surface these results might imply that capacity markets are getting tighter, thus, squeezing out the nonfirm capacity market. However, transportation activity under various services provides only part of the story behind transportation market accessibility. In addition to throughput levels, the pipeline system's level of unsubscribed capacity must also be considered. For example, a pipeline system may have enough excess capacity to create a discounted firm transportation service that competes with interruptible transportation. Likewise, deliverability on the U.S. pipeline system is as much a product of availability as it is physical capacity. All the physical space on a pipeline system may be reserved under contract (fully subscribed), but if the reserved space is not in use by the firm shipper, it may be accessed by another shipper using interruptible or short-term firm service offered by the pipeline company. The underutilization of the pipeline system may also promote a strong market for released capacity. Therefore, all of these components should be reviewed to characterize the availability and accessibility of various transportation services.

\footnotetext{
${ }^{104}$ Includes capacity subject to recall and that not subject to recall.

${ }^{105}$ Based on information compiled by the Energy Information Administration from FERC Form 11, "Natural Gas Pipeline Company Quarterly Statement of Monthly Data" (1996).

106"Primary" refers to firm service obtained directly from the pipeline company.

${ }^{107}$ The volume of gas moved under pipeline company sales service has been virtually zero since 1995 .

${ }^{108}$ Interstate Natural Gas Association of America (INGAA), Gas Transportation Through 1996 (May 1997).
}

\section{Firm Transportation Service}

As previously discussed, most gas deliveries in 1996 were under firm transportation contracts. Shippers may elect to contract for firm transportation service on an annual or seasonal basis. With a firm transportation contract, the shipper may reserve, what it estimates to be, the highest demand it will incur on the pipeline system on any given day. ${ }^{109}$ Correspondingly, the pipeline company agrees to make that amount of capacity available to the shipper on a daily basis.

Pipeline companies disclose the amount of capacity reserved by each firm customer in the quarterly Index of Customers filing to the FERC. For each firm contract that is effective the first day of the calendar quarter, pipeline companies are required to provide: the name of the shipper, the amount of capacity reserved, the rate schedule under which service is provided, the beginning and ending dates of the contract, and whether the contract contains a rollover clause. The Index of Customers' filing provides the measurement of the reserved portion of the pipeline company's system capacity.

Data from these quarterly filings indicate that a large amount of pipeline capacity is reserved under firm contracts (Figure 21). In fact, the reservation concentration ratios-the percentage of maximum capability that is under a firm service contract- for the nonheating season (April through October) range from 76 to 86 percent in five of the six regions. The exception lies in the Southwest Region, which has a subscription rate of only 47 percent (Table 14). Subscription rates increased significantly during the heating season in the Central (from 82 to 96 percent), Midwest (from 78 to 91 percent), and Northeast (from 76 to 84 percent) regions, while all other regions experienced little change in reservation concentration between seasons.

Concentration ratios in the Southwest are lower than in the other regions because of the abundance of capacity on several production-oriented pipelines located in the region. Excluding these pipeline companies from the analysis would increase the concentration ratios in the Southwest from 47 to 73 percent for the nonheating season and from 49 to 77 percent for the heating season. However, removing these companies from the sample would not significantly alter the national concentration ratios; the ratios for the nonheating and heating seasons as well as the heating year would increase by 3 percentage points to 79,87 , and 81 percent, respectively.

\footnotetext{
${ }^{109} \mathrm{~A}$ few pipeline companies allow customers to elect different amounts of service for the heating and non-heating seasons. This enables a heating load customer to subscribe to the required winter capacity without holding unneeded capacity in the summer.
} 
Figure 21. Concentration of Reserved Firm Capacity by Region, April 1996 - April 1997

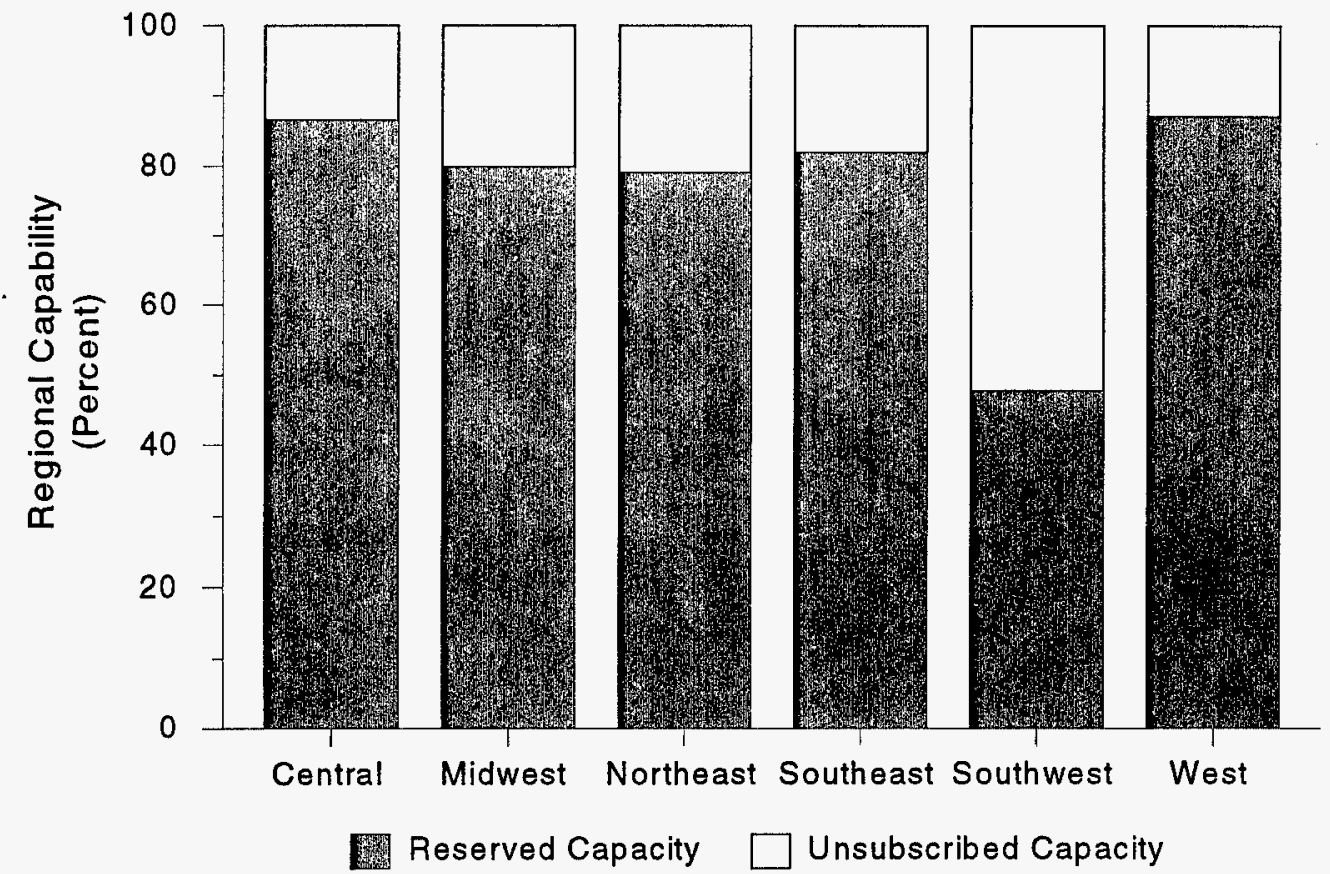

Note: Includes contracts for no-notice and firm transportation services.

Sources: Energy Information Administration (EIA), Office of Oil and Gas, derived from pipeline company reports filed with the Federal Energy Regulatory Commission (FERC): 1996 Peak-Day Capacity Report (18 CFR \$284.12); Index of Customers (April 1, 1996-April 1, 1997); Format FERC 567, "System Flow Diagrams" (1995); and FERC Form 2, "Annual Report of Major Natural Gas Companies" (1996).

Since shippers base their contracted amounts on their maximum demand for any given day, they will frequently have unused capacity during the course of a year. In addition, the average price of firm capacity tends to be high because of the cost classification and allocation methods used by the Federal Energy Regulatory Commission to determine maximum transportation rates. Shippers pay to reserve capacity whether it is used or not. Primary firm shippers frequently release their unused capacity to mitigate the high reservation charges.

\section{Capacity Release Market}

The capacity release market, established under FERC Order 636 , provides shippers a method to resell unused capacity on either a prearranged or open bid basis. ${ }^{110}$ Release transactions take place when a primary shipper places a notice on the

\footnotetext{
${ }^{110}$ Releasing shippers have the option of (1) prearranging a release for 1 month or less or for any length of time at maximum costs, or (2) posting a notice of capacity availability on the pipeline company's electronic bulletin board for open bidding.
}

pipeline company electronic bulletin board ${ }^{111}$ that it has available capacity. ${ }^{12}$ Interested parties then submit sealed bids to the pipeline company, which evaluates the bids and selects the winning replacement shipper based on selection criteria approved by the releasing shipper. This mechanism provides prospective shippers' access to firm capacity that otherwise may not have been available.

The growth in the capacity release market indicates that shippers are embracing this capacity trading system. The amount of capacity held daily by replacement shippers has grown significantly since the beginning of the capacity release market (Figure 22). The amount of capacity held by replacement shippers during the 12-month period ending March 1997 totaled 7.4 quadrillion Btu, a 22-percent increase over the previous 12-month period and almost double the level for the 12 months ending March 1995 (Figure 23).

\footnotetext{
${ }^{111}$ FERC Order 587-B (Docket RM 96-1-003) required that pipeline companies begin offering capacity release and other transactions through their Internet sites by June 1997.

${ }^{112} \mathrm{~A}$ primary shipper may release all or part of its capacity on a long-term or short-term basis and receive credit from the release to its pipeline company account.
} 
Figure 22. Growth in the Capacity Release Market, November 1993 - March 1997

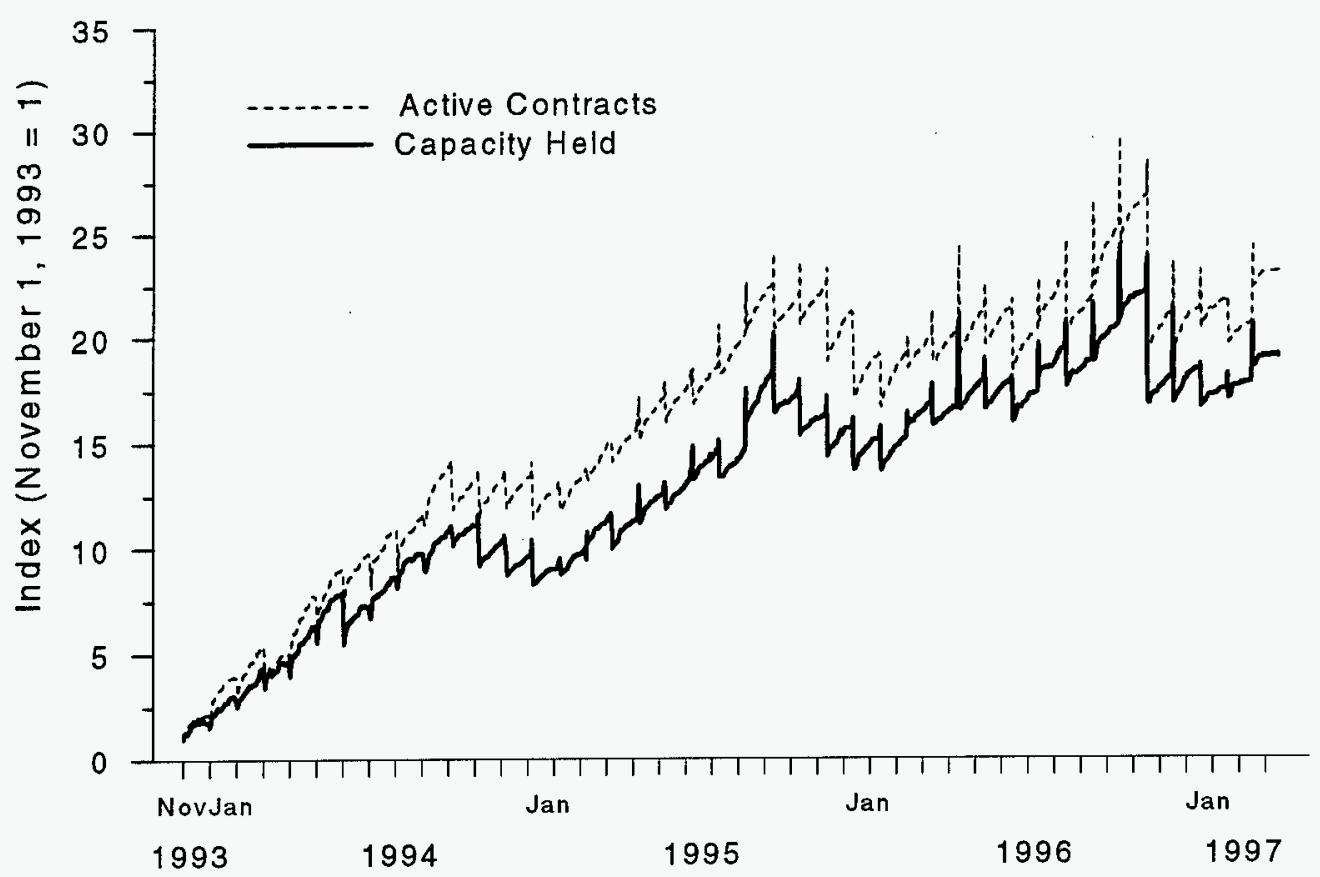

Source: Energy Information Administration, Office of Oil and Gas, derived from: November 1993 - July 1994: Pasha Publications, Inc. July 1994 - March 1997: Federal Energy Regulatory Commission, Electronic Data Interchange (EDI) data.

Figure 23. Capacity Held by Replacement Shippers, by Region and Heating Years, 1994-95 - 1996-97

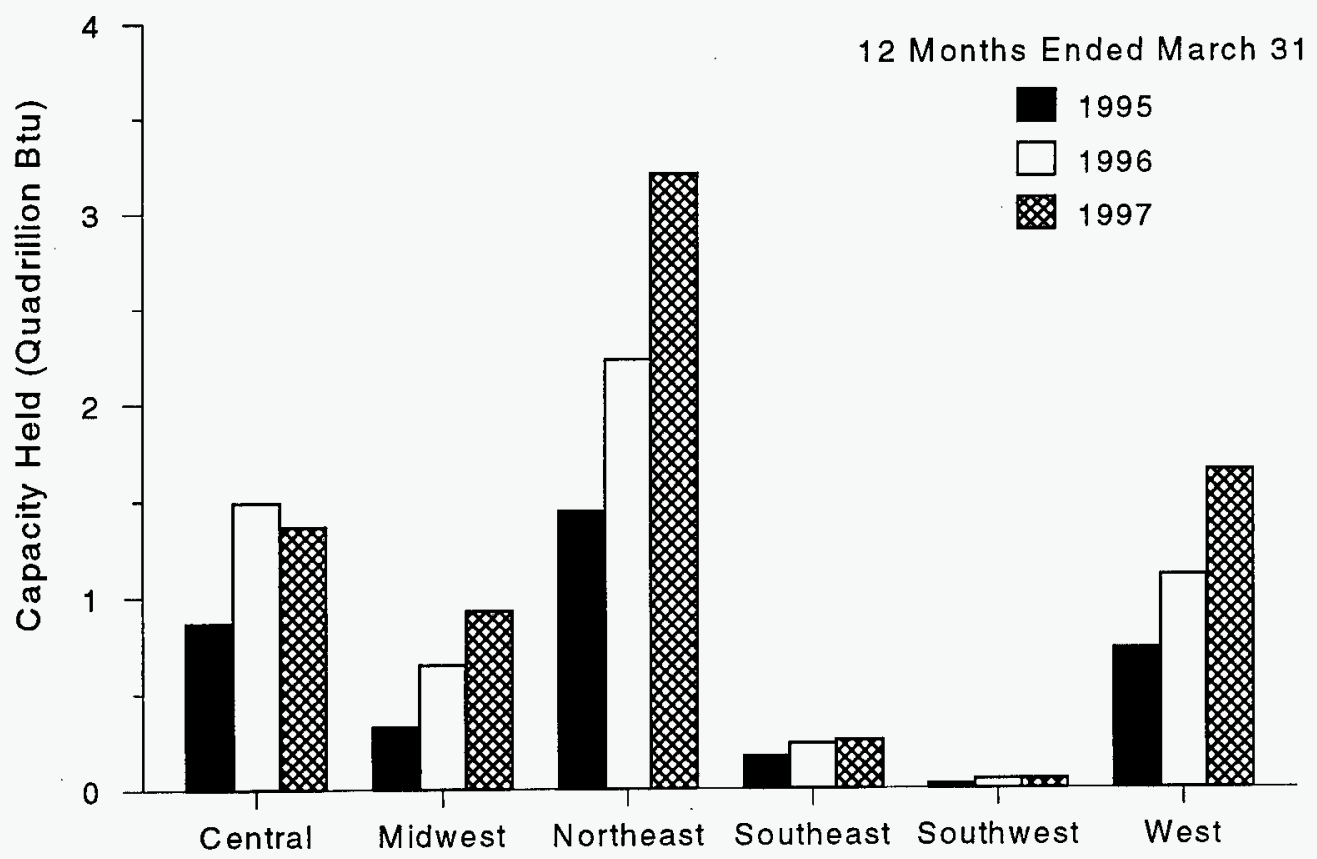

Source: Energy Information Administration, Office of Oil and Gas, derived from Federal Energy Regulatory Commission, Electronic Data Interchange (EDI) data. 
The activity in the capacity release market provides a measure of the reserved capacity that is unused by the primary shipper and is of value to the replacement shipper. The most comprehensive information available on the release market concerns data on capacity that is awarded to replacement shippers. While actual utilization cannot be accurately determined, a substantial amount of gas could be transported by use of released capacity. For example, if all the capacity held by replacement shippers (Figure 24) were fully utilized, 36 percent of the 20.4 quadrillion Btu of gas delivered to consumers during the 12 months ended March 31, 1997, could have moved under released capacity.

The amount of capacity held by replacement shippers ${ }^{113}$ generally declines during the heating season, but it still represents a sizeable amount. Based on capacity held, replacement shippers could have moved 28 percent of the 10.4 quadrillion Btu of gas delivered to consumers during the 1996-97 heating season by using released capacity. These levels of released capacity are not shared equally among all of the U.S. regions. The Northeast, which had 44 percent of the capacity held by replacement shippers, led other regions in the amount of capacity awarded during the year ended March 31, 1997 (Figures 23 and 24). The Southwest had the least amount of capacity awards in a region; less than 1 percent of the capacity held by replacement shippers occurred on pipeline companies that primarily serve the Southwest Region (Figure 24). Although the amount of capacity awarded varied between the heating and nonheating seasons, the regional proportion of capacity held by replacement shippers was essentially the same as that for the 12-month period ended March 1997.

Data from April 1994 through March 1997 indicate that the capacity release market provides a significant amount of access to transportation service in many areas of the United States. However, these data do not indicate whether these levels of capacity awards will be sustained or increase. There are indications that the market for released capacity in some regions may be maturing while considerable growth may continue in other regions. For example, the Northeast Region, in addition to having the highest level of awarded capacity, is experiencing substantial growth in the market for released capacity. The amount of capacity held in the Northeast increased by 977 trillion Btu, or 44 percent, between the 1995-96 and 1996-97 heating years (Figure 23).

\footnotetext{
${ }^{113}$ The total volume of released capacity held by replacement shippers during a season is the sum of the capacity effective on each day of the season. For example, if a 60-day contract for $Z$ thousand cubic feet per day is effective within a season, then the sum of capacity held for the season would include $Z$ thousand cubic feet 60 times for that contract. If that 60 -day contract were only effective, for example, for the last 20 days of the season, then the sum for the season would include $Z$ thousand cubic feet 20 times, and the sum for the next season would include $Z$ thousand cubic feet 40 times for that contract.
}

The West and Midwest regions also experienced significant percentage increases over their 1995-96 levels, although the capacity amounts are less than those of the Northeast Region. The amount of capacity held by replacement shippers in the West during the 1996-97 heating year increased by almost 50 percent over the 1995-96 level. The 50-percent increase was the result of an additional 542 trillion Btu of capacity held in the West Region during 1996-97. The capacity held by replacement shippers in the Midwest Region in 1996-97 increased by 280 trillion Btu, or 43 percent over the 1995-96 level.

In contrast to the Northeast, West, and Midwest regions, the Central and Southwest regions experienced declines in capacity release activity. In the Central Region, the amount of capacity held by replacement shippers decreased by 9 percent (128 trillion Btu) from the 1995-96 heating year level and the number of capacity awards decreased by 52 percent (1,911 fewer awards). While the declines in the Southwest were not as large as those in the Central in absolute terms, they still represented significant percentage reductions for the regions (Figure 23).

The reduction in capacity release awards in certain regions may not necessarily indicate a lack of available capacity in those regions. For example, in the past few years the Southwest has experienced a series of capacity turnbacks in which primary shippers notified the pipeline companies of their intent to reduce the amount of firm capacity reserved on the systems. While the settlements in these cases resulted in an allocation of the turnback costs among the parties, much of the physical space of the pipeline systems was no longer reserved. The shippers that turned back the capacity would not have as much excess capacity to release on the market; however, it would not affect the total capability on the pipeline system. Since this excess capacity is no longer reserved, shippers may be able to deliver more gas using interruptible transportation service.

\section{Interruptible Transportation Service}

A look at the utilization of interruptible service provides the perspective needed to complete an assessment of transportation deliverability. While amounts vary throughout the year and across regions, interruptible service represents a relatively constant share of national transportation throughput (Figure 25). More than 4,700 trillion Btu (TBtu) of gas was transported by use of interruptible service during the 1996-97 heating year (the 12 months ended March 31, 1997), representing 16 percent of the 29,135 TBtu total transportation throughput. 
Figure 24. Capacity Held by Replacement Shippers During the Nonheating and Heating Seasons, by Region

(Trillion Btu)

1996 Nonheating Season (April - October)

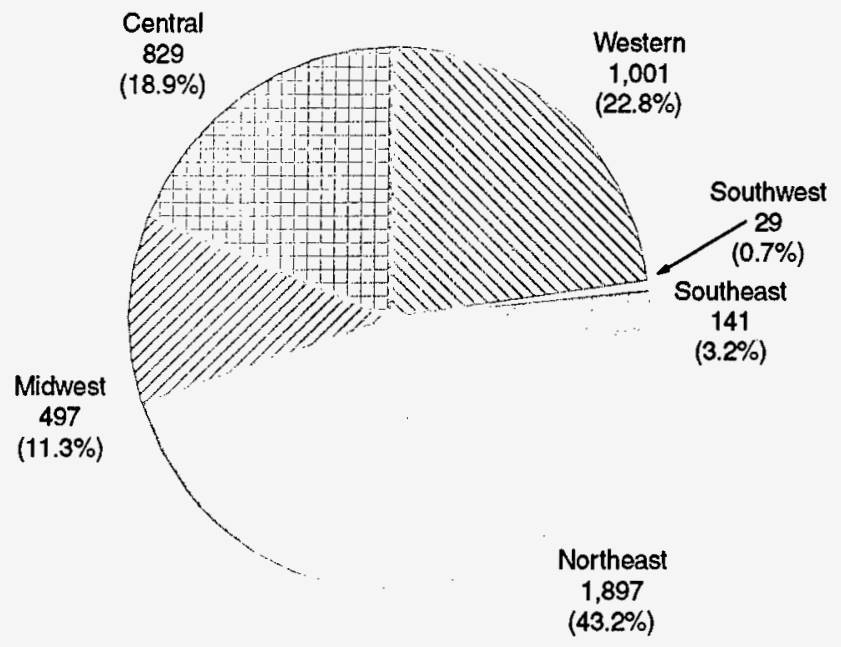

Total $=\mathbf{4 , 3 9 5}$ trillion Btu
1996-97 Heating Season (November - March)

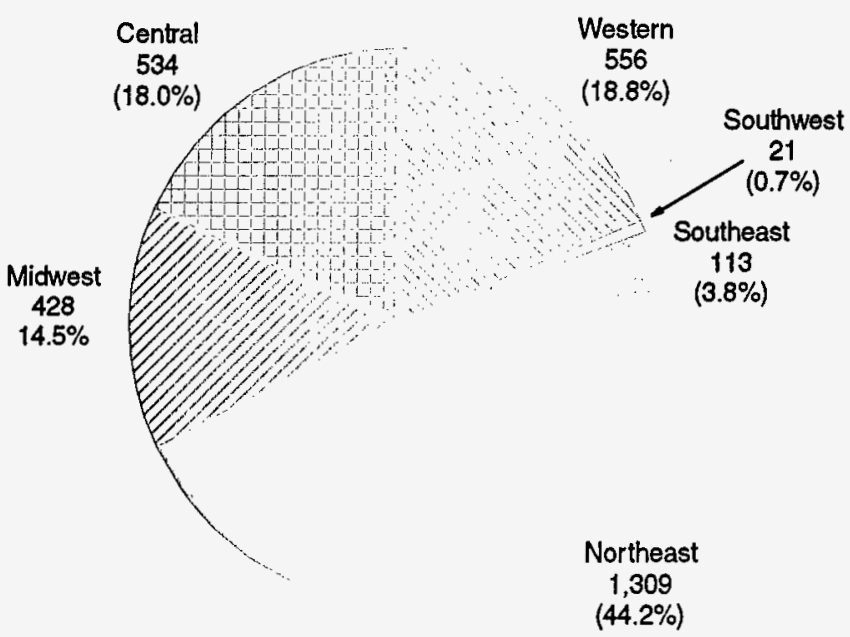

Total $=2,960$ trillion Btu

Total 1996-97 Heating Year $=7,355$ trillion Btu

Source: Energy Information Administration, Office of Oil and Gas, derived from Federal Energy Regulatory Commission, Electronic Data Interchange (EDI) data.

Figure 25. Natural Gas Pipeline Throughput Under Firm and Interruptible Service, January 1996 - September 1997

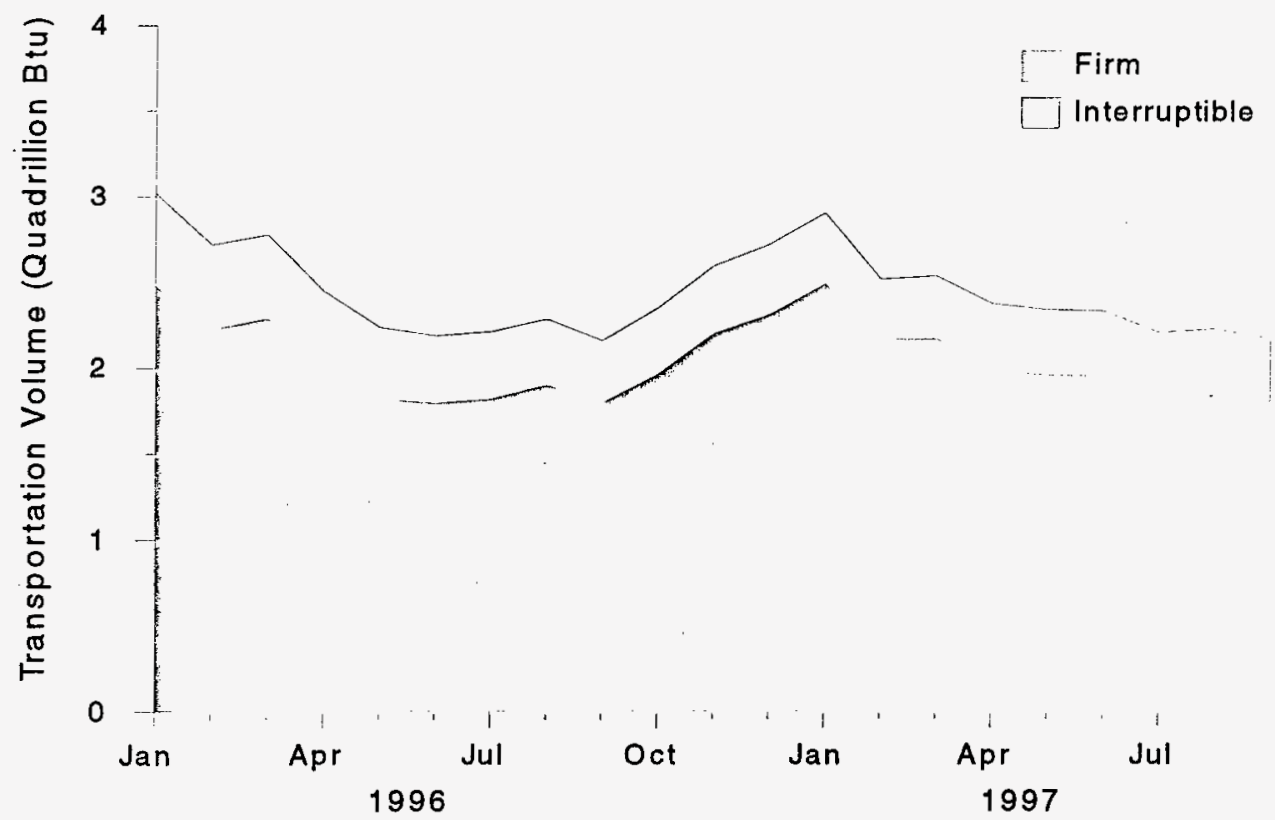

Note: Throughput volumes exclude natural gas transported for storage.

Source: Energy Information Administration, Office of Oil and Gas, derived from Federal Energy Regulatory Commission, FERC Form 11, "Natural Gas Pipeline Company Quarterly Statement of Monthly Data." 
Even during the heating season, when capacity is more apt to be constrained, almost 2,000 TBtu, or 15 percent, of gas moved under interruptible service. The share of interruptible service during the 1996-97 heating year varied across regions from a low of 7 percent of total transportation in the West to a high of 49 percent in the Southwest. The significant use of interruptible service clearly indicates that it represents a viable service option for shippers. Based on a 100-percent load factor, interruptible service represented an average daily capacity of about $13 \mathrm{TBtu}$ per day for the sample pipeline companies.

The future availability and use of interruptible service will in large part depend on the contracting practices of shippers. As the transportation market matures, terms or lengths of contract agreements may become shorter. The likelihood that contracts will be terminated upon reaching their expiration date will depend largely on the type, options, and requirements of the shipper holding the contract.

\section{Characteristics of Firm Capacity Held by Different Types of Shippers}

Shippers will contract for firm pipeline capacity for different quantities and terms, depending on the purpose for which the gas is being moved. For example, a local distribution company that is responsible for supplying the gas needs of core residential and commercial customers is likely to have a greater share of its transportation under firm contracts than an industrial shipper that can use interruptible service or easily switch to an alternate fuel. As another example of how shipper's needs differ, an industrial company, with welldefined and steady requirements for natural gas, may have contracts with longer terms than those of a marketer who values flexibility and needs to offer service to many types of customers.

To examine these and other characteristics of firm capacity, shippers were classified according to six different categories: $:^{114}$

- Electric utilities (including combination electric and natural gas utilities for which natural gas is the primary or alternative source of fuel for generating electricity)

\footnotetext{
${ }^{114}$ The Index of Customers lists only the names of shippers without identifying the company types. Thus, shipper types were identified by Energy Information Administration (EIA) staff by cross-referencing shipper names with other information sources and through Internet searches (see Appendix D).
}

- Industrial companies (including independent power producers, cogenerators, and commercial firms)

- Local distribution companies (including intrastate pipeline companies and combination electric and natural gas utilities for which natural gas is not the primary or alternative source of fuel for generating electricity)

\section{- Marketers}

- Interstate pipeline companies

- Other (including producers, gatherers, and other companies).

Differences between these types of shippers were then examined, focusing on the data for April 1, 1997. The findings include:

- Local distribution companies (LDCs) held the largest portion of firm capacity, 44 percent. This was more than twice that of the next largest portion held by electric utilities.

- Virtually all (96 percent) of the firm capacity was held under long-term contracts (those with terms of 1 year or more).

- The average lengths of the long-term contracts ranged from 6.7 years for marketers to 11.9 years for pipeline companies.

- Marketers held 75 percent of the firm capacity under short-term contracts (those with terms of less than 1 year), while LDCs held the largest proportion of capacity under long-term contracts, 46 percent.

- The average size of long-term contracts varied widely, from 57.0 billion Btu per day per contract for pipeline companies to 7.6 billion Btu per day for industrial shippers.

- The greatest shares of total firm capacity were held in the Northeast (36 percent) and the Midwest ( 25 percent). LDCs held the largest proportion of firm capacity within each region except for the Western Region, where marketers held the largest share.

- New contracts that became effective April 1, 1996, through April 1, 1997, accounted for 31 percent more firm transportation capacity than was associated with contracts that expired during the period. 


\section{Capacity and Contract Terms}

Shippers held 101 trillion Btu per day of firm capacity on April 1, 1997, based on the sample of pipeline companies examined in this analysis (Table 15). ${ }^{115}$ The sample includes 63 interstate pipeline companies, 17 more than in the analysis of transportation system access presented earlier in the chapter. LDCs accounted for the largest portion of this capacity, 44 percent (Figure 26), more than twice that of the next largest portion, 21 percent, which was held by electric utilities.

Industrial companies had the smallest share of firm capacity, 5 percent, but industrial companies probably had indirect access to more firm capacity than is implied by this statistic. As end users, industrial companies are likely to have had access to other firm capacity through contracts with marketers and LDCs or any of the other types of shippers listed. Consider that in 1996, 5.5 quadrillion Btu of natural gas consumed by industrial companies was delivered under firm contracts. ${ }^{16}$ Assuming a 100 -percent load factor, this is equivalent to an average of 15 trillion Btu per day. On April 1, 1997, industrial companies held just over 5 trillion Btu per day in firm capacity, which is only about one-third the amount of actual firm consumption in 1996. One must use caution when making direct comparisons between consumption and capacity because companies must often reserve capacity on different segments of a pipeline even though not all segments are used for every delivery of natural gas. Still, even this rough comparison shows that industrial companies use more firm gas supplies than can be provided through the firm capacity contracts they own directly.

The relative shares of firm capacity held by shippers are similar whether it is the middle of the winter, when demand for natural gas for space heating is high, or in the summer, when capacity is more readily available and a shipper could more likely receive interruptible service. On January 1, 1997, LDCs held 43 percent of total firm capacity, and industrial users held only 5 percent (total firm capacity was 108 trillion Btu per day). On July 1, 1997, LDCs held 42 percent and industrials held 6 percent of firm capacity (which totaled 94 trillion Btu per day).

Almost all of the firm capacity held by shippers on April 1, 1997, 96 percent, was held under long-term contracts (1 year

\footnotetext{
${ }^{115}$ The 63 pipeline companies included in this sample are those companies that file Index of Customers (IOC) information with the Federal Energy Regulatory Commission for which there was complete and consistent information for each of the quarters from April 1, 1996, to April 1, 1997. This resulted in the exclusion of data for eight companies that file IOC information.

${ }^{116}$ Energy Information Administration, Natural Gas Annual 1996, DOE/EIA-0131(96) (Washington, DC, September 1997), Table 22.
}

or longer). The overall average length of these contracts for all shippers was 9.1 years. The distribution of long-term capacity among the different types of shippers was almost identical to that of total capacity-LDCs held the most, 46 percent, followed by electric utilities, which held 21 percent, and industrials held the least, 5 percent.

The average lengths of these long-term contracts were quite varied among the different types of shippers (Figure 27). Average terms ranged from 6.7 years for marketers, reflecting their need for flexibility, to 11.9 years for pipeline companies. Pipeline companies held a relatively small amount of the total firm capacity, 6.6 trillion Btu, or 7 percent of the total. They typically reserve capacity on other pipeline systems to assist in the operational control of natural gas flows on their own systems. ${ }^{117}$ Most pipeline companies have had decades of experience in moving large volumes of gas. Their capacity requirements are fairly stable over time and they are thus able to benefit from longer length contracts. The average length of long-term firm contracts held by LDCs, which had the largest proportion of capacity, was 9.7 years.

The characterization of what type of shipper holds capacity changes dramatically for short-term contracts (less than 1 year long). Here, marketers held the overwhelming amount of short-term capacity, 75 percent. The next largest share was only 8 percent held by shippers in the "Other" category. Industrial companies again held 5 percent of capacity, but in this case they were only the second smallest group. Pipeline companies held no short-term capacity at all. The 6.6 trillion Btu per day of firm capacity held by pipeline companies was all long term. ${ }^{118}$

The average length of short-term contracts was 3.5 months and ranged from 2.2 to 4.0 months among the different types of shippers. Marketers, with the largest volume, have the longest average term and industrials, the shortest. Even with the predominant role played by marketers in the area of shortterm contracts, marketers still had 81 percent of their total firm capacity of 17.5 trillion Btu per day under long-term contracts as of April 1, 1997.

There are seasonal variations in the average length of shortterm contracts held by some types of shippers. For example, as of January 1, 1997, a date toward the middle of the heating season, both electric utilities and marketers held short-term firm capacity contracts that averaged just over 5 months in length, matching the length of the heating season. As of

\footnotetext{
${ }^{117}$ Pipeline companies also retain control over a certain amount of capacity on their own systems for purposes of operational control. These capacity amounts are not part of the data contained in the Index of Customers because pipeline companies are not considered to be shippers on their own systems.

${ }^{118}$ Pipeline companies did hold short-term capacity contracts in all the other 3-month periods examined for this study.
} 
Table 15. Characteristics of Firm Contract Capacity as of April 1, 1997, by Shipper

\begin{tabular}{|c|c|c|c|c|c|c|c|c|c|}
\hline \multirow[b]{2}{*}{ Shlpper Type } & \multicolumn{3}{|c|}{ All Contracts } & \multicolumn{3}{|c|}{ Long-Term Contracts ${ }^{a}$} & \multicolumn{3}{|c|}{ Short-Term Contracts ${ }^{b}$} \\
\hline & $\begin{array}{c}\text { Capacity } \\
\text { (trillion Btu } \\
\text { per day) }\end{array}$ & $\begin{array}{c}\text { Number } \\
\text { of } \\
\text { Contracts }\end{array}$ & $\begin{array}{c}\text { Average } \\
\text { Term } \\
\text { (years) }\end{array}$ & $\begin{array}{c}\text { Capacity } \\
\text { (trillion Btu } \\
\text { per day) }\end{array}$ & $\begin{array}{c}\text { Number } \\
\text { of } \\
\text { Contracts }\end{array}$ & $\begin{array}{c}\text { Average } \\
\text { Term } \\
\text { (years) }\end{array}$ & $\begin{array}{c}\text { Capacity } \\
\text { (trillion Btu } \\
\text { per day) }\end{array}$ & $\begin{array}{c}\text { Number } \\
\text { of } \\
\text { Contracts }\end{array}$ & $\begin{array}{c}\text { Average } \\
\text { Term } \\
\text { (months) }\end{array}$ \\
\hline Electric Utility & 20.7 & 645 & 10.1 & 20.4 & 620 & 10.5 & 0.2 & 25 & 2.6 \\
\hline Industrial & 5.5 & 739 & 7.1 & 5.3 & 690 & 7.6 & 0.2 & 49 & 2.2 \\
\hline LDC & 44.2 & 2,544 & 9.5 & 43.9 & 2,486 & 9.7 & 0.3 & 58 & 3.5 \\
\hline Marketer & 17.5 & 938 & 5.1 & 14.2 & 704 & 6.7 & 3.3 & 234 & 4.0 \\
\hline Other ${ }^{c}$ & 6.4 & 349 & 7.7 & 6.1 & 293 & 9.1 & 0.3 & 56 & 2.6 \\
\hline Pipeline Company & 6.6 & 115 & 11.9 & 6.6 & 115 & 11.9 & 0.0 & 0 & NA \\
\hline Total & 100.8 & 5,330 & 8.4 & 96.4 & 4,908 & 9.1 & 4.4 & 422 & 3.5 \\
\hline
\end{tabular}

aLong-term contracts are for 1 year or longer.

'Short-term contracts are for less than 1 year.

'Other includes producers, gatherers, and those shippers for which a category could not be determined.

$\mathrm{LDC}=$ Local distribution company. NA = Not available.

Note: Totals may not equal sum of components because of independent rounding.

Source: Energy Information Administration, Office of Oil and Gas, derived from Federal Regulatory Energy Commission (FERC) Index of Customers.

Figure 26. Share of Total Firm Capacity Held on April 1, 1997, by Type of Shipper (Capacity in Trillion Btu per Day)

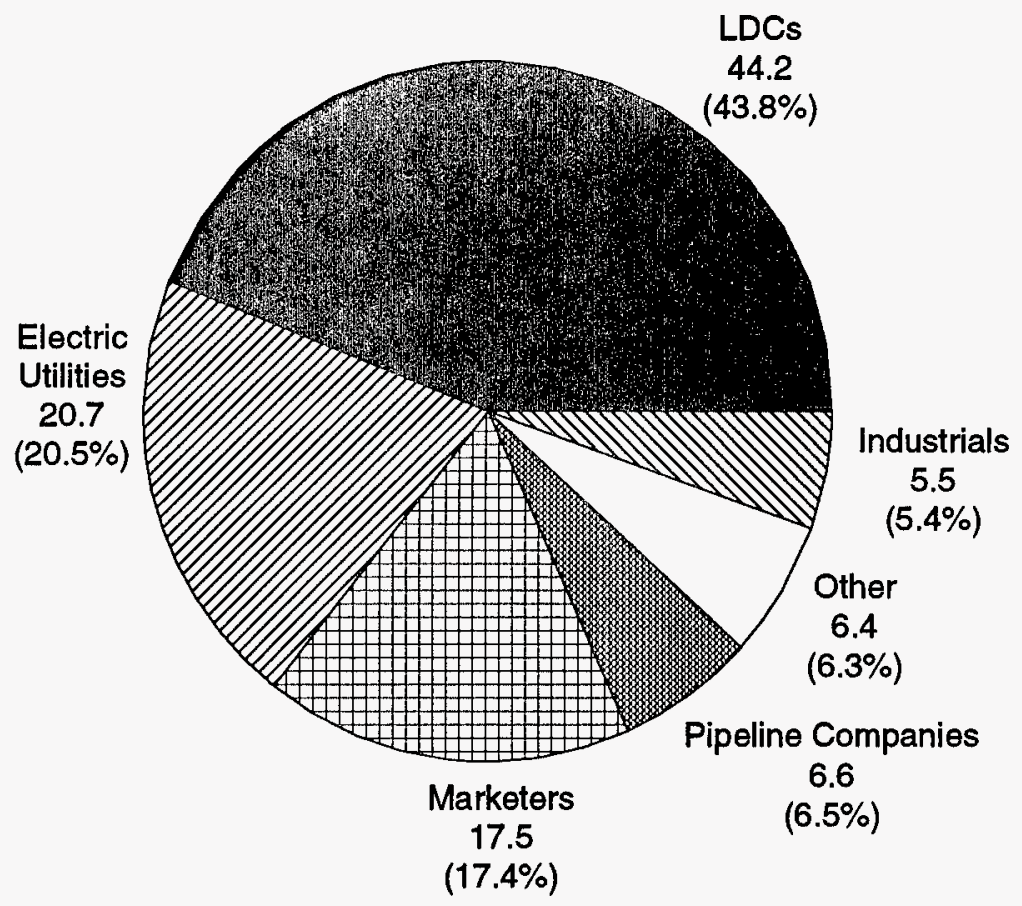

Total firm capacity is 101 trillion Btu

LDC = Local distribution company.

Note: Sum of percentage does not equal 100 percent because of independent rounding.

Source: Energy Information Administration, Office of Oil and Gas, derived from Federal Energy Regulatory Commission (FERC) Index of Customers. 
Figure 27. Average Length of Long-Term Firm Contracts as of April 1, 1997

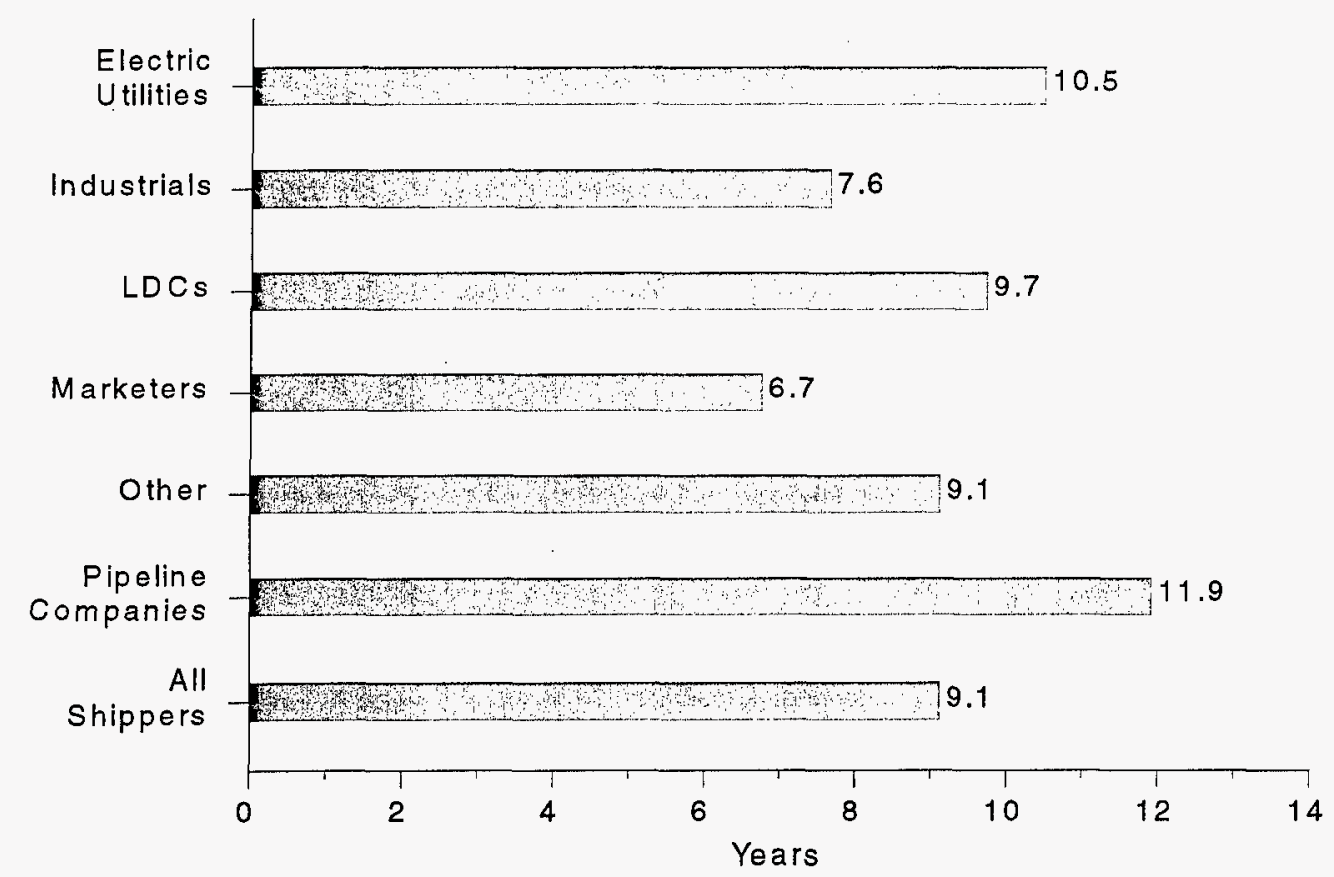

LDC $=$ Local distribution company.

Note: Long-term contracts are for 1 year or longer.

Source: Energy Information Administration, Office of Oil and Gas, derived from Federal Energy Regulatory Commission (FERC) Index of Customers.

April 1, 1997, the beginning of the refill season, the average length of short-term contracts fell to 2.6 months for electric utilities and to 4.0 months for marketers (Figure 28).

The average length of short-term contracts declined between January and April because of the increased proportion of contracts with terms of 1 month or less as the heating season ended. For example, as of January 1, 1997, electric utilities did not hold any short-term capacity under contracts that were for terms of 1 month or less; however, as of April 1, 1997, 38 percent of their total short-term capacity was under 30-day contracts. The situation is similar for marketers, who on January 1,1997 , held only 6 percent of short-term capacity under contracts for 1 month or less but held 25 percent of their short-term capacity under such contracts on April 1, 1997.

Total capacity held by different types of shippers provides one view of the firm capacity market, but the average capacity per contract provides another view of the contracting practices of firm shippers. For all types of shippers, the average amount of capacity under long-term contracts is much larger than under short-term contracts, reflecting the general use of short-term firm capacity to meet incremental loads or to meet unexpected demand.
When considering the long-term contracts, LDCs held the greatest total amount of firm daily capacity, yet the average capacity per contract for LDCs was much lower than for either pipeline companies or electric utilities (Figure 29). Also, the average daily capacity of LDC contracts, 17.7 billion Btu, was close to, but still smaller than that of contracts held by both marketers and companies in the Other category. Pipeline companies held the highest capacity longterm contracts, averaging 57.0 billion Btu per day per contract. Even though pipeline companies held a relatively small proportion of total firm capacity, the large amount of capacity per contract may reflect their role as movers of large volumes of gas from producing to consuming areas of the country. Electric utilities held the second highest capacity contracts, averaging 33.0 billion Btu per day per contract. The smallest contracts, averaging 7.6 billion Btu per day each, were held by industrial companies.

\section{Regional Shipper Characteristics}

Shippers hold the most firm capacity in those regions with larger populations and colder temperatures and that are farthest away from both domestic and Canadian sources of supply-the Northeast and the Midwest. LDCs, which are 
Figure 28. Average Length of Short-Term Firm Contracts, January and April 1997

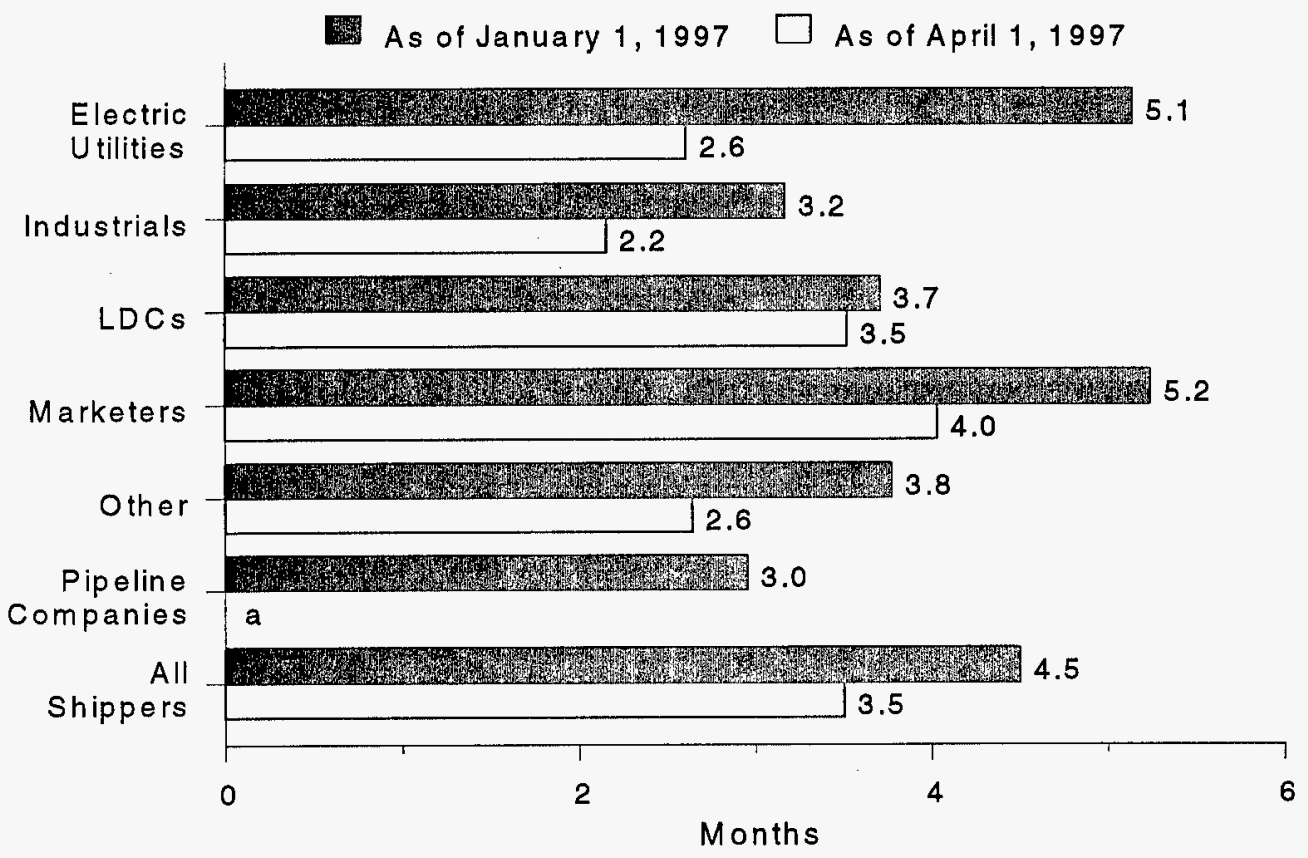

aPipeline companies did not have any contracts for short-term, firm capacity on April 1, 1997.

$L D C=$ Local distribution company.

Note: Short-term contracts are for less than 1 year.

Source: Energy Information Administration, Office of Oil and Gas, derived from Federal Energy Regulatory Commission (FERC) Index of Customers.

Figure 29. Average Firm Capacity per Contract as of April 1, 1997

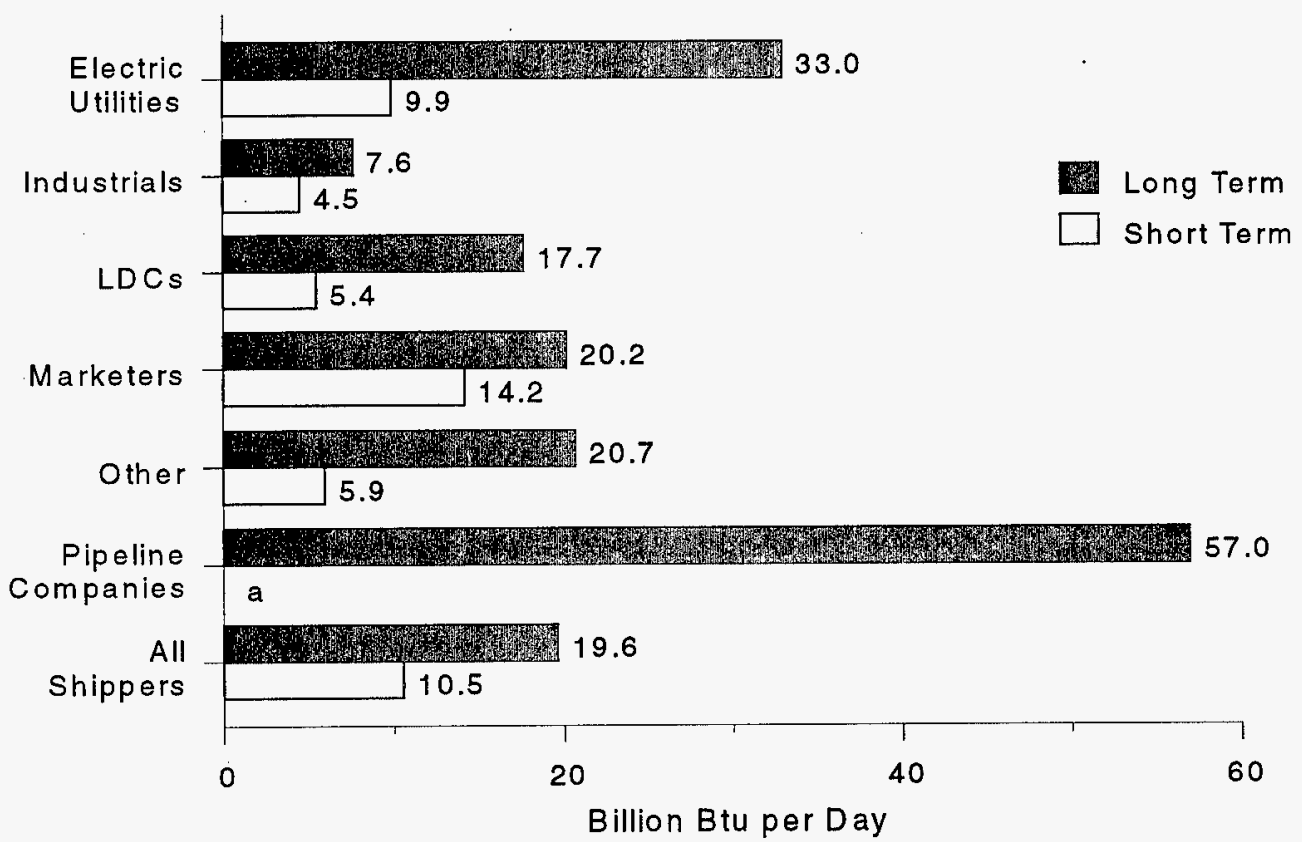

apeline companies did not have any contracts for short-term firm capacity on April 1, 1997.

LDC = Local distribution company.

Notes: Long-term contracts are for 1 year or longer. Short-term contracts are for less than 1 year.

Source: Energy Information Administration, Office of Oil and Gas, derived from Federal Energy Regulatory Commission (FERC) Index of Customers. 
often the only source of natural gas for weather-sensitive residential and commercial users, held the largest proportion of firm capacity in almost every region, sometimes far exceeding that held by the second largest shipper in the region. Electric utilities (which include combination electric and gas utilities) and marketers also tend to hold larger shares of regional firm capacity compared with other types of shippers.

Of the 101 trillion Btu per day in firm capacity held on April 1,1997 , the largest share, 36 percent, was held on pipelines that deliver most of their gas in the Northeast Region. The next largest share, 25 percent, was in the Midwest. These regions rank first and third, respectively, in terms of 1995 population (Table 11, Chapter 4) and they were the third and second coldest, respectively, in 1996 (Table 10, Chapter 4).

These two regions alone accounted for 58 percent of the total residential and commercial consumption of natural gas in 1996 (Table 12, Chapter 4), and LDCs held the largest share of firm capacity in both regions. In the Northeast, LDCs held
21.3 trillion Btu (TBtu), or 59 percent of regional firm daily capacity. This was nearly three times the 7.2 TBtu held by the second-place electric utilities in the Northeast. In the Midwest, LDCs held 8.6 TBtu of firm daily capacity, or 34 percent of the regional total. Marketers played a greater role as holders of firm capacity in this region, having the second highest level, at $5.8 \mathrm{TBtu}$ ( 23 percent of the regional total). In the Northeast, marketers held only 8 percent of regional firm capacity.

The Central Region had the most uniform distribution of contracted capacity among the different types of shippers (Figure 30). In part, this may be because the natural gas delivered in the region is destined for final delivery in the Midwest or Northeast rather than for consumption within the region. The Central Region acts as a conduit of gas from Rocky Mountain producers and for some imports from Canada. LDCs still held the largest share of regional firm capacity, 29 percent, but shippers in the Other category, which includes producers, held the third largest proportion, 19 percent.

\section{Figure 30. Share of Regional Firm Capacity as of April 1, 1997, by Shipper for Selected Regions}

(Capacity in Trillion Btu per Day)

\section{Central Region}

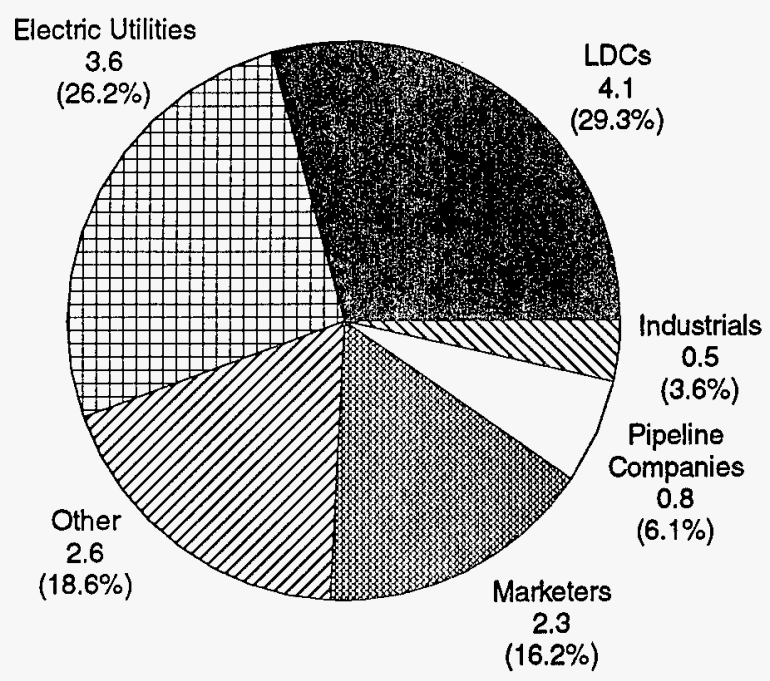

Total firm capacity is 14 trillion Btu

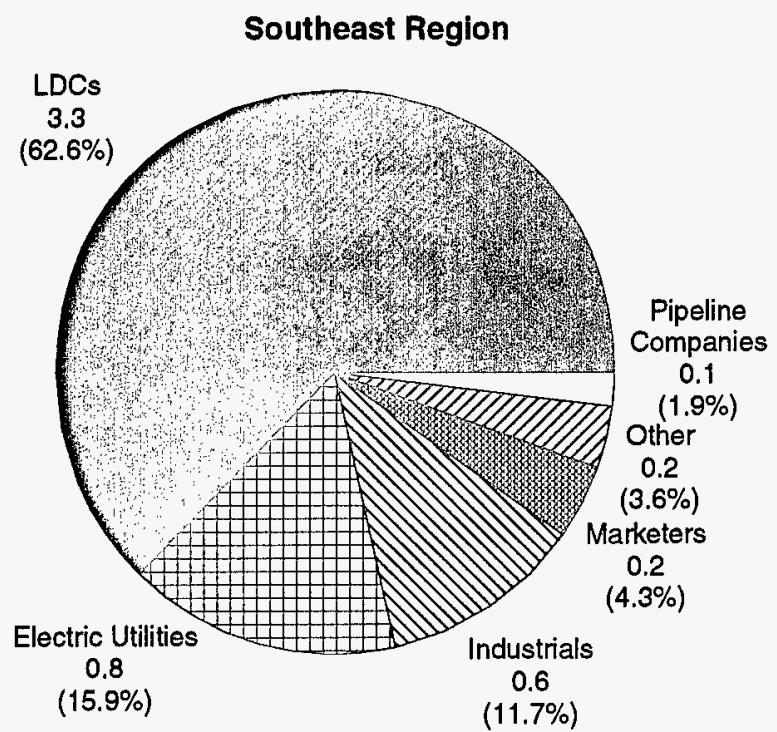

Total firm capacity is 5 trillion Btu

$L D C=$ Local distribution company

Source: Energy Information Administration, Office of Oil and Gas, derived from Federal Energy Regulatory Commission (FERC) Index of Customers. 
Figure 31. Capacity Under New and Expiring Firm Contracts, April 1, 1996 - April 1, 1997
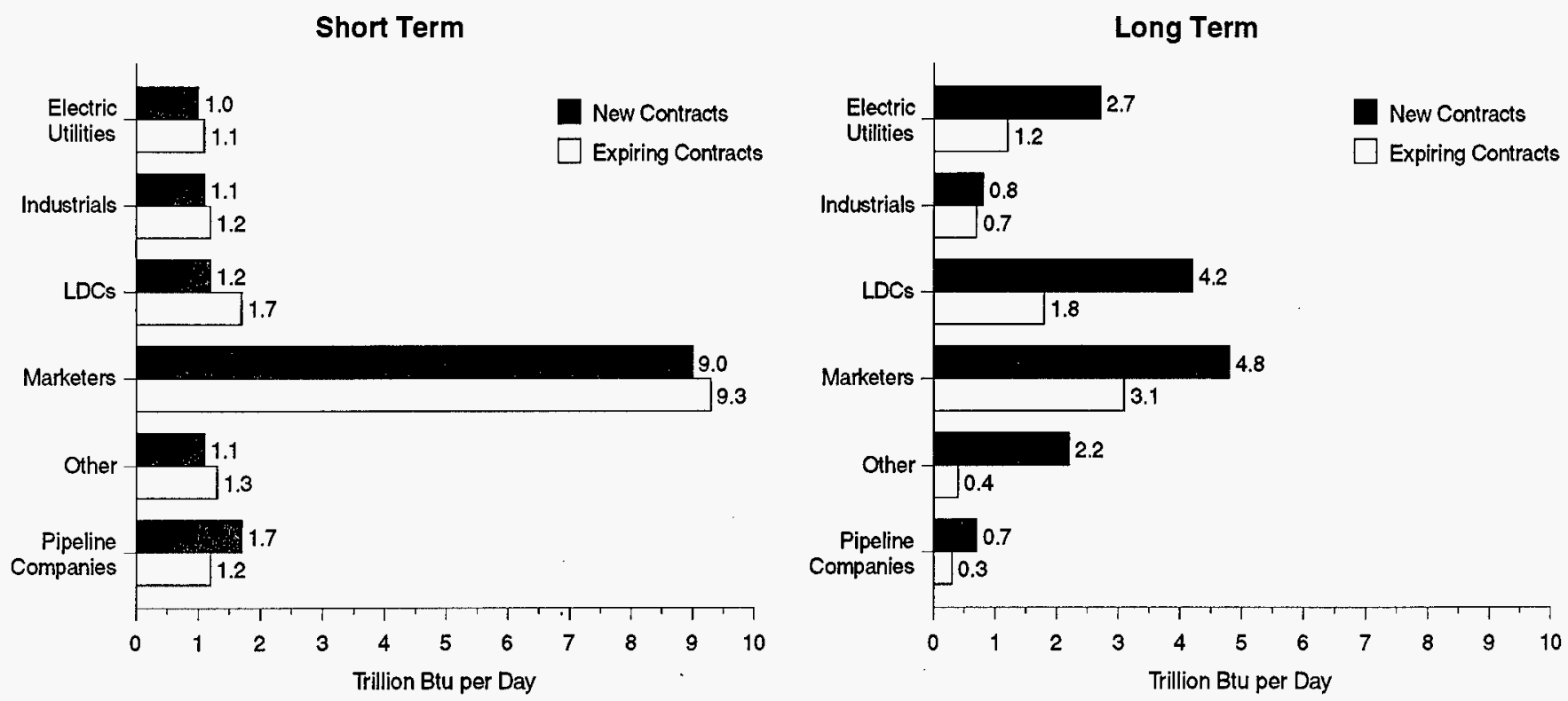

LDC $=$ Local distribution company.

Notes: Short-term contracts are for less than 1 year. Long-term contracts are for 1 year or longer.

Source: Energy Information Administration, Office of Oil and Gas, derived from Federal Energy Regulatory Commission (FERC) Index of Customers.

The Southeast Region had the greatest concentration of contracted capacity assigned to a single type of shipper. The 3.3 TBtu per day held by LDCs accounted for 63 percent of the regional total and was approximately four times the amount held by the shippers in second place, electric utilities (16 percent). The high concentration of capacity held by LDCs may be caused by two circumstances that exist in the Southeast Region. First, many of the LDCs whose service areas are in the Northeast Region hold capacity on Southeast pipelines. Second, the Southeast may not have implemented retail unbundling initiatives to the same extent as other regions. Thus, LDCs must continue to serve the majority of customers' needs. This would also explain the low share of firm capacity held by marketers in this region, only 4 percent.

In contrast, marketers held the largest proportion of firm capacity in the Western Region, 33 percent $(4.8 \mathrm{~TB}$ tu per day). The Western Region includes California, where retail unbundling began as early as 1986 . In the West, electric utilities held the second highest proportion of firm capacity, 27 percent, followed closely by LDCs with 26 percent.

\section{New and Expiring Long-Term Contracts}

Contract expiration is of particular interest in the natural gas industry today. To see if there are differences between types of shippers when it comes to contract expiration or the initiation of new contracts, data from the Index of Customers were examined for the 12-month period of April 1, 1996 through April 1, 1997. ${ }^{119}$ During this time, new contracts for 30.4 trillion Btu (TBtu) per day of firm transportation capacity became effective, while contracts accounting for 23.1 TBtu per day expired. Thus, newly contracted capacity exceeded expiring capacity by 31 percent. Marketers accounted for the largest shares of both new and expiring capacity, but the relative shares among the different types of shippers varied, depending on whether the contracts were short- or long-term.

Marketers totally dominated short-term capacity under both new and expiring contracts during the period (Figure 31). Marketers accounted for 60 percent of the 15.0 TBtu per day of new short-term firm capacity and for 59 percent of the 15.7 TBtu per day of expiring capacity. The shippers with the next largest share of new short-term capacity were the pipeline companies, with 11 percent of the total. For the expiring contracts, LDCs held the next largest share, which was also 11 percent.

\footnotetext{
${ }^{119}$ New contracts are those that started any time from April 2, 1996, through April 1, 1997. Expiring contracts are those that ended any time from April 1, 1996, through March 31, 1997.
} 
Capacity under new short-term contracts was almost equal to that under expiring contracts during the period, but for longterm contracts, new capacity was more than double that under expiring contracts. Thus, shippers showed a preference for longer term contracts as they increased their holdings of firm transportation capacity during the period. New long-term contracts accounted for 15.4 TBtu per day of firm capacity, while long-term contracts for $7.5 \mathrm{TBtu}$ of daily capacity expired. As with short-term contracts, marketers held the largest shares of both new and expiring capacity under longterm contracts, but both LDCs and electric utilities also held significant shares of each.

Marketers held 4.8 TBtu per day of firm capacity under new long-term contracts, 31 percent of the total. This new capacity was 56 percent more than that held by marketers under expiring contracts during the period. LDCs held 4.2 TBtu per day of new capacity under long-term contracts, accounting for 27 percent of the total. The new capacity held by LDCs was more than double that held under expiring contracts. New capacity held by electric utilities during the period was also more than double the amount held by these shippers under expiring contracts. With 2.7 TBtu, electric utilities held 18 percent of the new, long-term daily capacity that became effective during the period.

\section{Summary}

The unused capability of the interstate pipeline system for transportation service appears to be substantial. Based on an estimated maximum system capability of 127 trillion Btu (TBtu) per day, on average, 37 percent or 47 TBtu per day of the pipeline system capability was unused during the 1996-97 heating year (Figure 32). Shippers using firm transportation services accounted for an average of 67 TBtu of gas per day, utilizing only 53 percent of the system capability and only 67 percent of the reserved capacity during the 1996-97 heating year. This allowed interruptible shippers to move an average of 13 TBtu per day, which represented 10 percent of the system capability. While $100 \mathrm{TBtu}$ per day, or 78 percent of the system capability, was reserved during 1996-97, 20 TBtu of that was released to other firm shippers.

\section{Figure 32. Reserved, Utilized, and Available Capacity for the 1996-97 Heating Year}

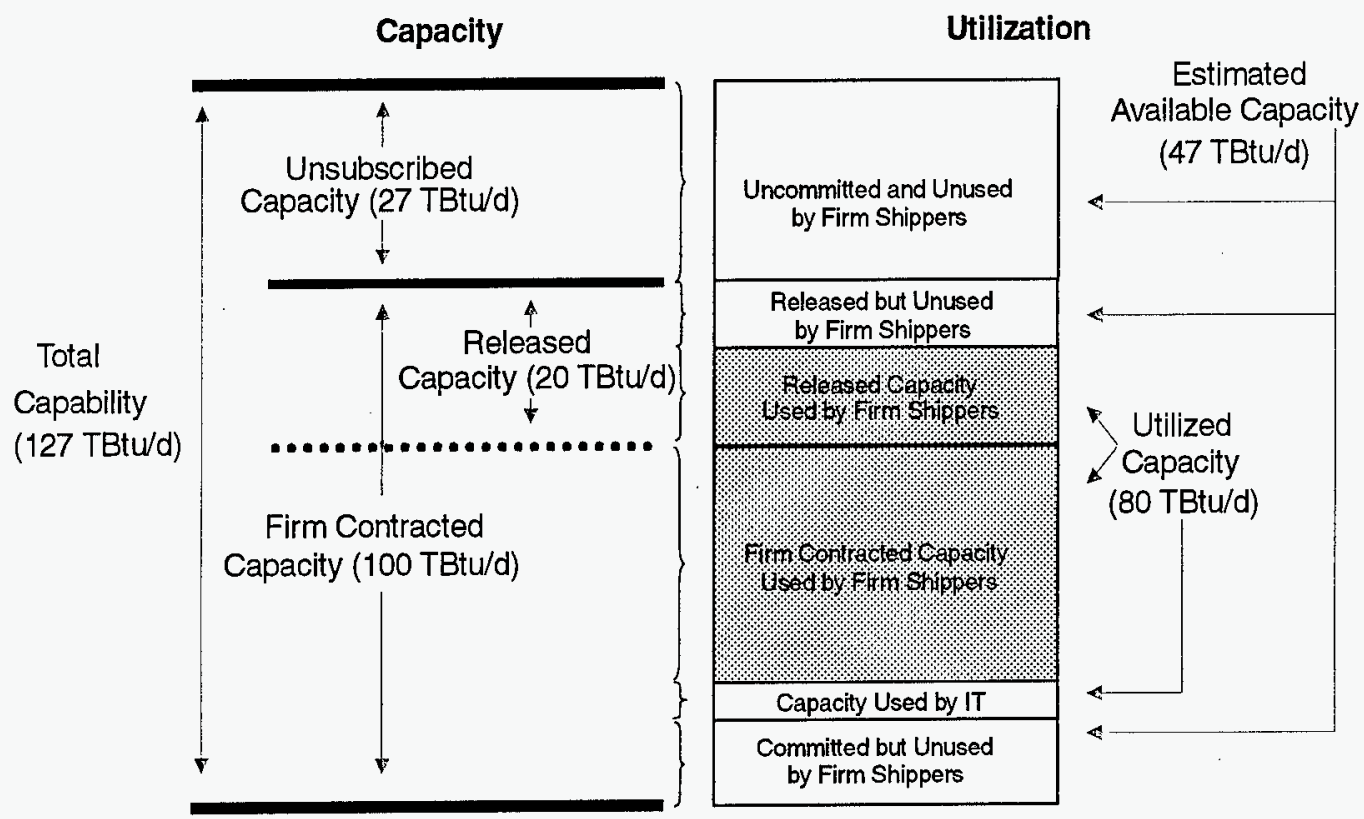

TBtu/d = Trillion Btu per day. IT = Interruptible transportation service.

Note: A firm shipper is one using firm transportation services.

Source: Energy Information Administration, Office of Oil and Gas. 
Transportation access during the heating season was less than the 12-month average, but market conditions indicate that the system can support significant additional load during this period as well. On average, 31 percent or 39 TBtu per day of the pipeline system capability was unused during the 1996-97 heating season. An average of $75 \mathrm{~TB}$ tu of gas per day was transported under firm transportation services, utilizing 59 percent of the system capability and 70 percent of the reserved capacity. Interestingly, interruptible service capacity utilization during the heating season was at the same level as during the nonheating season, 13 TBtu per day. The amount of reserved capacity increased to $107 \mathrm{TBtu}$ per day during the heating season, but 20 TBtu per day was still released to secondary shippers.
Whether these levels of unsubscribed and accessible capacity remain unchanged in the future will largely depend on what happens when firm transportation capacity contracts come up for renewal. If significant capacity is turned back to the system, shippers may respond by transporting more gas using interruptible service.

As of April 1997, virtually all (96 percent) of the firm capacity was held under long-term contracts (those with terms of 1 year or more), with local distribution companies holding the largest portion of firm capacity, 44 percent. The greatest shares of total firm capacity were held in the Northeast (36 percent) and the Midwest ( 25 percent). 


\section{Appendix A}

\section{State-to-State Natural Gas Pipeline Capacity and Usage Levels}

This appendix presents data on State-to-State capacity and usage levels for major interstate pipeline companies in 1996 and the percentage change between 1990 and 1996. The appendix consists of six maps and six tables, which correspond to the six U.S. geographic regions used throughout the report (Alaska, the District of Columbia, and Hawaii are not included). The six regions are defined and ordered as follows:

- Central Region - Colorado, Iowa, Kansas, Missouri, Montana, Nebraska, North Dakota, South Dakota, Utah, and Wyoming.

- Midwest Region - Ilinois, Indiana, Michigan, Minnesota, Ohio, and Wisconsin.

- Northeast Region - Connecticut, Delaware, Maine, Maryland, Massachusetts, New Hampshire, New Jersey, New York, Pennsylvania, Rhode Island, Vermont, Virginia, and West Virginia.

- Southeast Region - Alabama, Florida, Georgia, Kentucky, Mississippi, North Carolina, South Carolina, and Tennessee.

- Southwest Region - Arkansas, Louisiana, New Mexico, Oklahoma, and Texas.

- Western Region - Arizona, California, Idaho, Nevada, Oregon, and Washington.

Each regional map portrays the States included in the region and the approximate routes of the major interstate pipelines operating in the region. Routes of some of the smaller pipeline systems are not displayed because they are difficult to distinguish from the major systems. Underground storage site locations are included in the maps to give the reader a perspective on the proximity and accessibility of storage to pipelines within a region. Although the maps do not include capacity levels, the reader can find a mapped regional State-toState capacity summary representation in Chapters 3 and 5 of the report.

Each table represents one region, with the States within the region presented in alphabetical order. For each State, a line item is listed for each interstate pipeline company capable of transporting gas from an adjoining State. It should be noted that in a number of instances a pipeline company may have more than one branch or mainline segment crossing to another State. In such cases, data for the several points are combined and summed rather than being separately identified in the table. Data regarding any of these individuals points, if wanted, are available within the supporting database.

(The data contained in the tables may be downloaded from the Energy Information Administration's (EIA) Internet site in either a spreadsheet or database format, or from EIA's FTP site at ftp://ftp.eia.doe.gov/pub/oil_gas/natural_gas/analysis_publications/deliverability/data. The format and data element definitions for the STBORDER database and spreadsheet can be found in the EIAGIS-NG (see Appendix C) data dictionary DATADICT. DBF, also available from these sites.)

For each adjoining State, a summary line displaying the combined total capacity, 1996 average daily flows, and the weighted average usage rate of all pipelines exiting the State is listed. Similarly, a summary of all pipeline routes entering the receiving State is presented for each of these values. In some cases, no flow data were reported in 1996 for a known State-toState pipeline combination. In these cases, the capacity value for the route is not included as part of the denominator (weighting factor) when average utilization rates at the State and regional summary levels were calculated.

The measure of capacity that is shown represents an estimate of the maximum throughput capability of the interstate natural gas pipeline network at a regional or State boundary. Specifically, it is an estimate of how much gas can be transported under normal operating conditions for a sustained period of time. Information on capacity levels for the interstate pipeline systems was compiled by using data available from filings at the Federal Energy Regulatory Commission (FERC) and through contacts with the companies themselves.

The average daily flow volumes presented in Tables A1 through A6 are based upon 1996 data extracted from Form EIA-176, "Annual Report of Natural and Supplemental Gas Supply and Disposition." They are the sum of data that can be identified as volumes brought across a border. The data on Form EIA-176 are annual; average daily levels were computed on a 366-day basis (1996 was a leap year). More information on how Form EIA-176 data were compiled and included in this report can be found in Appendix D. 
Figure A1. Major Interstate Natural Gas Pipelines in the Central Region

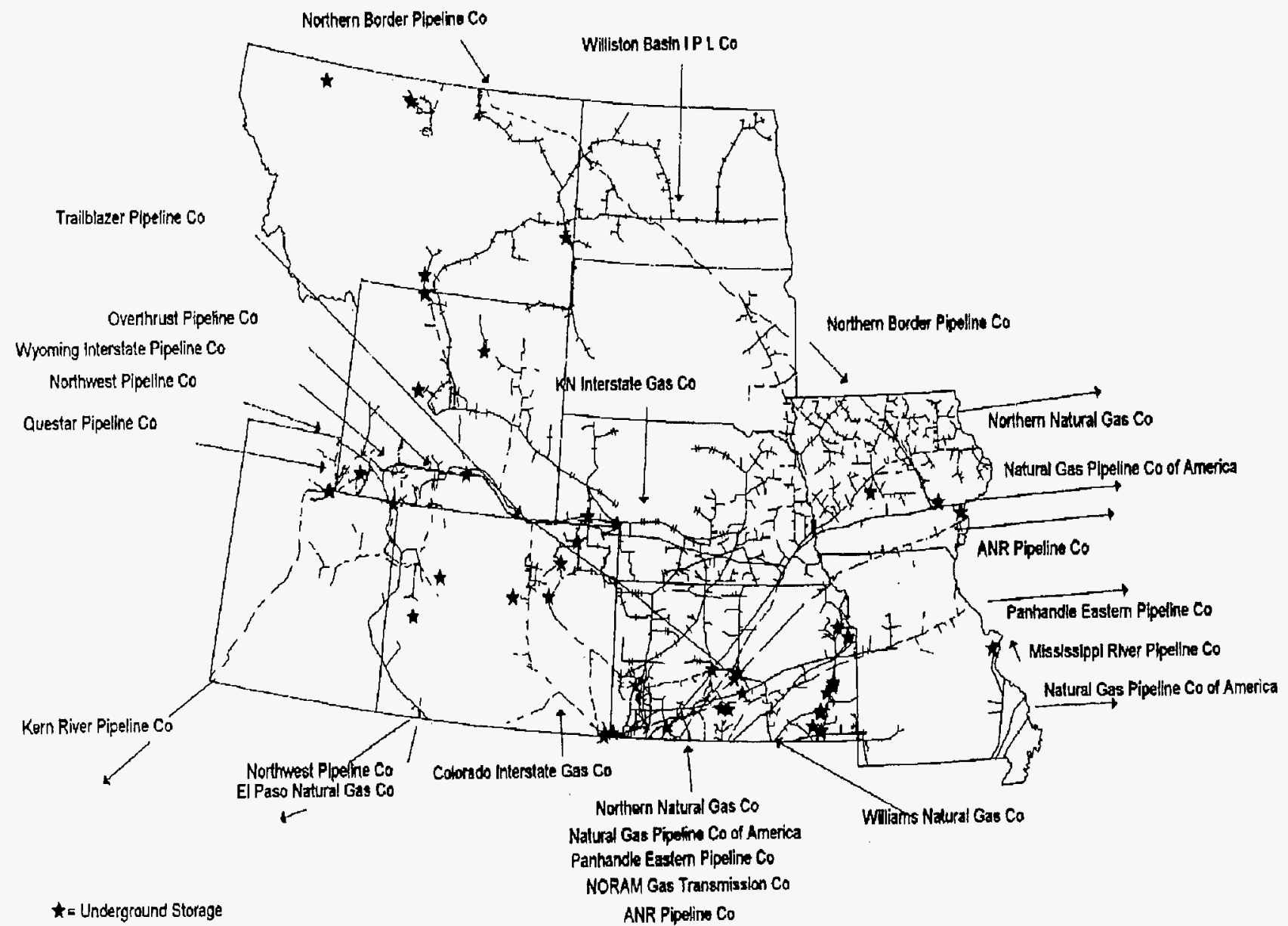

Source: Energy Information Administration (EIA), EIAGIS-NG Geographic Information System, as of December 1997. 
Table A1. State Border Capacity, Flows, and Utilization Rates of Interstate Natural Gas Pipelines Operating in the Central Region, by State, 1990 and 1996

(Volumes in Million Cubic Feet per Day)

\begin{tabular}{|c|c|c|c|c|c|c|c|c|c|}
\hline \multirow[b]{3}{*}{$\begin{array}{l}\text { Receiving State/ } \\
\text { Via Pipeline Company }\end{array}$} & \multicolumn{9}{|c|}{ Transmission Throughput Capabilities and Flows } \\
\hline & \multicolumn{3}{|c|}{ Estimated Entering Capacity } & \multicolumn{2}{|c|}{ Average Dally Flow ${ }^{\mathrm{a}}$} & \multicolumn{2}{|c|}{$\begin{array}{c}\text { Average Usage } \\
\text { Rate }^{b}\end{array}$} & \multicolumn{2}{|c|}{ Exiting Capacity } \\
\hline & $\begin{array}{l}\text { Upstream } \\
\text { State }\end{array}$ & 1996 & \begin{tabular}{|c|} 
Percent \\
Change \\
$1990-1996$
\end{tabular} & 1996 & $\begin{array}{c}\text { Percent } \\
\text { Change } \\
\text { 1990-1996 }\end{array}$ & 1996 & \begin{tabular}{|c|}
$\begin{array}{c}\text { Percent } \\
\text { Change } \\
1990-1996\end{array}$ \\
\end{tabular} & $\begin{array}{c}\text { Downstream } \\
\text { State }\end{array}$ & 1996 \\
\hline \multirow{4}{*}{$\begin{array}{l}\text { Colorado } \\
\text { Colorado Interstate Gas } \\
\text { Panhandle Eastern P L Co }\end{array}$} & & & & & & & & & \\
\hline & Kansas & ${ }^{c} 340$ & 0 & 0 & -- & -- & - & Kansas & 244 \\
\hline & & 45 & 0 & 0 & - & -- & -- & None & \\
\hline & Total & 385 & $\mathbf{0}$ & $\mathbf{0}$ & - & 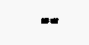 & 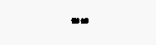 & & \\
\hline \multirow{3}{*}{$\begin{array}{l}\text { KN Interstate Gas Co } \\
\text { Trailblazer Pipeline Co }\end{array}$} & Nebraska & ${ }^{\circ} 97$ & 144 & 2 & -90 & 2 & -96 & Kansas/NE & 60 \\
\hline & & 500 & 0 & 490 & 141 & 98 & 141 & Nebraska & 500 \\
\hline & Total & 597 & 11 & 492 & 123 & 82 & 102 & & \\
\hline Transwestern Pipeline Co & New Mexico & ${ }^{\circ} 276$ & 84 & 0 & - & -- & -- & New Mexico & 500 \\
\hline Colorado Interstate Gas & Oklahoma & ${ }^{c} 200$ & 0 & 71 & -- & 35 & -- & Oklahioma & 250 \\
\hline Colorado Interstate Gas & Utah & 165 & & 104 & -- & 63 & -- & Wyoming & 180 \\
\hline Northwest Pipeline Corp & & ${ }^{\circ} 337$ & 60 & 84 & 100 & 25 & 25 & Utah & 587 \\
\hline \multirow{2}{*}{ Questar P L Co } & & ${ }^{c} 23$ & 0 & 2 & -93 & 10 & -93 & None & \\
\hline & Total & 525 & 125 & 190 & 164 & 36 & 17 & & \\
\hline Colorado Interstate Gas & Wyoming & 625 & 0 & 554 & 12 & 89 & 12 & Oklahoma & 250 \\
\hline Questar P L Co & & ${ }^{8} 313$ & 6 & 0 & - & - & -- & None & \\
\hline Williams Natural Gas Co & & 178 & 24 & 146 & 15 & 82 & -7 & Kansas & 186 \\
\hline \multirow{2}{*}{ Wyoming Interstate Co } & & 499 & 0 & 480 & 123 & 96 & 123 & None & \\
\hline & Total & 1,615 & 3 & 1,180 & 35 & 91 & 62 & & \\
\hline Total & & 3,597 & 17 & 1,934 & 46 & 74 & 49 & & \\
\hline \multicolumn{10}{|l|}{ lowa } \\
\hline Northern Border Pipeline Co & Minnesota & 1,575 & 42 & 1,541 & 61 & 98 & 13 & None & \\
\hline ANR Pipeline Co & Missouri & 680 & 13 & 669 & 17 & 99 & 4 & Illinois & 603 \\
\hline Nat Gas P L Co of America & Nebraska & 1,330 & 0 & 1,067 & 14 & 80 & 14 & Illinois & 1,665 \\
\hline Northern Natural Gas Co & & 1,295 & 0 & 740 & 33 & 57 & 20 & Minnesota/IL/SD & 2,035 \\
\hline & Total & 2,625 & 0 & 1,801 & 21 & 69 & 15 & & \\
\hline Total & & 4,880 & 13 & 4,019 & 33 & 82 & 15 & & \\
\hline \multicolumn{10}{|l|}{ Kansas } \\
\hline Colorado Interstate Gas & Colorado & ${ }^{\circ} 244$ & 0 & 83 & 15 & 34 & 15 & Colorado & 340 \\
\hline KN Interstate Gas Co & & 20 & 0 & 13 & 63 & 66 & 63 & Nebraska & 81 \\
\hline \multirow[t]{2}{*}{ Williams Natural Gas Co } & & 186 & 19 & 164 & 15 & 88 & -4 & Nebraska & 6 \\
\hline & Total & 450 & 7 & 261 & 16 & 58 & 9 & & \\
\hline KN Interstate Gas Co & Nebraska & ${ }^{\circ} 40$ & 0 & 4 & 17 & 9 & -12 & None & \\
\hline ANR Pipeline Co & Oklahoma & 853 & 0 & 697 & 16 & 82 & 16 & Nebraska & 693 \\
\hline Nat Gas P L Co of America & & ${ }^{\circ} 1,153$ & 0 & 689 & -8 & 60 & -8 & Nebraska & 1,175 \\
\hline Noram Gas Transmission Co & & 40 & -20 & 18 & -13 & 45 & 8 & None & \\
\hline Northern Natural Gas Co & & 1,330 & 0 & 546 & 38 & 41 & 5 & Nebraska & 2,050 \\
\hline Panhandle Eastern P L Co & & 1,395 & -5 & 834 & 62 & 60 & 71 & Missouri & 1,559 \\
\hline Transwestern Pipeline Co & & 5 & 0 & 2 & -20 & 32 & -20 & None & \\
\hline \multirow[t]{2}{*}{ Williams Natural Gas Co } & & 496 & 0 & 280 & -17 & 56 & -17 & Missouri/OK & 1,231 \\
\hline & Total & 5,272 & -2 & 3,067 & 17 & 58 & 18 & & \\
\hline Total & & 5,762 & -1 & 3,331 & 17 & 58 & 17 & & \\
\hline \multicolumn{10}{|l|}{ Missourl } \\
\hline Associated Natural Gas Co & Arkansas & 10 & 0 & 9 & 50 & 88 & 54 & Arkansas & 30 \\
\hline Mississippi River Trans Corp & & 730 & 0 & 339 & 29 & 46 & 29 & Illinois & 590 \\
\hline Nat Gas P L Co of America & & 1,650 & 4 & 1,184 & 30 & 72 & 25 & Illinois & 1,650 \\
\hline Noram Gas Transmission Co & & 100 & -33 & 15 & -21 & 15 & 18 & None & \\
\hline \multirow[t]{2}{*}{ Texas Eastern Trans Corp } & & 324 & 0 & 264 & 100 & 81 & 100 & Illinois & 300 \\
\hline & Total & 2,814 & 1 & 1,811 & 37 & 64 & 36 & & \\
\hline Mississippi River Trans Corp & Illinois & 695 & 10 & 0 & -- & -. & - & None & \\
\hline
\end{tabular}


Table A1. State Border Capacity, Flows, and Utilization Rates of Interstate Natural Gas Pipelines Operating in the Central Region, by State, 1990 and 1996 (Continued) (Volumes in Million Cubic Feet per Day)

\begin{tabular}{|c|c|c|c|c|c|c|c|c|c|}
\hline \multirow{2}{*}{$\begin{array}{l}\text { Receiving Statel } \\
\text { Via Pipeline Company }\end{array}$} & \multicolumn{9}{|c|}{ Transmission Throughput Capabilities and Flows } \\
\hline & \multicolumn{3}{|c|}{ Estimated Entering Capacity } & \multicolumn{2}{|c|}{ Average Daily Flow ${ }^{\mathrm{a}}$} & \multicolumn{2}{|c|}{$\begin{array}{c}\text { Average Usage } \\
\text { Rate }^{b}\end{array}$} & \multicolumn{2}{|c|}{ Exiting Capacity } \\
\hline $\begin{array}{l}\text { Panhandle Eastern P L Co } \\
\text { Williams Natural Gas Co }\end{array}$ & $\begin{array}{l}\text { Kansas } \\
\text { Total }\end{array}$ & $\begin{array}{r}1,559 \\
972 \\
2,531\end{array}$ & $\begin{array}{r}-2 \\
0 \\
-1\end{array}$ & $\begin{array}{r}1,447 \\
262 \\
1,710\end{array}$ & $\begin{array}{l}18 \\
11 \\
17\end{array}$ & $\begin{array}{l}93 \\
27 \\
68\end{array}$ & $\begin{array}{l}21 \\
11 \\
18\end{array}$ & $\begin{array}{l}\text { Illinois } \\
\text { None }\end{array}$ & 1,361 \\
\hline ANR Pipeline Co & Nebraska & 693 & 14 & 679 & 17 & 98 & 3 & lowa & 680 \\
\hline $\begin{array}{l}\text { Williams Natural Gas Co } \\
\text { Total }\end{array}$ & Oklahoma & $\begin{array}{r}47 \\
6,780\end{array}$ & $\begin{array}{l}0 \\
2\end{array}$ & $\begin{array}{r}45 \\
4,244\end{array}$ & $\begin{array}{l}22 \\
25\end{array}$ & $\begin{array}{l}96 \\
70\end{array}$ & $\begin{array}{l}22 \\
23\end{array}$ & & None \\
\hline Montana & & & & & & & & & \\
\hline $\begin{array}{l}\text { Montana Power Co } \\
\text { Northern Border Pipeline Co } \\
\text { Northern Natural Gas Co }\end{array}$ & Total & $\begin{array}{r}64 \\
1,489 \\
10 \\
1,563\end{array}$ & $\begin{array}{r}25 \\
39 \\
-92 \\
25\end{array}$ & $\begin{array}{r}64 \\
1,475 \\
5 \\
1,542\end{array}$ & $\begin{array}{r}144 \\
79 \\
-100 \\
67\end{array}$ & $\begin{array}{l}97 \\
99 \\
-- \\
98\end{array}$ & $\begin{array}{l}89 \\
26 \\
\cdots \\
31\end{array}$ & $\begin{array}{l}\text { Canada } \\
\text { North Dakota } \\
\text { Canada }\end{array}$ & $\begin{array}{r}6 \\
1,480 \\
60\end{array}$ \\
\hline Williston Basin I P L Co & North Dakota & ${ }^{\circ} 268$ & 17 & 28 & -48 & 10 & -56 & North Dakota & 304 \\
\hline $\begin{array}{l}\text { Colorado Interstate Gas } \\
\text { Montana Power Co } \\
\text { Williston Basin I P L Co } \\
\text { Total }\end{array}$ & Wyoming & $\begin{array}{r}{ }^{\circ} 60 \\
2 \\
2 \\
188 \\
250 \\
2,081\end{array}$ & $\begin{array}{r}- \\
0 \\
43 \\
88 \\
29\end{array}$ & $\begin{array}{r}\cdots \\
0 \\
47 \\
47 \\
1,617\end{array}$ & $\begin{array}{r}-5 \\
-53 \\
90 \\
87 \\
58\end{array}$ & $\begin{array}{l}-- \\
12 \\
25 \\
25 \\
80\end{array}$ & $\begin{array}{r}-- \\
-53 \\
16 \\
15 \\
25\end{array}$ & $\begin{array}{l}\text { None } \\
\text { None } \\
\text { Wyoming }\end{array}$ & 162 \\
\hline $\begin{array}{l}\text { Nebraska } \\
\text { KN Interstate Gas Co } \\
\text { Trailblazer Pipeline Co }\end{array}$ & $\begin{array}{l}\text { Colorado } \\
\text { Total }\end{array}$ & $\begin{array}{l}{ }^{c} 40 \\
500 \\
540\end{array}$ & $\begin{array}{l}0 \\
0 \\
0\end{array}$ & $\begin{array}{r}3 \\
491 \\
494\end{array}$ & $\begin{array}{l}-44 \\
137 \\
132\end{array}$ & $\begin{array}{r}8 \\
98 \\
91\end{array}$ & $\begin{array}{l}-44 \\
137 \\
132\end{array}$ & Colorado & $\begin{array}{r}\text { None } \\
500\end{array}$ \\
\hline $\begin{array}{l}\text { ANR Pipeline Co } \\
\text { KN Interstate Gas Co } \\
\text { Nat Gas P L Co of America } \\
\text { Northern Natural Gas Co } \\
\text { Williams Natural Gas Co }\end{array}$ & Kansas & $\begin{array}{r}693 \\
{ }^{c} 81 \\
1,176 \\
2,050 \\
6 \\
4,005\end{array}$ & $\begin{array}{r}14 \\
0 \\
-30 \\
0 \\
0 \\
-10\end{array}$ & $\begin{array}{r}679 \\
12 \\
712 \\
974 \\
2 \\
2,379\end{array}$ & $\begin{array}{r}17 \\
-52 \\
-10 \\
26 \\
-10 \\
10\end{array}$ & $\begin{array}{l}98 \\
15 \\
61 \\
47 \\
36 \\
59\end{array}$ & $\begin{array}{r}3 \\
-52 \\
30 \\
26 \\
-10 \\
22\end{array}$ & $\begin{array}{l}\text { Missouri } \\
\text { Colorado } \\
\text { lowa } \\
\text { lowa/SD } \\
\text { None }\end{array}$ & $\begin{array}{r}693 \\
96 \\
1,330 \\
1,365\end{array}$ \\
\hline $\begin{array}{l}\text { North Dakota } \\
\text { Viking Gas Transmission Co }\end{array}$ & Minnesota & 84 & 223 & 22 & 21 & 26 & -62 & None & \\
\hline $\begin{array}{l}\text { Northern Border Pipeline Co } \\
\text { Williston Basin I P L Co }\end{array}$ & $\begin{array}{l}\text { Montana } \\
\text { Total }\end{array}$ & $\begin{array}{r}1,480 \\
c_{5} \\
1,785\end{array}$ & $\begin{array}{r}38 \\
139 \\
48\end{array}$ & $\begin{array}{r}1,472 \\
87 \\
1,559\end{array}$ & $\begin{array}{r}59 \\
290 \\
70\end{array}$ & $\begin{array}{l}99 \\
29 \\
90\end{array}$ & $\begin{array}{l}20 \\
63 \\
15\end{array}$ & $\begin{array}{l}\text { South Dakota } \\
\text { Montana }\end{array}$ & $\begin{array}{r}1,685 \\
268\end{array}$ \\
\hline $\begin{array}{l}\text { Williston Basin I P L Co } \\
\text { Total }\end{array}$ & South Dakota & $\begin{array}{r}53 \\
1,922\end{array}$ & $\begin{array}{r}166 \\
54\end{array}$ & 1,581 & $\ddot{64}$ & $\ddot{85}$ & 97 & None & \\
\hline $\begin{array}{l}\text { South Dakota } \\
\text { Northern Natural Gas Co }\end{array}$ & lowa & $\begin{array}{l}30 \\
70\end{array}$ & $\begin{array}{l}0 \\
0\end{array}$ & $\begin{array}{r}2 \\
34\end{array}$ & $\begin{array}{r}-58 \\
26\end{array}$ & $\begin{array}{r}5 \\
48\end{array}$ & $\begin{array}{r}-58 \\
26\end{array}$ & None & \\
\hline Northern Natural Gas Co & Nebraska & 70 & 0 & 34 & 26 & 48 & 26 & None & \\
\hline $\begin{array}{l}\text { Northern Border Pipeline Co } \\
\text { Williston Basin I P L Co }\end{array}$ & $\begin{array}{l}\text { North Dakota } \\
\text { Total }\end{array}$ & $\begin{array}{r}1,675 \\
c_{4}^{4} \\
1,729\end{array}$ & $\begin{array}{r}38 \\
3 \\
37\end{array}$ & $\begin{array}{r}1,656 \\
22 \\
1,677\end{array}$ & $\begin{array}{r}52 \\
-16 \\
51\end{array}$ & $\begin{array}{l}99 \\
40 \\
97\end{array}$ & $\begin{array}{r}10 \\
-19 \\
16\end{array}$ & $\begin{array}{l}\text { Minnesota } \\
\text { None }\end{array}$ & 1,655 \\
\hline $\begin{array}{l}\text { Williston Basin I P L Co } \\
\text { Total }\end{array}$ & Wyoming & $\begin{array}{r}{ }^{\circ} 27 \\
1,856\end{array}$ & $\begin{array}{r}3 \\
33\end{array}$ & $\begin{array}{r}0 \\
1,793\end{array}$ & $\begin{array}{r}0 \\
57\end{array}$ & $\ddot{97}$ & $\overline{155}$ & None & \\
\hline
\end{tabular}


Table A1. State Border Capacity, Flows, and Utilization Rates of Interstate Natural Gas Pipelines Operating in the Central Region, by State, 1990 and 1996 (Continued)

(Volumes in Million Cubic Feet per Day)

\begin{tabular}{|c|c|c|c|c|c|c|c|c|c|}
\hline \multirow[b]{3}{*}{$\begin{array}{l}\text { Receiving State/ } \\
\text { Via Pipeline Company }\end{array}$} & \multicolumn{9}{|c|}{ Transmission Throughput Capabilities and Flows } \\
\hline & \multicolumn{3}{|c|}{ Estimated Entering Capacity } & \multicolumn{2}{|c|}{ Average Daily Flow ${ }^{\mathrm{a}}$} & \multicolumn{2}{|c|}{$\begin{array}{c}\text { Average Usage } \\
\text { Rate }^{b}\end{array}$} & \multicolumn{2}{|c|}{ Exiting Capacity } \\
\hline & $\begin{array}{l}\text { Upstream } \\
\text { State }\end{array}$ & 1996 & $\begin{array}{c}\text { Percent } \\
\text { Change } \\
1990-1996\end{array}$ & 1996 & $\begin{array}{c}\text { Percent } \\
\text { Change } \\
1990-1996\end{array}$ & 1996 & $\begin{array}{c}\text { Percent } \\
\text { Change } \\
1990-1996\end{array}$ & $\begin{array}{c}\text { Downstream } \\
\text { State }\end{array}$ & 1996 \\
\hline \multicolumn{10}{|l|}{ Utah } \\
\hline $\begin{array}{l}\text { Northwest Pipeline Corp } \\
\text { Questar P L Co }\end{array}$ & $\begin{array}{l}\text { Colorado } \\
\text { Total }\end{array}$ & $\begin{array}{r}{ }^{c} 337 \\
{ }^{c} 51 \\
388\end{array}$ & $\begin{array}{r}105 \\
0 \\
81\end{array}$ & $\begin{array}{r}0 \\
42 \\
42\end{array}$ & $\begin{array}{r}-- \\
39 \\
-60\end{array}$ & $\begin{array}{l}-- \\
83 \\
83\end{array}$ & $\begin{array}{l}-- \\
39 \\
39\end{array}$ & $\begin{array}{l}\text { Colorado } \\
\text { Wyoming }\end{array}$ & $\begin{array}{l}366 \\
269\end{array}$ \\
\hline Northwest Pipeline Corp & Idaho & ${ }^{\circ} 298$ & 19 & 0 & -100 & -- & -- & Wyoming & 360 \\
\hline $\begin{array}{l}\text { Kern River Gas Trans Co } \\
\text { Northwest Pipeline Corp } \\
\text { Questar P L Co } \\
\text { Total }\end{array}$ & Wyoming & $\begin{array}{r}831 \\
{ }^{\circ} 430 \\
c^{c} 704 \\
1,965 \\
2,651\end{array}$ & $\begin{array}{r}-- \\
0 \\
3 \\
76 \\
68\end{array}$ & $\begin{array}{r}739 \\
72 \\
233 \\
1,044 \\
1,086\end{array}$ & $\begin{array}{r}- \\
9 \\
-10 \\
220 \\
73\end{array}$ & $\begin{array}{l}89 \\
17 \\
33 \\
53 \\
\mathbf{5 4}\end{array}$ & $\begin{array}{r}-. \\
9 \\
-13 \\
82 \\
35\end{array}$ & $\begin{array}{l}\text { Nevada } \\
\text { Colorado } \\
\text { Colorado }\end{array}$ & $\begin{array}{r}750 \\
310 \\
23\end{array}$ \\
\hline \multicolumn{10}{|l|}{ Wyoming } \\
\hline $\begin{array}{l}\text { Colorado Interstate Gas } \\
\text { Questar P L Co } \\
\text { Trailblazer Pipeline Co }\end{array}$ & Colorado & $\begin{array}{r}180 \\
c_{165} \\
500 \\
845\end{array}$ & $\begin{array}{r}175 \\
0 \\
51\end{array}$ & $\begin{array}{r}146 \\
46 \\
490 \\
682\end{array}$ & $\begin{array}{r}-- \\
27 \\
141 \\
184\end{array}$ & $\begin{array}{l}81 \\
28 \\
98 \\
81\end{array}$ & $\begin{array}{r}-- \\
-54 \\
80 \\
74\end{array}$ & $\begin{array}{l}\text { Colorado } \\
\text { Utah } \\
\text { Nebraska }\end{array}$ & $\begin{array}{l}625 \\
703 \\
500\end{array}$ \\
\hline $\begin{array}{l}\text { Colorado Interstate Gas } \\
\text { Williston Basin I P L Co }\end{array}$ & $\begin{array}{l}\text { Montana } \\
\text { Total }\end{array}$ & $\begin{array}{r}{ }^{c} 60 \\
c_{163} \\
223\end{array}$ & $\begin{array}{r}- \\
0 \\
37\end{array}$ & $\begin{array}{l}0 \\
0 \\
0\end{array}$ & $\begin{array}{l}0 \\
-- \\
-\end{array}$ & $\begin{array}{l}-- \\
-- \\
--\end{array}$ & $\begin{array}{l}-- \\
-- \\
--\end{array}$ & $\begin{array}{l}\text { None } \\
\text { Montana }\end{array}$ & 188 \\
\hline Williston Basin I P L Co & South Dakota & ${ }^{\mathrm{c}} 26$ & 13 & 0 & -- & -- & -- & None & \\
\hline $\begin{array}{l}\text { Northwest Pipeline Corp } \\
\text { Questar P L Co } \\
\text { Total }\end{array}$ & $\begin{array}{l}\text { Utah } \\
\text { Total }\end{array}$ & $\begin{array}{r}{ }^{\circ} 360 \\
c^{c} 269 \\
629 \\
1,723\end{array}$ & $\begin{array}{r}44 \\
0 \\
21 \\
36\end{array}$ & $\begin{array}{r}0 \\
46 \\
46 \\
728\end{array}$ & $\begin{array}{r}-- \\
113 \\
-68 \\
71\end{array}$ & $\begin{array}{l}-- \\
94 \\
94 \\
79\end{array}$ & $\begin{array}{l}-- \\
113 \\
248 \\
135\end{array}$ & $\begin{array}{l}\text { Utah } \\
\text { Colorado }\end{array}$ & $\begin{array}{l}310 \\
312\end{array}$ \\
\hline
\end{tabular}

${ }^{a}$ Average daily flow based upon annual volumes (reported as delivered from one State to another) divided by days in the year.

${ }^{\circ}$ Average usage rate is equal to the average daily flow derived by estimated capacity. Utilization computation does not include capacity against which no flow was reported.

'Bidirection flow occur on some or all of the pipeline company lines that cross the State border. The value shown represents the capacity, or sum of capacity, for only the flow in the direction indicated.

'Less than 0.5 percent and greater than -0.5 percent.

$--=$ Not applicable, pipeline not in service in 1990 and/or no flow reported in 1990 or 1996.

Note: Totals may not equal sum of components because of independent rounding.

Source: Energy Information Administration (EIA), EIAGIS-NG Geographic Information System, Natural Gas Pipeline State Border Capacity Database, as of December 1997. 
Figure A2. Major Interstate Natural Gas Pipelines Serving the Midwest Region

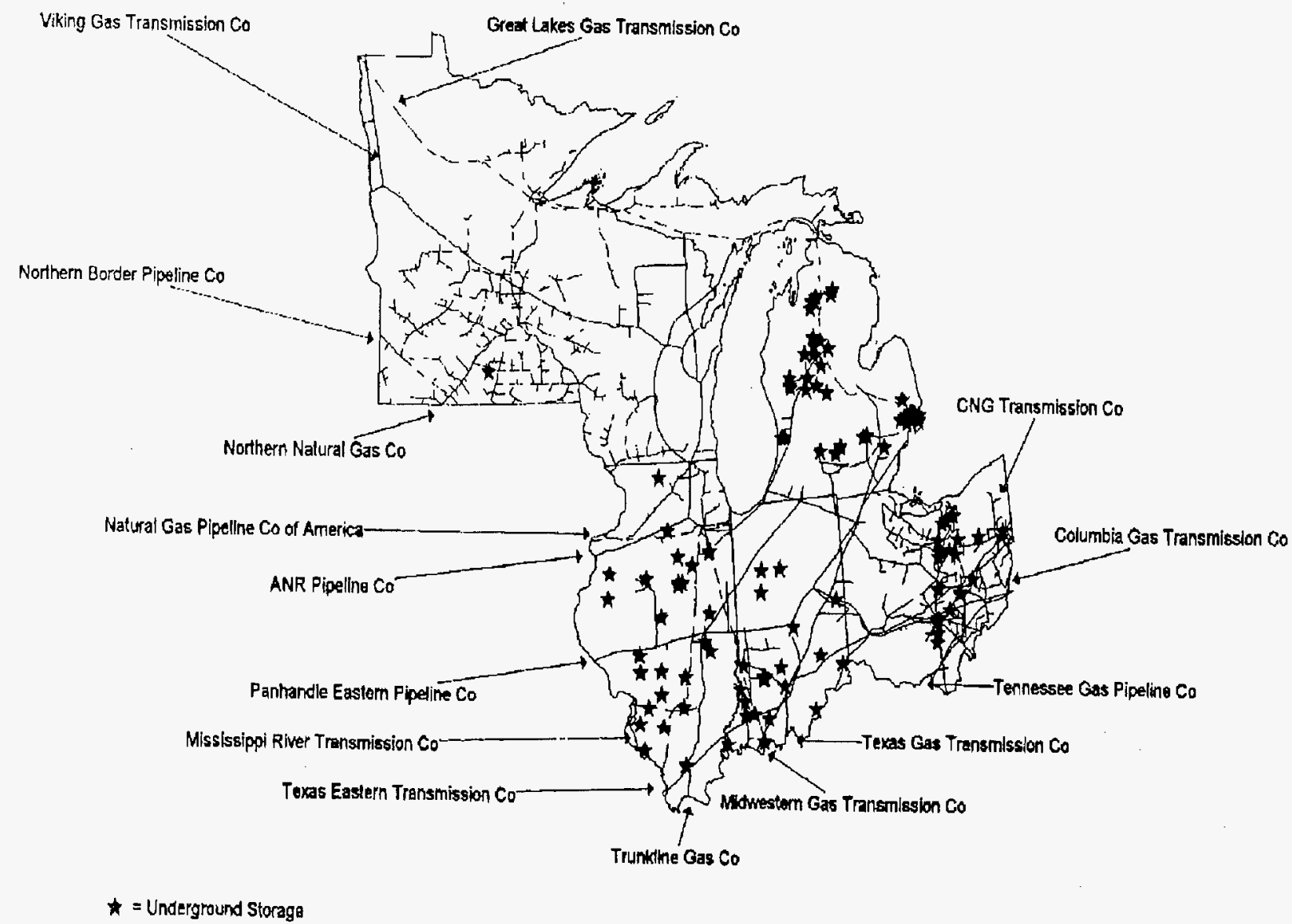

Source: Energy Information Administration (EIA), EIAGIS-NG Geographic Information System, as of December 1997. 
Table A2. State Border Capacity, Flows, and Utilization Rates of Interstate Natural Gas Pipelines Operating in the Midwest Region, by State, 1990 and 1996

(Volumes in Million Cubic Feet per Day)

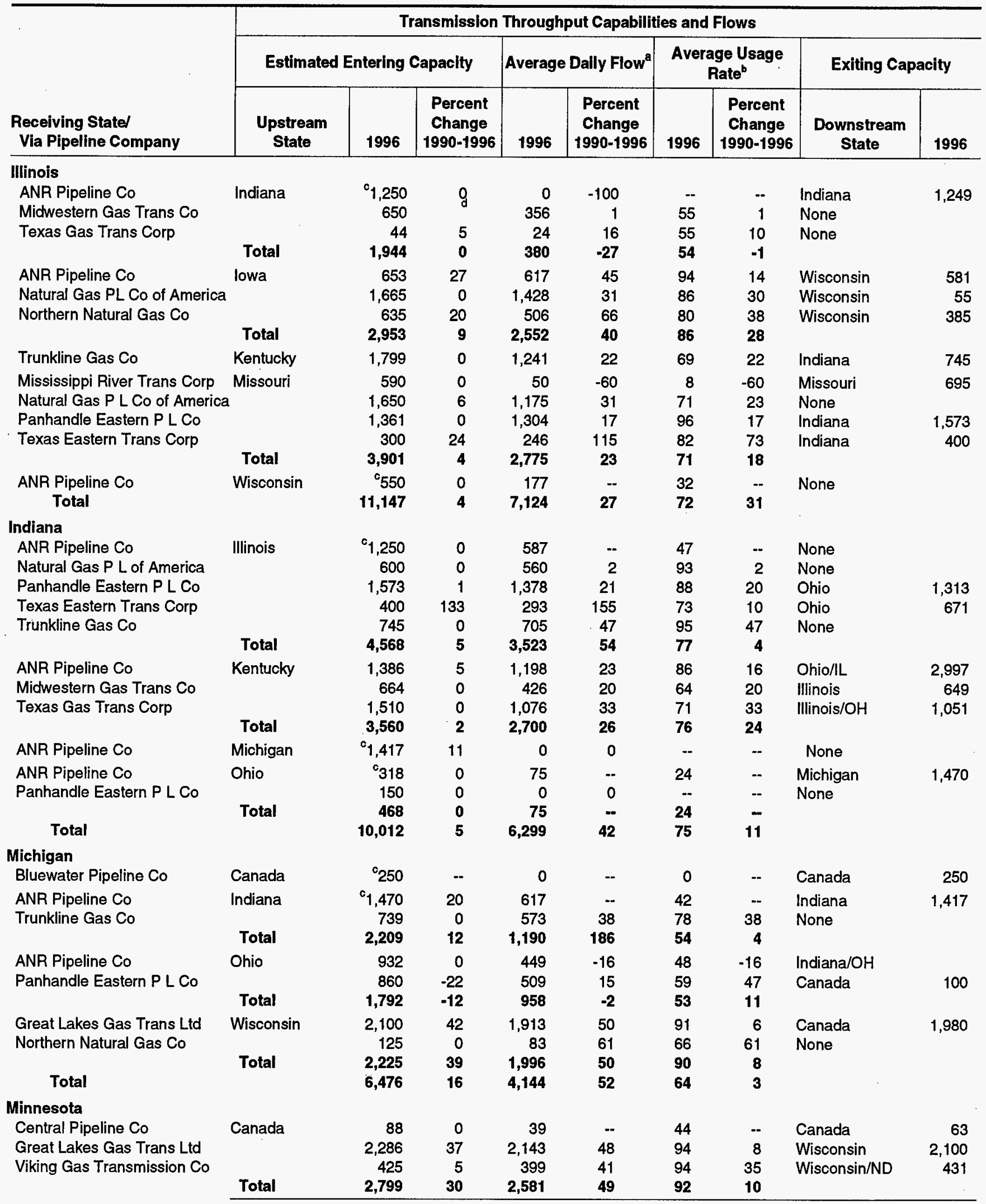


Table A2. State Border Capacity, Flows, and Utilization Rates of Interstate Natural Gas Pipelines Operating in the Midwest Region, by State, 1990 and 1996 (Continued)

(Volumes in Million Cubic Feet per Day)

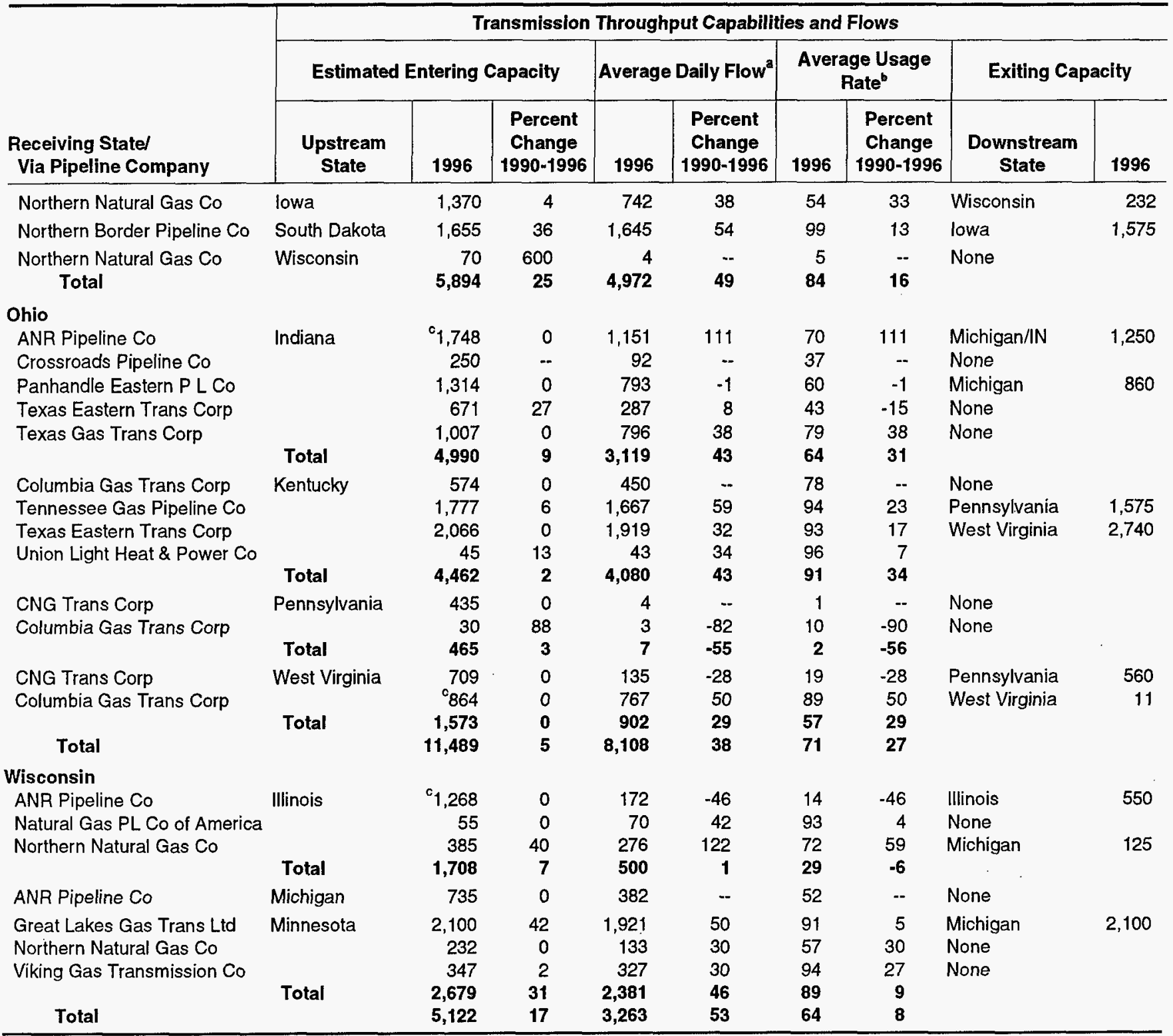

average daily flow based upon annual volumes (reported as delivered from one State to another) divided by days in the year.

${ }^{b}$ Average usage rate is equal to the average daily flow derived by estimated capacity. Utilization computation does not include capacity against which no flow was reported.

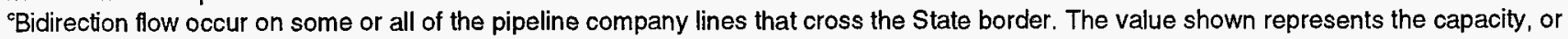
sum of capacity, for only the flow in the direction indicated.

¿Less than 0.5 percent and greater than -0.5 percent.

$--=$ Not applicable, pipeline not in service in 1990 and/or no flow reported in 1990 or 1996.

Note: Totals may not equal sum of components because of independent rounding.

Source: Energy Information Administration (EIA), EIAGIS-NG Geographic Information System, Natural Gas Pipeline State Border Capacity Database, as of December 1997. 
Figure A3. Major Interstate Natural Gas Pipelines Serving the Northeast Region

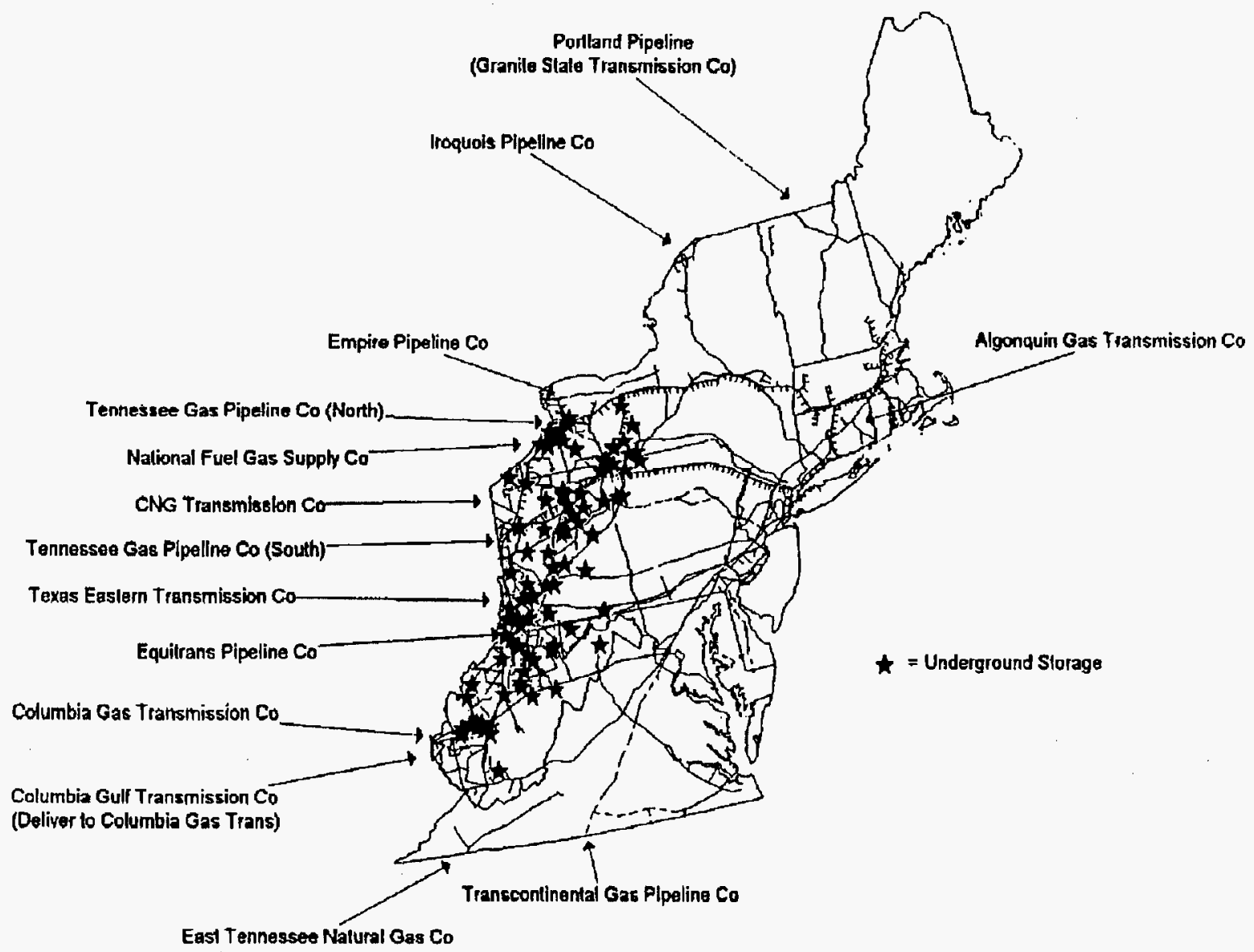

Source: Energy Information Administration (EIA), EIAGIS-NG Geographic Information System, as of December 1997. 
Table A3. State Border Capacity, Flows, and Utilization Rates of Interstate Natural Gas Pipelines Operating in the Northeast Region, by State, 1990 and 1996

(Volumes in Million Cubic Feet per Day)

\begin{tabular}{|c|c|c|c|c|c|c|c|c|c|}
\hline \multirow[b]{3}{*}{$\begin{array}{l}\text { Receiving Statel } \\
\text { Via Pipeline Company }\end{array}$} & \multicolumn{9}{|c|}{ Transmission Throughput Capabilities and Flows } \\
\hline & \multicolumn{3}{|c|}{ Estimated Entering Capacity } & \multicolumn{2}{|c|}{ Average Daily Flow ${ }^{a}$} & \multicolumn{2}{|c|}{$\begin{array}{c}\text { Average Usage } \\
\text { Rate }^{b}\end{array}$} & \multicolumn{2}{|c|}{ Exiting Capacity } \\
\hline & $\begin{array}{l}\text { Upstream } \\
\text { State }\end{array}$ & 1996 & $\begin{array}{c}\text { Percent } \\
\text { Change } \\
\text { 1990-1996 }\end{array}$ & 1996 & $\begin{array}{c}\text { Percent } \\
\text { Change } \\
\text { 1990-1996 }\end{array}$ & 1996 & $\begin{array}{c}\text { Percent } \\
\text { Change } \\
1990-1996\end{array}$ & $\begin{array}{c}\text { Downstream } \\
\text { State }\end{array}$ & 1996 \\
\hline \multicolumn{10}{|l|}{ Connecticut } \\
\hline Tennessee Gas Pipeline Co & Massachusetts & ${ }^{c} 81$ & 0 & 7 & -5 & 8 & -5 & Massachusetts & 80 \\
\hline Algonquin Gas Trans Co & New York & 1,030 & 10 & 565 & 12 & 55 & 2 & Rhode Island & 665 \\
\hline Iroquois Pipeline Co & & 420 & -- & 389 & -- & 93 & - & New York & 260 \\
\hline Tennessee Gas Pipeline Co & & 121 & 4 & 101 & -8 & 84 & -12 & None & \\
\hline & Total & 1,571 & 50 & 1,056 & 72 & 67 & 15 & & \\
\hline Total & & 1,652 & 46 & 1,063 & 71 & 64 & 17 & & \\
\hline \multicolumn{10}{|l|}{ Delaware } \\
\hline Eastern Shore Nat Gas Co & Maryland & 28 & 0 & 0 & . & -- & -- & None & \\
\hline Columbia Gas Trans Corp & Pennsylvania & 172 & 48 & 34 & 42 & 20 & -4 & New Jersey & 141 \\
\hline Eastern Shore Nat Gas Co & & 60 & 171 & 43 & 516 & 72 & 127 & Maryland & 10 \\
\hline Transcontinental Gas P L Co & & 76 & 27 & 50 & 31 & 65 & 3 & None & \\
\hline & Total & 308 & 55 & 126 & 84 & 41 & 19 & & \\
\hline Total & & 336 & 48 & 126 & 35 & 41 & -1 & & \\
\hline \multicolumn{10}{|l|}{ Maine } \\
\hline Granite State Gas Trans Inc & New Hampshire & 31 & 50 & 16 & 46 & 52 & -43 & New Hampshire & 31 \\
\hline Total & & 31 & 50 & 16 & 46 & 52 & -43 & & \\
\hline \multicolumn{10}{|l|}{ Maryland } \\
\hline Eastern Shore Nat Gas Co & Delaware & 10 & 0 & 9 & 21 & 85 & 21 & Delaware & 28 \\
\hline CNG Trans Corp & Pennsylvania & 533 & 29 & 117 & 95 & 22 & 51 & Virginia & 350 \\
\hline Columbia Gas Trans Corp & & 42 & 0 & 0 & 0 & -- & - & None & \\
\hline Eastern Shore Nat Gas Co & & 28 & $g$ & 0 & -- & - & -- & None & \\
\hline Texas Eastern Trans Corp & & ${ }^{c} 163$ & & -- & -- & - & - & Pennsylvania & 163 \\
\hline & Total & 953 & 25 & 117 & 43 & 22 & 19 & & \\
\hline Columbia Gas Trans Corp & Virginia & 1,113 & 18 & 448 & -1 & 40 & -16 & Pennsylvania & 146 \\
\hline Transcontinental Gas P L Co & & 2,100 & & 1,835 & -5 & 87 & -5 & Pennsylvania & 2,050 \\
\hline & Total & 3,213 & 6 & 2,283 & -4 & 71 & -9 & & \\
\hline Columbia Gas Trans Corp & West Virginia & 4 & 0 & 0 & -- & -- & - & None & \\
\hline Total & & 4,170 & 8 & 2,409 & -2 & 64 & -9 & & \\
\hline \multicolumn{10}{|l|}{ Massachusetts } \\
\hline Tennessee Gas Pipeline Co & Connecticut & 80 & 0 & 0 & -- & -- & - & None & None \\
\hline Tennessee Gas Pipeline Co & New York & 1,059 & 41 & 891 & 152 & 84 & 79 & $\mathrm{NH} / \mathrm{Al} / \mathrm{CT}$ & 329 \\
\hline Algonquin Gas Trans Co & Rhode Island & 560 & 5 & 296 & 4 & 53 & -1 & Rhode Island & 145 \\
\hline Total & & 1,699 & 25 & 1,187 & 86 & 73 & 48 & & \\
\hline \multicolumn{10}{|l|}{ New Hampshire } \\
\hline Granite State Gas Trans Inc & Maine & ${ }^{c} 31$ & 50 & 11 & 919 & 36 & 294 & None & \\
\hline Granite State Gas Trans Inc & Massachusetts & 31 & 19 & 10 & -62 & 31 & -68 & Maine & 31 \\
\hline Tennessee Gas Pipeline Co & & 75 & 10 & 45 & 82 & 61 & 65 & None & \\
\hline & Total & 106 & 13 & 55 & 10 & 52 & -2 & & \\
\hline Granite State Gas Trans Inc & Vermont & 31 & 29 & 22 & -1 & 70 & -24 & None & \\
\hline Total & & 168 & 29 & 88 & 20 & 52 & -7 & & \\
\hline \multicolumn{10}{|l|}{ New Jersey } \\
\hline Columbia Gas Trans Corp & Delaware & 141 & $\cdots$ & 0 & - & - & -- & None & \\
\hline Columbia Gas Trans Corp & Pennsylvania & 245 & 47 & 219 & 216 & 89 & 114 & None & \\
\hline Tennessee Gas Pipeline Co & & 499 & 3 & 263 & 27 & 53 & 24 & New York & 377 \\
\hline Texas Eastern Trans Corp & & 2,850 & 24 & 1,271 & 11 & 45 & -10 & New York & 562 \\
\hline Transcontinental Gas P L Co & & 2,387 & 0 & 1,573 & 11 & 66 & 11 & New York & 885 \\
\hline & Total & 5,981 & 12 & 3,325 & 17 & 56 & 5 & & \\
\hline Total & & 6,122 & 15 & 3,325 & 17 & 56 & 6 & & \\
\hline
\end{tabular}


Table A3. State Border Capacity, Flows, and Utilization Rates of Interstate Natural Gas Pipelines Operating in the Northeast Region, by State, 1990 and 1996 (Continued)

(Volumes in Million Cubic Feet per Day)

\begin{tabular}{|c|c|c|c|c|c|c|c|c|c|}
\hline \multirow[b]{3}{*}{$\begin{array}{l}\text { Receiving State/ } \\
\text { Via Pipeline Company }\end{array}$} & \multicolumn{9}{|c|}{ Transmission Throughput Capabilities and Flows } \\
\hline & \multicolumn{3}{|c|}{ Estimated Entering Capacity } & \multicolumn{2}{|c|}{ Average Daily Flow ${ }^{\mathrm{a}}$} & \multicolumn{2}{|c|}{$\begin{array}{c}\text { Average Usage } \\
\text { Rate }^{\mathrm{b}}\end{array}$} & \multicolumn{2}{|c|}{ Exiting Capacity } \\
\hline & $\begin{array}{l}\text { Upstream } \\
\text { State }\end{array}$ & 1996 & $\begin{array}{c}\text { Percent } \\
\text { Change } \\
1990-1996\end{array}$ & 1996 & $\begin{array}{c}\text { Percent } \\
\text { Change } \\
1990-1996\end{array}$ & 1996 & $\begin{array}{c}\text { Percent } \\
\text { Change } \\
1990-1996\end{array}$ & $\begin{array}{l}\text { Downstream } \\
\text { State }\end{array}$ & 1996 \\
\hline \multicolumn{10}{|l|}{ New York } \\
\hline Empire Pipeline Co & Canada & 503 & - & 124 & -- & 25 & -- & None & \\
\hline Iroquois Pipeline Co & & 858 & -- & 782 & -- & 91 & -- & Connecticut & 420 \\
\hline North Country P L Co & & 56 & -- & 44 & -. & 79 & -- & & \\
\hline St Lawrence Gas & & 62 & 44 & 37 & 69 & 60 & 18 & None & \\
\hline Tennessee Gas Pipeline Co & & 843 & 129 & 796 & 222 & 94 & 40 & None & \\
\hline & Total & 2,322 & 466 & 1,783 & 563 & 77 & 17 & & \\
\hline Iroquois Pipeline Co & Connecticut & 250 & -- & 200 & -- & 80 & -- & New York & 250 \\
\hline Algonquin Gas Trans Co & New Jersey & 1,150 & 13 & 629 & 8 & 55 & -5 & Connecticut & 1,030 \\
\hline Tennessee Gas Pipeline Co & & 377 & 0 & 120 & 66 & 32 & 66 & Connecticut & 121 \\
\hline Texas Eastern Trans Corp & & 562 & 4 & 250 & -4 & 45 & -8 & None & \\
\hline Transcontinental Gas P L Co & & 886 & 0 & 742 & -9 & 84 & -9 & None & \\
\hline & Total & 2,975 & 5 & 1,741 & 1 & 59 & -5 & & \\
\hline CNG Trans Corp & Pennsylvania & $c_{1,565}$ & 8 & 446 & 26 & 29 & -10 & None & \\
\hline Columbia Gas Trans Corp & & 131 & 33 & 73 & -14 & 56 & -35 & Pennsylvania & 1 \\
\hline National Fuel Gas Supply Co & & ${ }^{c} 116$ & 0 & 97 & 160 & 83 & 160 & Pennsylvania & 321 \\
\hline Penn York Energy Corp & & '95 & 0 & 45 & 32 & 47 & 32 & Pennsylvania & 60 \\
\hline Tennessee Gas Pipeline Co & & 823 & 21 & 684 & 58 & 83 & 1 & Massachusetts & 1,059 \\
\hline & Total & 2,730 & 12 & 1,348 & 26 & 9 & 9 & & \\
\hline Total & & 8,277 & 46 & 5,072 & 65 & 61 & 12 & & \\
\hline \multicolumn{10}{|l|}{ Pennsylvania } \\
\hline Columbia Gas Trans Corp & Maryland & 206 & 41 & 0 & -- & -- & -- & Delaware/NY/NJ & 547 \\
\hline Transcontinental Gas P L Co & & 2,050 & 0 & 1,748 & -8 & 85 & -8 & Maryland/DE/NJ & 2,463 \\
\hline & Total & 2,256 & 3 & 1,748 & -11 & 85 & -4 & & \\
\hline Transcontinental Gas P L Co & New Jersey & 1,900 & 9 & 0 & -- &.- & -- & None & \\
\hline Columbia Gas Trans Corp & New York & 1 & 0 & 0 & -47 & 40 & -47 & None & \\
\hline National Fuel Gas Supply Co & & ${ }^{\circ} 321$ & 23 & 234 & -- & 73 & -- & None & \\
\hline Penn York Energy Corp & & ${ }^{\circ} 60$ & 0 & 0 & - & -- & -- & None & \\
\hline & Total & 382 & 19 & 235 & 1,017 & 73 & 111 & & \\
\hline CNG Trans Corp & Ohio & 560 & 0 & 0 & -- & $\ddot{-}$ & - & New York/MD & 2,098 \\
\hline Tennessee Gas Pipeline Co & & 1,575 & 0 & 1,433 & 13 & 91 & 11 & New York/NJ & 1,322 \\
\hline & Total & 2,135 & 0 & 1,433 & 13 & 91 & 11 & & \\
\hline Carnegie Natural Gas Co & West Virginia & 30 & 0 & 20 & 100 & 84 & 23 & None & \\
\hline CNG Trans Corp & & 500 & 0 & 507 & 316 & 67 & 100 & Ohio & 435 \\
\hline Columbia Gas Trans Corp & & 1,179 & 0 & 479 & 0 & 81 & 234 & Ohio/MD/WV & 651 \\
\hline Equitrans Inc & & ${ }^{\mathrm{c}} 255$ & 7 & 51 & -19 & 49 & 21 & West Virginia & 70 \\
\hline Texas Eastern Trans Corp & & 2,625 & 4 & 2,400 & 20 & 91 & 16 & New Jersey & 2,850 \\
\hline & Total & 4,589 & 3 & 3,458 & 30 & 75 & 26 & & \\
\hline Total & & 11,262 & 4 & 7,241 & -4 & 80 & 12 & & \\
\hline \multicolumn{10}{|l|}{ Rhode Island } \\
\hline Algonquin Gas Trans Co & Connecticut & 760 & 14 & 495 & 38 & 65 & 21 & Massachusetts & 705 \\
\hline Algonquin Gas Trans Co & Massachusetts & 145 & 9 & 72 & -29 & 50 & -35 & None & \\
\hline Tennessee Gas Pipeline Co & & 173 & 518 & 146 & 597 & 85 & 13 & None & \\
\hline & Total & 318 & 98 & 218 & 78 & 69 & -10 & & \\
\hline Total & & 1,078 & 31 & 714 & 48 & 66 & 13 & & \\
\hline \multicolumn{10}{|l|}{ Vermont } \\
\hline Granite State Gas Trans Inc & Canada & 31 & 24 & 30 & 37 & 97 & 10 & New Hampshire & 31 \\
\hline Vermont Gas Sys inc & & 40 & 25 & 21 & 17 & 53 & -6 & None & \\
\hline & Total & 71 & 25 & 51 & 28 & 72 & 3 & & \\
\hline Total & & 71 & 25 & 51 & 28 & 72 & 0 & & \\
\hline
\end{tabular}


Table A3. State Border Capacity, Flows, and Utilization Rates of Interstate Natural Gas Pipelines Operating in the Northeast Region, by State, 1990 and 1996 (Continued)

(Volumes in Million Cubic Feet per Day)

\begin{tabular}{|c|c|c|c|c|c|c|c|c|c|}
\hline \multirow[b]{3}{*}{$\begin{array}{l}\text { Receiving Statel } \\
\text { Via Pipeline Company }\end{array}$} & \multicolumn{9}{|c|}{ Transmission Throughput Capabilities and Flows } \\
\hline & \multicolumn{3}{|c|}{ Estimated Entering Capacity } & \multicolumn{2}{|c|}{ Average Daily Flow ${ }^{\mathrm{a}}$} & \multicolumn{2}{|c|}{$\begin{array}{c}\text { Average Usage } \\
\text { Rate }^{b}\end{array}$} & \multicolumn{2}{|c|}{ Exiting Capacity } \\
\hline & $\begin{array}{l}\text { Upstream } \\
\text { State }\end{array}$ & 1996 & $\begin{array}{c}\text { Percent } \\
\text { Change } \\
1990-1996\end{array}$ & 1996 & $\begin{array}{c}\text { Percent } \\
\text { Change } \\
1990-1996\end{array}$ & 1996 & \begin{tabular}{|c|} 
Percent \\
Change \\
$1990-1996$
\end{tabular} & $\begin{array}{l}\text { Downstream } \\
\text { State }\end{array}$ & 1996 \\
\hline \multicolumn{10}{|l|}{ Virginia } \\
\hline CNG Trans Corp & Maryland & 350 & 10 & 73 & 317 & 21 & 281 & West Virginia & 21 \\
\hline Transcontinental Gas $P$ L Co & North Carolina & 2,587 & 7 & 2,033 & -3 & 79 & -9 & Maryland/NC & 2,520 \\
\hline East Tennessee Nat Gas Co & Tennessee & 26 & 102 & 0 & -97 & 1 & -98 & None & \\
\hline $\begin{array}{l}\text { Columbia Gas Trans Corp } \\
\text { Total }\end{array}$ & West Virginia & $\begin{array}{l}1,943 \\
4,906\end{array}$ & $\begin{array}{l}15 \\
10\end{array}$ & $\begin{array}{r}829 \\
2,935\end{array}$ & $\begin{array}{l}5 \\
1\end{array}$ & $\begin{array}{l}43 \\
60\end{array}$ & $\begin{array}{l}-8 \\
-8\end{array}$ & Maryland/NC & 1,137 \\
\hline $\begin{array}{l}\text { West Virginia } \\
\text { Columbia Gas Trans Corp } \\
\text { Tennessee Gas Pipeline Co }\end{array}$ & $\begin{array}{l}\text { Kentucky } \\
\text { Total }\end{array}$ & $\begin{array}{r}1,855 \\
681 \\
2,536\end{array}$ & $\begin{array}{l}0 \\
0 \\
0\end{array}$ & $\begin{array}{r}1,829 \\
569 \\
2,398\end{array}$ & $\begin{array}{l}17 \\
36 \\
21\end{array}$ & $\begin{array}{l}98 \\
84 \\
95\end{array}$ & $\begin{array}{l}16 \\
36 \\
21\end{array}$ & $\begin{array}{l}\text { Virginia/PA } \\
\text { None }\end{array}$ & 3,121 \\
\hline Columbia Gas Trans Corp & Maryland & 5 & 0 & 0 & -- & -- & -- & & \\
\hline $\begin{array}{l}\text { Columbia Gas Trans Corp } \\
\text { Texas Eastern Trans Corp }\end{array}$ & $\begin{array}{l}\text { Ohio } \\
\text { Total }\end{array}$ & $\begin{array}{r}12 \\
2,740 \\
2,752\end{array}$ & $\begin{array}{r}0 \\
12 \\
12\end{array}$ & $\begin{array}{r}0 \\
2,421 \\
2,421\end{array}$ & $\begin{array}{l}-99 \\
21 \\
21\end{array}$ & $\begin{array}{r}1 \\
88 \\
88\end{array}$ & $\begin{array}{r}-96 \\
8 \\
8\end{array}$ & $\begin{array}{l}\text { None } \\
\text { Pennsylvania }\end{array}$ & 2,625 \\
\hline $\begin{array}{l}\text { Columbia Gas Trans Corp } \\
\text { Equitrans Inc }\end{array}$ & $\begin{array}{l}\text { Pennsylvania } \\
\text { Total }\end{array}$ & $\begin{array}{r}579 \\
70 \\
649\end{array}$ & $\begin{array}{l}0 \\
0 \\
0\end{array}$ & $\begin{array}{r}0 \\
29 \\
29\end{array}$ & $\begin{array}{r}-- \\
32 \\
-33\end{array}$ & $\begin{array}{l}-- \\
41 \\
40\end{array}$ & $\begin{array}{r}-- \\
32 \\
-33\end{array}$ & $\begin{array}{l}\mathrm{OH} / \mathrm{KY} \\
\text { Pennsylvania }\end{array}$ & $\begin{array}{l}938 \\
255\end{array}$ \\
\hline $\begin{array}{c}\text { CNG Trans Corp } \\
\text { Total }\end{array}$ & Virginia & $\begin{array}{r}21 \\
5,962\end{array}$ & $\begin{array}{r}-34 \\
5\end{array}$ & $\begin{array}{r}7 \\
4,855\end{array}$ & $\begin{array}{r}271 \\
20\end{array}$ & $\begin{array}{l}31 \\
90\end{array}$ & $\begin{array}{r}465 \\
27\end{array}$ & Ohio/PA & 1,209 \\
\hline
\end{tabular}

average daily flow based upon annual volumes (reported as delivered from one State to another) divided by days in the year.

${ }^{b}$ Average usage rate is equal to the average daily flow derived by estimated capacity. Utilization computation does not include capacity against which no flow was reported.

'Bidirection flow occur on some or all of the pipeline company lines that cross the State border. The value shown represents the capacity, or sum of capacity, for only the flow in the direction indicated.

'Less than 0.5 percent and greater than -0.5 percent.

$--=$ Not applicable, pipeline not in service in 1990 and/or no flow reported in 1990 or 1996.

Note: Totals may not equal sum of components because of independent rounding.

Source: Energy Information Administration (EIA), EIAGIS-NG Geographic Information System, Natural Gas Pipeline State Border Capacity Database, as of December 1997. 
Figure A4. Major Interstate Natural Gas Pipelines in the Southeast Region

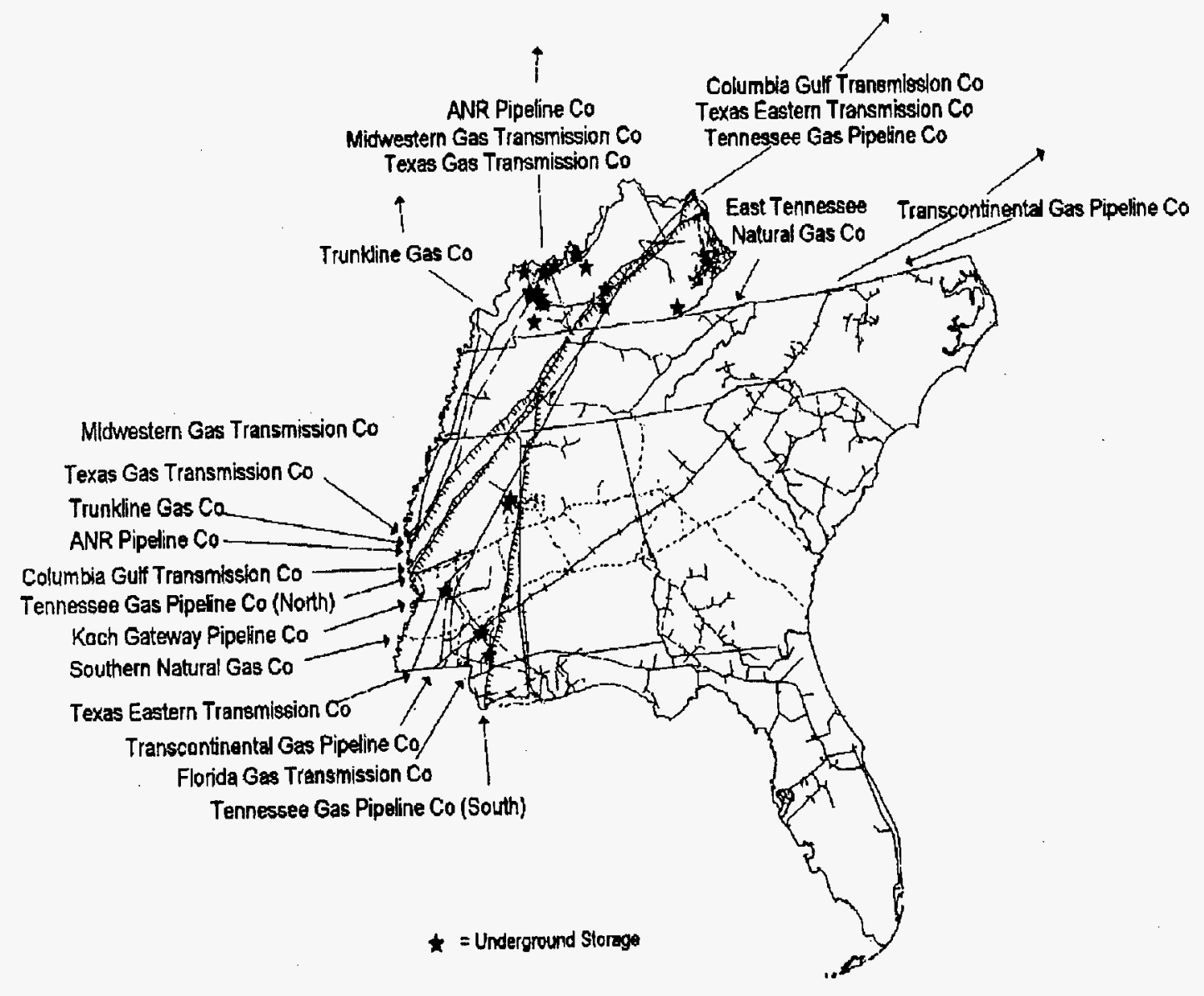

Source: Energy Information Administration (EIA), EIAGIS-NG Geographic Information System, as of December 1997. 
Table A4. State Border Capacity, Flows, and Utilization Rates of Interstate Natural Gas Pipelines Operating in the Southeast Region, by State, 1990 and 1996

(Volumes in Million Cubic Feet per Day)

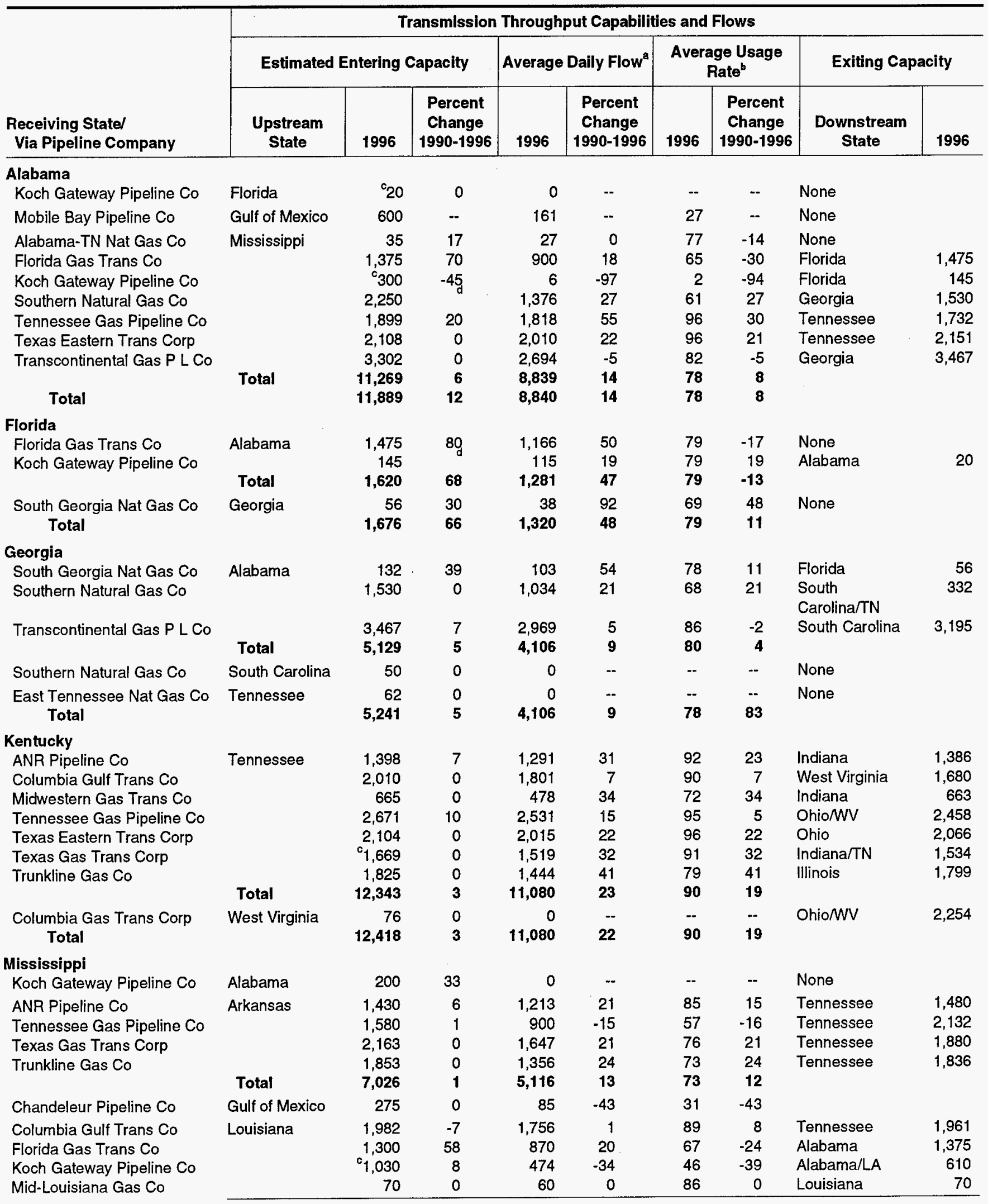


Table A4. State Border Capacity, Flows, and Utilization Rates of Interstate Natural Gas Pipelines Operating in the Southeast Region, by State, 1990 and 1996 (Continued)

(Volumes in Million Cubic Feet per Day)

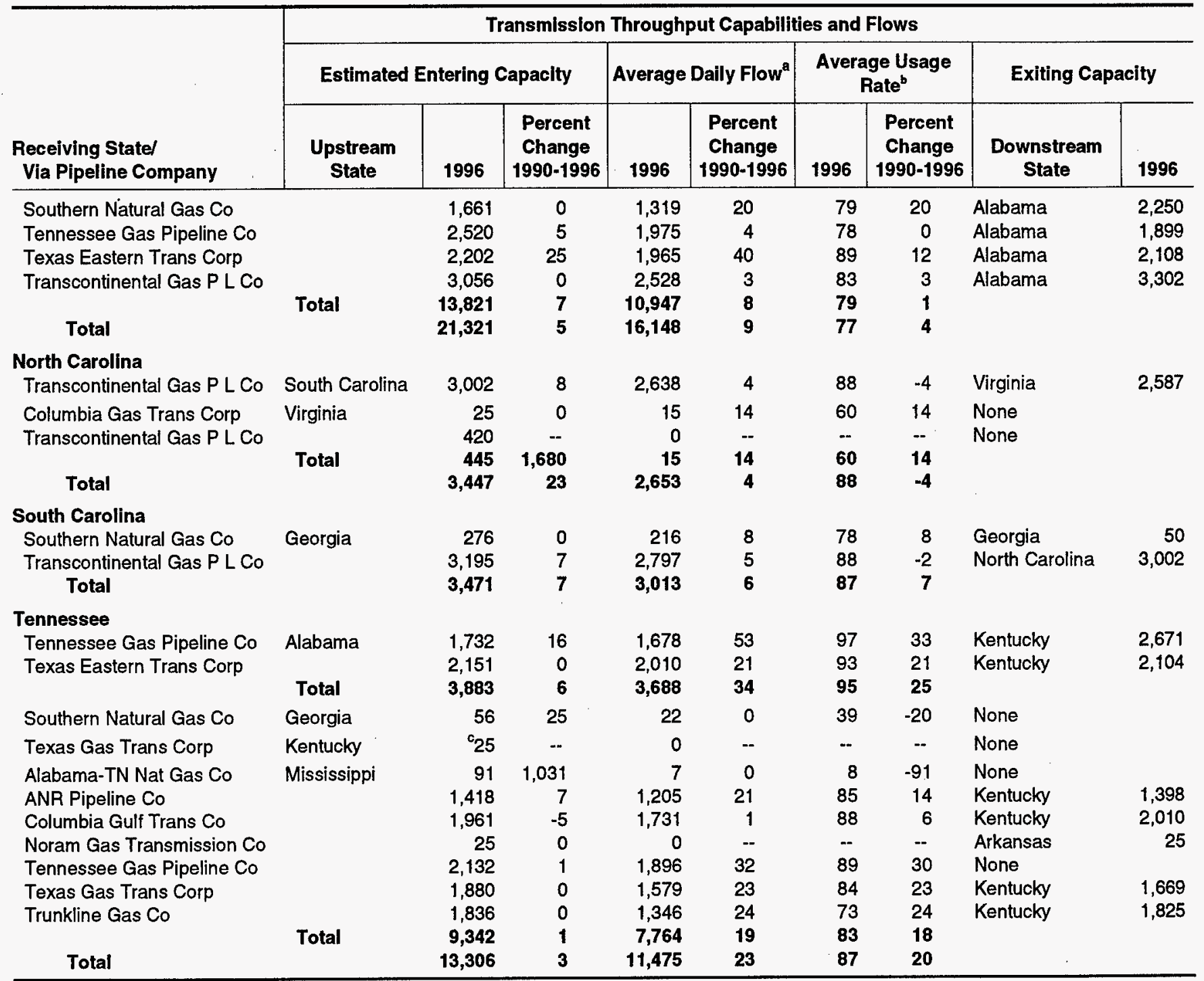

'Average daily flow based upon annual volumes (reported as delivered from one State to another) divided by days in the year.

bAverage usage rate is equal to the average daily flow derived by estimated capacity. Utilization computation does not include capacity against which no flow was reported.

${ }^{\circ}$ Bidirection flow occur on some or all of the pipeline company lines that cross the State border. The value shown represents the capacity, or sum of capacity, for only the flow in the direction indicated.

'Less than 0.5 percent and greater than -0.5 percent.

.- = Not applicable, pipeline not in service in 1990 and/or no flow reported in 1990 or 1996.

Note: Totals may not equal sum of components because of independent rounding.

Source: Energy Information Administration (EIA), EIAGIS-NG Geographic Information System, Natural Gas Pipeline State Border Capacity Database, as of December 1997. 
Figure A5. Major Interstate Natural Gas Pipelines Exporting from the Southwest Region

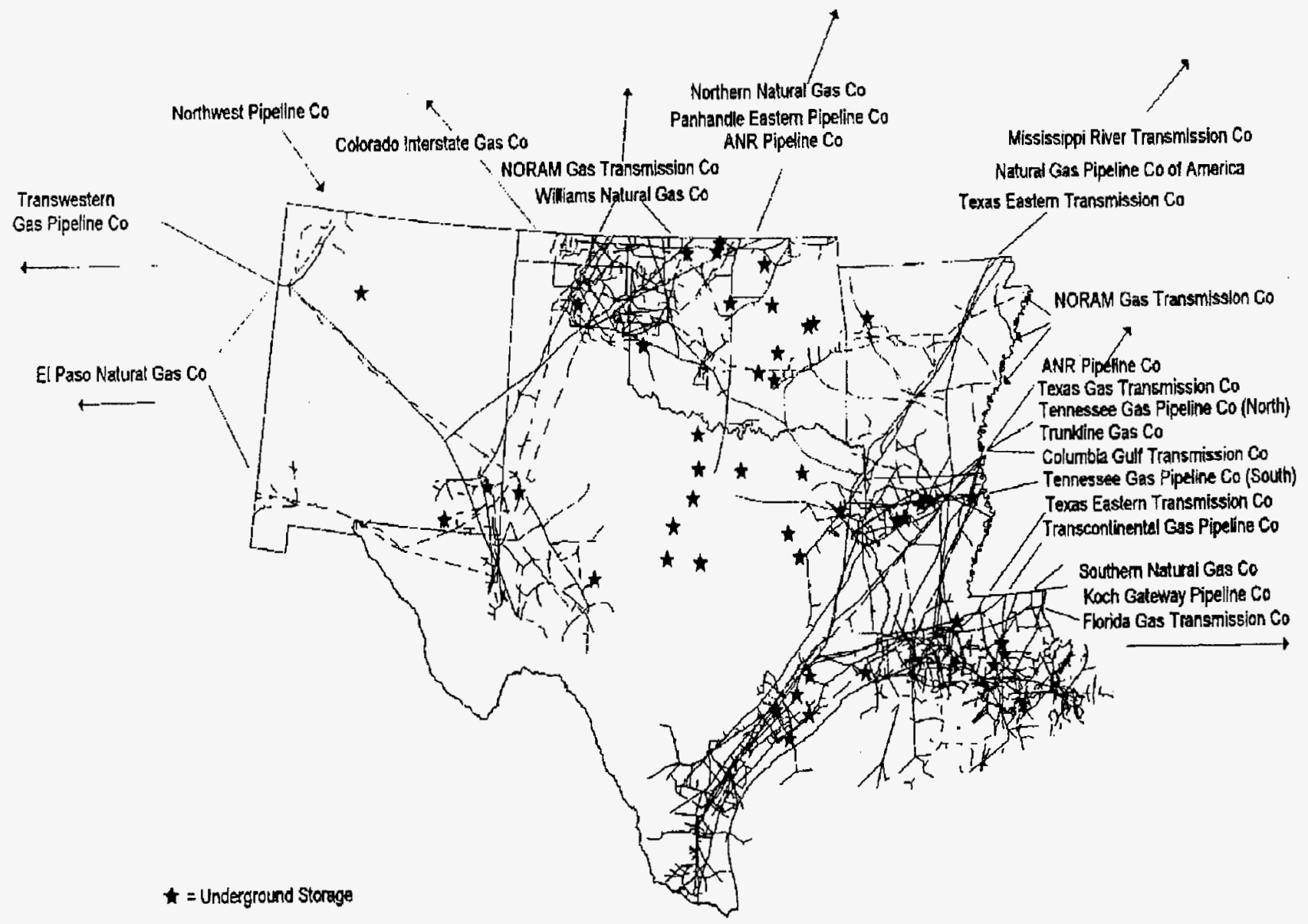

Source: Energy Information Administration (EIA), EIAGIS-NG Geographic Information System, as of December 1997. 
Table A5. State Border Capacity, Flows, and Utilization Rates of Interstate Natural Gas Pipelines Operating in the Southwest Region, by State, 1990 and 1996

(Volumes in Million Cubic Feet per Day)

\begin{tabular}{|c|c|c|c|c|c|c|c|c|c|}
\hline \multirow[b]{3}{*}{$\begin{array}{l}\text { Receiving State/ } \\
\text { Via Pipeline Company }\end{array}$} & \multicolumn{9}{|c|}{ Transmission Throughput Capabilities and Flows } \\
\hline & \multicolumn{3}{|c|}{ Estimated Entering Capacity } & \multicolumn{2}{|c|}{ Average Daily Flow ${ }^{\mathrm{a}}$} & \multicolumn{2}{|c|}{ Average Usage Rate } & \multicolumn{2}{|c|}{ Exiting Capacity } \\
\hline & $\begin{array}{l}\text { Upstream } \\
\text { State }\end{array}$ & 1996 & $\begin{array}{c}\text { Percent } \\
\text { Change } \\
1990-1996\end{array}$ & 1996 & $\begin{array}{c}\text { Percent } \\
\text { Change } \\
1990-1996\end{array}$ & 1996 & $\begin{array}{c}\text { Percent } \\
\text { Change } \\
1990-1996\end{array}$ & $\begin{array}{c}\text { Downstream } \\
\text { State }\end{array}$ & 1996 \\
\hline $\begin{array}{l}\text { Arkansas } \\
\text { ANR Pipeline Co } \\
\text { Mississippi River Trans Corp } \\
\text { Noram Gas Transmission Co } \\
\text { Tennessee Gas Pipeline Co } \\
\text { Texas Gas Trans Corp } \\
\text { Trunkline Gas Co }\end{array}$ & Louisiana & $\begin{array}{r}1,430 \\
{ }^{7} 730 \\
c_{120} \\
1,581 \\
2,002 \\
1,853 \\
7,716\end{array}$ & $\begin{array}{r}7 \\
35 \\
0 \\
0 \\
0 \\
0 \\
4\end{array}$ & $\begin{array}{r}1,213 \\
111 \\
44 \\
901 \\
1,592 \\
1,356 \\
5,218\end{array}$ & $\begin{array}{r}21 \\
-57 \\
- \\
-14 \\
24 \\
24 \\
11\end{array}$ & $\begin{array}{l}85 \\
15 \\
37 \\
57 \\
80 \\
73 \\
68\end{array}$ & $\begin{array}{r}14 \\
-68 \\
-- \\
-14 \\
24 \\
24 \\
6\end{array}$ & $\begin{array}{l}\text { Mississippi } \\
\text { Missouri/LA } \\
\text { Missouri } \\
\text { Mississippi } \\
\text { Mississippi } \\
\text { Mississippi }\end{array}$ & $\begin{array}{r}1,430 \\
1,280 \\
100 \\
1,580 \\
2,163 \\
1,852\end{array}$ \\
\hline Associated Natural Gas Co & Missouri & ${ }^{c_{30}}$ & 0 & 26 & 250 & 88 & 250 & Missouri & 10 \\
\hline $\begin{array}{l}\text { Noram Gas Transmission Co } \\
\text { Ozark Gas Trans Sys }\end{array}$ & $\begin{array}{l}\text { Oklahoma } \\
\text { Total }\end{array}$ & $\begin{array}{r}1,654 \\
170 \\
1,824\end{array}$ & $\begin{array}{l}0 \\
0\end{array}$ & $\begin{array}{r}1,010 \\
81 \\
1,091\end{array}$ & $\begin{array}{r}47 \\
353 \\
55\end{array}$ & $\begin{array}{l}61 \\
48 \\
60\end{array}$ & $\begin{array}{r}47 \\
353 \\
55\end{array}$ & $\begin{array}{l}\text { Louisiana/TX } \\
\text { None }\end{array}$ & 206 \\
\hline Noram Gas Transmission Co & Tennessee & 25 & 0 & 0 & -- & -- & -- & None & \\
\hline $\begin{array}{l}\text { Natural Gas P L Co of America } \\
\text { Texas Eastern Trans Corp }\end{array}$ & $\begin{array}{l}\text { Texas } \\
\text { Total }\end{array}$ & $\begin{array}{r}{ }^{\circ} 1,893 \\
267 \\
2,160 \\
11,755\end{array}$ & $\begin{array}{r}19 \\
5 \\
17 \\
5\end{array}$ & $\begin{array}{r}1,167 \\
179 \\
1,345 \\
7,680\end{array}$ & $\begin{array}{r}32 \\
257 \\
44 \\
21\end{array}$ & $\begin{array}{l}62 \\
67 \\
62 \\
65\end{array}$ & $\begin{array}{r}11 \\
241 \\
23 \\
13\end{array}$ & $\begin{array}{l}\text { Missouri } \\
\text { Missouri }\end{array}$ & $\begin{array}{r}2,250 \\
300\end{array}$ \\
\hline $\begin{array}{l}\text { Louisiana } \\
\text { Mississippi River Trans Corp } \\
\text { Noram Gas Transmission Co }\end{array}$ & $\begin{array}{l}\text { Arkansas } \\
\text { Total }\end{array}$ & $\begin{array}{l}{ }^{c} 550 \\
156 \\
706\end{array}$ & $\begin{array}{r}0 \\
-31 \\
-9\end{array}$ & $\begin{array}{r}539 \\
0 \\
539\end{array}$ & $\begin{array}{r}10 \\
-. \\
10\end{array}$ & $\begin{array}{l}98 \\
-- \\
98\end{array}$ & $\begin{array}{l}10 \\
-- \\
10\end{array}$ & $\begin{array}{l}\text { None } \\
\text { Texas }\end{array}$ & 25 \\
\hline $\begin{array}{l}\text { ANR Pipeline Co } \\
\text { Columbia Gulf Trans Co } \\
\text { High Island Offshore Co } \\
\text { Koch Gateway Pipeline Co } \\
\text { Quivira Gas Co } \\
\text { Sea Robin Pipeline Co } \\
\text { Shell Gas Pipeline Co } \\
\text { Southern Natural Gas Co } \\
\text { Stingray Pipeline Co } \\
\text { Tennessee Gas Pipeline Co } \\
\text { Texas Eastern Texas Trans Co }\end{array}$ & Gulf of Mexico $^{d}$ & $\begin{array}{r}1,919 \\
1,210 \\
1,800 \\
530 \\
120 \\
1,595 \\
600 \\
2,012 \\
1,170 \\
2,755 \\
990 \\
1,700 \\
1,226 \\
17,627\end{array}$ & $\begin{array}{l}\text { NA } \\
\text { NA } \\
\text { NA } \\
\text { NA } \\
\text { NA } \\
\text { NA } \\
\text { NA } \\
\text { NA } \\
\text { NA } \\
\text { NA } \\
\text { NA } \\
\text { NA } \\
\text { NA } \\
\text { NA }\end{array}$ & $\begin{array}{l}\text { NA } \\
\text { NA } \\
\text { NA } \\
\text { NA } \\
\text { NA } \\
\text { NA } \\
\text { NA } \\
\text { NA } \\
\text { NA } \\
\text { NA } \\
\text { NA } \\
\text { NA } \\
\text { NA } \\
\text { NA }\end{array}$ & $\begin{array}{l}-. \\
-- \\
- \\
.- \\
-- \\
- \\
-- \\
-- \\
-- \\
- \\
- \\
- \\
- \\
-\end{array}$ & $\begin{array}{l}\text { NA } \\
\text { NA } \\
N A \\
N A \\
N A \\
N A \\
N A \\
N A \\
N A \\
N A \\
N A \\
N A \\
N A \\
N A\end{array}$ & $\begin{array}{l}-- \\
-- \\
- \\
-- \\
-- \\
-- \\
-- \\
-- \\
- \\
-- \\
-- \\
- \\
- \\
--\end{array}$ & $\begin{array}{l}-- \\
- \\
-- \\
- \\
- \\
-- \\
- \\
-- \\
-- \\
- \\
- \\
- \\
-- \\
-\end{array}$ & \\
\hline $\begin{array}{l}\text { Koch Gateway Pipeline Co } \\
\text { Mid-Louisiana Gas Co }\end{array}$ & $\begin{array}{l}\text { Mississippi } \\
\text { Total }\end{array}$ & $\begin{array}{r}{ }^{c} 310 \\
70 \\
380\end{array}$ & $\begin{array}{l}0 \\
0 \\
0\end{array}$ & $\begin{array}{r}0 \\
60 \\
60\end{array}$ & $\begin{array}{l}-- \\
- \\
-\end{array}$ & $\begin{array}{l}-. \\
86 \\
16\end{array}$ & $\begin{array}{l}-- \\
-- \\
--\end{array}$ & $\begin{array}{l}\text { None } \\
\text { None }\end{array}$ & \\
\hline $\begin{array}{l}\text { Florida Gas Trans Co } \\
\text { Gulf States Transmission Corp } \\
\text { Koch Gateway Pipeline Co } \\
\text { Mississippi River Trans Corp } \\
\text { Natural Gas P L Co of America } \\
\text { Noram Gas Transmission Co } \\
\text { Sabine Pipe Line Company } \\
\text { Southern Natural Gas Co } \\
\text { Tennessee Gas Pipeline Co } \\
\text { Texas Eastern Trans Corp } \\
\text { Texas Gas Trans Corp } \\
\text { Transcontinental Gas P L Co } \\
\text { Trunkline Gas Co }\end{array}$ & Texas & $\begin{array}{r}320 \\
75 \\
825 \\
85 \\
{ }^{\circ} 725 \\
140 \\
270 \\
110 \\
1,307 \\
{ }^{c} 743 \\
179 \\
725 \\
334 \\
5,838\end{array}$ & $\begin{array}{r}7 \\
8 \\
0 \\
0 \\
87 \\
0 \\
18 \\
13 \\
10 \\
30 \\
0 \\
0 \\
6\end{array}$ & $\begin{array}{r}253 \\
9 \\
731 \\
58 \\
663 \\
93 \\
98 \\
48 \\
1,231 \\
602 \\
161 \\
702 \\
307 \\
4,958\end{array}$ & $\begin{array}{r}23 \\
17 \\
39 \\
97 \\
357 \\
44 \\
-- \\
81 \\
23 \\
-1 \\
38 \\
12 \\
21 \\
38\end{array}$ & $\begin{array}{l}79 \\
13 \\
89 \\
68 \\
91 \\
67 \\
36 \\
44 \\
94 \\
81 \\
90 \\
97 \\
92 \\
85\end{array}$ & $\begin{array}{r}16 \\
17 \\
40 \\
97 \\
357 \\
-23 \\
-- \\
54 \\
9 \\
-9 \\
6 \\
12 \\
21 \\
23\end{array}$ & $\begin{array}{l}\text { Mississippi } \\
\text { None } \\
\text { Mississippi } \\
\text { Arkansas } \\
\text { None } \\
\text { Arkansas } \\
\text { None } \\
\text { Mississippi } \\
\text { Mississippi/AR } \\
\text { Mississippi } \\
\text { Arkansas } \\
\text { Mississippi } \\
\text { Arkansas }\end{array}$ & $\begin{array}{r}1,340 \\
1,030 \\
1,340 \\
825 \\
1,661 \\
4,101 \\
2,201 \\
2,002 \\
3,056 \\
1,852\end{array}$ \\
\hline $\begin{array}{l}\text { ANR Pipeline Co } \\
\text { Columbia Gulf Transmission Co } \\
\text { Natural Gas PL Co of America } \\
\text { Transwestern Pipeline Corp } \\
\text { Total }\end{array}$ & Louisiana & $\begin{array}{c}e \\
e \\
e \\
e \\
24,560\end{array}$ & $\begin{array}{l}-- \\
-- \\
-- \\
4\end{array}$ & $\begin{array}{r}-. \\
-. \\
-- \\
-- \\
8,093\end{array}$ & $\begin{array}{l}-- \\
-- \\
-- \\
50\end{array}$ & $\begin{array}{c}-. \\
-- \\
-- \\
- \\
78\end{array}$ & $\begin{array}{l}-- \\
-- \\
-- \\
11\end{array}$ & $\begin{array}{l}\text { Arkansas } \\
\text { Mississippi } \\
\text { Texas } \\
\text { Texas }\end{array}$ & $\begin{array}{r}1,338 \\
2,133 \\
509 \\
199\end{array}$ \\
\hline
\end{tabular}


Table A5. State Border Capacity, Flows, and Utilization Rates of Interstate Natural Gas Pipelines Operating in the Southwest Region, by State, 1990 and 1996 (Continued)

(Volumes in Million Cubic Feet per Day)

\begin{tabular}{|c|c|c|c|c|c|c|c|c|c|}
\hline \multirow[b]{3}{*}{$\begin{array}{l}\text { Receiving State/ } \\
\text { Via Pipeline Company }\end{array}$} & \multicolumn{9}{|c|}{ Transmission Throughput Capabilities and Flows } \\
\hline & \multicolumn{3}{|c|}{ Estimated Entering Capacity } & \multicolumn{2}{|c|}{ Average Daily Flow ${ }^{\mathrm{a}}$} & \multicolumn{2}{|c|}{ Average Usage Rate ${ }^{b}$} & \multicolumn{2}{|c|}{ Exiting Capacity } \\
\hline & $\begin{array}{l}\text { Upstream } \\
\text { State }\end{array}$ & 1996 & $\begin{array}{c}\text { Percent } \\
\text { Change } \\
1990-1996\end{array}$ & 1996 & $\begin{array}{c}\text { Percent } \\
\text { Change } \\
1990-1996\end{array}$ & 1996 & $\begin{array}{c}\text { Percent } \\
\text { Change } \\
\text { 1990-1996 }\end{array}$ & $\mid \begin{array}{c}\text { Downstream } \\
\text { State }\end{array}$ & 1996 \\
\hline \multicolumn{10}{|l|}{ New Mexico } \\
\hline $\begin{array}{l}\text { El Paso Natural Gas Co } \\
\text { Transcolorado Gas Trans Co } \\
\text { Transwestern Pipeline Co }\end{array}$ & Colorado & $\begin{array}{r}650 \\
120 \\
500 \\
\mathbf{1 , 2 7 0}\end{array}$ & $\begin{array}{r}50 \\
-- \\
233 \\
118\end{array}$ & $\begin{array}{l}573 \\
100 \\
277 \\
949\end{array}$ & $\begin{array}{r}47 \\
-- \\
-- \\
143\end{array}$ & $\begin{array}{l}88 \\
83 \\
55 \\
75\end{array}$ & $\begin{array}{l}-2 \\
-- \\
-- \\
17\end{array}$ & $\begin{array}{l}\text { Arizona } \\
\text { None } \\
\text { Arizona }\end{array}$ & $\begin{array}{l}650 \\
500\end{array}$ \\
\hline $\begin{array}{l}\text { El Paso Natural Gas Co } \\
\text { Natural Gas P L Co of America } \\
\text { Transwestern Pipeline Co }\end{array}$ & Texas & $\begin{array}{r}{ }^{c} 2,750 \\
c 550 \\
c 950 \\
4,250 \\
5,520\end{array}$ & $\begin{array}{l}7 \\
91 \\
21 \\
17 \\
30\end{array}$ & $\begin{array}{r}7 \\
4 \\
0 \\
11 \\
960\end{array}$ & $\begin{array}{r}-99 \\
-95 \\
- \\
-99 \\
-53\end{array}$ & $\begin{array}{r}0 \\
1 \\
- \\
1 \\
52\end{array}$ & $\begin{array}{r}-99 \\
-97 \\
-- \\
-98 \\
4\end{array}$ & $\begin{array}{l}\text { Arizona } \\
\text { Texas } \\
\text { Arizona }\end{array}$ & $\begin{array}{r}4,261 \\
720 \\
1,090\end{array}$ \\
\hline \multicolumn{10}{|l|}{ Oklahoma } \\
\hline $\begin{array}{l}\text { KN Interstate Gas Co } \\
\text { Natural Gas P L Co of America } \\
\text { Williams Natural Gas Co }\end{array}$ & Kansas & $\begin{array}{r}5 \\
{ }^{\circ} 300 \\
259 \\
564\end{array}$ & $\begin{array}{r}0 \\
0 \\
48 \\
18\end{array}$ & $\begin{array}{r}4 \\
0 \\
87 \\
91\end{array}$ & $\begin{array}{r}-- \\
212 \\
227\end{array}$ & $\begin{array}{l}80 \\
-\overline{34} \\
36\end{array}$ & $\begin{array}{r}-- \\
111 \\
117\end{array}$ & $\begin{array}{l}\text { Texas } \\
\text { Texas } \\
\text { Missouri }\end{array}$ & $\begin{array}{r}35 \\
750 \\
496\end{array}$ \\
\hline $\begin{array}{l}\text { ANR Pipeline Co } \\
\text { Colorado Interstate Gas } \\
\text { EI Paso Natural Gas Co } \\
\text { KN Interstate Gas Co } \\
\text { Natural Gas P L Co of America } \\
\text { Northern Natural Gas Co } \\
\text { Panhandle Eastern P L Co } \\
\text { Transok Inc } \\
\text { Transwestern Pipeline Co } \\
\text { Williams Natural Gas Co } \\
\text { Total }\end{array}$ & Texas & $\begin{array}{r}580 \\
c_{200} \\
c_{152} 152 \\
c^{c} 135 \\
{ }^{1} 1,765 \\
c_{2,500} \\
c^{3} 389 \\
30 \\
75 \\
100 \\
5,926 \\
6,740\end{array}$ & $\begin{array}{r}21 \\
0 \\
0 \\
0 \\
16 \\
0 \\
-4 \\
-- \\
0 \\
0 \\
6 \\
8\end{array}$ & $\begin{array}{r}319 \\
100 \\
51 \\
70 \\
617 \\
451 \\
289 \\
24 \\
40 \\
66 \\
2,027 \\
2,318\end{array}$ & $\begin{array}{r}457 \\
-- \\
-- \\
- \\
52 \\
74 \\
82 \\
-- \\
-36 \\
-3 \\
100 \\
95\end{array}$ & $\begin{array}{l}55 \\
50 \\
33 \\
52 \\
35 \\
18 \\
74 \\
80 \\
53 \\
66 \\
34 \\
36\end{array}$ & $\begin{array}{c}362 \\
-- \\
-- \\
-- \\
22 \\
25 \\
89 \\
-- \\
-36 \\
-3 \\
45 \\
41\end{array}$ & $\begin{array}{l}\text { Kansas } \\
\text { None } \\
\text { None } \\
\text { None } \\
\text { Kansas/TX } \\
\text { Kansas } \\
\text { Kansas/TX } \\
\text { None } \\
\text { Kansas } \\
\text { Kansas }\end{array}$ & $\begin{array}{r}1,903 \\
1,330 \\
1,451 \\
\\
5 \\
496\end{array}$ \\
\hline \multicolumn{10}{|l|}{ Texas } \\
\hline $\begin{array}{l}\text { Natural Gas P L Co of America } \\
\text { Noram Gas Transmission Co }\end{array}$ & $\begin{array}{l}\text { Arkansas } \\
\text { Total }\end{array}$ & $\begin{array}{r}600 \\
50 \\
650\end{array}$ & $\begin{array}{r}0 \\
43 \\
2\end{array}$ & $\begin{array}{r}0 \\
12 \\
12\end{array}$ & $\begin{array}{r}0 \\
-55 \\
-55\end{array}$ & $\begin{array}{l}-- \\
23 \\
23\end{array}$ & $\begin{array}{l}-- \\
-68 \\
-68\end{array}$ & $\begin{array}{l}\text { None } \\
\text { Louisiana }\end{array}$ & 140 \\
\hline $\begin{array}{l}\text { Black Marlin Pipeline Co } \\
\text { Natural Gas PL Co of America } \\
\text { Sea Rim Pipeline Co } \\
\text { Seagulf Interstate Corp } \\
\text { Superior Offshore Pipeline Co } \\
\text { Transcontinental Gas PL Co }\end{array}$ & Gulf of Mexico $^{d}$ & $\begin{array}{r}384 \\
115 \\
176 \\
95 \\
360 \\
400 \\
1,530\end{array}$ & $\begin{array}{l}\text { NA } \\
\text { NA } \\
\text { NA } \\
\text { NA } \\
\text { NA } \\
\text { NA }\end{array}$ & $\begin{array}{l}\text { NA } \\
\text { NA } \\
\text { NA } \\
\text { NA } \\
\text { NA } \\
\text { NA }\end{array}$ & $\begin{array}{l}-- \\
-- \\
-- \\
- \\
- \\
--\end{array}$ & $\begin{array}{l}\text { NA } \\
\text { NA } \\
\text { NA } \\
\text { NA } \\
\text { NA } \\
\text { NA }\end{array}$ & $\begin{array}{l}-- \\
-- \\
-- \\
-- \\
-- \\
--\end{array}$ & $\begin{array}{l}-- \\
-- \\
- \\
-- \\
-- \\
--\end{array}$ & \\
\hline $\begin{array}{l}\text { Koch Gateway Pipeline Co } \\
\text { Natural Gas P L Co of America } \\
\text { Noram Gas Transmission Co } \\
\text { Texas Eastern Trans Corp }\end{array}$ & Louisiana & $\begin{array}{r}20 \\
140 \\
25 \\
0199 \\
384\end{array}$ & $\begin{array}{r}0 \\
-90 \\
0 \\
0 \\
-77\end{array}$ & $\begin{array}{r}4 \\
0 \\
14 \\
0 \\
18\end{array}$ & $\begin{array}{r}-- \\
138 \\
-\overline{-} \\
-\overline{43}\end{array}$ & $\begin{array}{l}19 \\
-- \\
58 \\
- \\
41\end{array}$ & $\begin{array}{c}-- \\
138 \\
\overline{45}\end{array}$ & $\begin{array}{l}\text { None } \\
\text { Arkansas } \\
\text { None } \\
\text { Louisiana }\end{array}$ & $\begin{array}{r}1,873 \\
743\end{array}$ \\
\hline Texas Eastern Trans Corp & Mexico & ${ }^{c} 350$ & 0 & 37 & -. & 11 & -- & None & \\
\hline $\begin{array}{l}\text { El Paso Natural Gas Co } \\
\text { Natural Gas P L Co of America } \\
\text { Northern Natural Gas Co } \\
\text { Transwestern Pipeline Co }\end{array}$ & New Mexico & $\begin{array}{r}{ }^{c} 1,546 \\
c^{7} 720 \\
c^{2} 200 \\
{ }^{c} 800 \\
3,266\end{array}$ & $\begin{array}{r}0 \\
41 \\
0 \\
2 \\
7\end{array}$ & $\begin{array}{r}601 \\
282 \\
141 \\
523 \\
1,548\end{array}$ & $\begin{array}{l}-- \\
56 \\
23 \\
62 \\
43\end{array}$ & $\begin{array}{l}39 \\
39 \\
70 \\
65 \\
47\end{array}$ & $\begin{array}{l}-\overline{81} \\
23 \\
40 \\
78\end{array}$ & $\begin{array}{l}\text { None } \\
\text { Oklahoma } \\
\text { Oklahoma } \\
\text { Oklahoma }\end{array}$ & $\begin{array}{r}1,765 \\
2,500 \\
75\end{array}$ \\
\hline $\begin{array}{l}\text { ANR Pipeline Co } \\
\text { Colorado Interstate Gas } \\
\text { El Paso Natural Gas Co } \\
\text { KN Interstate Gas Co } \\
\text { Natural Gas P L Co of America }\end{array}$ & Oklahoma & $\begin{array}{r}150 \\
{ }^{\circ} 200 \\
{ }^{\circ} 250 \\
{ }^{\circ} 35 \\
{ }^{c} 750 \\
\end{array}$ & $\begin{array}{r}0 \\
0 \\
0 \\
0 \\
22 \\
\end{array}$ & $\begin{array}{r}119 \\
24 \\
12 \\
3 \\
572 \\
\end{array}$ & $\begin{array}{r}332 \\
-56 \\
-95 \\
-81 \\
18 \\
\end{array}$ & $\begin{array}{r}79 \\
12 \\
5 \\
8 \\
76 \\
\end{array}$ & $\begin{array}{r}332 \\
-56 \\
-95 \\
-81 \\
-4 \\
\end{array}$ & $\begin{array}{l}\text { None } \\
\text { New Mexico } \\
\text { None } \\
\text { New Mexico }\end{array}$ & $\begin{array}{r}\text { None } \\
2,750 \\
550 \\
\end{array}$ \\
\hline
\end{tabular}


Table A5. State Border Capacity, Flows, and Utilization Rates of Interstate Natural Gas Pipelines Operating in the Southwest Region, by State, 1990 and 1996 (Continued) (Volumes in Million Cubic Feet per Day)

\begin{tabular}{|c|c|c|c|c|c|c|c|c|c|}
\hline \multirow[b]{3}{*}{$\begin{array}{l}\text { Receiving State/ } \\
\text { Via Pipeline Company }\end{array}$} & \multicolumn{9}{|c|}{ Transmission Throughput Capablities and Flows } \\
\hline & \multicolumn{3}{|c|}{ Estimated Entering Capacity } & \multicolumn{2}{|c|}{ Average Daily Flow ${ }^{\mathrm{a}}$} & \multicolumn{2}{|c|}{ Average Usage Rateb } & \multicolumn{2}{|c|}{ Exiting Capacity } \\
\hline & $\begin{array}{l}\text { Upstream } \\
\text { State }\end{array}$ & 1996 & $\begin{array}{c}\text { Percent } \\
\text { Change } \\
\text { 1990-1996 }\end{array}$ & 1996 & $\begin{array}{c}\text { Percent } \\
\text { Change } \\
1990-1996\end{array}$ & 1996 & $\begin{array}{c}\text { Percent } \\
\text { Change } \\
\text { 1990-1996 }\end{array}$ & $\begin{array}{c}\text { Downstream } \\
\text { State }\end{array}$ & 1996 \\
\hline Noram Gas Transmisssion Co & & 139 & 0 & 13 & 141 & 9 & 141 & None & \\
\hline Northern Natural Gas Co & & $c_{1,050}$ & 75 & 175 & 41 & 17 & -19 & None & \\
\hline Panhandle Eastern P L Co & & 56 & 0 & 34 & 7 & 60 & 7 & Oklahoma & 389 \\
\hline Transok Inc & & 50 & -- & 11 & -- & 22 & .. & None & \\
\hline Transwestern Pipeline Co & & 115 & 35 & 26 & -58 & 23 & -69 & New Mexico & 950 \\
\hline & Total & 2,795 & 31 & 988 & .5 & 38 & -22 & & \\
\hline Total & & 8,575 & -4 & 2,759 & 95 & 41 & 73 & & \\
\hline ANR Pipeline Co & Texas & e & - & -- & -- & - & -- & Oklahoma & 250 \\
\hline Florida Gas Transmission Co & & e & $\therefore$ & -- & -- & -- & -- & Louisiana & 300 \\
\hline Mississippi River Transm Co & & e & -- & -- & -- & -- & -- & Louisiana & 85 \\
\hline Southern Natural Gas Co & & e & -- & -. &.- & -- & - & Louisiana & 93 \\
\hline Tennessee Gas Pipeline Co & & e & -- & -- & -- & -- & -- & Louisiana & 1,153 \\
\hline Texas Eastern Trans Corp & & e & -. & .- & -. & -. & .. & Arkansas/LA & 937 \\
\hline Texas Gas Transmission Corp & & e & -- & -. & -- & - & -- & Louisiana & 138 \\
\hline Transcontinental Gas Pipeline Co & & e & -- & -- & .- & -- & -- & Louisiana & 725 \\
\hline Trunkline Gas Co & & e & -- & -- & -- & -- & -- & Louisiana & 334 \\
\hline United Gas Pipeline Co & & e & -- & -- & -- & -- & -- & Louisiana & 830 \\
\hline Williams Natural Gas Co & & e & -- & -- & -. & -- & -- & Oklahoma & 50 \\
\hline
\end{tabular}

Average daily flow based upon annual volumes (reported as delivered from one State to another) divided by days in the year.

'Average usage rate is equal to the average daily flow derived by estimated capacity. Utilization computation does not include capacity against which no flow was reported.

'Bidirection flow occur on some or all of the pipeline company lines that cross the State border. The value shown represents the capacity, or sum of capacity, for only the flow in the direction indicated.

¿List of Offshore-to-Onshore capacity levels is not all inclusive. In some cases capacity levels may be understated.

-The pipeline, or a portion of the pipeline system, begins service in the "Receiving State." Pipeline is shown here for purposes of showing capacity exiting the State.

$--=$ Not applicable, pipeline not in service in 1990 and/or no flow reported in 1990 or 1996. NA = Not available.

Note: Totals may not equal sum of components because of independent rounding.

Source: Energy Information Administration (EIA), EIAGIS-NG Geographic Information System, Natural Gas Pipeline State Border Capacity Database, as of December 1997. 
Figure A6. Major Interstate Natural Gas Pipelines Serving the Western Region

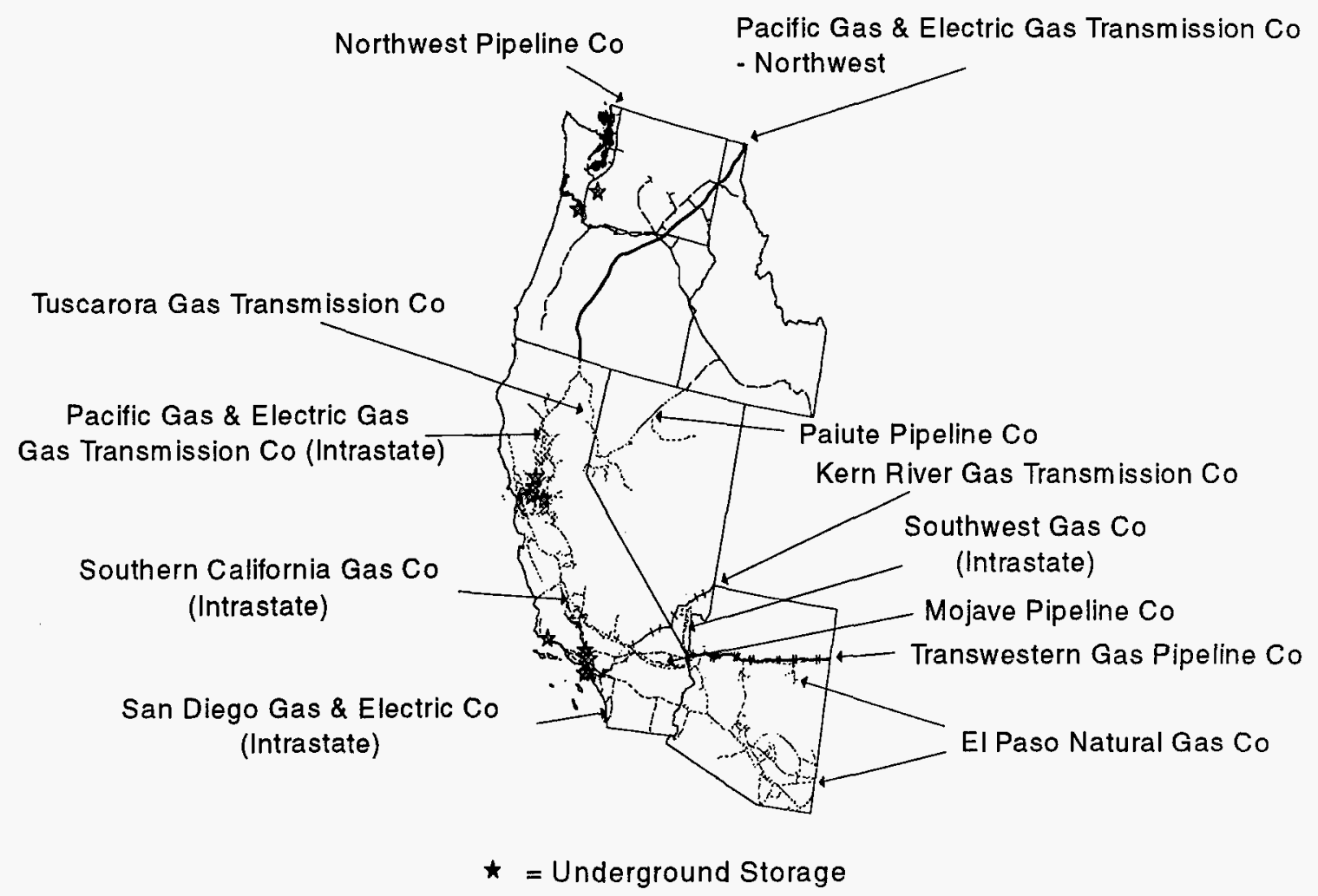

Source: Energy Information Administration (EIA), EIAGIS-NG Geographic Information System, as of December 1997. 
Table A6. State Border Capacity, Flows, and Utilization Rates of Interstate Natural Gas Pipelines Operating in the Western Region, by State, 1990 and 1996

(Volumes in Million Cubic Feet per Day)

\begin{tabular}{|c|c|c|c|c|c|c|c|c|c|}
\hline \multirow[b]{3}{*}{$\begin{array}{l}\text { Receiving State/ } \\
\text { Via Pipeline Company }\end{array}$} & \multicolumn{9}{|c|}{ Transmission Throughput Capabilities and Flows } \\
\hline & \multicolumn{3}{|c|}{ Estimated Entering Capacity } & \multicolumn{2}{|c|}{ Average Daily Flow ${ }^{\mathrm{a}}$} & \multicolumn{2}{|c|}{$\begin{array}{c}\text { Average Usage } \\
\text { Rate }^{b}\end{array}$} & \multicolumn{2}{|c|}{ Exiting Capacity } \\
\hline & $\begin{array}{l}\text { Upstream } \\
\text { State }\end{array}$ & 1996 & $\begin{array}{c}\text { Percent } \\
\text { Change } \\
\text { 1990-1996 }\end{array}$ & 1996 & $\begin{array}{c}\text { Percent } \\
\text { Change } \\
1990-1996\end{array}$ & 1996 & $\begin{array}{c}\text { Percent } \\
\text { Change } \\
1990-1996\end{array}$ & $\begin{array}{c}\text { Downstream } \\
\text { State }\end{array}$ & 1996 \\
\hline \multicolumn{10}{|l|}{ Arizona } \\
\hline $\begin{array}{l}\text { El Paso Nat Gas Co } \\
\text { Transwestern Pipeline Co } \\
\text { Total }\end{array}$ & New Mexico & $\begin{array}{l}4,261 \\
1,090 \\
5,351\end{array}$ & $\begin{array}{l}19 \\
41 \\
23\end{array}$ & $\begin{array}{r}2,285 \\
130 \\
2,415\end{array}$ & $\begin{array}{l}-29 \\
-81 \\
-38\end{array}$ & $\begin{array}{l}54 \\
12 \\
45\end{array}$ & $\begin{array}{l}-41 \\
-87 \\
-50\end{array}$ & $\begin{array}{l}\text { California/NV/MX } \\
\text { California }\end{array}$ & $\begin{array}{l}3,679 \\
1,225\end{array}$ \\
\hline \multicolumn{10}{|l|}{ California } \\
\hline $\begin{array}{l}\text { El Paso Nat Gas Co } \\
\text { Mojave Pipeline Co } \\
\text { Transwestern Pipeline Co }\end{array}$ & Total & $\begin{array}{r}3,443 \\
450 \\
1,225 \\
5,118\end{array}$ & $\begin{array}{l}21 \\
\cdots \\
61 \\
42\end{array}$ & $\begin{array}{r}1,607 \\
295 \\
430 \\
2,332\end{array}$ & $\begin{array}{l}-40 \\
-3 \\
-38 \\
-31\end{array}$ & $\begin{array}{l}47 \\
66 \\
35 \\
46\end{array}$ & $\begin{array}{l}-50 \\
-- \\
-61 \\
-51\end{array}$ & $\begin{array}{l}\text { None } \\
\text { None } \\
\text { None }\end{array}$ & \\
\hline Pacific Interstate Offshore Co & Offshore Calif. & 60 & 0 & 14 & -53 & 23 & -53 & None & \\
\hline $\begin{array}{l}\text { Kern River Gas Trans Co } \\
\text { Paiute Pipeline Co }\end{array}$ & $\begin{array}{l}\text { Nevada } \\
\text { Total }\end{array}$ & $\begin{array}{r}750 \\
30 \\
780\end{array}$ & $\begin{array}{r}3 \ddot{39} \\
3,530\end{array}$ & $\begin{array}{r}658 \\
8 \\
666\end{array}$ & $\begin{array}{l}- \\
-49 \\
-49\end{array}$ & $\begin{array}{l}89 \\
27 \\
85\end{array}$ & $\begin{array}{r}-- \\
-63 \\
14\end{array}$ & $\begin{array}{l}\text { None } \\
\text { None }\end{array}$ & \\
\hline $\begin{array}{l}\text { Pacific Gas Transmission Co } \\
\text { Tuscarora Pipeline Co }\end{array}$ & $\begin{array}{l}\text { Oregon } \\
\text { Total }\end{array}$ & $\begin{array}{r}1,950 \\
113 \\
2,063\end{array}$ & $\begin{array}{l}62 \\
\overline{72}\end{array}$ & $\begin{array}{r}1,594 \\
53 \\
1,647\end{array}$ & $\begin{array}{r}54 \\
-24 \\
49\end{array}$ & $\begin{array}{l}82 \\
48 \\
80\end{array}$ & $\begin{array}{l}-10 \\
-\overline{-18}\end{array}$ & $\begin{array}{l}\text { None } \\
\text { Nevada }\end{array}$ & 95 \\
\hline Total & & 7,961 & 65 & 4,646 & -3 & 59 & -37 & & \\
\hline \multicolumn{10}{|l|}{ Idaho } \\
\hline Pacific Gas Transmission Co & Canada & 2,660 & 55 & 2,301 & 63 & 87 & -2 & Washington & 2,632 \\
\hline Northwest Pipeline Corp & Oregon & ${ }^{c} 481$ & 9 & 344 & 1,250 & 72 & 1,138 & Nevada & 158 \\
\hline Northwest Pipeline Corp & Utah & ${ }^{c} 444$ & 22 & 0 & -100 & -- & -- & Utah & 298 \\
\hline $\begin{array}{l}\text { Northwest Pipeline Corp } \\
\text { Total }\end{array}$ & Washington & $\begin{array}{r}122 \\
3,707\end{array}$ & $\begin{array}{r}0 \\
39\end{array}$ & $\begin{array}{r}0 \\
2,645\end{array}$ & $\begin{array}{r}0 \\
62\end{array}$ & $\ddot{90}$ & $\ddot{5}$ & None & \\
\hline \multicolumn{10}{|l|}{ Nevada } \\
\hline El Paso Nat Gas Co & Arizona & 191 & 14 & 109 & 27 & 57 & 11 & None & \\
\hline Tuscarora Pipeline Co & California & 95 & -- & 53 & -12 & 56 & - & None & \\
\hline Northwest Pipeline Corp & Idaho & 158 & 32 & 132 & 28 & 84 & -3 & None & \\
\hline $\begin{array}{l}\text { Kern River Gas Trans Co } \\
\text { Total }\end{array}$ & Utah & $\begin{array}{r}750 \\
1,194\end{array}$ & 310 & $\begin{array}{r}712 \\
1,006\end{array}$ & 304 & $\begin{array}{l}95 \\
84\end{array}$ & $\overline{-3}$ & California & 750 \\
\hline \multicolumn{10}{|l|}{ Oregon } \\
\hline Northwest Pipeline Corp & Idaho & ${ }^{c} 254$ & 6 & 0 & -- & -- & -- & Washington & 941 \\
\hline $\begin{array}{l}\text { Northwest Pipeline Corp } \\
\text { Pacific Gas Transmission Co }\end{array}$ & $\begin{array}{l}\text { Washington } \\
\text { Total }\end{array}$ & $\begin{array}{r}{ }^{c} 739 \\
2,378 \\
3,117\end{array}$ & $\begin{array}{l}77 \\
57 \\
61\end{array}$ & $\begin{array}{r}228 \\
2,095 \\
2,323\end{array}$ & $\begin{array}{r}277 \\
60 \\
69\end{array}$ & $\begin{array}{l}31 \\
88 \\
75\end{array}$ & $\begin{array}{r}113 \\
-3 \\
3\end{array}$ & $\begin{array}{l}\text { Idaho } \\
\text { California }\end{array}$ & $\begin{array}{r}481 \\
2,063\end{array}$ \\
\hline Total & & 3,371 & 55 & 2,323 & 69 & 75 & 3 & & \\
\hline \multicolumn{10}{|l|}{ Washington } \\
\hline $\begin{array}{l}\text { Ferndale P L Co } \\
\text { Northwest Pipeline Corp } \\
\text { Sumas International PI Co }\end{array}$ & Canada & $\begin{array}{r}45 \\
1,066 \\
15 \\
1,126\end{array}$ & $\begin{array}{r}-- \\
29 \\
0 \\
34\end{array}$ & $\begin{array}{r}2 \\
969 \\
4 \\
975\end{array}$ & $\begin{array}{r}- \\
110 \\
40 \\
110\end{array}$ & $\begin{array}{r}4 \\
91 \\
28 \\
87\end{array}$ & $\begin{array}{l}-- \\
62 \\
40 \\
57\end{array}$ & $\begin{array}{l}\text { None } \\
\text { Oregon } \\
\text { None }\end{array}$ & 1,289 \\
\hline Pacific Gas Transmission Co & Idaho & 2,632 & 66 & 2,251 & 62 & 86 & -10 & Oregon & 2,378 \\
\hline $\begin{array}{l}\text { Northwest Pipeline Corp } \\
\text { Total }\end{array}$ & Oregon & $\begin{array}{r}\circ 941 \\
4,699\end{array}$ & $\begin{array}{l}24 \\
47\end{array}$ & $\begin{array}{r}0 \\
3,226\end{array}$ & $\overline{70}$ & $\overline{91}$ & $\overline{20}$ & Idaho & 122 \\
\hline
\end{tabular}

"Average daily flow based upon annual volumes (reported as delivered from one State to another) divided by days in the year.

${ }^{b}$ Average usage rate is equal to the average daily flow derived by estimated capacity. Utilization computation does not include capacity against which no flow was reported.

'Bidirection flow occur on some or all of the pipeline company lines that cross the State border. The value shown represents the capacity, or sum of capacity, for only the flow in the direction indicated.

-- = Not applicable, pipeline not in service in 1990 and/or no flow reported in 1990 or 1996.

Note: Totals may not equal sum of components because of independent rounding.

Source: Energy Information Administration (EIA), EIAGIS-NG Geographic Information System, Natural Gas Pipeline State Border Capacity Database, as of December 1997. 


\section{Appendix B}

\section{Natural Gas Pipeline and System Expansions, 1997-2000}

A great deal of new pipeline capability has been proposed for development throughout North America between now and the turn of the century. The most extensive development is focused on expanding the deliverability of Canadian gas to the U.S. Midwest and Northeast and to Canadian markets. Several new pipelines and system expansions are planned that not only would improve access to natural gas supplies in Western Canada but also to production from the developing areas, such as the Sable Island field in Eastern Canada. The second-largest focus is on improving access to the increasing deep-water production in the Gulf of Mexico. Next are those projects whose objectives are to increase the flow of lowercost supplies located in the Central United States to markets located primarily in the Midwest. Currently, the capability to do so is limited in some areas. The latter series of expansions will be competing, to some degree, with the projects slated to increase flows of Western Canadian gas to the Midwest marketplace.

Although there is a question as to whether or not the market can support all these expansions, it must be kept in mind that these projects can proceed only if sufficient commitments are entered into by future customers. ${ }^{120}$ Most of the proposed projects have, or are, undergoing market-testing through "open-season" offerings whereby potential customers have placed bids for future capacity on the proposed projects. The planned capacity of the proposed projects usually reflects the results of these open seasons and indicates that, at least at the moment, local distribution companies and other major customers believe demand will grow sufficiently to support the incremental supplies destined for these markets.

This appendix examines expansions to the North American natural gas pipeline network during 1997 and the nature and type of proposed pipeline projects announced or approved for construction during the next several years in the United States. It includes those projects in Canada and Mexico that tie in with U.S. markets or projects. Additional details on some of the proposed projects and an analysis of their potential impact on a regional basis or on the overall North American natural gas pipeline network may be found in the main body of the report.

\footnotetext{
${ }^{120}$ Without firm customer commitments, neither the necessary regulatory approval nor any needed external financing will be forthcoming. Nevertheless, it is possible that some customers might back out of these commitments after initial regulatory approval, thereby leaving the final implementation of a project in doubt.
}

\section{Overview}

At least 41 pipeline expansion projects were completed and placed in service in the United States during 1997 (Figure B1) representing more than 6.3 billion cubic feet per day (Bcf/d) of added pipeline capacity. These projects either added capacity directly to the interstate network, improved local intrastate service, or expanded access to producing fields or natural gas market centers. Seven of the projects increased interregional transmission capability by 750 million cubic feet per day (MMcf/d): $513 \mathrm{MMcf} / \mathrm{d}$ in the United States and $237 \mathrm{MMcf} / \mathrm{d}$ into Mexico (Tables ES1 and B1). These projects, plus others, increased overall daily interstate capability by a little more than 2 percent, or $4.6 \mathrm{Bcf}$, which is double the interstate capacity added in $1996 .{ }^{121}$ Moreover, the total number of completed projects in the United States was substantially more than in 1995 (41 vs. 26).

Almost all the natural gas pipeline projects slated for completion in 1997 were placed in service on schedule. ${ }^{122}$ Two were canceled because of changes in market conditions or competitive pressures. A few others were postponed while their original designs were reevaluated in light of conditional regulatory approval or shifts in construction priorities.

As of February 1998, the Energy Information Administration was tracking more than 100 proposed pipeline expansions and new pipeline projects at various stages of development in the United States, Canada, and Mexico, with planned in-service dates between 1998 and the end of 2000 (Figure B2). A number of these projects are slated to be phased in over several years or are jurisdictionally segmented (for instance, U.S. versus Canadian segments). If all U.S. projects were completed, overall daily deliverability on the national network would increase by almost 30 billion cubic feet (3 gathering system projects in the Gulf of Mexico and 11 Canadian projects, some of which are counted in the U.S. projects, are not included). Of all phases/projects, 62 are proposed for completion in 1998, 38 in 1999, and 20 in 2000. Thirty-nine of the projects call for development of new pipeline systems or facilities at new international border points (Table B2).

\footnotetext{
${ }^{121}$ Energy Information Administration, "Natural Gas Pipeline and System Expansions," Natural Gas Monthly," DOE/EIA-0130(97/04) Washington, DC, April 1997).

${ }^{122}$ Energy Information Administration, "Natural Gas Pipeline and System Expansions," Natural Gas Monthly (April 1997), Table SR2.
} 
Figure B1. General Location of Major Natural Gas Pipeline Construction Projects Completed in 1997 (Keyed to Table B1)

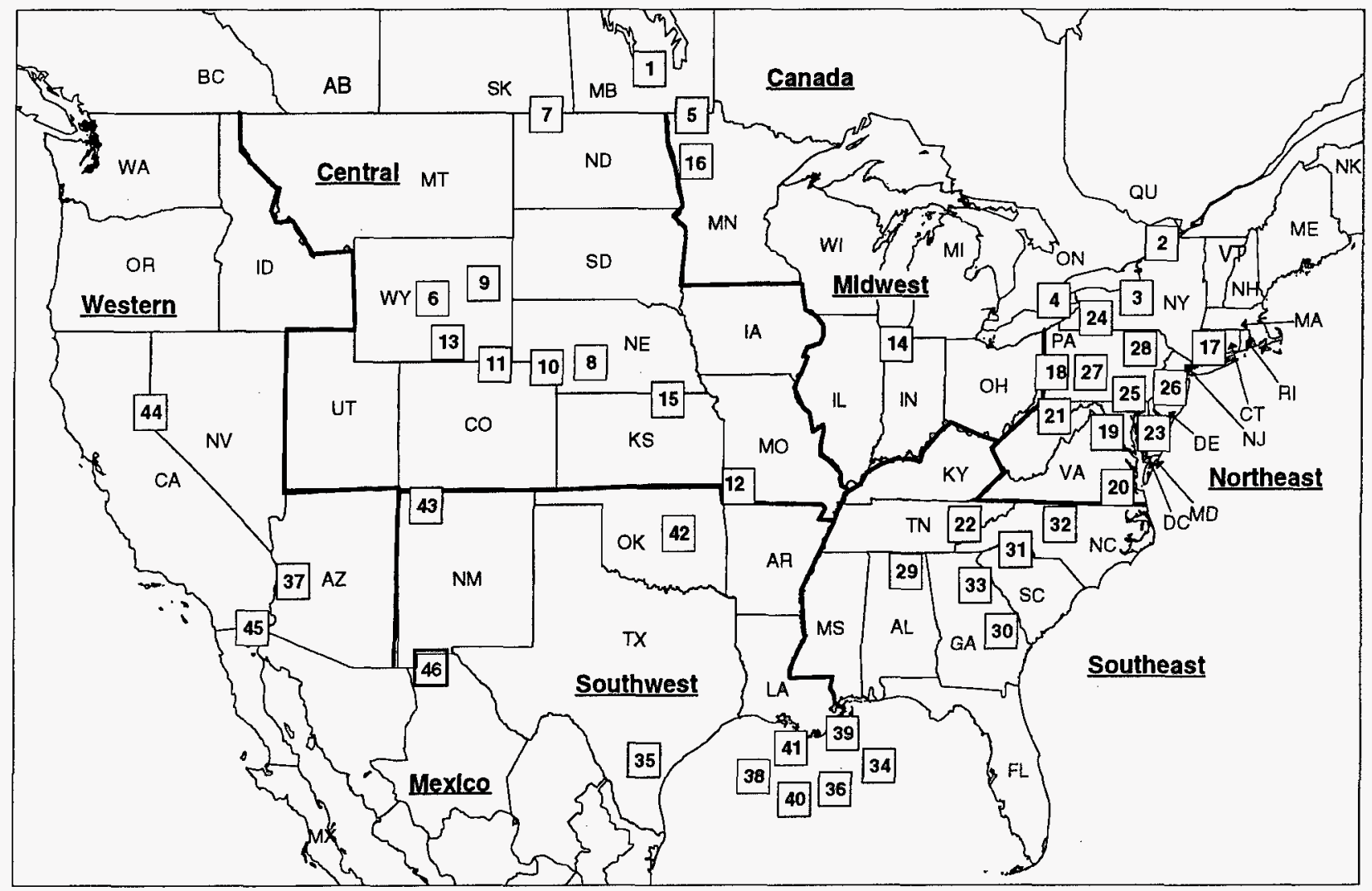

Source: Energy Information Administration (EIA), EIAGIS-NG Geographic Information System, Natural Gas Pipeline Construction Database, as of March 1998.

\section{Recent Developments and Proposals}

The least amount of interstate pipeline development in 1997 occurred in the Western Region with the completion of only one small project (13 MMcf/d) serving the Reno area of Nevada and California. ${ }^{123}$ In addition, the Western Region has the least amount of proposed new pipeline capacity development of the regions. This is not surprising since the region currently has an excess of interstate capacity. Between 1990 and the end of 1996, interstate capacity into the region increased by 45 percent, from 7.1 to $10.3 \mathrm{Bcf} / \mathrm{d}$, more than for any other region (see Chapter 4).

\footnotetext{
${ }^{123}$ One other project was completed within the Western Region in 1997, the El Paso Havasu Crossover expansion. However, the purpose of this expansion was to increase the capability of the El Paso system to deliver additional supplies to West Texas, not for service within the Western Region
} itself.
Other regions of North America saw more extensive pipeline development in 1997 or are slated for significant expansions in the next several years. These expansions can be looked at in two ways. First are those projects that are designed to improve access to developing production areas which have become capacity constrained. On the opposite side of the coin are the pipeline expansions that are designed to improve transportation to expanding market areas and which may or may not be tied in with accessing developing production sources. The following sections look first at projects and trends that are production-area focused and then at those that are geared toward specific markets.

\section{Production Areas}

\section{Gulf of Mexico}

One of the more significant events of the past several years has been the increased attention to development of gas 
Table B1. Major Natural Gas Pipeline Construction Projects Completed in 1997, by Terminating Region

\begin{tabular}{|c|c|c|c|c|c|c|c|c|c|c|c|}
\hline Year & $\begin{array}{c}\text { Ends } \\
\text { in } \\
\text { State }\end{array}$ & $\begin{array}{r}\text { Beg } \\
\text { State }\end{array}$ & $\begin{array}{l}\text { gins in } \\
\text { Region }\end{array}$ & $\begin{array}{l}\text { Map } \\
\text { Key }\end{array}$ & Pipeline/Project Name & $\begin{array}{l}\text { FERC } \\
\text { Docket } \\
\text { Number }\end{array}$ & $\begin{array}{c}\text { In } \\
\text { Service } \\
\text { Date }\end{array}$ & $\begin{array}{c}\text { New } \\
\text { or } \\
\text { Expansion }\end{array}$ & Miles & $\begin{array}{c}\text { Cost } \\
\text { Estimate } \\
\text { (million } \$ \text { ) }\end{array}$ & $\begin{array}{c}\text { Added } \\
\text { Capacity } \\
\text { (MMct/d) }\end{array}$ \\
\hline \multicolumn{12}{|c|}{ Canada } \\
\hline 1997 & QU & SK & Canada & 1 & TransCanada System Expn & - & $11-1-97$ & Expn & 128 & NA & 119 \\
\hline 1997 & NY & QU & Canada & 2 & TransCanada Import (Iroquois NY) & - & $11-1-97$ & Expn & NA & NA & 24 \\
\hline 1997 & NY & QU & Canada & 3 & TransCanada Import (Chippawa NY) & - & $11-1-97$ & Expn & NA & NA & 48 \\
\hline 1997 & NY & QU & Canada & 4 & TransCanada Import (Niagara NY) & - & $11-1-97$ & Expn & NA & NA & 39 \\
\hline 1997 & $\mathrm{MN}$ & SK & Canada & 5 & TransCanada Import (Noyes MN) & - & $11-1-97$ & Expn & NA & NA & 56 \\
\hline \multicolumn{12}{|c|}{ Central } \\
\hline 1997 & WY & WY & Central & 6 & CIG Wind River Lateral Expn & CP96-289 & $11-1-97$ & Expn & NA & 11 & 40 \\
\hline 1997 & ND & SK & Canada & 7 & ISP "Solution Gas" Imports & CP96-684 & $11-1-97$ & New & 1 & 1 & 3 \\
\hline 1997 & MO & WY & Central & 8 & KN Interstate Pony Express & CP96-477 & $8-1-97$ & New & 850 & 154 & 255 \\
\hline 1997 & WY & WY & Central & 9 & MIGC HiLight Plant Expn & CP97-183 & $10-1-97$ & Expn & NA & 6 & 45 \\
\hline 1997 & NE & $\mathrm{CO}$ & Central & 10 & Trailblazer Eastward Expn & CP96-506 & $11-1-97$ & Expn & 445 & NA & 105 \\
\hline 1997 & KS & WY & Central & 11 & Williams Gas WY-KS Expn & CP97-7 & $12-15-97$ & Expn & NA & 9 & 30 \\
\hline 1997 & MO & KS & Central & 12 & Williams Gas KS-MO Expn & CP97-776 & $11-1-97$ & Expn & 13 & 6 & 21 \\
\hline 1997 & CO & WY & Central & 13 & Wyoming Interstate Eastward & CP96-288 & $8-1-97$ & Expn & NA & 40 & 192 \\
\hline \multicolumn{12}{|c|}{ Midwest } \\
\hline 1997 & MI & IL & Midwest & 14 & ANR Michigan Leg Expn & CP96-641 & $12-1-97$ & Expn & 12 & 19 & 135 \\
\hline 1997 & WI & KS & Central & 15 & Northern Natural Peak Day 2000 I & CP97-25 & $11-1-97$ & Expn & 39 & 102 & 244 \\
\hline 1997 & WI & $\mathrm{MB}$ & Canada & 16 & Viking System-Wide Expn & CP97-93 & $11-1-97$ & Expn & 30 & 28 & 62 \\
\hline \multicolumn{12}{|c|}{ Northeast } \\
\hline 1997 & CT & CT & Northeast & 17 & Algonquin Electric Load Lateral & CP96-201 & $11-1-97$ & Expn & 8 & 15 & 82 \\
\hline 1997 & PA & WV & Northeast & 18 & CNGG Seasonal Service Expn & CP96-492 & $12-15-97$ & Expn & NA & 1 & 30 \\
\hline 1997 & VA & PA & Northeast & 19 & CNG PL-1 Phase I & CP96-492 & $11-1-97$ & Expn & NA & 15 & 19 \\
\hline 1997 & VA & VA & Northeast & 20 & Columbia/Commonwealth PL Expn & NA & $11-1-97$ & Expn & NA & NA & 18 \\
\hline 1997 & VA & PA & Northeast & 21 & Columbia Gas Market Expn I & CP96-213 & $11-1-97$ & Expn & 379 & 22 & 242 \\
\hline 1997 & VA & TN & Southeast & 22 & East Tennessee System Wide & CP96-696 & $11-1-97$ & Expn & 6 & 13 & 24 \\
\hline 1997 & MD & DE & Northeast & 23 & Eastern Shore Bridgeville Expn & CP96-97 & $11-1-97$ & Expn & 29 & 7 & 5 \\
\hline 1997 & PA & NY & Northeast & 24 & National Fuel Niagara Expn & CP96-545 & $11-1-97$ & Expn & 139 & 6 & 25 \\
\hline 1997 & PA & PA & Northeast & 25 & Texas Eastern Virginia Natural Expn & CP96-606 & $11-1-97$ & Expn & NA & NA & 20 \\
\hline 1997 & PA & PA & Northeast & 26 & Texas Eastern Columbia Expn & CP96-559 & $11-1-97$ & Expn & 81 & 67 & 142 \\
\hline 1997 & PA & PA & Northeast & 27 & Texas Eastern Line 1-A Expn & CP97-276 & $12-31-97$ & Expn & 23 & 13 & 128 \\
\hline 1997 & PA & PA & Northeast & 28 & Transco Pocono Project & CP97-328 & $11-1-97$ & Expn & 5 & 10 & 37 \\
\hline \multicolumn{12}{|c|}{ Southeast } \\
\hline 1997 & $A L$ & AL & Southeast & 29 & MidCoast Pipeline System Expn & CP97-343 & $11-1-97$ & Expn & NA & 2 & 8 \\
\hline 1997 & SC & GA & Southeast & 30 & SONAT Zone 3 GA-SC-TN & CP96-541 & $11-1-97$ & Expn & 27 & $3 \overline{6}$ & 45 \\
\hline 1997 & SC & SC & Southeast & 31 & South Carolina Pipeline Expn & - & $11-1-97$ & Expn & NA & 10 & 200 \\
\hline 1997 & NC & NC & Southeast & 32 & Transco Maiden Lateral Expn & CP97-193 & $12-1-97$ & Expn & 18 & 13 & 38 \\
\hline 1997 & $\mathrm{SC}$ & MS & Southeast & 33 & Transco Sunbelt Project & NA & $11-1-97$ & Expn & 570 & 85 & 145 \\
\hline \multicolumn{12}{|c|}{ Southwest } \\
\hline 1997 & $\mathrm{GM}$ & GM & Offshore & 34 & DIGS Main Pass Gathering & CP97-300 & $12-20-97$ & New & 63 & 54 & 200 \\
\hline 1997 & $\mathrm{TX}$ & $\mathrm{TX}$ & Southwest & 35 & Delhi Pipeline South Texas Expn & - & $11-1-97$ & Expn & 53 & NA & 90 \\
\hline 1997 & LA & GM & Offshore & 36 & Discovery Pipeline & CP96-712 & $11-1-97$ & New & 147 & 189 & 600 \\
\hline 1997 & $T X$ & $A Z$ & Western & 37 & El Paso Havasu Crossover & CP96-321 & $11-1-97$ & Expn & 98 & 20 & 180 \\
\hline 1997 & GM & GM & Offshore & 38 & Garden Banks Offshore System & CP96-113 & $11-1.97$ & New & 50 & NA & 600 \\
\hline 1997 & LA & GM & Offshore & 39 & Koch Bastian Bay & CP96-572 & $11-1-97$ & Expn & 16 & NA & 861 \\
\hline 1997 & GM & GM & Offshore & 40 & Manta Ray Gathering System & CP96-796 & $11-1-97$ & New & 47 & 60 & 300 \\
\hline 1997 & LA & GM & Offshore & 41 & Nautilus System & CP96-790 & $11-1-97$ & New & 87 & 121 & 600 \\
\hline 1997 & OK & OK & Southwest & 42 & Transok West-to-East System Expn & - & $11-1-97$ & Expn & 130 & 75 & 255 \\
\hline 1997 & NM & NM & Southwest & 43 & Transwestern Bloomfield Expn & CP97-286 & $12-1-97$ & Expn & - & NA & 25 \\
\hline \multicolumn{12}{|c|}{ Western } \\
\hline 1997 & CA & NV & Western & 44 & Paiute Pipeline North Taho Lateral & CP94-29 & $12-15-97$ & New & 23 & 10 & 13 \\
\hline \multicolumn{12}{|c|}{ Mexico } \\
\hline 1997 & $M X$ & $\mathrm{CA}$ & Western & 45 & SoCal Calexico/Mexicali Expont & NA & $7-31-97$ & New & 1 & $\mathbf{a}$ & 25 \\
\hline 1997 & $M X$ & $\mathrm{TX} \underline{\mathbf{s}}$ & Southwest & 46 & El Paso Samalayucca II & CP93-252 & $12-20-97$ & New & 21 & 15 & 212 \\
\hline
\end{tabular}

"Less than $\$ 1$ million. All cost estimates are in U.S. dollars.

$\mathrm{MMct} / \mathrm{d}=$ Million cubic feet per day. Expn $=$ Expansion. $\mathrm{NA}=$ Not available. $--=$ Not applicable.

$\mathrm{CIG}=$ Colorado Interstate Gas Co.; CNG = CNG Transmission Co; DIGS = Dauphin Island Gathering System; GM = Gulf of Mexico; NGPL = Natural Gas Pipeline Co. of America; NSPC = Northern States Power Co.; SoCal = Southern California Gas Co.; SONAT = Southern Natural Gas Co.; Tenneco = Tennessee Gas Pipeline Co.; TCPL = TransCanada Pipeline Ltd.; Transco = Transcontinental Gas Pipeline Co.

Note: Bold underlined items indicate project crosses regional boundary.

Source: Energy Information Administration, EIAGIS-NG Geographic Information System, Natural Gas Proposed Pipeline Construction Database, as of March 1998, compiled from Federal Energy Regulatory Commission filings and various industry news sources. 
Figure B2. General Location of Major Proposed Natural Gas Pipeline Construction Projects, 1998-2000 (Keyed to Table B2)

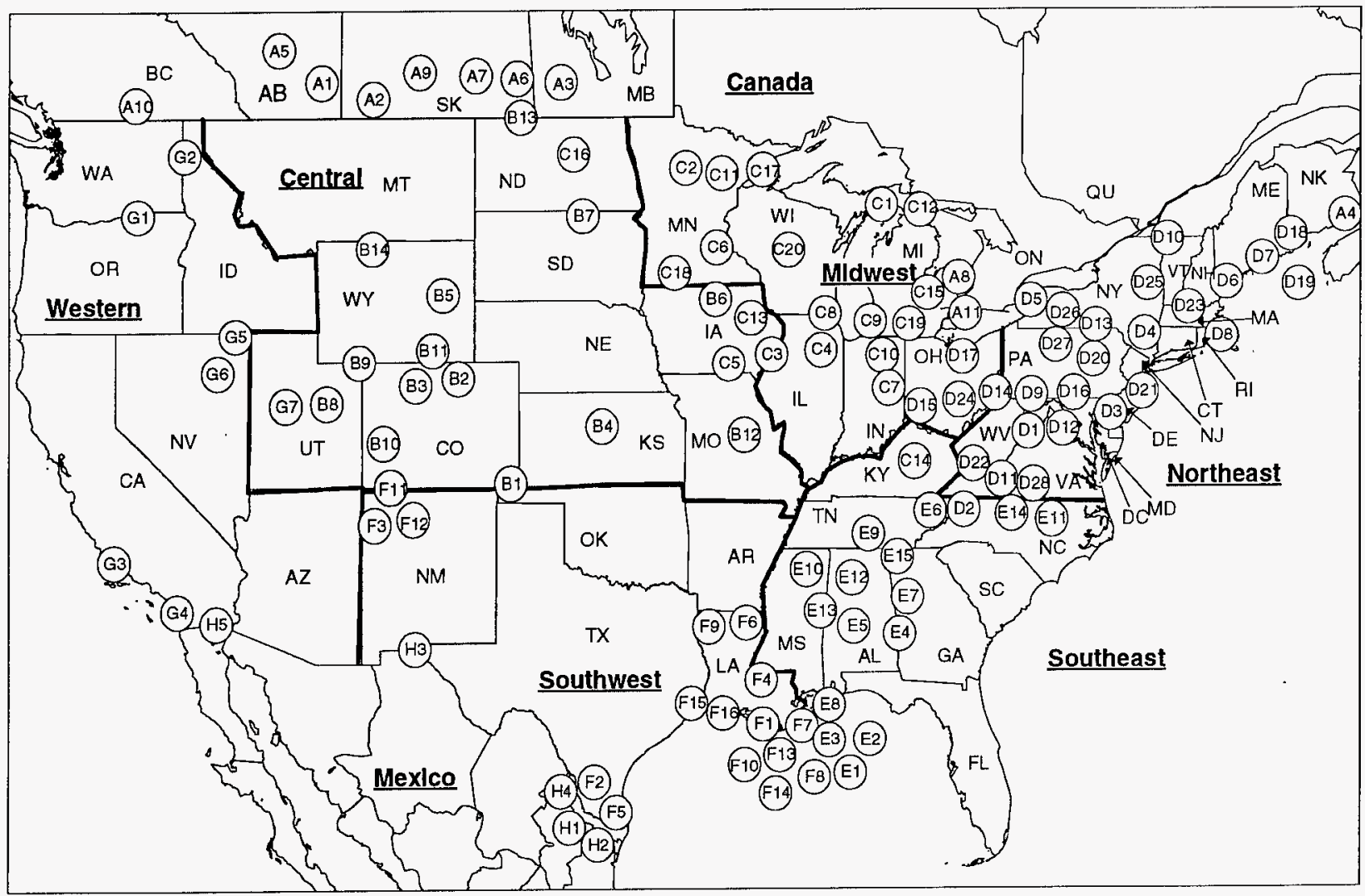

Source: Energy Information Administration (EIA), EIAGIS-NG Geographic Information System, Natural Gas Pipeline Construction Database, as of March 1998.

resources in the Gulf of Mexico and, specifically, in the deeper waters (greater than 200 meters) of offshore Louisiana, Alabama, and Mississippi. In 1997, six natural gas pipeline projects were completed in the Gulf, representing a total of $3.2 \mathrm{Bcf} / \mathrm{d}$ of new pipeline capacity (Table B1). Three of these projects now bring an additional $2.1 \mathrm{Bcf} / \mathrm{d}$ to onshore Louisiana, while the other three $(1.1 \mathrm{Bcf} / \mathrm{d})$ operate as gathering systems linking producing platforms in the Gulf with mainlines directed to onshore facilities. The largest of the new systems include the Nautilus and Texaco Discovery pipelines, both with capacities of $0.6 \mathrm{Bcf} / \mathrm{d}$.

At least 10 offshore projects, representing more than $3.7 \mathrm{Bcf} / \mathrm{d}$ of capacity, have been proposed for development in 1998/1999. Most of these projects would reach into the deep water area of the Gulf to tap several new production sources being developed there-most notably in the Ship Shoal, Green Canyon, Destin Corridor, Garden Banks, and Mississippi Canyon areas. ${ }^{124}$ Companies such as Shell Oil, Transcontinental Pipeline, and Williams Natural Gas Transmission are involved (Table B2). Development of offshore and deep water pipeline-related projects represents 52 percent of the $3.7 \mathrm{Bcf} / \mathrm{d}$ of planned additions in the Southwest Region and 44 percent of the $4.0 \mathrm{Bcf} / \mathrm{d}$ in the Southeast Region.

The remaining proposed onshore expansion projects in the Southwest Region are designed primarily to increase access to supplies in the east and south Texas and in the San Juan Basin of New Mexico. Several proposed projects in south Texas are designed to support exports to Mexico, if and when the connecting export facilities are finally put in place.

\footnotetext{
${ }^{124}$ Three projects would direct supply to the Southeast (Alabama and Mississippi) and three to the Southwest (Louisiana). The other projects would be gathering systems.
} 
Table B2. Major Proposed Natural Gas Pipeline Construction Projects, by Terminating Region and Planned In-Service Year, 1998-2000

\begin{tabular}{|c|c|c|c|c|c|c|c|c|c|c|c|}
\hline Year & $\begin{array}{l}\text { Ends } \\
\text { In } \\
\text { State }\end{array}$ & & $\begin{array}{l}\text { 3egins In } \\
\text { te Reglon }\end{array}$ & $\begin{array}{l}\text { Map } \\
\text { Key }\end{array}$ & Pipeline/Project Name & $\begin{array}{l}\text { FERC } \\
\text { Docket } \\
\text { Number }\end{array}$ & $\begin{array}{c}\text { Status } \\
\text { As of } \\
3-31-98^{a}\end{array}$ & $\begin{array}{c}\text { New } \\
\text { or } \\
\text { Expanslon }\end{array}$ & Mlles & $\begin{array}{c}\text { Cost } \\
\text { Estlmate } \\
\text { (million \$) }\end{array}$ & $\begin{array}{c}\text { Added } \\
\text { Capacity } \\
\text { (MMcf/d) }\end{array}$ \\
\hline \multicolumn{12}{|c|}{ Canada } \\
\hline 1998 & SK & $A B$ & Canada & A1 & Alberta Energy/TransCanada Expn & -- & Approved & Expn & 71 & 18 & 200 \\
\hline 1998 & SK & SK & Canada & $\mathrm{A} 2$ & Foothills Pipeline Eastem Expn & -- & Approved & New & 70 & 18 & 700 \\
\hline 1998 & QU & SK & Canada & $A 3$ & TransCanada 1998 System Expn & - & Pending & Expn & 235 & 840 & 447 \\
\hline 1999 & NB & NS & Canada & A4 & Maritimes \& Northeast Phase II & -- & Pending & New & 386 & 434 & 465 \\
\hline 1999 & $A B$ & $A B$ & Canada & A5 & NOVA System Expn & -- & Pending & Expn & 125 & 1,070 & 2,250 \\
\hline 1999 & QU & SK & Canada & A6 & TransCanada System 1999 Expn & -- & Pending & Expn & NA & NA & NA \\
\hline 1999 & MB & $A B$ & Canada & A7 & TransCanada Voyageur Link & -- & Announced & Expn & NA & NA & 1,400 \\
\hline 1999 & ON & MI & Mldwest & A8 & Vector Pipeline (Canada Portion) & -- & Pending & New & 15 & 24 & 1,000 \\
\hline 2000 & SK & $\mathrm{BC}$ & Canada & $\mathrm{Ag}$ & Alliance Pipeline (Canada Portion) & -- & Pending & New & 982 & 700 & 1,325 \\
\hline 2000 & $\mathrm{BC}$ & $\mathrm{BC}$ & Canada & A10 & ANG Kootenay Pacific Pipeline & $-\cdots$ & Pending & New & 351 & 381 & 550 \\
\hline 2000 & ON & MI & Midwest & A11 & TriStatePipeline (Canada Portion) & - & Announced & Expn & $\stackrel{\text { NA }}{\text { Tota }}$ & $\begin{array}{c}\text { NA } \\
\text { lew Capacity }\end{array}$ & $\begin{array}{r}300 \\
8,637\end{array}$ \\
\hline \multicolumn{12}{|c|}{ Central } \\
\hline 1998 & co & $\mathrm{CO}$ & Central & B1 & CIG Campo Lateral & CP97-769 & Approved & Expn & 115 & 21 & 81 \\
\hline 1998 & $\mathrm{CO}$ & $\mathrm{CO}$ & Central & $\mathrm{B} 2$ & PSCO Front Range & -. & Pending & Expn & 53 & 25 & 269 \\
\hline 1998 & WY & $\mathrm{CO}$ & Central & B3 & KN Interstate Front Runner & CP97-707 & Pending & New & 109 & NA & 254 \\
\hline 1998 & NE & OK & Southwest & $B 4$ & NGPL Amarillo Upgrade & CP94-577 & Approved & Expn & 14 & 33 & -25 \\
\hline 1998 & WY & WY & Central & B5 & MIGC Southern Mainline Expn & CP98-125 & Pending & Expn & NA & 6 & 40 \\
\hline 1998 & IA & IA & Central & B6 & Northem Border Harper Expn & CP95-194 & Approved & Expn & 142 & NA & 962 \\
\hline 1998 & IA & SK & Canada & B7 & Northem Border Monchy Expn & CP95-194 & Approved & Expn & 243 & 797 & 700 \\
\hline 1998 & WY & UT & $\overline{\text { Central }}$ & B8 & Questar Utah Mainline Expn & CP98-66 & Approved & Expn & NA & 8 & 90 \\
\hline 1998 & UT & WY & Central & $\mathrm{Bg}$ & Questar Mainline (Line 58) Expn & CP96-820 & Approved & Expn & 41 & 18 & 55 \\
\hline 1998 & $\mathrm{CO}$ & $\mathrm{CO}$ & Central & B10 & TransColorado Pipeline (Northern) & CP90-1777 & Approved & New & 266 & 184 & 300 \\
\hline 1998 & WY & WY & Central & B11 & WIG Larimie Compressor Expn & CP98-128 & Pending & Expn & NA & 15 & 52 \\
\hline 1998 & MO & MO & Central & $\mathrm{B} 12$ & Williams Natural Gas St Louis Expn & -- & Announced & Expn & 200 & NA & 52 \\
\hline 2000 & ND & SK & Canada & $\mathrm{B} 13$ & Alliance Pipeline (Import Station) & CP97-169 & Approved & New & 1 & 139 & 1,600 \\
\hline 2000 & WY & SK & Canada & $\mathrm{B} 14$ & Altamont Pipeline & CP90-1372 & Approved & New & 620 & 139 & 737 \\
\hline & & & & & & & & & Tota & Jew Capaclty & 5,143 \\
\hline \multicolumn{12}{|c|}{ Midwest } \\
\hline 1998 & MI & MI & Midwest & C1 & Great Lakes Security Looping II & CP96-297 & Approved & Expn & 25 & 44 & 0 \\
\hline 1998 & M! & $M B$ & Canada & C2 & Great Lakes System Wide Expn & CP96-647 & Approved & Expn & 72 & 149 & 129 \\
\hline 1998 & IL & IA & Central & $\mathrm{C3}$ & NGPL Amarillo Expn & CP96-27 & Approved & Expn & 4 & 24 & 110 \\
\hline 1998 & $\mathrm{IL}$ & IA & $\overline{\text { Central }}$ & $\mathrm{C} 4$ & Northern Border Manhattan Extn & CP95-194 & Approved & New & 200 & NA & 648 \\
\hline 1998 & WI & KS & Central & C5 & Northem Natural Peak Day 2000 II & CP97-25 & Approved & Expn & 5 & NA & 32 \\
\hline 1998 & MN & MN & Midwest & $\mathrm{C} 6$ & Northem Natural Line D Expn & CP98-132 & Approved & Expn & 10 & 9 & 40 \\
\hline 1998 & $\mathrm{OH}$ & IN & Midwest & C7 & Texas Eastern Spectrum Expn & CP97-626 & On hold & Expn & 114 & 31 & 305 \\
\hline 1999 & WI & IL & Midwest & $\mathrm{C} 8$ & ANR IL-WI Expn & CP97-765 & Approved & Expn & 11 & 24 & 116 \\
\hline 1999 & $\mathrm{OH}$ & IL & Midwest & $\mathrm{Cg}$ & ANR Independence Tie-in Expn & CP97-319 & Pending & Expn & 30 & NA & 750 \\
\hline 1999 & IN & $\mathrm{IL}$ & Midwest & C10 & Crossroads/CNG & - & Announced & Expn & 20 & NA & 150 \\
\hline 1999 & MN & MN & Midwest & $\mathrm{C} 11$ & Great Lakes Carlton Project & CP98-96 & Pending & Expn & 4 & 9 & 67 \\
\hline 1998 & $\mathrm{Ml}$ & $\mathrm{MI}$ & Midwest & $\mathrm{C} 12$ & Great Lakes Sault Looping & CP98-143 & Pending & Expn & 14 & 11 & 0 \\
\hline 1999 & IL & IA & Central & $\mathrm{C} 13$ & Northem Natural Gas East Leg 2000 & -- & Announced & Expn & 264 & 835 & 450 \\
\hline 1999 & $\mathrm{OH}$ & TN & Southeast & $\mathrm{C} 14$ & Tenneco Eastern Express & -- & Announced & Expn & NA & 200 & 500 \\
\hline 1999 & $\mathrm{MI}$ & IL & Midwest & C15 & Vector Pipeline (US Portion) & -- & Pending & New & 328 & 447 & 1,000 \\
\hline 2000 & IL & SK & Canada & C16 & Alliance Project (US Portion) & CP97-168 & Pending & New & 886 & 600 & 1,325 \\
\hline 2000 & MI & MB & $\overline{\text { Canada }}$ & $\mathrm{C} 17$ & Great Lakes 300 Expn & CP98-309 & Pending & Expn & 258 & 620 & 312 \\
\hline 2000 & IN & SK & $\overline{\text { Canada }}$ & C16 & Northem Border Project 2000 & -. & Announced & Expn & NA & NA & 400 \\
\hline 2000 & $\mathrm{Ml}$ & IL & Midwest & $\mathrm{C19}$ & TriState Pipeline Project & -- & Announced & New & 275 & NA & 500 \\
\hline 2000 & IL & MB & Canada & $\mathrm{C} 20$ & Viking Voyageur Project & NA & Pending & New & 773 & 1,240 & 1,400 \\
\hline & & & & & & & & & Tota & Jew Capaclty & 8,234 \\
\hline \multicolumn{12}{|c|}{ Northeast } \\
\hline 1998 & VA & PA & Northeast & D1 & Columbia Gas Market Expn II & CP96-213 & Pending & Expn & 379 & 21 & 167 \\
\hline 1998 & VA & VA & Northeast & $\mathrm{D} 2$ & East Tenn Roanoke Expn & CP98-40 & Pending & Expn & 60 & NA & 10 \\
\hline 1998 & MD & $\mathrm{DE}$ & Northeast & D3 & Eastern Shore System Expn & NA & Pending & Expn & 98 & NA & 5 \\
\hline 1998 & NY & QU & Canada & D4 & Iroquois Import Expn & CP96-687 & Pending & Expn & 200 & 22 & 35 \\
\hline 1998 & $\mathrm{PA}$ & NY & Northeast & D5 & National Fuel Niagara/Leidy I & CP98-94 & Approved & Expn & 139 & 5 & 23 \\
\hline 1998 & ME & MA & Northeast & D6 & Portland/Maritimes \& Northeast I & CP97-238 & Approved & New & 100 & 175 & 631 \\
\hline 1998 & ME & QU & Canada & D7 & Portland Pipeline Project & CP95-248 & Approved & New & 293 & 303 & 178 \\
\hline 1998 & MA & MA & Northeast & D8 & Tenneco/DOMAC & CP96-164 & Pending & New & 8 & 26 & 55 \\
\hline 1998 & $\mathrm{PA}$ & PA & Northeast & $\mathrm{D} 9$ & Texas Eastem Virginia Nalural Expn & CP96-606 & Pending & Expn & NA & NA & 20 \\
\hline 1998 & VT & QU & Canada & D10 & Vermont Gas System Import Expn & CP97-324 & Approved & Expn & 190 & NA & 9 \\
\hline 1998 & VA & VA & Northeast & D11 & VNG Saltville P-25 Line & -- & Approved & Expn & 72 & 15 & 30 \\
\hline 1999 & VA & PA & Northeast & D12 & CNG PL-1 Phase II & CP96-492 & On Hold & Expn & NA & NA & 25 \\
\hline 1999 & NY & ON & Canada & D13 & Columbia's Millennium PL & CP98-150 & Pending & New & 442 & 683 & 700 \\
\hline 1999 & PA & WV & Northeast & D14 & CNG SSE Expn & CP96-492 & On Hold & Expn & 40 & 35 & 178 \\
\hline 1999 & PA & $\mathrm{OH}$ & Mldwest & D15 & CNG Market Value Project & NA & Announced & Expn & NA & NA & 150 \\
\hline 1999 & VA & PA & Northeast & D16 & CNG MAS (Market Area Storage) & CP97-774 & Pending & Expn & NA & NA & 10 \\
\hline 1999 & VA & PA & Northeast & D1 & Columbia Gas Market Expn III & CP96-213 & Pending & Expn & 379 & 20 & 108 \\
\hline 1999 & PA & $\mathrm{OH}$ & Midwest & D17 & Independence Pipeline & CP97-315 & Pending & New & 400 & 678 & 1,001 \\
\hline 1999 & $\mathrm{ME}$ & NB & Canada & D18 & Maritimes \& Northeast II (US Portion) & CP96-809 & Approved & New & 386 & 425 & 440 \\
\hline 1999 & $\mathrm{ME}$ & QU & Canada & D7 & Portland Pipeline 1999 Expn & -- & Announced & Expn & NA & NA & 500 \\
\hline 1999 & PA & PA & Northeast & $\mathrm{Dg}$ & Texas Eastem Virginia Natural Expn & CP96-606 & Pending & Expn & NA & NA & 12 \\
\hline 1999 & NY & PA & Northeast & $\mathrm{D} 20$ & Transco MarketLink Expn & -. & Announced & Expn & 2 & 600 & 400 \\
\hline 1999 & NY & $\mathrm{NJ}$ & Northeast & $\mathrm{D} 21$ & Duke Energy Crossbay Project & - & Announced & New & 44 & NA & 700 \\
\hline 1999 & VA & VA & Northeast & $\mathrm{D} 22$ & VNG Saltville P-24 Line & -- & Pending & Expn & 40 & NA & 50 \\
\hline
\end{tabular}


Table B2. Major Proposed Natural Gas Pipeline Construction Projects, by Terminating Region and Planned In-Service Year, 1998-2000 (Continued)

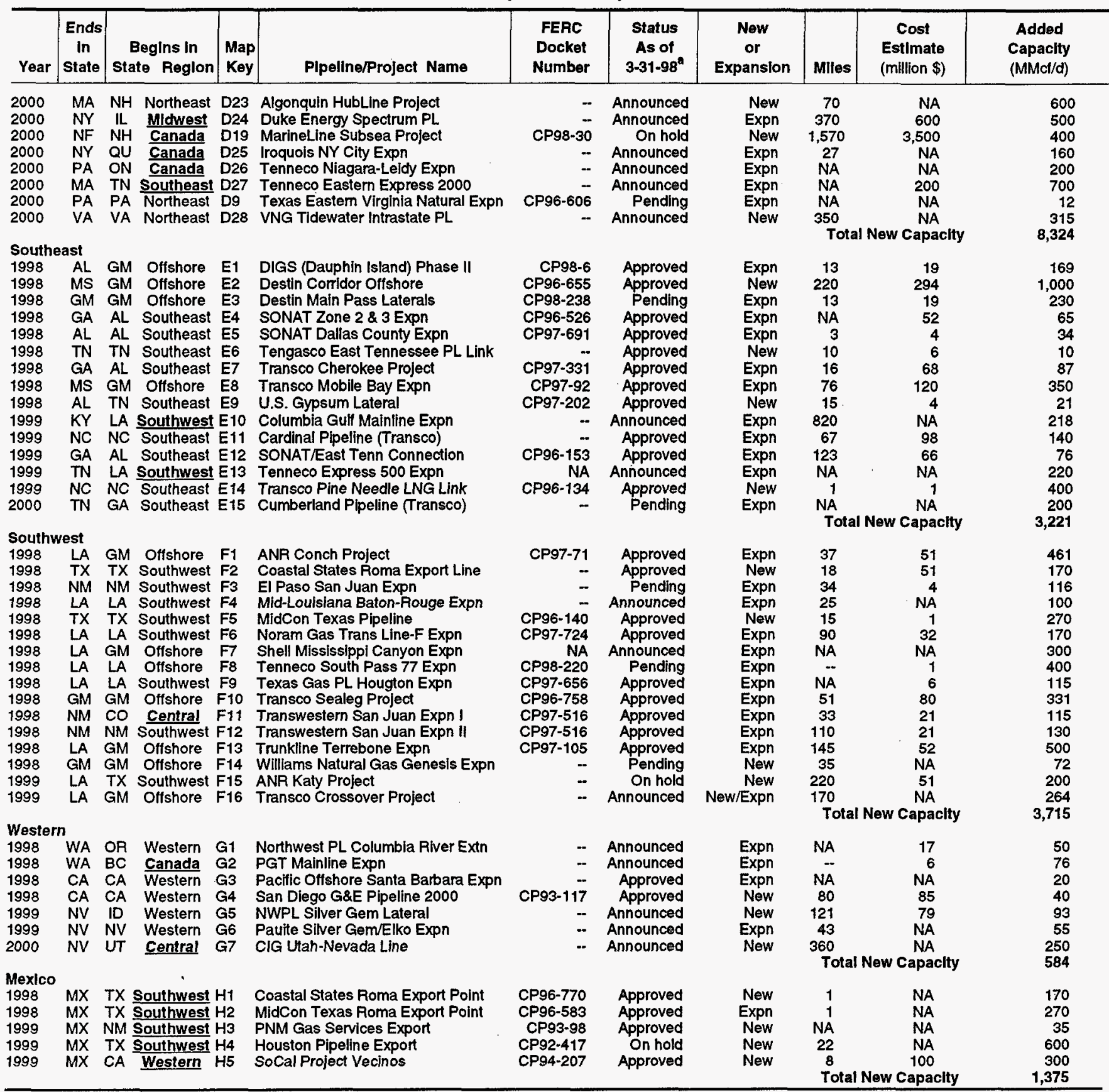

"Announced = Prior to filing with regulatory authorities. Pending = Before regulatory authority for review and acceptance. Approved = Fully or conditionally approved by regulating cuthority; may or may not be under construction. On Hold = May be canceled or postponed due to changed market or regulatory conditions.

${ }^{b}$ Cost and added capacity are the same for this and previous line item.

MMcf $/ \mathrm{d}=$ Million cubic feet per day. Expn $=$ Expansion. $\mathrm{NA}=$ Not available. $--=$ Not applicable. Extn $=$ Extension. $\mathrm{ClG}=\mathrm{Colorado}$ Interstate Gas Co.; CNG = CNG Transmission Co; DIGS = Dauphin Island Gathering System; GM = Gulf of Mexico; NGPL = Natural Gas Pipeline Co. of America; NSPC = Northern States Power Co.; NWPL = Northwest Pipeline Co.; PSCO = Public Service Co. of Colorado; SoCal = Southern California Gas Co.; SONAT = Southern Natural Gas Co.; Tenneco = Tennessee Gas Pipeline Co.; TCPL = TransCanada Pipeline Ltd.; Transco = Transcontinental Gas Pipeline Co.; VNG = Virginia Natural Gas Co.

Notes: All cost estimates are in U.S. dollars. Bold underlined items indicate project crosses regional boundary.

Source: Energy Information Administration, EIAGIS-NG Geographic Information System, Natural Gas Proposed Pipeline Construction Database, as of March 1998, compiled from Federal Energy Regulatory Commission filings and various industry news sources. 


\section{San Juan Basin (New Mexico) Access}

Until recently, the capacity available to move gas from the San Juan Basin area eastward was limited. The rapid development of the area's coalbed methane and other supplies in the area during the late 1980's led to an excess in productive capacity. Originally the new production was expected to be consumed in the California market, and pipeline capacity was developed with that in mind. Today, however, the emphasis is on finding ways to expand deliverability for producers in the basin and move some of this supply eastward to link with market centers in the Texas Panhandle as well as those located in the Waha area of southwestern Texas. From there the gas could be redirected through northern and eastern Texas to Midwest and Northeast markets. The two major interstate pipeline companies in the area, Transwestern Pipeline Company and El Paso Natural Gas Company, have undertaken efforts to expand and enhance facilities on their respective systems, which would allow them to direct more production eastward to the Waha/Permian Basin centers.

In 1997 , both pipeline companies completed projects that improved deliverability out of the San Juan Basin and planned several additional projects that would relieve the ongoing capacity constraint issue in the area. For instance, Transwestern Pipeline Company added an additional $25 \mathrm{MMcf} / \mathrm{d}$ with the expansion of compression on its system. within the basin (Table B1). It also has Federal Energy Regulatory Commission (FERC) approval to expand its local capabilities by $245 \mathrm{MMcf} / \mathrm{d}$ in 1998. El Paso Natural Gas Company also plans to expand its local San Juan Basin capabilities by $116 \mathrm{MMf} / \mathrm{d}$ in 1998 (pending FERC approval) in response to rising production demands.

In addition, with the completion of the full TransColorado Pipeline system (from northern Colorado to northern New Mexico) in 1998, a portion of its $0.3 \mathrm{Bcf} / \mathrm{d}$ capacity could be available to local producers/shippers on an as-available basis.

The El Paso Natural Gas Company's completed its Havasu Crossover expansion project in mid-1997. This project uses expanded capacity on the westward-bound portion of the system to move supplies that are redirected eastward (either physically or by displacement) just east of the California border. The expansion upgraded the Havasu Crossover, which links the north and south parts of the El Paso system. These system enhancements increased El Paso deliverability in the Waha area of West Texas by an additional $180 \mathrm{MMcf} / \mathrm{d}$.

\section{Potential East and South Texas Expansions}

Although no pipeline projects have been proposed for the area, the Cotton Valley Trend of East Texas is expected to become a major new source of gas production over the next several years. The same is true of the area around Southeast Texas. In 1997, Delhi Pipeline Company and several other intrastate pipelines expanded parts of their gathering and mainline systems to accommodate current and future new production. The question remains, however, whether current interstate capacity levels, which are not fully utilized at the present, can handle the new production without expansion. The proposed ANR Katy project, which was, in part, targeted at shippers who potentially might want to access this new production, did not generate as much interest as the company expected when an "open-season" was offered in mid-1997. The future of the project is currently under review by the company.

\section{Rocky Mountain Area Access}

In the past, Rocky Mountain supplies (Colorado, Wyoming and Utah) generally moved to a strong southern California gas market, but the current emphasis of area producers is to increase their presence in local energy markets and to extend their customer base further in U.S. Midwestern and Eastern markets. Customers in the Midwest and East are also very interested in having greater access to these relatively lower priced supplies.

In 1997, several natural gas pipeline projects were completed that furthered that goal. For instance, KN Interstate Pipeline Company placed its "Pony Express" line $(0.26 \mathrm{Bcf} / \mathrm{d})$ in service in August and the Trailblazer/Overthrust/Wyoming Interstate system ( 0.1 to $0.2 \mathrm{Bcf} / \mathrm{d})$ expansion was completed in the last quarter of the year. The latter expansion increased the system's deliverability to its interconnection with the Natural Gas Pipeline Company of America's Amarillo line, which transports supplies to the Midwest Region.

The proposed pipeline expansion projects in the area, for the most part, target expanding regional service as an outlet for expanding area production. Two major project proposals, the KN Interstate Pipeline Company's Front Runner projects (Table B2), both intend to transport Wyoming supplies to a growing Denver, Colorado, marketplace. The Questar Pipeline Company proposes to expand its capabilities in the Salt Lake City area.

In addition to the expanding production in areas of the Rocky Mountains located in Wyoming, Utah, and northern Colorado, the Powder River area of southern Montana and northern Wyoming is expected to develop into a major producing area over the next decade. Already several of the pipeline projects discussed earlier have anticipated access to this area's production in their design. 


\section{Improved Access to Canadian Supply}

During 1997, the TransCanada Pipeline system increased its domestic deliverability by $119 \mathrm{MMcf} / \mathrm{d}$ and expanded several of its export points to the United States. However, only one of the interconnecting U.S. pipelines (Viking Gas Transmission Company) expanded its capacity accordingly. The TransCanada export upgrades were primarily to alleviate some of its own limitations. Most of the U.S. pipelines were already capable of accepting the increased flows.

The completion of these projects in 1997 only partially relieved the existing capacity constraint problem on the TransCanada system. Flow restrictions on the system have limited western Alberta (Canada) natural gas producers' access to markets to the east during the past several years. However, within Canada, a number of projects are planned that will improve operational flows significantly and add to export capability. Although it is doubtful that all will be built, 11 projects within Canada, representing more than $8.6 \mathrm{Bcf} / \mathrm{d}$ of new capacity, ${ }^{125}$ have been proposed for development by the end of 2000. Several, like the NOVA system expansion and the new ANG Kootenay Pacific Pipeline, would increase production area exit capacity. However, the bulk of the new capacity that is being proposed would be longhaul system capacity targeted for eastern Canadian natural gas markets (which are growing rapidly) and to expand export capabilities (Figure B3).

Reflecting the growing Canadian production and desire to flow more of that gas to U.S. markets, 14 projects have been proposed that could add as much as $5.9 \mathrm{Bcf} / \mathrm{d}$ to U.S. import capacity from Canada during the next 3 years, an increase of 52 percent from the 1997 level. ${ }^{126}$ The volume increase is 17 percent more than the total Canadian import capacity added from 1991 through 1997, 5.0 Bcf/d (see Chapter 3). This anticipated growth also reflects the continuing U.S. demand for Canadian natural gas, especially in the Midwest and Northeast regions.

These efforts include several very large projects. For example, a new natural gas pipeline (the Alliance project) would bring gas from British Columbia to the Chicago, Illinois, area along the right-of-way of an existing oil pipeline. Several other projects are competing with the Alliance project, including

\footnotetext{
${ }^{125}$ Final capacity levels for TransCanada Pipeline Company's 1999 expansion effort were not available as of March 1998.

${ }^{126}$ Does not include two projects, representing $1.1 \mathrm{Bcf} / \mathrm{d}$ capacity, whose chances of success are marginal. It also does not include the Columbia Millennium project into the Northeast Region whose capacity is tied in with the import capacity into the Midwest and the $1.6 \mathrm{Bcf} / \mathrm{d}$ Alliance Pipeline import station, which for the most part is accounted for in that project.
}

the Viking Voyageur Pipeline, which is a $1.4 \mathrm{Bcf} / \mathrm{d}$ line between the Noyes, Minnesota, import point and the Chicago, Illinois, area, and the Northern Border Project 2000, which is a $400 \mathrm{MMcf} / \mathrm{d}$ expansion ${ }^{127}$ that includes a proposal to extend the system to Indiana and possibly to the Michigan-Canada border to serve the Ontario marketplace. (Note: In late April 1998 the sponsors of the Viking Voyageur Project announced that it was unlikely that they would be able to secure enough future shipper commitments and available production in Canada to make the project viable at its proposed level. As a result, the project may terminate or downsize. Since its $1999 / 2000$ expansion plans are predicated in part upon the Viking Project, TransCanada Pipeline's expansion plans may have to cut back as well.) In addition, Great Lakes Gas Transmission in the Midwest Region and Iroquois Transmission in the Northeast plan to expand their existing systems by 441 and $160 \mathrm{MMcf} / \mathrm{d}$, respectively, during the next several years.

Because of the growing demand for Western Canadian supplies in Eastern Canada and the United States, TransCanada Pipeline Ltd. applied to the Canadian National Energy Board in early 1998 to extend its expansion plans to accommodate an interconnection with the Viking Voyageur project and larger potential demand in the Canadian domestic market. The new capacity would be phased in over 2 years beginning in 1999. Currently, TransCanada is in the process of revising its expansion plans for 1999 to reflect its commitments to the Voyageur expansion.

In August 1996, the Federal Energy Regulatory Commission approved construction of the Northern Border Pipeline Company expansion project, which would add $0.7 \mathrm{Bcf} / \mathrm{d}$ to import capacity at the Montana border. Correspondingly, Foothills Pipe Line Ltd. of Canada, which interconnects with Northern Border Pipeline at Monchy, Montana, would expand its eastern leg by the same amount.

On the Canadian east coast, several new pipelines have been proposed to move gas supplies being developed off the Canadian Atlantic coast near Sable Island to markets in Canada and the United States (Table B2). The Maritimes \& Northeast pipeline project would move Sable Island supplies to the Northeastern United States. The Maritimes \& Northeast pipeline project's route will take it directly into the State of Maine and through New Hampshire to interconnections with the Tennessee Gas Pipeline system in Massachusetts. Another project, the MarineLine Subsea pipeline has been proposed. ${ }^{128}$ It would not only provide an alternative transportation route

\footnotetext{
${ }^{127}$ Original plans were for a $1.3 \mathrm{Bcf} / \mathrm{d}$ expansion, but the project's size has been cut because of less-than-expected market interest.

${ }^{128}$ In March 1998, this project was placed in an inactive status, pending completion of additional geological and geophysical surveys.
} 
Figure B3. Planned Projects Related to Imports of Canadian Gas, 1998-2000

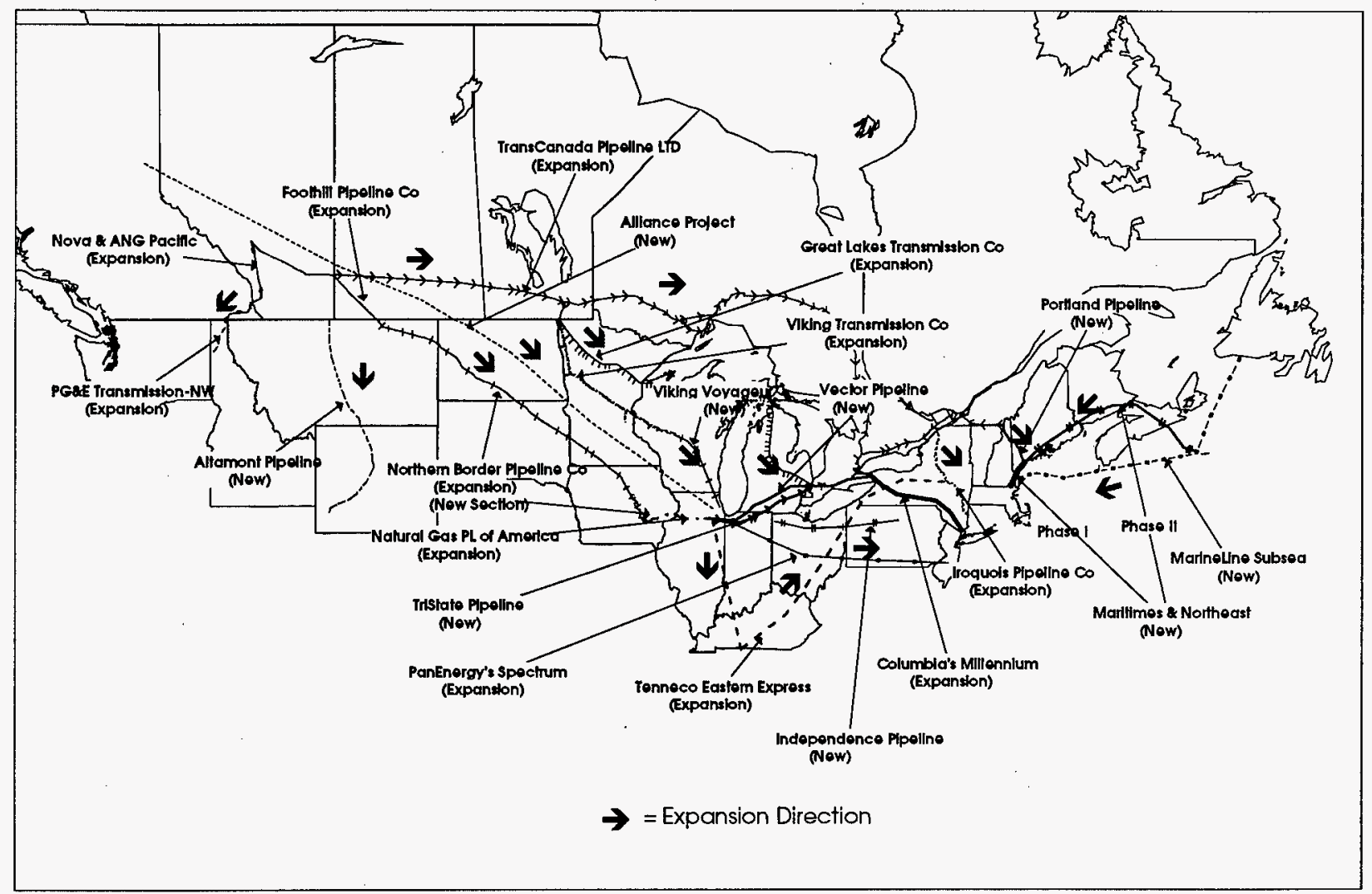

Source: Energy Information Administration (EIA), EIAGIS-NG Geographic Information System, Natural Gas Pipeline Construction Database, as of March 1998.

from Sable Island but also would handle receipts (supplies) from as far north as Newfoundland, through a sea route passing through the Sable Island fields and southward to landfall in New Hampshire.

\section{Market Areas}

\section{Midwest}

In 1997, only three interstate pipeline projects were completed in the Midwest Region (Table B1), adding $441 \mathrm{MMcf} / \mathrm{d}$ of new capacity. These projects represented an increase to intraregional capacity of only about one-half of 1 percent. However, one project (ANR Michigan Leg expansion) resolves a capacity bottleneck in the region, while the other two expanded deliverability to growing markets in Wisconsin and vicinity.

Based upon current proposals, natural gas pipeline deliverability to the Midwest Region will grow substantially by the end of 2000 , with $8.2 \mathrm{Bcf} / \mathrm{d}$ of new interstate capacity planned overall, the second highest of the six regions. But what really distinguishes the growth in the Midwest is that the vast majority of new capacity would be on newly built trunklines or extensions to existing pipelines bringing supplies from Canada. Ten of these projects would increase interregional deliverability by a total of $5.3 \mathrm{Bcf} / \mathrm{d}$. The Midwest will be the terminus for the Alliance project, which alone would increase area service by $1.3 \mathrm{Bcf} / \mathrm{d}$. Excluding the extension of Canadian supplies via the Northern Border Pipeline to Manhattan, Illinois (near Chicago), and Natural Gas Pipeline Company of America's (NGPL) Amarillo expansion (110 MMcf/d) destined for the same area, the Midwest Region's access to Canadian supplies could increase by as much as 117 percent (3.6 Bcf/d) from the 1997 level (3.0 Bcf/d).

Two new pipelines, TriState $(0.5 \mathrm{Bcf} / \mathrm{d})$ and Vector $(1.0 \mathrm{Bcf} / \mathrm{d})$, have been proposed to tranship supplies arriving via Voyageur, Alliance, and Northern Border pipelines in the Chicago area to markets in eastern Michigan and southern 
Ontario, Canada. The Vector pipeline would provide an integral link in support of Columbia Gas Transmission Company's Millennium project, which has been proposed to begin gas deliveries in the fall of 1999 to customers in the Northeast (see next section). Vector would tranship supplies through Canada via the Union Gas System (Ontario) from the St. Clair export point and Dawn (Ontario) storage to the Millennium pipeline at Niagara, New York.

\section{Northeast}

More pipeline expansion projects were completed in the Northeast Region in 1997 than in any other part of North America. Twelve projects, accounting for about $770 \mathrm{MMcf} / \mathrm{d}$ of additional deliverability, or 2 percent of intraregional pipeline capabilities, were placed in service. However, only one of these projects ( $24 \mathrm{MMcf} / \mathrm{d})$ increased interregional deliverability (Table B1). The capacity increase within the region was exceeded only in the Southwest Region. Almost all of the projects were to improve deliverability within local markets or to address bottlenecks that were limiting service in areas of growing demand. Texas Eastern Transmission's several expansion projects were implemented primarily to resolve the latter problem.

The Northeast has the most natural gas pipeline projects (28) slated for development and they represent the largest amount of proposed new pipeline capacity within any region of the United States, $8.3 \mathrm{Bcf} / \mathrm{d}$. Several of the projects are continuations of ones that began in 1996 or 1997 and are being phased in over several years. While many of the proposed projects are smaller regional expansions serving local market areas, more than 59 percent of the added capacity would be on pipeline systems delivering from outside the Northeast Region. Of the $5.0 \mathrm{Bcf} / \mathrm{d}$ of proposed new interregional capacity, more than 53 percent would carry supplies originating in Canada.

Many of these projects have been planned because of expectations that an excess deliverability situation could occur in the Chicago area if all the projects slated to bring Canadian supplies into the Midwest are completed. This possibility has spurred several companies to plan large-scale projects that would extend some of this new capacity further eastward to Northeast markets. For example, ANR Pipeline Company and Transcontinental Gas Pipeline Company have proposed the jointly owned Independence project, which could carry $1.0 \mathrm{Bcf} / \mathrm{d}$ from ANR's line in northwestern Ohio to a major interconnection with Transcontinental's line in Leidy, Pennsylvania, a major hub serving the Northeastern marketplace. The new line would also be attractive to Canadian-gas shippers seeking an alternative route to Northeast markets. It could also provide an alternative route and opportunity for shippers now moving gas from the
Southwest to the Midwest to reach customers in the Northeast.

Other projects that would move some of the new Midwestern pipeline supplies eastward include Tennessee Gas Pipeline Company's proposed Eastern Express project and Duke Energy Corporation's Spectrum project. These two projects alone represent a total of $1.2 \mathrm{Bcf} / \mathrm{d}$ of new capacity into the Northeast. Including the Independence and Millennium projects, as well as other import projects slated for development during the next several years, new capacity into the region could reach $5.2 \mathrm{Bcf} / \mathrm{d}$, adding significantly to the $12.4 \mathrm{Bcf} / \mathrm{d}$ existing at the close of 1997.

The Spectrum project $(0.5 \mathrm{Bcf} / \mathrm{d})$ would extend from the Chicago, Illinois, area to New York and New England, mostly using expanded facilities along Duke Energy's affiliated pipelines: Panhandle Eastern, Texas Eastern, and Algonquin Gas Transmission systems (west to east). In addition, an interconnection with another affiliate, Trunkline Gas Company, could be utilized to move gas supplies from the Southwest Region if appropriate (as could the Panhandle Eastern Pipeline system). The Eastern Express project $(0.7 \mathrm{Bcf} / \mathrm{d})$ would utilize Midwestern Gas Transmission Company (an affiliate of Tennessee Gas Pipeline Company) to ship supplies southward (or though displacement) to Tennessee Gas's interconnection in northern Tennessee and then, through expanded facilities on its existing system, transport supplies from the Midwest to the east coast. In addition, the Eastern Express project would include expansion (0.2 Bcf/d) of Tennessee Gas's pipeline between its Niagara, New York, import point and its interconnections near Leidy, Pennsylvania, and its northern line extending directly to New England.

Canadian import expansions slated for development in 1998 and 1999 will result in increased capacity at several import points into the Northeastern United States and development of at least one new import point (for Columbia Gas Transmission's Millennium project). For example, in response to TransCanada's multiyear expansion plans, Iroquois Pipeline Company has proposed to expand its system by about $195 \mathrm{MMcf} / \mathrm{d}$, phased in during 1998 and 2000. Also supported by the TransCanada expansion will be the new Portland Natural Gas Pipeline (178 MMcf/d), which would replace and expand Granite State Pipeline Company's leased line (31 MMcf/d) that currently brings Canadian gas to Maine via Vermont and New Hampshire. Combined with the Millennium import level of $0.7 \mathrm{Bcf} / \mathrm{d}$ and several import expansions related to other projects, direct Canadian export capacity to the U.S. Northeast could increase by about $2.6 \mathrm{Bcf} / \mathrm{d}$ by the end of 2000 , a 91 -percent increase over the 1997 level. 
Planned expansions in the Northeast Region are also somewhat unique in that several projects represent cooperative efforts among regional pipeline systems. For example, the Texas Eastern expansion of service to some of its Virginia and eastern Pennsylvania service areas depends partly upon the completion of the CNG Transmission PL-1 line and Seasonal Service expansion projects, including improvements to storage deliverability. Columbia Gas Transmission, with its "Market Expansion" project, is also planning improvements (especially to storage services) on its system that would increase deliverability to several major interconnections with these same pipelines. National Fuel Gas Supply Company, another major regional system, has proposed upgrades to its system based upon the eventual completion of projects by Columbia, CNG, and Texas Eastern. In particular, National Fuel's project will complement CNG's planned improvement to its system for flowing gas between Leidy, Pennsylvania, a major storage area and hub interconnection point, and Steuben County, New York, and then northward where CNG and National Fuel have major interconnections. The first phases of several of these projects were completed in 1997.

Of the 28 singular projects planned within the region representing $8.3 \mathrm{Bcf} / \mathrm{d}$ of new capacity, a number are either directly or indirectly linked by mutual service needs or partnerships. ${ }^{129}$ These projects constitute about 18 percent, or $1.1 \mathrm{Bcf} / \mathrm{d}$, of the new capacity additions in the region.

\section{Southeast}

Natural gas pipeline expansions completed in the Southeast Region in 1997 (436 MMcf/d) were intended mainly to improve Deliverability within the region, primarily in North and South Carolina, Georgia, and Alabama. These expansions represent less than 1 percent of the total 1996 regional pipeline capacity levels (Table ES1). One system, Transcontinental Gas Pipeline Company, was involved in three of the five projects completed in 1997. In addition to increasing service from its North Carolina mainline, completion of its Sunbelt project supported the expansion of the South Carolina Pipeline system, which was also completed in 1997.

Fifteen expansion projects, representing a potential 3.2 Bcf/d of new capacity development, are proposed for the Southeast Region. About 54 percent of this capacity is geared toward improving regional access to deep water production in the Gulf of Mexico. Offshore projects represent about 1.7 Bcf/d

\footnotetext{
${ }^{129}$ Transcontinental Gas Pipeline Company and Tennessee Gas Pipeline Company also have several projects in the region that will benefit from and support expansions in the region.
}

of proposed capacity additions, all of which are scheduled to be in service sometime in 1998.

Five of these projects (1.2 Bcf/d of expansion capacity) represent an increased commitment by Transcontinental Gas Pipeline Company to customers within the region. Four other projects also represent greater service to regional markets, especially in the Atlanta, Georgia, area and the service territory of Atlanta Gas Light Company. Growth in the regional industrial market is helping to spur demand for additional natural gas supplies.

Also not to be overlooked in the expansion mix are the several projects that are designed to transport some of the growing Southwest regional production through the Southeast to markets in the Midwest and Northeast. The Tennessee Gas Pipeline Company's Express 500 is one such proposal, with up to $0.2 \mathrm{Bcf} / \mathrm{d}$ additional capacity to be added by 2000 , increasing the existing capacity of its Line 500 located within the region. Columbia Gulf Transmission Company also will increase its mainline capacity by more than $0.2 \mathrm{Bcf} / \mathrm{d}$. For the past several years, Columbia Gulf system has been operating below its original design capacity because of an aging infrastructure; the problem would be resolved with the completion of this project.

\section{Mexico Market}

Several projects have been proposed to add to the export capability of U.S. natural gas companies located near the border with Mexico (Table B2), although only two projects (237 MMcf/d) were completed in 1997. These were the first new export points to Mexico installed in 5 years (Table B1). None of the proposed projects represents enhancements to import capabilities, currently at about $350 \mathrm{MMcf} / \mathrm{d}$, a figure that has not changed since the 1980s. All of the proposed projects are to support mostly industrial and power generation customers located in the border area.

If completed, the currently proposed projects would represent about $1.4 \mathrm{Bcf} / \mathrm{d}$ of additional export capacity (Table B2). Currently (1997), export capacity to Mexico stands at 1.1 Bcf/d. Several of the proposed projects are competing within and for the same market. For example, Both the MidConTexas Pipeline Company (Figure B2) and Coastal States Gas Transmission Company are seeking to negotiate with Mexican buyers for firm shipping agreements to essentially the same general area. Nevertheless, both companies view their projects as proceeding regardless of the outcome of negotiations. These two companies also have plans to construct pipelines within Mexico that will link with their border crossing project and Texas intrastate pipeline construction projects. 
Most of the proposed projects have been proceeding slowly for environmental, economic, and regulatory reasons. One obstacle has been overcome with the installation of Mexico's newly formed regulatory authority, the Comision de Energia (CRE). The CRE has issued less restrictive regulations on foreign investment in Mexico, which affects the ownership and operation of pipeline facilities owned by others. In the fall of 1996, the CRE announced its first award of a (privatization) license permitting the development of a local gas distribution system in the Baja area of northern Mexico. ${ }^{130}$ This action may hasten the approval and final implementation of several similar local service development proposals, which are linked to pending U.S. export proposals that have remained dormant for several years.

In December 1997, construction was completed on the El Paso Energy Company's Samalayucca project, which links Texas supply sources with customers in Mexico's Chihuahua State. The 45-mile, $210 \mathrm{MMcf} / \mathrm{d}$ pipeline is the first pipeline located in Mexico owned in part by a U.S. company. A major customer of the project will be a 700 megawatt combinedcycle electric generating plant located in Samalayucca, Mexico, which will begin operations in late 1998.

\section{Summary}

The amount of new capacity proposed for development by the end of 2000 is significant and, if fully implemented, would represent a 9-percent increase in intraregional capacity from the 1996 level and a 17-percent increase in interregional capacity (Table ES1). Although it is unlikely that all proposed expansions will be completed, additional projects continue to be proposed. During 1997 and early 1998, for instance, at least 22 pipeline companies instituted open-season exercises for 26 projects, with the expectation that the market will support additional expansion plans. These proposals, while not all sussessful, included expansions in all regions of the country.

Beyond what has already been proposed, there are areas of the country where additional pipeline expansion plans might develop in response to changing market profiles and the development of new supply sources. For instance, deep-water development in the Gulf of Mexico will continue over the next decade and with it could come additional complementary onshore expansions. In addition, the expanding production in areas of Texas and the Rocky Mountains will place pressure on local pipeline systems to expand their capabilities to reach nearby and distant markets. As a consequence, utilization rates on interconnecting interstate pipelines should increase and, in some cases, necessitate the development of new capacity on some systems.

The upcoming major increase in capacity from Canada to the U.S. Midwest may also spur additional development of new pipelines, or expansions of existing lines, that can provide alternative capacity for transhipment of some of this gas to the U.S. Northeast. Already several of the proposed Midwest-toNortheast expansion projects are premised on the assumption that excess capacity into the Chicago, Illinois, area could develop over the next several years as new (proposed Canadian source) pipelines are completed during the interim.

\footnotetext{
${ }^{130}$ The award was made to a consortium consisting of Pacific Enterprises International (PED), Enova International Corporation, and Proxima. The license will permit the group to transport gas from PEI's local system in lower California into the city of Mexicali in northern Mexico.
} 


\section{Appendix C}

\section{Changes in Natural Gas Markets}

This appendix presents several State summary data tables that detail energy use profiles of the geographic regions covered in this report and the availability of supplemental natural gas supplies. These tables supplement the regional tables in Chapter 5, "Deliverability to Markets."

The first table, Table C1, "Regional Weather and Gas Storage Profile," provides some basic data regarding the relative seasonal temperature variation among States (a key determinant of natural gas demand) and levels of underground and liquefied natural gas (LNG) storage. How much gas can be delivered from storage facilities and is available to the pipeline network during peak periods are crucial factors in analyzing the ability of the pipeline system to support estimated consumer requirements.

The second table, Table C2, "Regional and State Energy Profile Comparison of Annual Average Change," shows total energy consumption patterns for each of the lower 48 States, in particular how the use of natural gas increased (decreased) relative to all other fuel types between 1990 and 1995. The third table, Table C3, "Regional and State Natural Gas Customer Market Share Changes," illustrates how the use of natural gas among the various natural gas customer sectors within each State has changed since 1990.
These changes reflect the shifts in consumption patterns that have occurred as a result of market restructuring at both the national and local levels. They also reflect changes in market demand as a result of changes in a State's economic profile during the past several years.

Lastly, Table C4, "Regional and State Natural Gas Customers, Average Annual Growth" supplements Table $\mathrm{C} 3$ by providing data on the number of natural gas consumers for each end-use sector in 1996 and the average annual growth rate from 1990 through 1996. The change in these factors underlies the level and magnitude of the movements reflected in the market shares for natural gas customer groups.

Most of the annual data used to compile the annual average rates of change shown in these tables may be found in the following Energy Information Administration publications: the Natural Gas Annual, the Electric Power Annual, or the State Energy Data Report (SEDS). While the period of comparison, for the most part, was for the years 1990 through 1996, in some instances data were not yet available for 1996. Specifically, the SEDS data, which tabulate all annual energy use data on a common (Btu) basis, are not compiled until all individual fuel data are verified and complete; they were available only through 1995 when this report was prepared. 
Table C1. Regional Weather and Gas Storage Profile, 1996

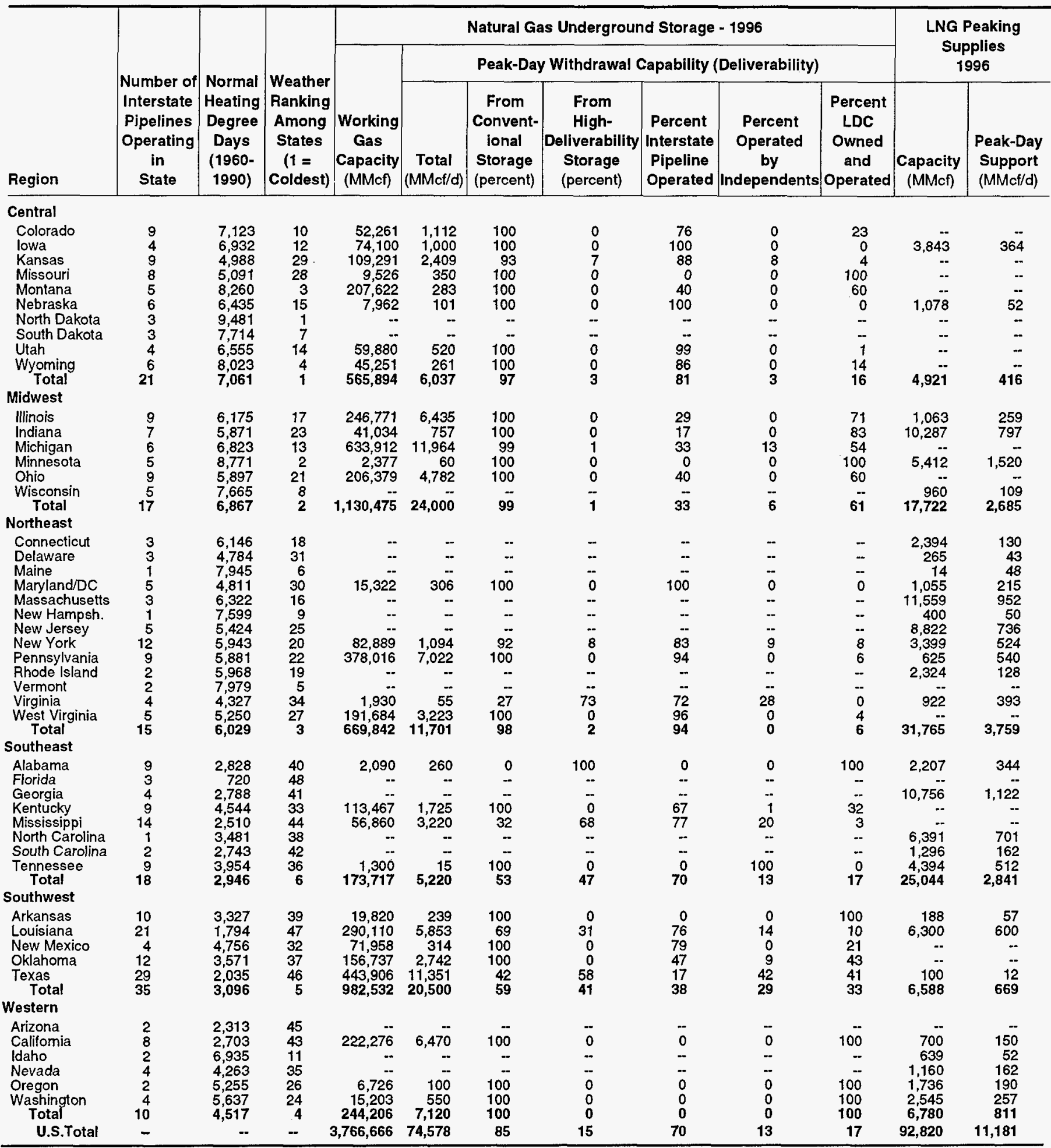

MMcf/d = Million cubic feet per day. LDC = Local distribution company. -- = Not applicable.

Sources: Normal Heating Degree Days: U.S. Department of Commerce, National Oceanic and Atmospheric Administration, "State Regional, and National Monthly and Seasonal Heating Degree Days Weighted by Population." Natural Gas Underground Storage: Energy Information Administration (EIA), Form EIA-191, "Underground Gas Storage Report." Llqueffed Natural Gas (LNG): EIAGIS-NG Geographic Information System, LNG Database, as of December 1997. 
Table C2. Regional and State Energy Profile Comparison of Annual Average Change, 1990-1995

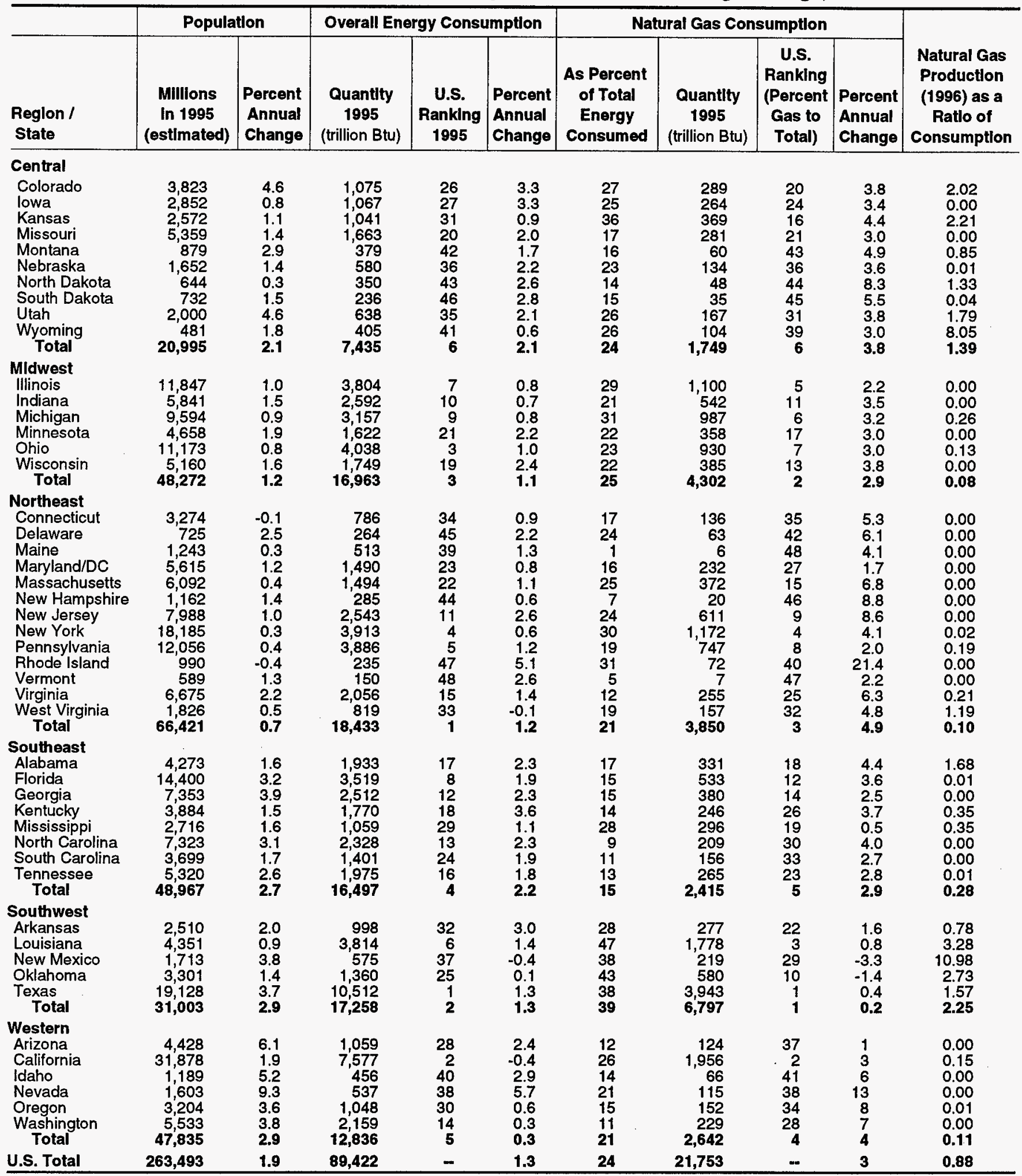

$--=$ Not applicable.

Sources: Natural Gas Production and Consumption: Energy Information Administration (EIA), Form ElA-176, "Annual Report of Natural and Supplemental Gas Supply and Disposition." Energy Consumption: ElA, State Energy Data Report, Consumption Estimates 1980-1995 (December 1997). Population: U.S. Department of Commerce, Bureau of the Census. 
Table C3. Regional and State Natural Gas Customer Market Share Changes, 1990-1996

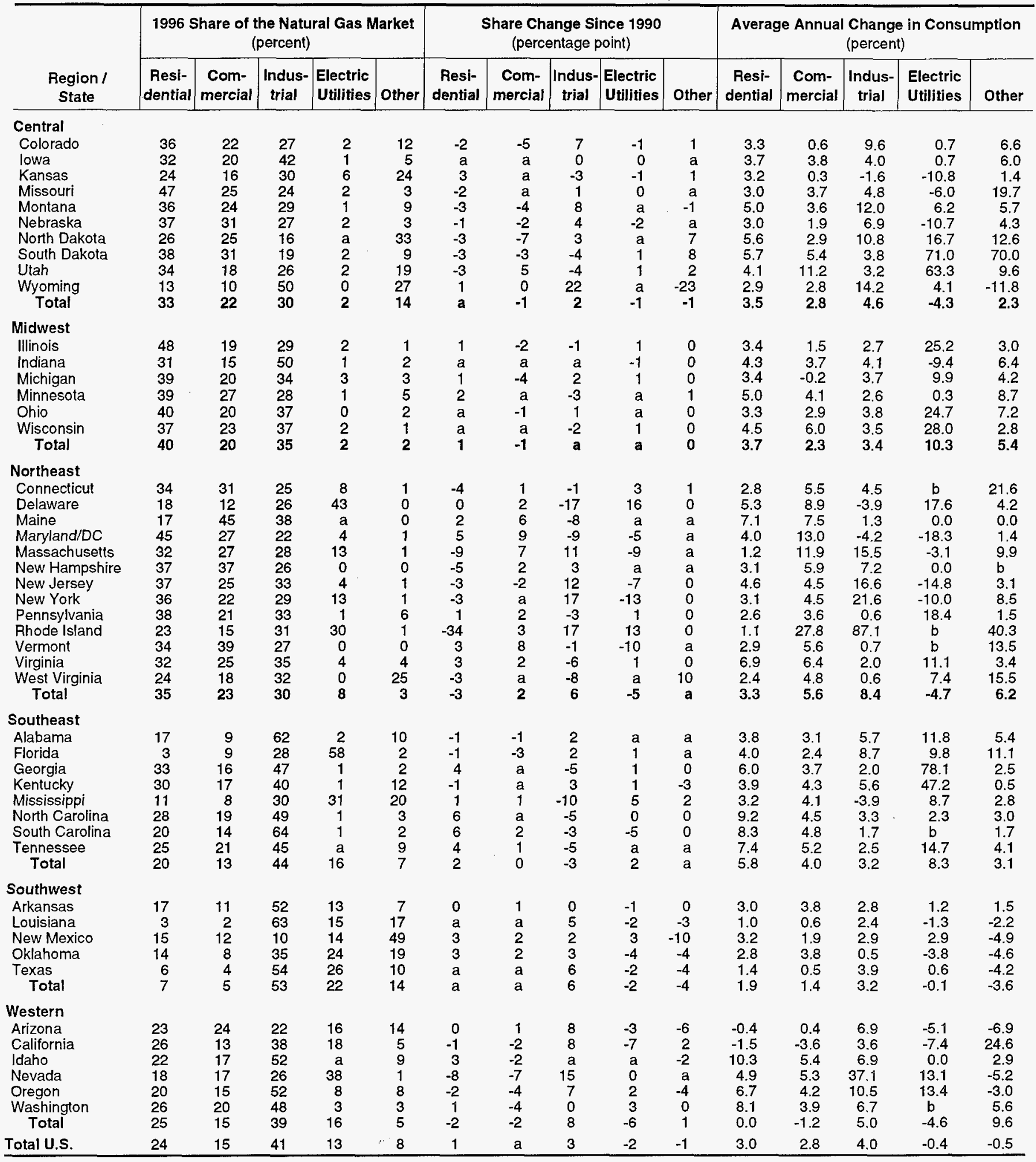

aBetween plus 0.5 percent and minus 0.5 percent.

bOver plus or minus 100 percent per annum. Result very large (small) due to large fluctuations in annual volumes reported in this category.

Note: Totals may not equal sum of components because of independent rounding.

Source: Energy Information Administration, Form ElA-176, "Annual Report of Natural and Supplemental Gas Supply and Disposition." 
Table C4. Regional and State Natural Gas Customers, Average Annual Growth, 1990-1996

\begin{tabular}{|c|c|c|c|c|c|c|c|c|c|c|c|c|c|}
\hline \multirow[b]{3}{*}{ Region } & \multicolumn{3}{|c|}{ Residential Customers } & \multicolumn{3}{|c|}{ Commercial Firms } & \multicolumn{3}{|c|}{ Industrial Firms } & \multirow{2}{*}{\multicolumn{4}{|c|}{$\begin{array}{c}\text { Electric Utilities } \\
\begin{array}{c}\text { Annual Change } \\
\text { (percent) }\end{array}\end{array}$}} \\
\hline & \multirow[b]{2}{*}{$\begin{array}{c}\text { Number } \\
\text { in } \\
1996\end{array}$} & \multicolumn{2}{|c|}{$\begin{array}{c}\text { Annual Change } \\
\text { (percent) }\end{array}$} & \multirow[b]{2}{*}{$\begin{array}{c}\text { Number } \\
\text { in } \\
1996\end{array}$} & \multicolumn{2}{|c|}{$\begin{array}{c}\text { Annual Change } \\
\text { (percent) }\end{array}$} & \multirow[b]{2}{*}{$\begin{array}{c}\text { Number } \\
\text { in } \\
1996\end{array}$} & $\begin{array}{l}\text { Annual } \\
\text { (pere }\end{array}$ & $\begin{array}{l}\text { Change } \\
\text { cent) }\end{array}$ & & & & \\
\hline & & $\begin{array}{c}\text { In } \\
\text { Number } \\
\text { of Users }\end{array}$ & $\begin{array}{c}\text { In } \\
\text { Average } \\
\text { Use }\end{array}$ & & $\begin{array}{c}\text { In } \\
\text { Number } \\
\text { of Users }\end{array}$ & $\begin{array}{c}\text { In } \\
\text { Average } \\
\text { Use }\end{array}$ & & $\begin{array}{c}\text { In } \\
\text { Number } \\
\text { of Users }\end{array}$ & $\begin{array}{c}\text { In } \\
\text { Average } \\
\text { Use }\end{array}$ & $\begin{array}{c}\text { In } \\
\text { Number } \\
\text { of Al! } \\
\text { Type } \\
\text { Units }\end{array}$ & $\begin{array}{c}\text { In } \\
\text { Number } \\
\text { of Gas- } \\
\text { Fired } \\
\text { Units }\end{array}$ & $\begin{array}{l}\text { In Total } \\
\text { Summer } \\
\text { Capacity }\end{array}$ & $\begin{array}{c}\text { In Gas } \\
\text { Fired } \\
\text { Capacity }\end{array}$ \\
\hline Central & & & & & & & & & & & & & \\
\hline Colorado & $1,147,743$ & 2.6 & 0.6 & 121,221 & 1.2 & -0.6 & 2,099 & 13.8 & -3.4 & -1.3 & -0.8 & 0.5 & 1.3 \\
\hline lowa & 771,109 & 1.5 & 2.1 & 89,663 & 1.3 & 2.4 & 2,066 & 1.6 & 2.4 & -2.8 & -5.0 & -15.3 & -9.4 \\
\hline Kansas & 804,213 & 1.2 & 1.9 & 89,168 & 0.7 & -0.4 & 2,988 & -6.6 & 7.7 & -1.3 & -1.1 & 0.2 & -0.5 \\
\hline Missouri & $1,275,465$ & 0.8 & 2.0 & 133,445 & 4.1 & -0.6 & 3,408 & 1.5 & 3.3 & 0.3 & 0.3 & 0.9 & 7.2 \\
\hline Montana & 205,199 & 2.8 & 2.0 & 26,374 & 2.1 & 1.3 & 466 & 0.3 & 11.6 & -1.1 & 0.0 & 0.1 & 0.0 \\
\hline Nebraska & 439,931 & 1.3 & 1.6 & 61,117 & 0.2 & 1.6 & 2,234 & 36.0 & -23.4 & -0.9 & 1.2 & 0.6 & 2.3 \\
\hline North Dakota & 97,761 & 2.2 & 3.2 & 13,789 & 1.3 & 1.6 & 206 & 3.8 & 6.6 & -2.8 & 0.0 & -1.2 & 0.0 \\
\hline South Dakota & 127,269 & 3.3 & 2.3 & 16,880 & 4.0 & 1.3 & 444 & 8.4 & -4.9 & -6.1 & 1.1 & 1.7 & 30.9 \\
\hline Utah & 562,343 & 3.7 & 0.2 & 40,107 & 2.5 & 8.4 & 923 & -11.1 & 23.0 & 2.1 & 4.6 & 0.4 & -2.2 \\
\hline Wyoming & 131,910 & 2.6 & 0.3 & 17,036 & 3.7 & -1.0 & 170 & -9.9 & 25.6 & 1.6 & 33.3 & 0.5 & 18.7 \\
\hline Total & $5,562,943$ & 1.8 & 1.5 & 608,800 & 1.9 & 0.8 & 15,004 & 1.5 & 3.2 & -1.3 & -1.0 & -0.5 & 1.2 \\
\hline Midwest & & & & & & & & & & & & & \\
\hline Illinois & $3,494,545$ & 1.0 & 2.3 & 265,007 & 0.5 & 1.0 & 29,493 & 2.2 & 0.5 & -2.3 & -1.1 & 0.2 & 14.0 \\
\hline Indiana & $1,489,647$ & 1.9 & 2.3 & 139,097 & 1.8 & 1.8 & 6,586 & 0.4 & 3.7 & 0.5 & 1.2 & 0.1 & 1.0 \\
\hline Michigan & $2,812,876$ & 1.5 & 1.9 & 214,843 & 1.6 & -1.8 & 11,848 & 0.5 & 3.2 & -0.6 & 4.3 & -0.2 & 22.3 \\
\hline Minnesota & $1,103,709$ & 2.6 & 2.3 & 105,531 & 1.7 & 2.3 & 2,564 & -0.1 & 2.7 & -0.4 & -2.6 & 0.7 & -15.8 \\
\hline Ohio & $2,994,891$ & 1.3 & 2.0 & 259,663 & 1.8 & 1.1 & 8,672 & 0.7 & 3.0 & 0.1 & 2.1 & 0.2 & 10.5 \\
\hline Wisconsin & $1,324,570$ & 2.8 & 1.6 & 129,146 & 3.3 & 2.6 & 5,861 & -3.6 & 7.3 & -0.1 & 2.3 & 2.0 & 20.7 \\
\hline Total & $13,220,238$ & 1.6 & 2.0 & $1,113,287$ & 1.6 & 0.7 & 65,024 & 0.8 & 2.6 & -0.6 & 0.3 & 0.3 & 8.0 \\
\hline Northeast & & & & & & & & & & & & & \\
\hline Connecticut & 433,778 & 0.2 & 2.6 & 47,055 & 0.6 & 4.9 & 3,435 & 2.4 & 1.4 & -2.8 & 30.6 & -2.1 & 11.7 \\
\hline Delaware & 106,548 & 3.1 & 2.1 & 9,518 & 4.1 & 4.6 & 250 & 0.7 & -4.6 & -0.6 & 4.9 & 2.3 & 4.3 \\
\hline Maine & 14,982 & 3.8 & 3.1 & 6,414 & 7.1 & 0.2 & 87 & 1.8 & 0.0 & -0.2 & 0.0 & -0.1 & 0.0 \\
\hline Maryland/DC & $1,006,227$ & 1.7 & 2.3 & 80,943 & 3.3 & 5.9 & 430 & -167.6 & 125.7 & -1.4 & 6.7 & 1.8 & 6.9 \\
\hline Massachusett & $1,188,317$ & 1.0 & 0.2 & 105,889 & 0.9 & 11.6 & 10,952 & 11.5 & 8.2 & -1.3 & -0.5 & -1.6 & 9.1 \\
\hline New Hampsh. & 75,175 & 2.4 & 0.6 & 12,755 & 3.3 & 2.5 & 367 & 0.2 & 7.2 & -3.1 & 16.7 & -0.9 & 34.6 \\
\hline New Jersey & $2,147,622$ & 1.3 & 3.1 & 224,749 & 0.5 & 4.0 & 10,139 & 10.8 & 4.8 & -2.5 & 0.0 & 0.1 & 1.8 \\
\hline New York & $4,048,166$ & 0.6 & 2.5 & 315,855 & 2.0 & 2.5 & 15,300 & -9.7 & 33.3 & -2.0 & -1.4 & -0.5 & 3.6 \\
\hline Pennsylvania & $2,431,909$ & 0.8 & 1.7 & 214,340 & 2.3 & 1.2 & 6,441 & 0.5 & -0.1 & -1.0 & 3.4 & 4.0 & 41.3 \\
\hline Rhode Island & 204,259 & 0.8 & 0.3 & 21,664 & 3.5 & 23.6 & 363 & -33.6 & 118.7 & -8.8 & -25.0 & 20.2 & 37.1 \\
\hline Vermont & 24,383 & 4.9 & -2.2 & 3,790 & 4.3 & 1.3 & 27 & 11.2 & -10.3 & 1.5 & -- & 0.4 & 1.1 \\
\hline Virginia & 789,985 & 4.0 & 2.7 & 77,284 & 3.3 & 3.1 & 2,822 & 28.2 & -25.9 & 3.0 & -0.8 & 1.4 & -10.8 \\
\hline West Virginia & 358,049 & 0.4 & 2.0 & 33,837 & 0.5 & 4.3 & 182 & 0.0 & 0.9 & -3.2 & -- & 0.0 & -- \\
\hline Total & $12,829,400$ & 1.1 & 2.1 & $1,154,093$ & 1.8 & 3.8 & 50,795 & -1.5 & 9.7 & -1.1 & 0.4 & 0.1 & 4.4 \\
\hline Southeast & & & & & & & & & & & & & \\
\hline Alabama & 766,322 & 1.9 & 1.9 & 62,064 & 1.5 & 1.6 & 2,512 & 0.6 & 5.1 & 1.1 & 10.8 & 0.6 & 6.5 \\
\hline Florida & 521,674 & 2.2 & 1.7 & 47,578 & 1.5 & 0.9 & 517 & 2.2 & 6.1 & -0.2 & 2.0 & 2.1 & 1.7 \\
\hline Georgia & $1,538,458$ & 2.4 & 3.4 & 123,200 & 2.2 & 1.4 & 3,310 & 0.8 & 1.1 & 0.3 & 8.7 & 1.6 & 19.5 \\
\hline Kentucky & 696,989 & 1.8 & 1.9 & 76,079 & 2.1 & 2.2 & 1,633 & 0.9 & 4.6 & 0.2 & 5.1 & 0.1 & 24.5 \\
\hline Mississippi & 418,442 & 1.5 & 1.7 & 46,029 & 1.1 & 3.0 & 1,241 & -1.0 & -2.9 & 0.3 & 0.4 & 0.4 & 2.6 \\
\hline North Carolina & 699,159 & 5.1 & 3.9 & 93,504 & 5.5 & -1.0 & 3,973 & 6.6 & -3.1 & -1.2 & 8.9 & 0.6 & 23.8 \\
\hline South & 426,088 & 3.9 & 4.1 & 48,650 & 3.4 & 1.4 & 1,759 & 4.3 & -2.6 & 1.5 & 2.2 & 2.6 & 1.3 \\
\hline Tennessee & 841,232 & 5.0 & 2.2 & 103,867 & 2.7 & 2.4 & 2,306 & -0.4 & 2.9 & -0.7 & -- & 0.3 & -2.0 \\
\hline Total & $5,908,364$ & 2.9 & 2.7 & 600,971 & 2.6 & 1.3 & 17,251 & 1.9 & 1.4 & 0.1 & 3.2 & 1.2 & 4.2 \\
\hline Southwest & & & & & & & & & & & & & \\
\hline Arkansas & 539,952 & 1.7 & 1.2 & 67,293 & 1.5 & 2.2 & 1,486 & 1.1 & 1.8 & 0.2 & -2.4 & 0.0 & -0.1 \\
\hline Louisiana & 945,967 & 0.2 & 0.8 & 62,101 & -0.2 & 0.7 & 1,444 & -1.0 & 3.7 & -0.1 & 0.2 & 0.4 & 1.4 \\
\hline New Mexico & 428,621 & 2.5 & 0.6 & 37,796 & -0.1 & 2.0 & 1,365 & -33.1 & 29.4 & 0.6 & 2.3 & 0.1 & 31.4 \\
\hline Oklahoma & 866,531 & 1.0 & 1.7 & 89,852 & 0.8 & $3.0^{\circ}$ & 2,843 & -0.3 & 0.8 & 0.2 & 0.3 & 0.4 & 2.5 \\
\hline Texas & $3,501,853$ & 1.3 & 0.0 & 329,287 & 3.5 & -3.3 & 8,796 & -14.2 & 18.1 & -0.2 & -0.4 & 0.7 & 0.5 \\
\hline Total & $6,282,924$ & 1.2 & 0.6 & 586,329 & 2.2 & -0.9 & 15,934 & -7.8 & 11.0 & 0.1 & -0.1 & 0.5 & 1.4 \\
\hline Western & & & & & & & & & & & & & \\
\hline Arizona & 689,597 & 2.8 & -3.3 & 49,693 & 0.9 & -0.6 & 534 & 0.3 & 6.6 & 1.0 & 0.3 & 0.3 & 0.9 \\
\hline California & $8,969,308$ & 0.9 & .2 .4 & 408,294 & -0.3 & -3.3 & 36,613 & -4.0 & 7.5 & 0.5 & 0.8 & 0.2 & -0.3 \\
\hline Idaho & 187,756 & 8.7 & 1.0 & 25,271 & 4.5 & 0.7 & 183 & 22.9 & -15.6 & -0.9 & -- & 1.9 & - \\
\hline Nevada & 393,783 & 7.5 & -2.7 & 26,613 & 4.3 & 0.9 & 121 & 3.3 & 32.7 & 1.1 & 5.6 & 2.3 & 3.0 \\
\hline Oregon & 433,638 & 5.0 & 1.5 & 57,613 & 3.5 & 0.6 & 799 & 2.4 & 8.2 & 0.2 & 2.1 & -1.2 & 5.6 \\
\hline Washington & 673,357 & 6.6 & 1.0 & 73,708 & 4.0 & -0.3 & 3,587 & 0.8 & 5.9 & -0.1 & -4.2 & -1.1 & -1.0 \\
\hline Total & $11,347,439$ & 1.7 & -1.7 & 641,192 & 0.9 & -2.1 & 41,837 & -3.4 & 8.4 & 0.3 & 0.9 & 0.1 & 0.3 \\
\hline Total U.S. & $55,151,308$ & 1.6 & 1.4 & $4,704,672$ & 1.8 & 1.0 & 205,847 & -1.0 & 5.1 & -0.5 & 0.3 & 0.3 & 2.5 \\
\hline
\end{tabular}

'Includes both primary and secondary generating units.

-. = Not applicable.

Source: Natural Gas Usage: Energy Information Administration (EIA), Form EIA-176, "Annual Report of Natural and Supplemental Gas Supply and Disposition." Electrlc Generatlon Capacity: EIA, Form EIA-860, "Annual Electric Generation Report," 1990 through 1996. 


\section{Appendix D}

\section{Data Sources}

The data presented in the body of this report came from many sources and often required some adjustment to provide information on a comparable basis for use in the analysis. This appendix provides detailed information on the methodology and source material used to develop estimates of interstate pipeline capacity at State borders and the changes in energy usage patterns from 1990 through 1995.

The following is a list of the data sources discussed in this appendix.

- Annual pipeline company reports filed with the Federal Energy Regulatory Commission (FERC) under 18 CFR \$284.12, "Peak-Day Capacity Report," and \$260.8, Format FERC 567, "System Flow Diagrams."

- FERC Form 2, "Annual Report of Major Natural Gas Companies"

- FERC Form 11, "Natural Gas Pipeline Monthly Statement," 1995 and earlier years. (The survey became a quarterly report in 1996.)

- FERC Index of Customers

- Energy Information Administration (EIA), Form EIA-176, "Annual Report of Natural and Supplemental Gas Supply and Disposition"

- Energy Information Administration, Form EIA-191, "Underground Natural Gas Storage Report"

- Natural Gas Annual, DOE/EIA-0130, various issues.

\section{Pipeline Capacity}

The measure of pipeline capacity that was estimated and addressed in this report is the daily capacity of the interstate natural gas pipeline network at regional and State boundaries. Specifically, it is an estimate of the maximum volume of gas that can be transported under normal operating conditions for a sustained period of time. While pipeline systems have considerable operational flexibility to increase deliveries of natural gas above design capacity levels to certain areas for short periods of time, this often means that deliveries are reduced elsewhere or that line packing occurs. Neither measure is likely to be sustainable for more than a short period of time.

Information on capacity levels for the interstate pipeline systems is generally available from filings at the Federal Energy Regulatory Commission (FERC). However, this information is typically associated with compressor stations and not State border capacity. Thus, to estimate the State-to-State capacities on the pipelines, an approach was required. Further, while there is a regulatory requirement for the submission of design information, the terminology provided in the submissions sometimes is unclear as to whether the data provided by a company are in fact the information requested.

The original compilation of pipeline capacity estimates was done by the Energy Information Administration during 1991 and 1992, using 1990 as the base year. The initial approach taken to derive the State-to-State capacity information was the following:

- Develop initial capacity estimates by using compressor station data from FERC Format 567, "System Flow Diagrams."

- Adjust initial estimates by using delivery requirements of customers located between the State line and the station and for any contracted receipts from other pipelines.

- When compressor station data were unavailable on Format 567, derive a statistical estimate by using a regression equation based upon the diameter(s) of the pipeline segment in question.

- Impute remaining missing values by using proxies for capacity. Data used for this purpose include contract demand (CD) data for pipeline sales customers, which were available for the years 1988 and 1989. (CD data were no longer available once FERC Order 636 was implemented in November 1993.)

- Cross check the State border capacities for reasonableness by using contract demand levels (if not used as a proxy for capacity); flow data from Form EIA-176, "Annual Report of Natural and Supplemental Gas Supply and Disposition"; and consultations with FERC staff and company officials. 
The initial (1990) estimates of capacity on a pipeline segment at a State border were based on reported compressor station throughput, the daily output of whichever compressor station appeared to be closest to the State border. The working assumption was that throughput capability, even if only an estimated flow under current operating conditions, of any compressor station is a reasonably good estimate of peak-period throughput at that point on the line. (Note: Compressor station output may be a "constraint" on throughput when downstream pipeline diameter and other characteristics of the segment may allow the physical pipeline to handle greater loads than required under current customer peak-day commitments. Conversely, the designed compressor output may be greater than can be sent through existing pipeline configurations.)

When no delivery or receipt points were between the selected compressor station and the State line, the capacity at the State border was assumed to equal the station capability, even though some friction losses would occur because of the distance between the line and compressor. When data were available for both receipt and $C D$ deliveries between the compressor station and the State line, then the initial capacity estimates were adjusted to account for these volumes.

In some cases, peak-day information rather than design capacity was reported on the Format 567 . These estimates were considered a reasonable proxy for capacity.

Under certain conditions, contract demand data were used to estimate capacity levels at a State border. CD data were assumed to be a reasonable reflection of current peak-day demands on the pipeline system and, therefore, a close approximation of the capability or capacity of the pipeline to supply those customers. A pipeline's CD commitment levels within a State were used as a surrogate for a measure of that pipelines' capacity into the State when the pipeline system, or a branch, terminated in the State. Even in this instance, however, the pipeline company could meet a portion of its commitments from sources within the State borders.

In some cases, compressor station data and contract demand data were inadequate to develop an initial capacity estimate, and other methods were pursued to make the initial capacity estimate. For instance, regression equations to estimate capacity were developed by use of a universe of 814 compressor stations with known pipeline diameters, capacities, and pressures, extracted from the Format 567 filings. The results indicated that diameter alone was a good predictor of capacity in these equations.

Subsequently, updated annual capacity estimates were developed for years 1991 through 1996 by using the 1990 levels as starting points. First, the contents of the most recent annual FERC Format 567 "System Flow Diagram" for each pipeline system were compared with the previous year's submission. The primary items examined were the throughput capabilities of the pipeline's compressor stations and whether they had increased, had changed, or had new stations added. In addition, comparisons of receipt and delivery point volumes were also performed to determine changes in peakday deliverabilities and as a replacement for contract demand data which were no longer current. Available data on pipeline construction projects completed during the interim were also factored into any estimate adjustments. These comparisons were done, to the extent possible, through comparative analyses of updated databases. Initial estimates of revised capacity levels were produced and displayed on annotated pipeline maps.

These estimates were then presented to the pipeline company or FERC staff for evaluation. These inputs were used to settle upon a final estimate.

\section{Average Daily Pipeline Flow}

The data source for actual average daily pipeline volume flows across State borders was Form EIA-176, "Annual Report of Natural and Supplemental Gas Supply and Disposition." In addition, these data are the basis for Statelevel supply, consumption, and transportation volumes presented in this report.

The respondent universe of the Form EIA-176 includes interstate and intrastate pipeline companies; investor and municipally owned natural gas distributors; underground natural gas storage operators; synthetic natural gas plant operators; and field, well, or processing plant operators that deliver natural gas directly to consumers and/or transport gas to, across, or from a State border through field or gathering lines.

The average daily flow volumes presented in the "Region-toRegion Capacity" tables in the report are based upon preliminary 1996 data from Form EIA-176. They are the sum of data that can be identified as volumes brought across a border: on-system purchases received at a State border, plus transportation and/or exchange receipts received at a State line, plus transported into the report State. The data on Form EIA-176 are annual; average daily levels were computed on a 366-day basis (1996 was a leap year).

Greater detail concerning Form EIA-176, its background, and EIA processing methodology, may be found in the EIA publication Natural Gas Annual 1996, DOE/EIA-0131, Appendix A. 


\section{System Flow Rate Data}

The pipeline systemwide flow rate data discussed in this report (detailed in Appendix A) and used for utilization analyses are based on monthly throughput volume data reported on FERC Form 11, "Natural Gas Pipeline Monthly Statement." These data for the period January 1980 through December 1995 are maintained and available on computer tape.

Transportation, sales, and intercompany transfer throughput volumes are reported, but for the total pipeline system only. As a result, these data cannot be used to compute regional or State-level utilization levels. However, the historical data were used to identify and quantify the largest monthly throughput level occurring on the individual pipeline systems over the period 1980 through 1995. Average monthly throughput rates for 1989 and 1995 were then divided by the largest monthly throughput (which was used as an approximation of a 100-percent load factor or a surrogate measure for full capacity utilization) to estimate the overall relative flow rate (throughput) on the various pipeline systems in 1995.

This report also uses data from the FERC Form 2, "Annual Report of Major Natural Gas Companies," for discussions pertaining to system peak-day deliverability rates and utilization levels on those days. These data, which are reported on page 518, "Transmission System Peak Deliveries" of FERC Form 2, provide peak delivery volumes at several levels. Those periods are: highest day, $2^{\text {nd }}$ highest, and $3^{\text {rd }}$ highest days deliveries, highest 3 consecutive days, and highest month deliveries. These data are to be reported for the period "during the twelve months embracing the heating season overlapping the year's end for which this report is submitted." The latest such period available for this report was the 1995-96 heating year (April 1995 through March 1996).

The peak-day (highest one day) deliveries reported on FERC Form 2 were used in relation to system capacity levels reported on the annual pipeline company reports filed with the FERC under 18 CFR \$260.8. The comparison of the two items provides some insight into the systemwide level of pipeline usage during periods of highest user need and some indication of how well the system is able to meet its obligations to its customers under current capacity limitations.

\section{Transportation System Access}

The analysis of transportation system access (Chapter 5) employed a sample of 46 major interstate natural gas pipeline companies. The sample was selected to ensure that adequate and uniform peak-day and monthly transportation information was available for each pipeline company. All pipeline companies in the sample were required to have at least three of the four peak-delivery data necessary to determine maximum capability. The data used in the derivation of maximum capability are from the pipeline company reports filed with the Federal Energy Regulatory Commission (FERC). These data include: the estimated peak-day capacity of the pipeline company's system from the 1996 Peak-Day Capacity Report (18 CFR \$284.12); the quarterly contracted firm transportation capacity from the quarterly Index of Customers filings for the period April 1, 1996, through April 1, 1997; the coincident peak-day delivery from the 1995 FERC Format 567 "System Flow Diagrams"; and the transmission system peak deliveries from the 1996 filing of FERC Form 2, "Annual Report of Major Natural Gas Companies." In addition to having sufficient information to estimate maximum capability, the analysis required that each pipeline company in the sample had filed FERC Form 11, "Natural Gas Pipeline Company Quarterly Statement of Monthly Data," for the period April 1996 through March 1997. The transportation volumes from FERC Form 11 were used to assess the utilization of the reserved capacity.

These data requirements resulted in a sample size that was 17 pipeline companies smaller than the sample selected for the analysis of firm capacity contracts, also in Chapter 5. Although the accessibility analysis used 32 percent fewer pipeline companies than the sample for the contract analysis, it excluded only 1 percent, or 1.4 quadrillion Btu per day, of the firm contracted capacity (based on the April 1, 1997, FERC Index of Customer filing) included in the firm contract analysis.

\section{Firm Capacity Contracts}

The FERC Index of Customers filing was the principal source of information for the analysis of firm capacity contracts in Chapter 5. The guiding principal for the analysis was to assemble the most recent, reliable information available. Therefore, the quarterly FERC Index of Customers filings for April 1, 1996, through April 1, 1997, were used for the analysis. Several pipeline companies were excluded from the filed Index of Customers because their data were inconsistent or missing. The resulting sample consists of 63 interstate pipeline companies. Since the analysis was not concerned with consistency across several sources of information, it employed a much larger sample of pipeline companies than the accessability analysis.

Firm transportation capacity was examined by type of shipper. Pipeline companies are required to disclose the amount of capacity reserved by each firm customer in the 
quarterly Index of Customers filing to the Federal Energy Regulatory Commission. The Index of Customers provides the name of each company that contracted for firm transportation, but it does not provide any other information to identify what type of company each shipper was. Thus, EIA staff compared shipper names with lists of companies from other sources to classify each shipper. Four sources were used for comparison: (1) Form EIA-176, "Annual Report of Natural and Supplemental Gas Supply and Disposition"; (2) Benjamin Schlesinger and Associates, Inc., Directory of Natural Gas Marketing Service Companies, Eleventh Edition (May 1997) (a proprietary source); (3) Energy Planning, Inc., Directory of Natural Gas Consumers, 5th Edition (1996) (a proprietary source); and (4) Form EIA-860, "Annual Electric Generator Report."

The list of electric utilities from Form EIA-860 included combination electric and gas utilities. Shippers that appeared in this list and that used natural gas as either the primary or alternative source of fuel for electricity generation were classified as electric utilities, even the combination companies. Combination companies that did not use natural gas as the primary or alternative source of fuel for electricity generation were classified as local distribution companies. For example, Baltimore Gas and Electric Company was classified as an electric utility while Atlanta Gas Light Company was classified as a local distribution company.

The final set of shipper categories is as follows:

- Electric utilities (including combination electric and natural gas utilities for which natural gas is the primary or alternative source of fuel for generating electricity)

- Industrial companies (including independent power producers, cogenerators, and commercial firms)

- Local distribution companies (including intrastate pipeline companies and combination electric and natural gas utilities for which natural gas is not the primary or alternative source of fuel for generating electricity)

- Marketers

- Interstate pipeline companies

- Other companies (including producers and gatherers and companies that could not otherwise be classified).

\section{Underground Natural Gas Storage Data}

Each month, on the Energy Information Administration's Form EIA-191, "Underground Natural Gas Storage Report," U.S. storage operators are required to report their current estimates of injections and withdrawals occurring in the previous month at each site they operate. In addition, on an annual basis, each operator is expected to report any change to total, base, or working gas capacity, as well as daily deliverability (see Glossary) that may have occurred at the site during the previous calendar year.

These data have been compiled in a database with each site identified by such criteria as ownership type (interstate pipeline, local distribution company, or independent operator), type of facility (depleted reservoir, salt cavern, aquifer, or mine), and interconnecting pipeline. The combination of this information, in association with the capability (capacity level) of connecting pipeline systems, with an approximate location, permitted an analysis and a way of estimating the impact of storage availability and operational capability on service to producers and shippers and pipeline utilization.

\section{Maps and Mapped Data}

The geographic displays in this report were produced, in whole or in part, using the EIAGIS-NG Geographic Information System. The system consists of a series of sitespecific databases and digitized pipeline maps residing in a personal computer (PC) environment. The pipeline map files were developed from publicly available sources, although in some cases, more detailed maps were provided by the individual pipeline companies. Currently, the EIAGIS-NG contains map data for 61 interstate and 71 intrastate pipeline companies located in the United States, and 18 interstate pipeline companies located in Canada.

Many of the interstate pipeline map files also contain profile (attribute) data for each pipeline segment, such as pipe diameter, maximum allowable pressure, looping, etc. These data were compiled from the pipeline system schematic contained in the Form FERC-576, "System Flow Diagram." The individual databases supporting the system include the following pipeline-related data: 
- Compressor stations

- Delivery points

- Receipt points

- Major interconnections

- State border crossings and capacity levels.

Nonpipeline-related databases include:

- Underground storage sites

- Planned underground storage projects

- Proposed construction projects

- Local distribution company service areas

- Export and imports

- Market centers/hubs

- Electric power plants, etc.

The principal geographic data used in this report to compile capacity estimates were the pipeline maps and their receipt, delivery, interconnection, and compression station points. Planned and existing underground storage site data were used to develop estimates of supplemental peak-day deliverability to the pipeline network.

\section{U.S. Regional Definitions}

The six U.S. regions used in this report were based in whole or in part upon the 10 Federal regions originally defined by the Bureau of Labor Statistics. The groupings are as follows:

Northeast Region - Federal Region 1: Connecticut, Maine, Massachusetts, New Hampshire, Rhode Island, and Vermont. Federal Region 2: New Jersey, and New York. Federal Region 3: Delaware, District of Columbia, Maryland, Pennsylvania, Virginia, and West Virginia.

Southeast Region - Federal Region 4: Alabama, Florida, Georgia, Kentucky, Mississippi, North Carolina, South Carolina, and Tennessee.

Midwest Region - Federal Region 5: Illinois, Indiana, Michigan, Minnesota, Ohio, and Wisconsin.

Southwest Region - Federal Region 6: Arkansas, Louisiana, New Mexico, Oklahoma, and Texas.

Central Region - Federal Region 7: Iowa, Kansas, Missouri and Nebraska. Federal Region 8: Colorado, Montana, North Dakota, South Dakota, Utah, and Wyoming.

Western Region - Federal Region 9: Arizona, California, and Nevada. Federal Region 10: Idaho, Oregon, and Washington. 


\section{Glossary}

Abandonment: Regulatory permission to discontinue service by removing various facilities from the transmission and distribution system or to stop transporting gas to or for specific customers or to certain areas. For instance, to discontinue storage services, well production, or gathering systems.

Affiliated Company: A company that is either directly or indirectly controlled and/or owned by another firm or holding company.

Alternate Receipt and Delivery Points: Locations other than the primary points specified in a contract at which a shipper can schedule delivery on a firm basis.

Alternative Fuel Capacity: The on-site availability of apparatus to burn fuels other than natural gas.

Associated-Dissolved Gas: Natural gas produced in association with oil, also known as casinghead gas.

Baseload: A volume of gas that serves as a constant load over a period of time.

Blanket Certificate (Authority): Permission granted by the Federal Energy Regulatory Commission (FERC) for a certificate holder to engage in an activity (such as transportation service) on a self-implementing or prior notice basis, as appropriate, without case-by-case approval from FERC.

Btu: Abbreviation for British thermal unit. The quantity of heat needed to raise the temperature of 1 pound of water by 1 degree Fahrenheit at a specified temperature and pressure (from 59 degrees Fahrenheit to 60 degrees Fahrenheit at an atmospheric pressure of 29.92 inches of mercury).

Capacity Release Market: Where natural gas shippers may offer the rights of some or all of their firm capacity in exchange for revenue credits.

Capacity Turnback: When natural gas shippers, upon expiration of their contract(s) for pipeline capacity do not renew capacity rights, in whole or in part, with the original pipeline.

Certificated Capacity: The capability of a pipeline project to move gas volumes on a given day, based on a specific set of flowing parameters (operating pressures, temperature, efficiency, and fluid properties) for the pipeline system as stated in the dockets filed (and subsequently certified) in the application for the Certificate of Public Convenience and Necessity at the Federal Energy Regulatory Commission. Generally, the certificated capacity represents a minimum level of service that can be maintained over an extended period of time and does not always represent the maximum throughput capability of the system on any given day.

Citygate: Location where gas is delivered to a local distribution company by a pipeline transmission company.

Cogeneration: The production of steam (usually by natural gas), in conjunction with industrial operations or other nonutility gas-burning functions, which is used to power generators for the secondary production of electricity.

Coincidental Peak-Day Flow: The volume of gas that moves through a pipeline or section thereof or is delivered to a customer on the day of the year when the pipeline system handles the largest volume of gas.

Combined-Cycle Generation: System for generating electricity by use of a gas turbine or a heat recovery boiler and a steam turbine in tandem.

Commercial Service: Natural gas service to restaurants, retail stores, schools, institutions, etc.

Compressor Station: An installation located on a pipeline system and which contains engine- or turbine-driven compressors used to move natural gas through a pipeline by raising the pressure applied to the flow of gas. The capabilities of the station are defined primarily by level of installed horsepower and designed daily gas throughput capacity.

Contract Demand: The level of firm service in terms of the maximum daily and/or annual volumes of natural gas sold and/or moved by the pipeline company to the customer holding the contract. Failure of a pipeline company to provide service at the level of the contract demand specified in the contract can result in a liability for the pipeline company.

Cushion (Base) Gas: The volume of gas, including native gas, needed as a permanent inventory in a storage reservoir in order to maintain adequate reservoir pressure and deliverability rates.

Daily Average Flow: The volume of gas that moves through a section of pipe determined by dividing the total annual volume of gas that moves through a section of pipe by 365 days. Volumes are expressed in million cubic feet per day measured at a pressure of 14.73 psia and a temperature of 60 degrees Fahrenheit. For pipes that operate with bidirectional flow, the 
volume used in computing the average daily flow rate is the volume associated with the direction of flowing gas on the peak day.

Deliverability: Refers to the volumes of natural gas that may be transferred at a designated point on the transportation network. The specific volume level is normally stated on a peak-day capability basis and is a function of facility (system) design, which itself is premised upon actual or estimated market demand requirements. Pipeline network deliverability in this analysis is predicated upon a summary measure of pipeline capacity at regional and/or State boundaries. Pipeline capacity is, in part, a function of the number of pipes, their diameter, compression, and operating pressure situated at the transfer point. Deliverability from storage represents a volume level that may be transferred to the pipeline network on a peak day to supplement the pipeline capacity serving the regional market.

Deliverability (from storage): The output of gas from a storage reservoir, as expressed as a rate in thousand cubic feet (Mcf) per 24 hours, at a given total volume of gas in storage with a corresponding reservoir pressure and at a given flowing pressure at the wellhead.

Design Capacity: See certificated capacity. The design capacity of pipeline sections having bidirectional flow is the capacity associated with the direction of the flow observed on the peak day.

Design Day: A 24-hour period of demand which is used as a basis for planning gas capacity and service requirements.

Downstream Pipeline (State): A pipeline (State) closer to the market area, as opposed to an upstream one, which is closer to the production area.

Federal Energy Regulatory Commission (FERC): The Federal agency with jurisdiction over natural gas pricing, wholesale electric rates, hydroelectric licensing, oil pipeline rates, and gas pipeline certification.

Enhanced Oil Recovery: Use of steam injection, most often produced by burning natural gas as a secondary or tertiary oil recovery method. Electricity cogeneration is usually a by-product of such operations.

Extraction Plant: A processing plant that is used for the separation of liquid hydrocarbons from a natural gas stream.

Firm Service: Service offered to customers (regardless of class of service) under schedules or contracts which anticipate no interruptions. The period of service may be for only a specified part of the year as in off-peak service. Certain firm service contracts may contain clauses that permit unexpected interruption in case the supply to residential customers is threatened during an emergency.

Gathering System: A network of small pipelines which connect producing wells with a transmission system.

Gas Turbine: Power equipment of the turbine type which utilizes the gas combustion as a motive force.

Grid (Transmission) System: Natural gas pipeline system characterized by a large number of laterals or branches from the mainline that tend to form a network of integrated receipt, delivery, and pipeline interconnections operating in and serving major market areas. Similar to a local distribution company (LDC) network configuration but on a much larger scale.

Heating Degree Day: An index indicating the difference between 65 degrees Fahrenheit and the average temperature for a day, where the average temperature is the average of the day's high and low temperatures. If a day's average temperature were 45 , there would be 20 degree days for the date. If the average temperature were above 65 degrees Fahrenheit, then the heating degree day would equal zero.

Industrial Service: Natural gas service to factories, mines, pulp mills, smelters, etc.

Infill Drilling: There are two types of infill drilling: (1) The drilling of additional wells in a developed field in an effort to increase total ultimate recovery; and (2) drilling a replacement well within a proration unit, after the original well has been plugged and abandoned, in order to enter a new reservoir that could not be reached or drained by recompletion.

Interruptible Service: A sales volume or pipeline capacity made available to a customer without a guarantee for delivery. "Service on an interruptible basis" means that the capacity used to provide the service is subject to a prior claim by another customer or another class of service (18 CFR 284.9(a)(3)). Gas utilities may curtail service to their customers who have interruptible service contracts to adjust to seasonal shortfalls in supply or transmission plant capacity without incurring a liability.

Interstate Pipeline: A natural gas pipeline company that is engaged in the transportation, by pipeline, of natural gas across State boundaries, and is subject to the jurisdiction of FERC under the Natural Gas Act.

Intrastate Pipeline: A natural gas pipeline company engaged in the transportation, by pipeline, of natural gas not subject to the jurisdiction of FERC under the Natural Gas Act. 
Lateral: A section of natural gas pipeline that branches off from the mainline to connect with or serve a specific customer or group of customers.

LDC: Local Distribution Company. A natural gas utility company which receives gas from a mainline transmission pipeline company and distributes same to the ultimate consumer.

Line Packing: Increasing the amount of gas in the system or pipeline segment by temporarily increasing pressure to meet high demand for a short period of time. Often exercised overnight as a temporary storage medium to meet anticipated next-day peaking demands.

Liquefied Natural Gas (LNG): Natural gas that has been subjected to high pressure and very low temperatures and stored in a liquid state. It is returned to a gaseous state by the reverse process and used as a peaking fuel.

Load Balancing: Maintaining system integrity through measures which equalize pipeline (shipper) receipt volumes with delivery volumes during periods of high system usage. Withdrawal and injection operations into underground storage facilities are often used to balance load on a shortterm basis.

Load Factor: The ratio of average daily deliveries to peak-day deliveries over a given time period.

Looping: Increasing capacity on a pipeline system or segment by adding another pipeline running parallel to existing lines.

Mainline (Transmission Line): The wide-diameter, oftentimes long-distance portion of a natural gas pipeline system, excluding laterals, located between the gathering system (production area) or gas-processing plant and other receipt points and the principal customer service area(s).

Market Center/Hub: A transfer site or system where several interstate and/or intrastate natural gas pipelines interconnect and where shippers may obtain services to manage and facilitate their routing of supplies from production areas to markets. Title transfer, temporary storage, and imbalance management are some of the services usually available at such facilities.

Marketed Production: Gross withdrawals from gas/oil wells less gas used for repressuring, quantities vented and flared, and nonhydrocarbon gases removed in treating or processing operations.
Native Gas: The volume of gas remaining in a reservoir after economic production ceases and before conversion to use as a storage site.

NGPA Section 7 Authority: Section 7 of the Natural Gas Act of 1938 requires an interstate pipeline company to justify and acquire a certificate of public need and convenience before constructing facilities to transport gas. Pipeline companies may expand or construct facilities used solely to enable this transportation service, subject to certain conditions and reporting requirements.

NGPA Section 311: Section 311 of the Natural Gas Policy Act of 1978 allows an interstate pipeline company to transport gas "on behalf of" any intrastate pipeline or local distribution company. Pipeline companies may expand or construct facilities used solely to enable this transportation service, subject to certain conditions and reporting requirements.

No-notice Service: A bundled, citygate firm service under Order 636 that allows customers to receive gas on demand to meet peak service needs subject to delivering supplies into the pipeline under a pack or draft order and without paying daily balancing and scheduling penalties.

Nonassociated Gas: Natural gas produced from gas wells that do not contain or produce oil.

Noncoincidental Peak-Day Flow: The largest volume of gas delivered to a particular customer by a pipeline company in a single day during the year.

Off-Peak Period: Period of low contract demand, such as during the summer months in northern climates but may also apply to periods as short as certain periods of a day when usage is low.

Off-Peak Service: Service made available on special schedules or contracts, but only for a specified part of the year during the off-peak periods.

Open-Access Transportation: The contract carriage delivery of nonsystem supply gas on a nondiscriminatory basis for a fee. Generally subject to transportation tariffs, which are usually on an interruptible service basis on first-come, first-serve capacity usage.

Open Season: A period (often 1 month) when a pipeline offers to accept bids from shippers and others for potential new transportation capacity. Bidders may or may not have to provide "earnest" money, depending upon the type of open season. If enough interest is shown in the announced new capacity, the pipeline will refine the proposal and prepare an application for 
construction before the appropriate regulatory body for approval.

Operator: The person or firm responsible for the day-to-day operation of a plant or facility.

Optional Certificate (formerly known as Optional Expedited Certificate (OEC)): In 1987, FERC issued Order 500, which eliminated the requirement for FERC approval as to the financial "soundness" of a construction project if the pipeline company were willing to accept the market rate of return for the project.

Peak or Peak Load: The maximum demand for gas on a system during a specified interval: hour, week, month, or year.

Peak Shaving: Injection of supplemental supplies of natural gas, such as from underground storage or liquefied natural gas (LNG) facilities, into the pipeline system during periods of maximum demand. Also applies to the act of installing such facilities as a way of avoiding expanding (or building) the production-to-market capacity of the system to accommodate fully the potential maximum demand loads on the basic system.

Pipeline Sales Service: Before 1992, interstate pipeline companies provided bundled sales and transportation service at regulated rates. This bundled service was discontinued in 1993, for most customers, by Order 636, which allowed pipeline companies to sell unbundled gas at market-based rates. Order 636-A required pipeline companies to continue bundled sales service to their existing small customers at cost-based rates for a transitional 1-year period.

Psia: Pounds per square inch at atmospheric pressure.

Service Agreement: An agreement between a natural gas company and a gas purchaser or shipper specifying the service to be rendered, area to be served, maximum obligation to deliver, delivery points, delivery pressure, applicable rate schedules by reference to the tariff, effective date and term, and identification of any prior agreements being superseded.
Spot Market: A market for the buying and selling of short-term natural gas contracts, often for 30 days or less (although contracts as long as 1 to 2 years are sometimes categorized as short-term), usually on an interruptible or best-efforts basis.

Storage (Reservoir) Operating Capacity: The maximum volume of gas an underground storage reservoir can store, limited by such factors as facilities, operational procedures, confinement, and geological and engineering properties. This should include all native gas (recoverable and unrecoverable), cushion (base) gas, and working (current) gas.

System Supply: Gas supplies purchased, owned, and sold by the supplier or local distribution company to the ultimate end user. System gas is subject to FERC or State tariff and is generally sold under long-term (contract) conditions.

Throughput: Actual or estimated volume of natural gas that may be carried on a pipeline over a specified period of time.

Total Storage Capacity: The sum of working (current) gas capacity and the cushion (base) gas that must remain in the storage reservoir for purposes of pressure maintenance.

Trunkline (Transmission) System: Long-distance, widediameter pipeline system that generally links a major supply source with a major market area or with a major pipeline/LDC serving a market area. Trunklines tend to have only a few receipt points (usually at the beginning of its route), few delivery points or interconnections with other pipelines, and few, if any, associated lateral lines. Also see mainline.

Upstream Pipeline: A pipeline, or portion thereof, which is closer to the production area or primary receipt point for gas supplies.

Utilization Rate: Daily flow (throughput) as a percent of estimated capacity. For a segment of pipe, the average-day utilization rate equals the average-day flow divided by the estimated capacity.

Working (Current) Gas: The volume of gas in an underground storage reservoir in excess of total cushion (base) gas and which is available for delivery (withdrawal). 
M98005301

|||||||||||||||||||||

Report Number (14)DOE/E/A-- $06 / 8(98)$

Publ. Date (11) $\frac{199805}{\text { DDE/EI , XF }}$
Sponsor Code (18)
UC Category (19) UC-958,DOE/ER

mo 1332,15 in folder

19980622089

DOE

DTIC QUALTTY INBPECTED 2 


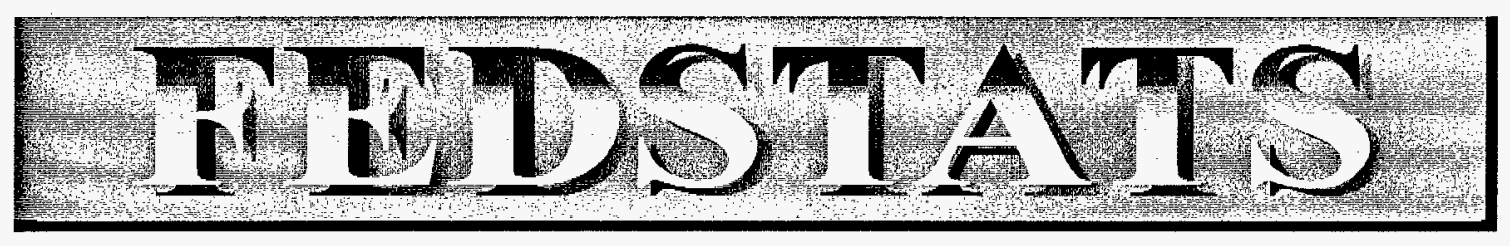

\section{Window on the \\ Spectrum of Federal Statistics}

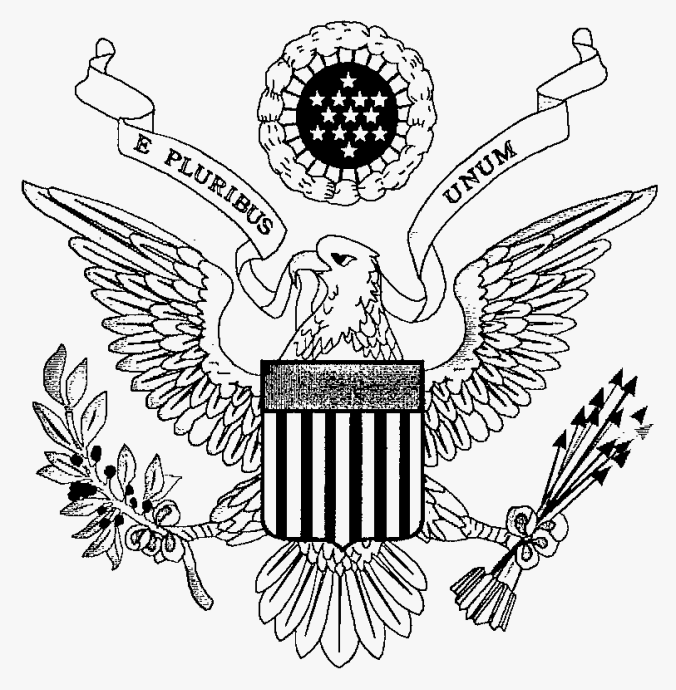

www.fedstats. gov

Easy Access to the Full Range of Federal Statistics Available for Public Use 